\title{
Pliocene glacial-interglacial sea-level change
}

\author{
By
}

Georgia Rose Grant

\author{
A thesis submitted to the \\ Victoria University of Wellington \\ in fulfilment of the requirements \\ for the degree of \\ Doctor of Philosophy \\ In \\ Geology
}

Victoria University of Wellington

School of Geography, Environment and Earth Sciences 


\section{Abstract}

The mid- to late Pliocene (3.3-2.6 Ma) spans one of the most significant climatic transitions of the Cenozoic. It is characterised by global cooling from a climate with an atmospheric $\mathrm{CO}_{2}$ concentration of $\sim 400 \mathrm{ppm}$ and temperatures of $2-3^{\circ} \mathrm{C}$ warmer-than-present, to one marked by the progressive expansion of ice sheets on northern hemisphere. Consequently, the midPliocene warm period (MPWP; 3.3-3.0 Ma) provides the most accessible and recent geological analogue for global sea-level variability relevant to future warming. Global mean sea level has been estimated at $22 \pm 10 \mathrm{~m}$ above present-day for MPWP. However, recent re-evaluations of this estimate suggest that spatially-varying visco-elastic responses of the crust, local gravitational changes and dynamic topography from mantle processes may preclude ever being able to reconstruct peak Pliocene mean sea level. The Whanganui Basin, New Zealand, contains a $\sim 5 \mathrm{~km}$ thick stratigraphic succession of Pliocene-Pleistocene (last $5 \mathrm{Ma}$ ), shallowmarine, cyclical sedimentary sequences demonstrated to record orbitally-paced, glacialinterglacial global sea-level fluctuations. A limitation of the Whanganui sea level record, to date, has been an inability to resolve the full amplitude of glacial-interglacial water depth change due to the occurrence of cycle bounding unconformities representing sub-aerial erosion during glacial lowstands.

This thesis analyses a new 900 m-thick, mid- (3.3-3.0 Ma) to late Pliocene (3.0-2.6 Ma), shallow-marine, cyclical sedimentary succession from a remote and relatively understudied part of Whanganui Basin. Unlike previous studies, these shelf sediments were continuously deposited, and were not eroded during sea-level lowstands, and thus provide the potential to reconstruct the full amplitude of glacial-interglacial sea-level change. On orbital timescales the influence of mantle dynamic processes is minimal. The approach taken applies lithofacies, sequence stratigraphy, and benthic foraminiferal analyses and a novel depth-dependent sediment grain size method to reconstruct the paleowater depths for, two continuously-cored drill holes, which are integrated with studies of outcropping sections. The thesis presents a new record of the amplitude and frequency of orbitally-paced, global sea-level changes from a wave-graded continental shelf, that is independent of the benthic $\delta^{18} \mathrm{O}$ proxy record of global ice-volume change.

Paleobathymetric interpretations are underpinned by analysis of extant benthic foraminiferal census data and a statistical correlation with the distribution of modern taxa. In general, water depths derived from foraminiferal modern analogue technique are consistent with variability recorded by lithofacies. The inferred sea-level cycles co-vary with a qualitative climate record reconstructed from a census of extant pollen and spores, and a modern temperature relationship. A high-resolution age model is established using magnetostratigraphy constrained by biostratigraphy, and the dating and correlation of tephra. This integrated chronostratigraphy allows the recognition of 23 individual sedimentary cycles, that are correlated "one-to-one" across the paleo-shelf and are compared to the deep-ocean benthic oxygen isotope $\left(\delta^{18} \mathrm{O}\right)$ record. 
A grain size-water depth technique was developed to quantify the paleobathymetry with more precision than the relatively insensitive benthic foraminifera approach. The method utilises a water depth threshold relationship between wave-induced near bed velocity and the velocity required to transport sand. The resulting paleobathymetric records of the most sensitive sites, the mid-Pliocene Siberia-1 drill core and the late Pliocene Rangitikei River section, were selected to compile a composite paleobathymetry. A one-dimensional backstripping method was then applied to remove the effects of tectonic subsidence, sediment and water loading on the record, to derive a relative sea level (RSL) curve.

The contribution of glacio-hydro-isostatic (GIA) processes to the RSL record was evaluated using a process-based forward numerical solid Earth model for a range of plausible meltwater scenarios. The Whanganui Basin RSL record approximates eustatic sea level (ESL) in all scenarios when variability is dominated by Antarctic Ice Sheet meltwater source during the mid-Pliocene, but overestimates ESL once Northern Hemisphere ice sheet variability dominates in the late Pliocene.

The RSL record displays 20 kyr precession-paced sea level variability during the MPWP with an average amplitude of $\sim 15 \pm 8 \mathrm{~m}$, in-phase with southern high-latitude summer insolation. These are interpreted as $\sim 20 \mathrm{~m}$ Antarctic Ice Sheet contributions, offset by $\sim 5 \mathrm{~m}$ anti-phased Greenland Ice Sheet contribution, in the absence of a significant Northern Hemisphere ice sheets. This interpretation is supported by a previously published ice-proximal precessionpaced, ice-berg-rafted debris record recovered off the coast of Wilkes Land. The Whanganui RSL record is not consistent with a dominant $40 \mathrm{kyr}$ pacing observed the benthic oxygen isotope stack at this time. While the deep ocean benthic $\delta^{18} \mathrm{O}$ stack is of varying temporal and spatial resolution, during this time interval, the Whanganui RSL record implies a more complex relationship between ice-volume and oxygen isotope composition of sea water $\left(\delta^{18} \mathrm{O}_{\text {seawater }}\right)$. The relative influences of varying composition of the polar ice sheets, marine versus land based ice, the out-of-phase behaviour of polar ice sheet growth and retreat, and a potential decoupling of ocean bottom water temperature and $\delta^{18} \mathrm{O}_{\text {seawater }}$ are explored.

The late Pliocene relative sea level record exhibits increasing $\sim 40 \mathrm{kyr}$ obliquity-paced amplitudes of $\sim 20 \pm 8 \mathrm{~m}$. This is interpreted as a response to the expansion of Northern Hemisphere ice sheets after $\sim 2.9 \mathrm{Ma}$. During this time the Antarctic proximal ice-berg rafted debris records display continuing precession-paced ice-volume fluctuations, but with decreasing amplitude suggesting cooling and stabilisation of the East Antarctic Ice Sheet. With the bipolar glaciation, the ocean $\delta^{18} \mathrm{O}$ signal became increasingly dominated by northern hemisphere ice-volume. However, the RSL record implies relatively limited ice-volume contributions (up to $\sim 25 \mathrm{~m}$ sea level equivalent) prior to $\sim 2.6 \mathrm{Ma}$.

The large amplitude contribution of Antarctic Ice Sheets to global sea level during the MPWP has significant implications for the sensitivity of the Antarctica Ice Sheet to global temperatures $2-3^{\circ} \mathrm{C}$ above preindustrial levels, and atmospheric $\mathrm{CO}_{2}$ forecast for the coming decades. 


\section{Acknowledgments}

Thanking and acknowledging everyone that has supported me through this journey seems impossible. But l'll start at the beginning.

To my supervisors, Prof. Tim Naish, thank you for your endless support and encouragement that gave me the confidence to challenge myself. Thank you Dr. Gavin Dunbar, for making sure my arguments were consistent.

To the many conversations, collaborations and contributions Prof. Michelle Kominz, Prof. Peter Kamp, Dr. Paolo Stocchi, Dr. Claudio Tapia, Dr. Alan Beu, Hugh Morgans, Dr. Joe Prebble, Assoc. Prof. Rob Mckay, Prof. Lionel Carter, Prof. Diane Seaward, Dr. Brent Alloway, Prof. Rob Dunbar, Dr. Ed Gasson, Dr. Molly O’Rourke Patterson, Juliet Sefton.

The Antarctic Research Centre and School of Geography, Environment and Earth Sciences colleagues, Warren, Rob, Alex, Ruzica, Lauren, Jamey, Katelyn, good time Dan, Benji, Matt, CRad, Dezzie, Jack, Tom, Lisa, always a pleasure never a chore. Darcy, thank you for having a sense of humour that matched my own.

This research was funded by the Royal Society of New Zealand Marsden Grant 13 VUW 112. Support from the Endowed Development Fund and Faculty Strategic Research Grants allowed me to carry out work at Stanford University, visit Western Michigan University and present at the Regional sea-level and coastal impacts conference in New York, USA and Past Antarctic Ice Sheet Dynamics conference in Trieste, IT.

Thank you, to the KVP whanau (Mya, Paora, Jamie, Hamish, Peter, Pete, Deb, Jamie, John, Isaac, Matty, Darcy and Emily) through all the highs and lows. Special thanks to Mya and Paora, for feeding my body, heart and soul, I promise l'll do the dishes next time! To my mates, Tami, Ame, Tamsin, Molly, Heidi, Mya and Zara, you can't imagine what your friendship has seen me through.

My family, thank you for your unwavering support, and my nephew Oscar, for making me smile on rainy days.

Ehara taku toa, he takitahi, he toa takitini

(My success is not mine alone but that of a collective) 
This thesis is dedicated to the memory of

Kristopher Karl Malcolm

$7^{\text {th }}$ July $1985-1^{\text {st }}$ February 2018

Forever laughing 


\section{Contents}

Abstract

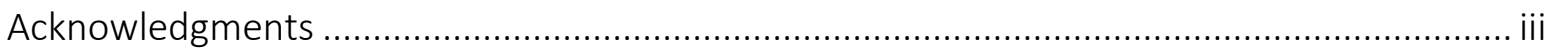

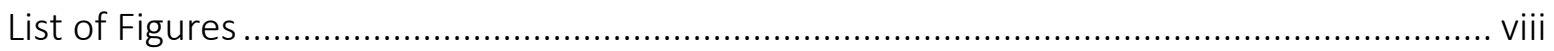

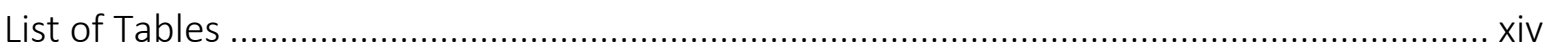

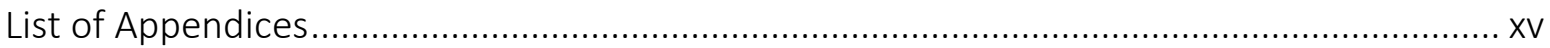

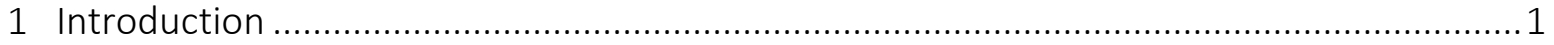

1.1 Rationale

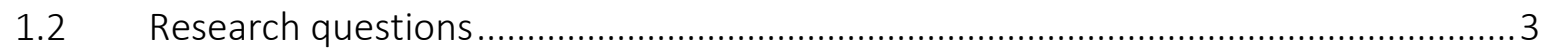

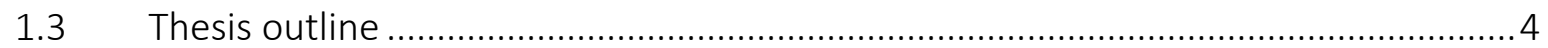

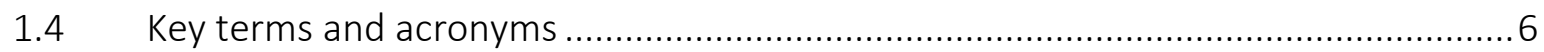

2 Literature review: Mid- to late Pliocene climate, sea level and the Whanganui Basin

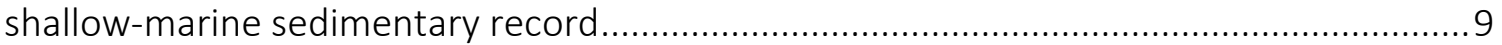

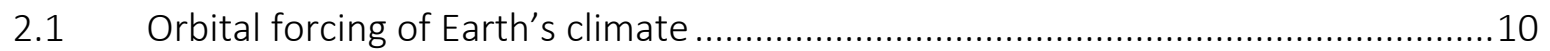

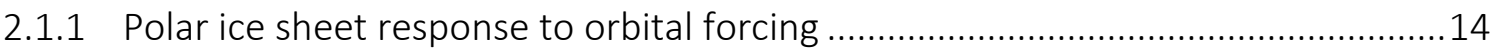

2.1.2 The role of climate feedbacks and polar amplification on ice sheet dynamics .....20

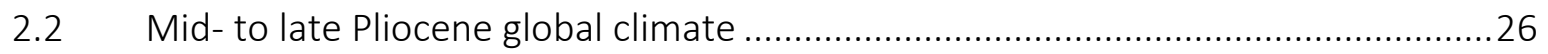

2.2.1 Polar ice sheet response to mid- to late Pliocene global climate ..........................28

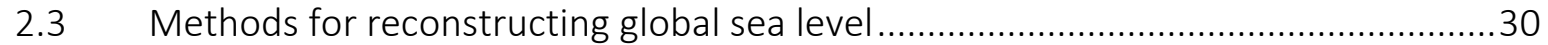

2.3.1 Regional sea-level variability: the influence of glacio-isostatic adjustment and

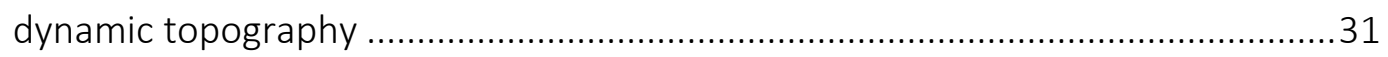

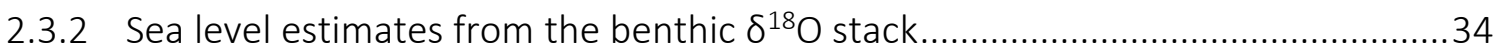

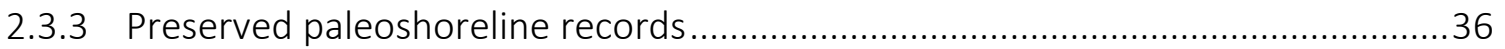

2.3.4 Backstripped shallow-marine continental margin records ...................................37

2.4 The Whanganui Basin shallow-marine sedimentary record as an archive of Pliocene-Pleistocene global sea-level change ........................................................40

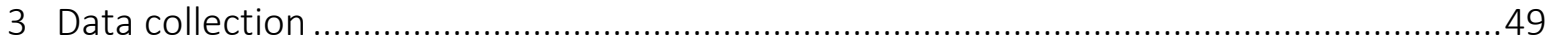

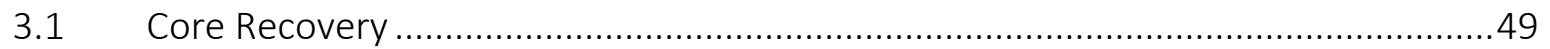

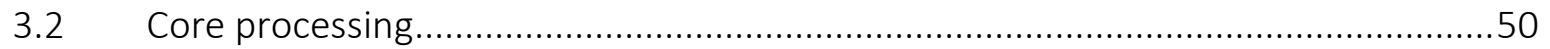

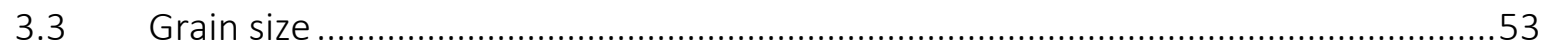

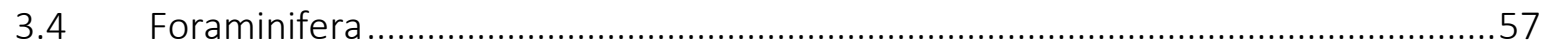


4 Mid- to late Pliocene (3.3-2.6 Ma) global sea-level fluctuations recorded on a continental shelf transect, Whanganui Basin, New Zealand

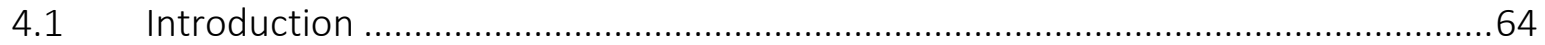

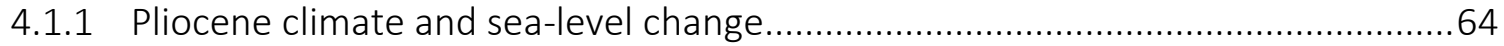

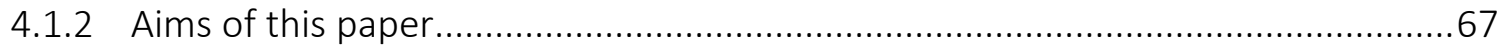

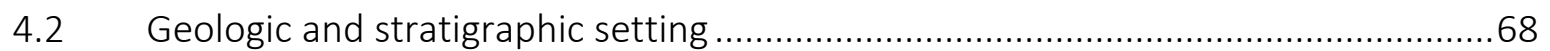

4.3 Lithofacies analysis and sequence stratigraphy ................................................... 77

4.4 Reconstructing paleoenvironment, water depth and climate ................................82

4.4.1 Depth estimates from extant benthic foraminiferal associations ..........................83

4.4.2 Depth estimates from foraminiferal modern analogue technique .......................88

4.4.3 Climate variability from terrestrial palynology from Siberia-1 drill core ................90

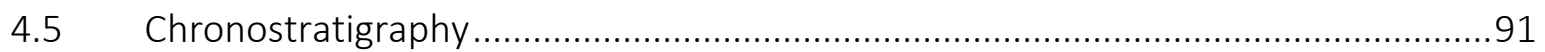

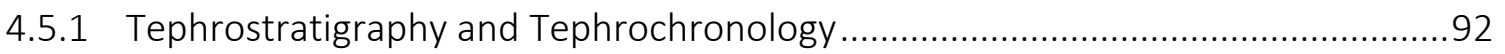

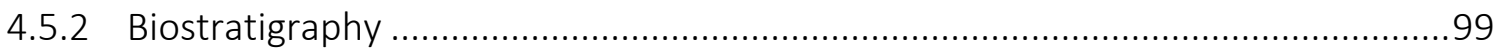

4.5.3 Magnetostratigraphy and correlation to the Geomagnetic Polarity Timescale ....99

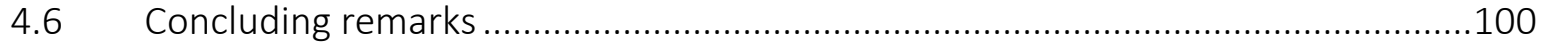

4.6.1 Orbitally-paced, glacial-interglacial shallow marine sedimentary cycles .............100

4.6.2 Implications for reconstructing glacial-interglacial sea-level change ...................101

5 Quantifying water depth changes and relative sea level for the mid- to late Pliocene...103

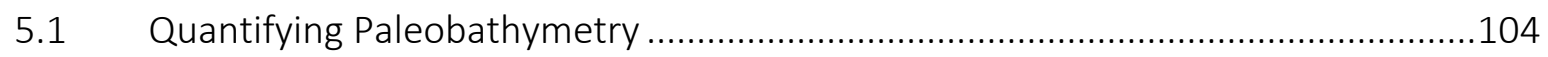

5.1.1 Estimating paleowater depth from grain size .................................................. 104

5.1.2 Mid- to late Pliocene paleobathymetry from the Whanganui Basin ....................118

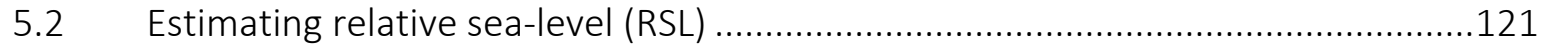

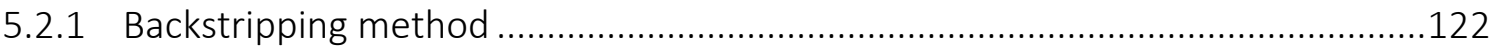

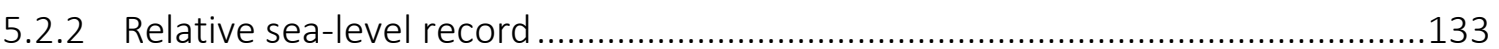

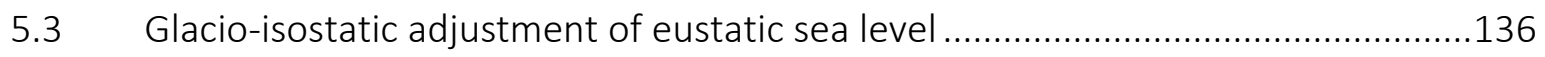

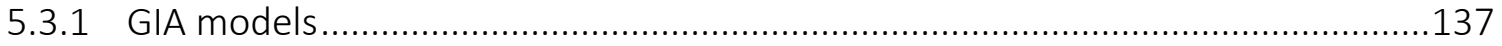

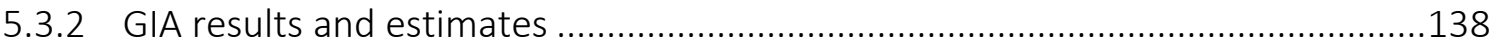

5.4 Conclusions - A new glacial- interglacial relative sea level for the mid- to late Pliocene ( 3.3-2.5 Ma).

6 Discussion and Conclusions: Amplitude and frequency of the relative sea-level record for the mid- to late Pliocene: Implications for orbital forcing and meltwater source...........143

6.1 Orbital pacing of relative sea level during the mid- to late Pliocene ......................144

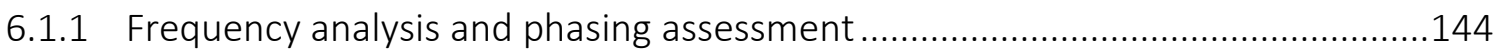


6.1.2 Using frequency to constrain ice sheet contributions to relative sea level for the mid- to late Pliocene

6.2 Using the amplitude to constrain polar ice sheet contributions to relative sea level

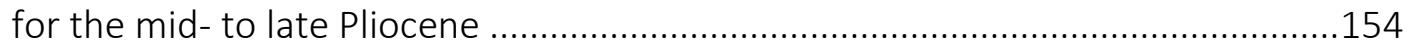

6.3 Sea level calibration of the benthic $\delta^{18} \mathrm{O}$ stack for the mid- to late Pliocene.........160

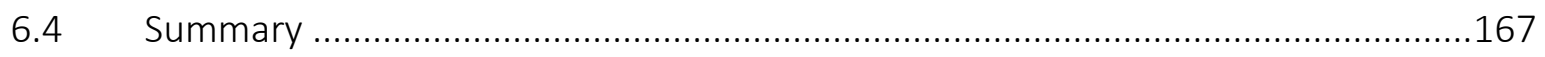

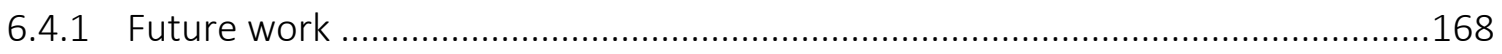

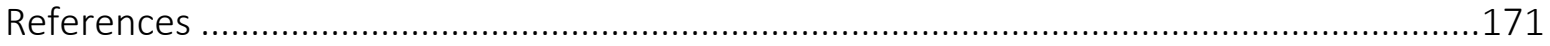




\section{List of Figures}

Figure 2.1 Schematic diagram illustrating parameters describing Earth's orbit about the sun, where eccentricity (e) is equal to $c / a$, climatic precession $=e \sin \varpi$, and the degree of tilt (obliquity) is measured in reference to the perpendicular of the ecliptic. The orange shaded regions display the effect of Kepler's Second Law for arbitrary solstice positions.

Figure 2.2 Orbital pacing and climate coupling for the last 3.5 Myr (including the MPWP 3.3 -3.0 Ma) of dust mass accumulation rates (Martinez-Garcia et al., 2011) and tropical sea-surface temperature stack (Herbert et al., 2010). Global sea-level calibration of the benthic $\delta^{18} O$ stack (blue line; Lisiecki and Raymo, 2005; Naish and Wilson, 2009), with estimates from Miller et al. (2012) for the mid Pliocene (red dots with 2 standard deviation of uncertainty), and Late Pleistocene reconstructions from coral terraces (green line; Waelbroeck et al., 2002) and the Red Sea (red line; Rohling et al., 2009). In comparison with background $\mathrm{pCO}_{2}$ concentration from Antarctic ice cores (green line, Petit et al., 1999; Siegenthaler et al., 2005; Lüthi et al., 2008), and estimates of $p \mathrm{CO}_{2}$ from boron isotopes $\left(\delta^{11} \mathrm{~B}\right)$ in foraminifera in marine sediments (blue triangles; Hönisch et al., 2009; Seki et al., 2010; Bartoli et al., 2011), and phytoplankton alkenone-derived carbon isotope proxies (red diamonds; Pagani et al., 2010; Seki et al., 2010), plotted with 2 standard deviation uncertainty. Present (2012) and preindustrial $\mathrm{pCO}_{2}$ concentrations are indicated with long-dashed and short-dashed grey lines, respectively.

Figure 2.3 Evolutionary harmonic analysis comparing the relative influence of eccentricity $(E)$, obliquity (T: tilt) and precession $(P)$ in the global benthic $\delta^{18} \mathrm{O}$ stack (Lisiecki and Raymo, 2005; left)) and $65^{\circ} \mathrm{S}$ Jan 1st insolation (Laskar et al., 2004; right) for 3.3-2.7 Ma displaying the dominance of precession in the insolation spectra and its relative absence in the benthic $\delta^{18} \mathrm{O}$ spectra. Of interest is the long-term node in obliquity, while eccentricity and precession continue to fluctuate in amplitude during the MPWP, highlighted in grey.

Figure 2.4 Global benthic $\delta^{18} \mathrm{O}$ stack (Lisiecki and Raymo, 2005) showing the transition from the $41 \mathrm{kyr}$ world to 100 kyr cyclicity of the Late Pleistocene in the first panel (a), with obliquity (Laskar et al., 2004) and obliquity paced integrated summer insolation (Huybers et al., 2006) in the second panel (b) and bipolar precession-paced summer insolation (Laskar et al., 2004) argued by Raymo et al. (2006) to produce a dominantly $40 \mathrm{kyr}$ world in the third panel (c).

Figure 2.5 Ba/AI (a) and IBRD MAR (b) from U1361 sediment core for 4.4-2.2 Ma correlated to $65^{\circ} \mathrm{S}$ Dec 21st summer insolation and summer energy calculated for a melt threshold $400 \mathrm{GJ} / \mathrm{m}^{2}(c)$, mean annual insolation and summer energy calculated for a melt threshold $250 \mathrm{GJ} / \mathrm{m}^{2}$ (d), eccentricity (e), and the benthic $\delta^{18} \mathrm{O}$ record (Lisiecki and Raymo, 2005) (f). Grey ellipse denotes alignment between a 1.2-Ma node in obliquity-modulated mean annual insolation and minimum in 400-kyr eccentricity and corresponds with the M2 event (arrow). Atmospheric $\mathrm{CO}_{2}$ reconstructions based on boron isotopes and alkenones (Pagani et al., 2010; Seki et al., 2010; Masson-Delmotte et al., 2013) (g) (Reproduced from Patterson et al. (2014).

Figure 2.6 Global oceanic ( $a$ and $b$ ) and continental ( $c$ and d) temperature anomalies for Representative Concentration Pathway 8.5 (top row; $3.7^{\circ} \mathrm{C}$ global warming estimated for 2081-2100 BC), the Last Glacial Maximum (20 ka; second row) and MPWP (bottom row) compiled by Masson-Delmotte et al. (2013 and references therein)...

Figure 2.7 Marine Ice Shelf Instability (MISI) and Marine Ice Cliff Instability (MICI) causing collapse of ice shelves and subsequent ice margin retreat (DeConto and Pollard, 2016).....

Figure 2.8 Antarctic BEDMAP2 (Fretwell et al., 2013) bed elevation ( $m$ above sea-level) displaying the marinebased West Antarctic and East Antarctic areas of subglacial basins referred to in text; George V Land (GVL), Wilkes Land (WL) and Lambert Glacier (LG).

Figure 2.9 Peak global mean temperature, $\mathrm{pCO}_{2}$ and global mean sea-level estimates with estimated meltwater source for the Mid-Pliocene, MIS 11 \& 5e and present (Dutton et al., 2015).

Figure 2.10 Sea-level compilation by Miller et al. (2012). Two different calibrated $\delta^{18} \mathrm{O}$ records $\left(\delta^{18} \mathrm{O}-\mathrm{Miller}\right.$ et al., 2012; New Zealand - Naish and Wilson, 2009), Mg/Ca estimates (Mg/Ca Dwyer - Dwyer and Chandler, 2009; Mg/Ca Sosdian data - Sosdian and Rosenthal, 2009) and geological deposits of Kiptopeke and Langley, 
VA (Hayden et al., 2008), Enewetak Atoll (Wardlaw and Quinn, 1991), Eyreville, VA (Miller et al., 2012) and Orangeburg Scarp (Doswett and Cronin, 1990).

Figure 2.11 Elevation of a shoreline indicator relative to modern sea-level, representing $+14 \mathrm{~m}$ of sea-level equivalent ice melt of which $7 \mathrm{~m}$ is allocated from the Greenland Ice Sheet and $7 \mathrm{~m}$ from AIS. The coloured regions represent the shoreline within $\pm 4 m$ (Raymo et al., 2011). Note the significant departure from ESL proximal to the polar ice sheet margins, while the broader global ocean experiences variance on a much smaller scale.

Figure 2.12 Schematic diagram illustrating the positive and negative effect of mantle convection on topography (Braun, 2010).

Figure 2.13 Schematic diagram displaying the response of a shallow-marine depositional environment to the relative effects of local tectonics (subsidence), sediment supply and eustatic sea-level variation. These combined influences determine the paleobathymetry and can be accounted for by using a sediment backstripping technique allowing the RSL to be estimated from a continental margin record.

Figure 2.14 a) Location of Whanganui Basin in relation to the Pacific and Indo-Australian Plate boundary (Hikurangi Trench). b) The subducting Pacific Plate coupled to the Indo-Australian Plate forming the Whanganui backarc basin is shown by the $A-A^{\prime}$ cross-section. c) The $B-B^{\prime}$ schematic cross-section conceptually illustrates the southward migration of the depocentre and contemporaneous uplift in the north, exposing the geological units onshore (after Stern et al., 2013).

Figure 2.15 Paleogeographic map of the Whanganui Basin showing the deep marine (>200 $\mathrm{m}$ water depth) and shallow marine (<200 $\mathrm{m}$ water depth) of the Whanganui embayment for 3 Ma (Trewick and Bland, 2014 )....43

Figure 2.16 Sequence stratigraphic interpretation of a how a relative sea-level cycle is recorded in a typical Whanganui outcrop motif (Naish et al., 2005).

Figure 2.17 Onshore cyclostratigraphic record from Rangitikei and correlation to offshore $\delta^{18} \mathrm{O}$ records within paleomagnetic, biostratigraphic and tephrostratigraphy age constraints (Pillans et al., 2005).

Figure 2.18 Simplified geologic map of Wanganui Basin based on Townsend et al. (1972), with the core sites (Siberia-1 and Tiriraukawa-1) and outcrop sections (Turakina [Patterson et al., 2014], Watershed Road [Sefton, 2015] and Rangitikei [Journeaux et al., 1996; Naish and Kamp, 1997a]) referred to in text. The schematic A-A' cross section (B) describes the westward deepening shelf during the deposition of the Utiku Group, and the location of core and outcrop across that transect.

Figure 3.1 Comparison of grain size distribution for selected samples for the variable $\mathrm{CaCO}_{3}$ and organic treatments (discussed in Appendix D).

Figure 3.2 Standard deviation (red dashed line) of $250 \mu \mathrm{m}$ and $68 \mu \mathrm{m}$ standards run during sample analysis of grain size distribution.

Figure 3.3 SEM image of Cibicides deliquatus, that shows evidence of abrasion but no recrystallization. The black adhesive on the margins of the image is carbon tape.....

Figure 3.4 Comparison of $\delta^{18} \mathrm{O}$ values for benthic (Uvigerina spp. and Cibicides deliquatus) and planktic (Globigerina bulloides) foraminifera from the Tiriraukawa-1 core.

Figure 4.1 a) Location map of Whanganui Basin in relation to the Pacific and Indo-Australian Plate boundary (Hikurangi Trench). ODP Site 1124 lies $\sim 500 \mathrm{~km}$ offshore to the southeast of Wellington. B) The location of the cores (Siberia-1 and Tiriraukawa-1; this study) and outcrop sections (Turakina: Patterson, 2014, Watershed Road: Sefton, 2015 and Rangitikei: Journeaux et al., 1996; Kamp et al., 1998) are shown on the geological map. Strata generally dip at $5^{\circ}$ southwest. C) The $A-A^{\prime}$ schematic cross-section conceptually illustrates the southward migration of the depocentre and contemporaneous uplift in the north, exposing the geological units onshore (after Stern et al., 2013).

Figure 4.2 A paleogeographic reconstruction after Bunce et al., (2009) and Trewick and Bland (2012), displaying an open semi-enclosed broad embayment open to the dominant westerly wind, with an arcuate 
shoreline forming a west-east to north-south orientation, with a deepening shelf westward. The locations of outcrop sections and cores shown in Figure1 are denoted by stars and signify (west to east) Turakina Valley, Tiriraukawa and Rangitikei Valley.

Figure 4.3 (a) Siberia-1 and (b) Tiriraukawa-1 drill core showing core magnetostratigraphy and stratigraphy, lithofacies, clay/silt/sand percentage, natural gamma-ray (NGR) and mass-corrected magnetic susceptibility physical property logs, planktic foraminiferal percentage and palynological glacial-interglacial indices (for Siberia-1 only). Water depths derived by the Modern Analogue Technique are displayed as mean values (dark blue rectangle) and minimum and maximum values (light blue bar), as discussed in text (also displayed in Figure 4.4) and sequence stratigraphy (Figure 4.5 \& 4.6).

Figure 4.4. Figure showing correlation of sedimentary cycles, tephra positions and mid- to late Pliocene chrons identified in outcrop sections of the Utiku Group and Mangaweka Mudstone (Rangikikei River, Watershed Road and Turakina River Sections) and drillcores (Tiriraukawa-1; Siberia-1) with published oxygen isotope records (ODP846, Shackleton et al., 1995 and LR04, Lisiecki and Raymo, 2005) giving the Whanganui Basin stratigraphy a sound chronostratigraphic framework. Sand percentage provides a high resolution signature for lithologic cycles, which are numbered 1 to 23. Water depths have been derived by application of the benthic foraminifera modern analogue technique (MAT). The paleomagnetic stratigraphy is after Naish et al., (1997) and Turner et al., (2005) for the Rangitikei River Section, Turner et al., (2005) for the Turakina section and Tapia et al., (submitted) for the drill cores. Biostratigraphic datums are after Cooper et al., (2004) and Raine et al., (2015). Tephra correlation and numeric ages discussed in the text are shown. This integrated chronostratigraphic framework allows correlation of Whanganui cycles 1-23 with the high-resolution, deep sea benthic $\delta^{18} \mathrm{O}$ record of ODP Site 846 (Shackleton et al., 1995; using the age model provided by Lisiecki and Raymo, 2005) and the benthic $\delta^{18} \mathrm{O}$ stack (LR04; Lisiecki and Raymo, 2005).

Figure 4.5 Conceptual model developed chiefly from lithofacies and sequence stratigraphic analysis of the midto late Pliocene outcrop sections and drillcore illustrated in Figure 4.4. Five representative sedimentary motifs $(A-E)$, named after the sections from which they have been synthesised, show the inferred stratigraphic position of sequence boundaries and intervening flooding surface. This helps infer onlap and offlap in a cycle of sea-level change.

Figure 4.6 Figure showing five sedimentary motifs (Figure 4.5) arranged at increasing paleobathymetry across a shore-normal shelf cross-section to characterise the changes in lithofacies character and relative height of sequence stratigraphic surfaces in a typical mid- to late Pliocene Whanganui Basin sedimentary record of a sealevel cycle in the Utiku Group and Mangaweka Mudstone. Note how the sequence surfaces correspond to the relative sea-level cycle shown on the right.

Figure 4.7 Dendrogram classification of the 221 samples referred to in the text (Rangitikei River Section, Journeaux et al., 1996; Watershed Road Section, Sefton, 2015; Siberia-1 and Tiriraukawa-1 cores, this study) for which six clusters are identified. Samples denoted TJ are for the Rangitikei River Section (Journeaux et al., 1996), WS apply to the Mangaweka Mudstone samples at the Watershed Road location (Sefton, 2015) and Tf (Tiriraukawa-1) or Sf (Siberia-1) samples were specifically collected for this investigation.

Figure 4.8 Two-dimensional Canonical Correspondance Analysis (PAST; Hammer et al., 2001) of Pliocene foraminiferal census data, with the genus, six clusters (identified in Figure 4.7) and vector arrows of the proxy environmental factors: sand and planktic foraminiferal percentage, for the two primary axes.

Figure 4.9. A. Plots of $\mathrm{SiO}_{2}$ vs $\mathrm{Na}_{2} \mathrm{O}+\mathrm{K}_{2} \mathrm{O}$ (wt. \%) compositions of glass shards from mid- to late Pliocene tephra beds exposed in Whanganui Basin compared with similar aged tephra from ODP Site 1124C. All tephra are rhyolitic in composition (after Le Maitre, 1982) except for M14 (ODP Site 1124C), which straddles the rhyolitedacite domains; $B-D$. Selected major element compositions (weight percent $\mathrm{FeO}$ vs $\mathrm{CaO}, \mathrm{K}_{2} \mathrm{O}$ and $\mathrm{TiO}_{2}$ ) of glass shards from Kowhai, Tiri-1, Eagle Hill, Tiri-2, and Siberia tephra (Sefton, 2015) in comparison with seven tephra (M9, M10, M12 (upper; formerly M11), M12 (lower), M13, M14 and M15) of broadly similar age analysed from ODP Site 1124C (Stevens, 2010). The ODP-tephra beds have been dated by linear interpolation of sedimentation rates between astronomically-tuned key paleomagnetic polarity boundaries and ITPFT-dated tephra (Carter et al., 2003, 2004; Alloway et al., 2005). Insets highlight those tephra that are correlated in this study. 
Figure 4.10 Selected trace element bivariate plots ( $S r v^{\prime} s \mathrm{Nd}, \mathrm{Zr}, \mathrm{Zr} \mathrm{v}^{\prime} \mathrm{s} \mathrm{Nd}, \mathrm{Y}$ and $\mathrm{Nd} v^{\prime}$ s Th) determined by grain discrete LA-ICP-MS analysis (SI Table 1). Here, Kowhai, Tiri-1, Eagle Hill, Tiri-2 and Siberia tephra (Sefton, 2015) are plotted with respect to seven tephra (M9, M10, M12-upper, M12-lower, M13, M14 and M15) of similar age analysed from ODP Site 1124C (Stevens, 2010). Tephra symbols are the same as those listed in Figure 4.9. .....97

Figure 5.1 Sediment transport mechanisms from the coast to shelf by wave and currents on a shallow-marine margin (Boggs, 2011). 105

Figure 5.2 Schematic diagram describing wave parameters $H s, L, T p$, $h$ and Uw, used in equations (5.1; 5.2; 5.3)...

Figure 5.3 All maximum grain size (Dmax) and sand percentage ( $\Sigma V>63)$ for Siberia-1 and Tiriraukawa-1 samples (light blue) with weighted mean (dark blue) for which the linear relationship is defined (Equation 5.4).

Figure 5.4 The water depth thresholds for deposition of sand (0\% and 100\%) as a function of selected wave periods (Tp: 5s, 10s, 15s and 20s) for varying wave heights (Hs).

Figure 5.5 The relative water depth difference between the deposition of $0 \%$ and $100 \%$ for the wave periods (Tp) $5 \mathrm{~s}, 10 \mathrm{~s}, 15 \mathrm{~s}$ and $20 \mathrm{~s}$.

Figure 5.6 Location map of the wave buoy used to determine wave height (Hs) and peak wave period (Tp) for sea floor near-bed velocity calculations and modern grain size transect for the Monterey Bay dataset (Table 5.1; Figure 5.8).

Figure 5.7 Location map of the hindcast wave models used to determine wave height and period for sea floor near-bed velocity calculations and grain size transects for the Whanganui and Manawatu coastlines (Table 5.1; Figure 5.8).

Figure 5.8 Observations of $\sum V_{>63}(\%)$ with water depth $(m)$ for three shelf transects (Manawatu: green, Dunbar and Barrett, 2005; Monterey Bay: blue, Chin et al., 1984 and Whanganui Bight: grey, Beaumont et al., 2013) in fill circles and respective model profiles (for wave parameters outlined in Table 5.1) in squares with the shaded bands representing the error described by Equation 5.8 (Appendix L). The red shaded band from $95-100 \%$ $\Sigma V_{>63}$ represents a limit of the method where all water depths below the respective maximum contain $100 \%$ $\Sigma V>63$.

Figure 5.9 (a) Whanganui wind rose and (b) Wave height rose for the same location; (c) Manawatu wave height rose by percentage of occurrence (Metocean View, 2018).

Figure 5.10 Paleogeographic reconstruction displaying open oceans to the west /south west, with the core and outcrop locations (Trewick and Bland, 2012).

Figure 5.11 Paleobathymetric reconstruction for the Rangitikei River Section, Watershed Road Section and Tiriraukawa-1 and Siberia-1 cores. Depth estimates by Modern Analogue Technique (orange) where the error bars represent the minimum and maximum water depths of the analogues for each sample are shown. The grain size-water depth technique (blue) displays the error derived from the minimum and maximum water depth for a given sand \% (Appendix L).

Figure 5.12 Schematic diagram displaying the relationship between accommodation space, sediment accumulation, bathymetry and eustatic sea-level for a Pleistocene Rangitikei cyclothem that experiences erosion during sea-level lowstand due to the amplitude of sea-level change and rate of basin subsidence (Naish and Wilson, 2009)......

Figure 5.13 Depth of burial and thus amount of exhumation and erosion above the Siberia-1 core site, determined by the calculation of porosity (orange; Equation 5-5) from the density core log for Siberia-1 in comparison to porosity-depth curves previously determined for silt (brown; Equation 5-6) and sand (green; Equation 5-7) after Kominz et al. (2011)... 
Figure 5.14 Geological map compiled by Prof. Peter Kamp with an example of the cross section from Siberia-1 drillcore to the coastal Stantiall1-exploration hole, focussing on the Siberia-1 site. This was used to determine unit thicknesses for the stratigraphic section, including exhumed material (projected formations). 125

Figure 5.15 Backstripping results for the long-term dataset of the Siberia-1 section (Table 5.2). Where Tsubmin, max and best, represents the tectonic subsidence (Tsub) of equation 5.4, and the minimum and maximum are a result of the range of water depth min , max, mean. The stratigraphy of the core and Mangaweka Mudstone outcrop have a well constrained mean water depth of deposition and thus show no associated max or min for the Tsub. A comparison between the observed sediment thickness and decompacted thickness are displayed, along with the tectonic subsidence induced by sediment loading (tsubs-sed).

Figure 5.16 Backstripping results for the long-term dataset of the Rangitikei pseudo-well section (Table 5.3). Where Tsub min, max and best, represents the tectonic subsidence (Tsub) of equation 5.4, and the minimum and maximum are a result of the range of water depth min, max and mean. The stratigraphy of the core and Mangaweka Mudstone outcrop have a well-constrained mean water depth of deposition and thus show no associated max or min for the Tsub. A comparison between the observed sediment thickness and decompacted thickness are displayed, along with the tectonic subsidence induced by sediment loading (tsubs-sed).

Figure 5.17 Relative sea-level ( $\triangle S L$; Equation 5.4b) for the high-resolution a) Siberia-1 (top figure) and b) Rangitikei pseudo-well (bottom figure). Where the RSL min, max and mean are now the product of the water depths derived from the grain size technique with the error determining the maximum and minimum water depths. The HFsed, represents the difference between the sediment loading of the long-term datasets (Table 5.3; Figures 5.15 \& 5.16) and the high-resolution datasets (Appendix M).

Figure 5.18 Relative sea-level maximum and minimum estimates for two scenarios (Scenario 1 deepening 60130 m; Scenario 2 deepening from 110-140m) testing the effect of subsidence rates on relative sea-level amplitudes.

Figure 5.19 Relative sea-level record for the mid-to late Pliocene, with the thickness of the shaded band representing the maximum and minimum estimates. The noted amplitudes of the cycles are taken from the mean values of each peak and trough and the error is variable. While the Rangitikei and Siberia sections can be placed on the same scale, there is no relevance in the baseline shift between sections, which is a product of the backstripping. The semi-circles are highlighting the longer frequency 100 kyr cycles in the MPWP. 134

Figure 5.20 Regional sea-level maps for meltwater scenarios 1-3 (Table 5-3) showing relative sea-level change for ESL contributions of a) $15 \mathrm{~m}$, b) $20 \mathrm{~m}$, c) $25 \mathrm{~m}$; with the ESL contour indicated by the black contour.

Figure 6.1 Spectral analysis using the a) Multi-taper Method with the Mann and Lees (1996) red noise test (function mtmML96 in Astrochron; Meyers, 2014) of the Whanganui RSL record for the mid-to Late Pliocene, displaying significant harmonic peaks at the 90\% Confidence Level in kyr: 1) 167.4; 2) 91.7; 3) 44.8; 4) 34.4; 5) 30.3 ; 6) 24.8; 7) 23.6; 8) 19; 9) 16.7. And b) EHA spectra of the RSL record using a $200 \mathrm{kyr}$ window, $3.5 \mathrm{kyr}$ step and power is normalised to unity, eccentricity (E: 0.08-0.11 kyr-1), obliquity (0: 0.18-0.024 kyr-1) and precession ( $P$ : 0.043-0.053 kyr-1) frequency bands are identified.

Figure 6.2 Phase comparison between the Whanganui RSL curve and peak summer insolation at $65^{\circ} \mathrm{N}$ (dotted) and $65^{\circ} \mathrm{S}$ (solid) highlighted for the three paleomagnetic transitions (red dashed lines) of the MPWP. Peak summer insolation for $65^{\circ} \mathrm{S}$ is shown with the whole RSL record untuned.

Figure 6.3 Evolutionary harmonic analysis of (left to right): the eccentricity, tilt, precession orbital solution (Laskar et al., 2004), global benthic 8180 stack (Lisiecki and Raymo, 2005), East Antarctic U1361A IBRD record (Patterson et al., 2014) , East Antarctic U1361A L* colour reflectance (Facies proxy; Grant, 2012), Whanganui RSL (this study). All evolutionary spectra display the general absence of obliquity in the climate records through the MPWP during a 1.2 Myr node in obliquity, with the obliquity returning strongly in the LRO4 stack, but not in the U1361A Antarctic ice volume proxy time series or the Antarctic-driven Whanganui basin RSL record until $\sim 2.8 \mathrm{Ma}$. Evolutionary spectra were obtained using the EHA function in Astrochron (Meyers, 2014) using a window of $200 \mathrm{kyr}$ for the RSL record and $400 \mathrm{kyr}$ for the others, with a step of the sampling interval and the 
power is normalised (maximum in each window in normalised to unity). Eccentricity (E: 0.08-0.11 kyr-1), obliquity (0: 0.18-0.024 kyr-1) and precession ( $P$ : 0.043-0.053 kyr-1) frequency bands are identified......

Figure 6.4. The Whanganui RSL record (untuned age model as per Chapter 5) correlated (from left to right) with summer insolation for $65^{\circ} \mathrm{N}$ (Laskar et al., 2004), summer insolation for $65 \mathrm{~S}$ (Laskar et al., 2004), summer energy for a melt threshold of $400 \mathrm{GJ} / \mathrm{m} 2$ (calculated after Huybers and Tziperman, 2008), mean annual insolation (Laskar, 2004), summer energy for a melt threshold of $250 \mathrm{GJ} / \mathrm{m} 2$ (calculated after Huybers and Tziperman, 2008) and the benthic $\delta 180$ stack (Lisiecki and Raymo, 2005).

Figure 6.5 Comparison of Whanganui Basin RSL amplitudes to the sea-level estimates of Miller et al., (2012) that include those discussed in text, two different calibrated $\delta^{18} \mathrm{O}$ records ( $\delta 180-$ Miller et al., 2012; New Zealand - Naish and Wilson, 2009), Mg/Ca estimates (Dwyer and Chandler, 2009; Sosdian and Rosenthal, 2009) and geological deposits (Miller et al., 2012 and references therein). The RSL record is scaled to the Miller et al. (2012) compilation, however the absolute magnitudes are not registered to present day and has been overlain for an observational best fit, but could move vertically. Note the RSL record is not tuned and therefore displays some offset of cycles between the benthic $\delta 180$ stack calibrated records. 156

Figure 6.6 GIA model for 15m ESL; Scenario 1) $20 \mathrm{~m}$ from AIS; 2) $15 \mathrm{~m}$ from AIS and $5 \mathrm{~m}$ from GIS; 3 ) $25 \mathrm{~m}$ from AIS offset by $5 \mathrm{~m}$ from GIA. The models display the amplitude of sea-level change from a glacial to interglacial period, where the black bold line demonstrates the location of ESL.

Figure 6.7 The RSL amplitude for Whanganui Basin (which approximates ESL) and Boston for Scenarios 1-3 (undifferentiated) with respect to the initial condition (halfway between interglacial and glacial).

Figure 6.8 Modelled Antarctic ice sheet $\delta^{18} O$ composition (DeConto and Pollard, 2016) for A) modern ice surface. B) modern ice basal layer, C) modern depth-averaged D) Pliocene depth-averaged.

Figure 6.9 One-to-one correlation of sea-level fluctuations in the Whanganui RSL record with sea-level cycles implied from the benthic $\delta^{18} \mathrm{O}$ stack (Lisiecki and Raymo, 2005). Note that only identified marine isotope stages are used for $\triangle \delta 180$ seawater calibration purposes. It is also noted that during the MPWP the LRO4 stack is of lower resolution than the Whanganui RSL. The pink shaded area defines the MPWP. The RSL record is untuned accounting for the offset of the one-to-one correlations to the benthic $\delta^{18} \mathrm{O}$ stack.

Figure 6.10 The Whanganui RSL record on the left with the precession-paced MPWP and obliquity-paced late Pliocene sections highlighted with different GIS, AIS and NHIS configurations and SLE illustrated for interglacial and glacial extreme conditions relative to present-day Antarctica $(0 \mathrm{~m}$; central figure). The anti-phased $15 \mathrm{~m}$ amplitudes of the MPWP are interpreted as $5 \mathrm{~m}$ from GIS offset by $\sim 20 \mathrm{~m}$ from AIS present day to peak interglacial. Higher amplitudes would then include larger-than-present AIS (nearing LGM; Clarke and Tarasov, 2014). While the late Pliocene amplitudes include increasing NHIS contributions and smaller interglacial configurations. 


\section{List of Tables}

Table 2.1 Comparison of modern $\delta^{18} \mathrm{O}$ ice sheet composition(Lhomme et al., 2005) and the respective, sea-level equivalent (Fretwell et al., 2013), linear $\delta^{18} \mathrm{O} /$ sea-level calibrations and the total possible contribution to $\delta^{18} O_{\text {seawater }}$ (after Winnick and Caves, 2015). Note the modern calibration for all ice sheets is much higher than that suggested for the Late Pleistocene $\left(0.011 \% . \mathrm{m}^{-1}\right)$ because of the absent Northern Hemisphere Ice Sheets.36

Table 3.1 Core recovery for PQ coring ( $81 \mathrm{~mm}$ diameter) and HQ coring (61 mm diameter) for Tiriraukawa-1 and Siberia-1 cores.

Table 3.2 Sample type, size and frequency of sampling for Siberia-1 and Tiriraukawa-1 cores. 52

Table 3.3 Average standard deviation in volume \% (from standard deviation of each size bin) of repeat grain size distribution samples.

Table 4.1 Lithofacies codes, description and depositional environments for the Utiku Group recovered by the cores (Facies 1-4) and described in outcrop for the Rangitikei River Section (Facies 5) by Journeaux et al., 1996. These facies were also applied to the Mangaweka Group outcrop sections.

Table 4.2 Extant genus abundant over $10 \%$ and $5 \%$ (in brackets) for the six clusters identified in Figure 7 with interpreted depositional environments.

Table 4.3 Genus used in Modern Analogue Technique determined by a significant correlation distance (1-r of Pearson's r; Hammer et al., 2001) of more than \pm 0.3 where 1 is a total positive correlation and -1 is a total negative correlation. Bold genus were excluded for reasons outlined in text.

Table 4.4 Summary of individual glass shard major-element compositions of tephra beds from the Mangaweka Mudstone at the Watershed Road section (Tiri-1 and -2 tephra), Ruahine Road Section, Mangaweka (Eagle Hill and Kowhai tephra), and the Siberia tephra located in Utiku Group in the Turakina Valley (Sefton, 2015). Seven tephra (M9, M10, M12-upper, M12-lower, M13, M14, M15) analysed from ODP-1124C (Stevens, 2010) are included for comparison. Data displayed are weight percent means calculated on a water-free basis. Standard deviation $( \pm 1 S D)$ is indicated in brackets below mean values.

Table 5.1 Significant wave height (Hs) and peak wave period (Tp) for the three modern transects (Monterey: Scripps Institution of Oceanography, 2018; Whanganui Bight and Manawatu: Metocean View, 2018).

Table 5.2 Input parameters for the long-term backstripping for the two stratigraphic sections (Siberia-1 and Rangitikei pseudo-core). The depositional environments (which dictate the water depth range), lithology (for porosity calculation), age of units (rate of subsidence) and stratigraphic thickness of each unit (to determine the decompacted sediment thickness) are required for the total stratigraphic section from the basement (including exhumed material).

Table 5.3 Mean amplitude of glacial-interglacial sea-level cycles with error defined by Equation 5.8.

Table 5.4 Three scenarios of Antarctic Ice Sheet and Greenland Ice Sheet meltwater contribution to $15 \mathrm{~m}, 20 \mathrm{~m}$ and 25 m eustatic sea-level used in the glacio-isostatic models.

Table $6.1 \mathrm{pCO}_{2}$ (compiled by Foster, 2015) and global mean temperature (Dowsett et al., 2012; Haywood et al 2013; Masson-Delmotte et al., 2013; Golledge et al., 2017) for the early Pliocene, MPWP and late Pliocene, with dominant orbital frequencies indicated by various proxy records for the Antarctic Ice sheet (AIS) and Greenland / Northern Hemisphere Ice sheets (GIS/NHIS), the benthic 8180stack (Lisiecki and Raymo, 2005) and relative sea-level of Whanganui Basin.

Table 6.2 Calibration of resulting $\Delta \delta 180$ seawater for variable $\Delta \delta 180$ temperature contributions with $R S L$ amplitudes for glacial-interglacial amplitudes of MIS 101-M2. Note the exclusion of WAISmarine $\Delta \delta 180$ seawater equivalent (Winnick and Caves, 2015) for the last two calibrations and the variable temperature component consists of 50\% for the late Pliocene and $33 \%$ for the MPWP.

Table 6.3 Modern $\delta^{18}$ Oice values (Lhomme et al., 2005) and sea-level equivalent (Fretwell et al., 2013) for calibrations after Winnick and Caves (2015). The WAISmarine total $\delta^{18}$ Oseawater equivalent is the value used in Table 6-1 and 6-3. 


\section{List of Appendices}

Appendix A. Drill logs and core storage

The drill logs note the cumulative depth and core recovery for each run. The length of the string and the height of string above the datum (well head), determines the top and bottom depths of the run. The recovered core length is assigned depths based on the fit of the core to the previous section, or from the base of the string if there is evidence of the core catcher and drill bit imprinted on the core. The core boxes are note the depth of each section, and lengths of no recovery (NR).

Appendix B. Physical property log procedure and processing

The standard specifications and measurements are outlined here, along with the calculations for core thickness, magnetic susceptibility and gamma-ray attenuated density used in this study.

Appendix C. Lithology log and sample register

Lithology logs carried out on-site and sampling sheet.

Appendix D. Grain size methodology testing

This outlines the methodology test undertaken to explore the effect of two different hydrogen peroxide $\left(\mathrm{H}_{2} \mathrm{O}_{2}\right)$ treatments and use of hydrochloric acid $(\mathrm{HCl})$ on the sediments prior to grain size analysis.

Appendix E. Grain size analysis of core sites

Grain size volume percentage for Tiriraukawa-1 and Siberia-1 samples.

Appendix F. Benthic foraminiferal census counts

Raw individual counts of benthic foraminifera species, with total benthic and planktic counts, the number of benthic stress markers after Van Hinsbergen et al. (2005) and the planktic percentage (Hayward and Triggs, 2016), and productivity (Kamp et al., 1998) from the benthic counts and weight of sediment specimens were counted from (washed residue weight $>63 \mu \mathrm{m}$ from 200 g; Number of splits; picked (+150 $\mu \mathrm{m})$ residue weight).

Appendix G. Magnetostratigraphy manuscript 
Magnetostratigraphy of the Siberia-1 and Tiriraukawa-1 cores and correlation to Geomagnetic Polarity Timescale has been generated as a publication submitted to Geophysical Journal International. Entitled "High-resolution magnetostratigraphy of mid-Pliocene warm period ( 3.6-3.0 Ma) shallow-marine sediments, Whanganui Basin, New Zealand" by Claudio A. Tapia, Georgia R. Grant, Gillian M. Turner, Christian Ohneiser, Tim R. Naish, Gavin Dunbar.

Appendix H. Modern Analogue Technique results

The abundance of extant benthic foraminifera grouped as genus for Siberia-1 (sf), Tiriraukwa1 (tf), Watershed Road Section (WS; Sefton, 2015) and Rangitikei River Section (TJ; Journeaux, 1995), used in the Modern Analogue Technique. Results of the Modern Analogue Technique by depth of sample for Tiriraukawa-1, Siberia-1, Watershed Road Section, Rangitikei Section displaying the water depths of the first modern analogue, and weighted average for the $1^{\text {st }}$ to $2^{\text {nd }}$ and $1^{\text {st }}$ to $3^{\text {rd }}$ analogue.

Appendix I. QSR supplementary information

This contains the supplementary text and figures submitted with the QSR manuscript, referred to in text of Chapter 4.

Appendix J. Stable isotope analysis

The stable oxygen and carbon isotope dataset from Siberia-1 and Tiriraukawa-1 cores and interpretation of the results.

Appendix K. Water depth threshold summary

Matlab script for calculating water depth thresholds for varying wave height, wave periods at different water depths and grain sizes. Summary of water depths where Uw>Ucr when grain size equals $64,146,117,160$ and $408 \mu \mathrm{m}$, that corresponds to $0 \%, 25 \%, 50 \%, 75 \%$ and $100 \%$ sand content respectively. For wave periods of 5 to $22 \mathrm{~s}$ and wave heights of 0.5 to $4 \mathrm{~m}$.

Appendix L. Grain size paleobathymetry technique

The modern grain size data from Manawatu (compiled from Perrett, 1990 and Dunbar and Barrett, 2005), Monterey Bay (Chin, 1984) and Whanganui Bight (Beaumont et al., 2013) alongside the calculations for sand percentage with minimum and maximum (outlined in the text of Section 5.1.1) from the maximum grain size diameter (Dmax in $\mu \mathrm{m}$ ) and the threshold water depths with Dmax for model profiles for Manawatu, Monetrey Bay and Whanganui Bight (applied to the dataset outlined in this thesis) discussed in the text of Section 5.1.1. And the paleobathymetry for Siberia-1, Tiriraukawa-1, Rangitikei River Section and Watershed Road. 
Appendix M. High resolution backstripping input

High-resolution stratigraphic datasets for Siberia-1 and Rangitikei, formatted for backstripping software that include section name, section thickness, density (derived from lithology as the sum of shale, micrite, sandstone, limestone, silt and limestone relative proportions), age (top of section), cement content ( $0 \%$ for all as relatively young sediments above basement) and paleowater depths. This contains the paleobathymetric records for the Utiku Sandstone from the Siberia-1 core and Mangaweka Mudstone from the Rangitikei River Section. 


\section{Introduction}

\subsection{Rationale}

Glacio-eustatic sea level is a direct response to fluctuations in global ice volume and represents one of the most dynamic and significant changes that occurs in response to changes in Earth's climate. Rising sea level is one of the most obvious consequences of the current warming climate (Masson-Delmotte et al., 2013), and quantifying past sea level is integral to understanding polar ice sheet sensitivity, and the potential rate and magnitude of future sealevel rise. The mid-Pliocene warm period (MPWP; 3.3-3.0 Ma) has been identified as the most recent period when atmospheric carbon dioxide $\left(\mathrm{pCO}_{2}\right)$ levels of $\sim 400 \mathrm{ppm}$ was similar to today (Seki et al., 2010; Martinez-Boti et al., 2015). The MPWP therefore represents an analogue for future warming climate scenarios (Naish and Zwartz, 2012; Masson-Delmotte et al., 2013) with temperatures of $2-3^{\circ} \mathrm{C}$ above present (Haywood et al., 2013). The termination of MPWP, the expansion of Northern Hemisphere Ice Sheets (NHIS) and the development of a bi-polar glacial system in the late Pliocene (3.0-2.6 Ma; Maslin et al., 1998; Jansen et al., 2000; Brigham-Grette et al., 2013) represents one of the most significant climatic events of the entire Cenozoic (last $66 \mathrm{Ma})$. Reconstructions of sea-level amplitudes for this period, will inform on ice sheet sensitivity under a climate of sustained $\mathrm{pCO}_{2}$ levels of $400 \mathrm{ppm}$, similar to that we observe today.

Previous estimates of sea level in the MPWP have focused on the absolute magnitude of peak interglacial global mean sea-level (GMSL), with respect to present day (Miller et al., 2012; Dutton et al., 2015). However, uncertainty arising from the visco-elastic response of the lithosphere due to polar ice mass changes (glacio-isostatic adjustment; GIA) and long-term changes in topographic expression due to mantle convection processes (dynamic topography), suggest that absolute peak Pliocene sea-level may be currently unknowable (Raymo et al., 2011; Rowley et al., 2013; Rovere et al., 2014). Additionally, the magnitude of glacialinterglacial sea-level change above present day, does not constrain the total meltwater contributions of the polar ice sheets unless MPWP glacial minima are assumed to be comparable to present day sea level. A continuous, direct sea level record that describes the 
full glacial-interglacial amplitude of sea-level cyclicity is needed in order to evaluate the relative contributions of polar ice sheet meltwater.

The link between orbital pacing of incoming solar radiation (insolation) and Earth's climate is now well-established (e.g. Hays et al., 1976; Masson-Delmotte et al., 2013). However, the variable dominance of orbital cycles (eccentricity: 100 kyr, obliquity: 41 kyr and precession 21 kyr) at different periods in Earth's history highlights the importance of background climate boundary conditions, such as million year-long changes in greenhouse gases and tectonics on the Earth system response (e.g. Zachos et al., 2001) and has been the focus of much debate (e.g. Raymo and Huybers, 2008). Moreover, the physical processes by which the orbital variation of insolation manifests itself as large-scale oceanic, atmospheric and cryospheric changes is still much debated. Direct records of sea-level changes that are continuous and independently dated are required to evaluate the current orbital climate-forcing hypotheses (Huybers, 2006; Raymo et al., 2006).

Arguably the most detailed record of climate cyclicity, over the last $5 \mathrm{Myr}$, is the deep-ocean benthic (oxygen isotope) $\delta^{18} \mathrm{O}$ stack (Lisiecki and Raymo, 2005). However, its signal both responds to changes in global ice volume and local temperature of the deep-sea. Successful, identification and removal of the temperature component of the benthic $\delta^{18} \mathrm{O}$ values are yet to be achieved due inherent uncertainties in proxy temperature methods (Dowsett and Cronin, 1990; Dwyer and Chandler, 2009; Sosdian and Rosenthal, 2009; Miller et al., 2012). Furthermore, the resulting ice volume may be complicated by differing polar ice sheet composition and recent studies have highlighted the non-linear relationship between ice mass change and sea-level for marine -based ice sheets (Winnick and Caves, 2015; Gasson et al., 2016). As a result of these ice mass-volume ambiguities, questions arise, such as, "Are the frequencies and magnitude of the glacial-interglacial amplitudes recorded in the benthic $\delta^{18} \mathrm{O}$ stack truly representative of polar ice sheet and global sea-level variability", and therefore, "Is a sea-level calibration of the benthic $\delta^{18} \mathrm{O}$ stack possible for the MPWP and late Pliocene".

The Whanganui Basin, New Zealand, contains a $5 \mathrm{~km}$ thick shallow-marine sedimentary record, that accumulated as basin subsidence kept pace with sediment supply through the PlioPleistocene (Fleming, 1953). Well-dated cyclical sequences representing transgressive, highstand and regressive stages of sea-level change, have been linked to glacial-interglacial global sea-level fluctuations (Naish et al., 1998; Saul et al., 1999; Naish and Wilson, 2009). 
Paleobathymetric reconstructions from water depth sensitive extant benthic foraminifera, have been backstripped to remove tectonic subsidence in order to reconstruct relative sea level (RSL; e.g. Naish and Wilson, 2009). However, these reconstructions are hampered by unconformity-bound sequences, irregular sampling from outcrop, and only first-order estimates for basin subsidence.

In this thesis, two new drill cores were recovered through the $300 \mathrm{~m}$-thick, mid-Pliocene Utiku Sandstone (3.3-3.0 Ma) from Whanganui basin. This enabled continuous sampling of middle to outer shelf depositional environments that does not contain unconformities associated with low sea-level. This record is extended into the late Pliocene (3.0-2.6 Ma) by re-evaluating previously described outcrop records, for paleobathymetric and RSL reconstruction. Dated and correlated tephra horizons, biostratigraphy and paleo-magnetostratigraphy provide a wellconstrained chronostratigraphic framework within which paleo-water depth changes are constrained by sedimentary facies analysis, benthic foraminiferal depth-ecology, and a quantitative sediment grain size-wave method. The paleobathymetry is "quantitativelybackstripped" (described later) to remove the local influence of tectonic subsidence and the resulting RSL curve is corrected for the influence of GIA. This enables:

(1) The development of an independent and unique record capturing the orbital frequency and full glacial-interglacial amplitude of mid- to late Pliocene global sea-level change.

(2) An assessment of the role of orbital forcing and climate system feedbacks, the relative influence of polar meltwater contributions, and comparison to the benthic $\delta^{18} \mathrm{O}$ stack.

\subsection{Research questions}

This project aims to answer:

- What is the amplitude of glacial-interglacial sea-level change and the relative meltwater contributions for mid- to late Pliocene global sea-level fluctuations?

Constraining the total contributions of polar ice sheet melt to sea level enables a better understanding of ice sheet sensitivity in the past. Currently, estimates of peak 
interglacial magnitude of GMSL for the MPWP, including all sources of error, is ranges between 6- $45 \mathrm{~m}$ (Dutton et al., 2015). A more robust, quantitative approach to reconstructing paleobathymetry is developed in this thesis, prior to backstripping the record of tectonic subsidence and sediment loading, to obtain a continuous relative sea-level record. Modelling of GIA is undertaken to estimate eustatic change from the RSL record of Whanganui Basin. This provides a continuous record of the amplitude of sea-level fluctuations during the mid- to late Pliocene and suggested meltwater contributions, taking into consideration the state of paleo ice sheets.

- What is the frequency of contributions mid-to late Pliocene, glacio-eustatic sea-level fluctuations?

The dominant orbital frequency apparent in geological records is widely debated. Here, the continuity of an independently-dated global sea-level record is used to determine orbital-pacing for comparison with that of other established climate records, particularly the benthic $\delta^{18} \mathrm{O}$ stack. This enables the relative influence of the polar ice sheets to be assessed in the context of long-standing orbital forcing hypotheses (e.g. Huybers, 2006; Raymo et al., 2006), together with questions outlined in more detail in Chapter 2.

- Can a sea-level calibration of the benthic $\delta^{18} \mathrm{O}$ stack be developed for the Pliocene? Calibrations for the Quaternary are made possible through direct sea level records from well-dated uplifted coral terraces (Fairbanks and Matthews, 1978; Chappell and Shackleton, 1986). However, the differing sources of meltwater for the MPWP and long-term secular changes in ocean bottom-water temperatures cause this calibration to change through time. Furthermore, marine-based ice sheet contributions (ice sitting below sea level and already displacing ocean volume) to deep-sea benthic $\delta^{18} \mathrm{O}$ values but not sea level (e.g. Gasson et al., 2016) complicates such a calibration. Nevertheless, a correlation of the Whanganui RSL record to the benthic $\delta^{18} \mathrm{O}$ stack was made and possible temperature contributions were removed, in an attempt to evaluate the suitability of the benthic $\delta^{18} \mathrm{O}$ stack as a global sea-level proxy.

\subsection{Thesis outline}


The thesis takes the following approach to developing the sea level record and addressing the questions outlined above.

Chapter 2: This literature review assesses our knowledge of how orbital (Milankovitch) cycles influence climate and ice volume in the context of the Pliocene climate with particular focus on ice sheet reconstructions. Different methods of sea level reconstruction are discussed using examples of previous studies and the rationale for why the Whanganui Basin provides an ideal location to develop a sea level record is outlined.

Chapter 3: This chapter outlines the core recovery, core processing and sampling, the collection of physical property logs, grain size analysis, benthic foraminiferal counts and identification, and stable isotope analysis. Further methods in the use of the datasets are outlined in the relevant chapters.

Chapter 4: This chapter is constructed as a manuscript submitted to Quaternary Science Reviews on the 18th of May, however it has been re-formatted in line with the thesis. This chapter provides the underpinning paleoenvironmental interpretation and high-resolution age model for the mid- to late Pliocene shallow-marine cyclic sediments recovered in the two drill cores. It encompasses the sedimentological analysis of the cores and outcrop, providing lithofacies, sequence stratigraphy and shelf architecture model. It also outlines the analysis of the foraminiferal census counts quantified using modern analogue technique to provide a depositional environment interpretation and first order paleobathymetry.

Chapter 5: A RSL record is developed from the cores and adjacent outcrops, firstly by quantifying the paleobathymetry, using sediment grain size as a function of water depth. A backstripping technique is then applied to remove the local influences of subsidence, sediment and water loading, to determine a RSL record. Finally, modelling the visco-elastic and gravitational response to various polar ice sheet meltwater scenarios is used to assess how the Whanganui RSL record relates to eustatic or global sea level.

Chapter 6: This chapter represents the conclusions drawn from this study, exploring the role of orbital forcing on the Whanganui RSL record and other climate proxies to evaluate the 
response of polar ice sheets during the mid- to late Pliocene. Assessing the relative influence of meltwater contributions to the RSL record and calibrations of the benthic $\delta^{18} \mathrm{O}$ stack, are evaluated using the RSL amplitudes from this study.

\subsection{Key terms and acronyms}

\begin{tabular}{|c|c|}
\hline Term/ Acronym & Definition \\
\hline MPWP & Mid-Pliocene warm period 3.3-3.0 Ma \\
\hline Late Pliocene & Defined here as 3.0-2.6 Ma \\
\hline Mid- to late Pliocene & Used when discussing the whole record (3.3-2.6 Ma) \\
\hline AIS & Antarctic Ice Sheets \\
\hline WAIS & West Antarctic Ice Sheet \\
\hline EAIS & East Antarctic Ice Sheet \\
\hline GIS & Greenland Ice Sheet \\
\hline NHIS & $\begin{array}{l}\text { Northern Hemisphere Ice sheet (refers to those outside } \\
\text { of the GIS) }\end{array}$ \\
\hline Benthic $\delta^{18} \mathrm{O}$ stack & $\begin{array}{l}\text { Lisiecki and Raymo (2005) compilation of deep-sea } \delta^{18} \mathrm{O} \\
\text { records, which comprises temperature and seawater } \\
\text { (ice volume) component, for which the seawater } \\
\text { component is regularly used to determine changes in } \\
\text { ice volume. }\end{array}$ \\
\hline IBRD & $\begin{array}{l}\text { Ice-berg rafted debris, used as a proxy of ice volume } \\
\text { fluctuation. }\end{array}$ \\
\hline GIA & $\begin{array}{l}\text { Glacio-isostatic adjustment; This refers to any visco- } \\
\text { elastic response of the lithosphere to redistribution of } \\
\text { mass and instantaneous gravitational attraction } \\
\text { variation of the ocean. }\end{array}$ \\
\hline Dynamic Topography & $\begin{array}{l}\text { The positive and negative topographic relief in response } \\
\text { to changes in mantle convection. }\end{array}$ \\
\hline Paleobathymetry & $\begin{array}{l}\text { Depositional water depth of sediments influenced by } \\
\text { combined tectonic subsidence, sediment and water } \\
\text { loading and global sea-level change. }\end{array}$ \\
\hline Backstripping & $\begin{array}{l}\text { A technique that identifies and removes the effects of } \\
\text { tectonic subsidence, sediment and water loading on } \\
\text { paleobathymetry to obtain a RSL record. }\end{array}$ \\
\hline RSL & $\begin{array}{l}\text { Relative sea level; sea level that has been corrected for } \\
\text { tectonic influences, but includes GIA effects and thus is } \\
\text { site specific. While GIA is modelled for scenarios in this } \\
\text { thesis, the effects are not unequivocally removed from } \\
\text { the RSL, and thus the record remains a RSL estimate. }\end{array}$ \\
\hline
\end{tabular}


ESL

GMSL

SLE

Tangahoe Mudstone

Utiku (Group)

Sandstone

Mangaweka

Mudstone

Siberia-1

Tiriraukawa-1

Watershed Road

Section

Rangitikei River

Section

Turakina Section
Eustatic sea-level; change in global sea level in response to changing volume. In this thesis, ESL is used to refer to mean change in sea level, unregistered, as a measure of meltwater contribution, which is distributed unevenly over the ocean.

Global mean sea-level; describes the mean height of sea-level from the centre of the earth (usually in reference to present day).

Sea-level equivalent, the global sea-level contribution of ice sheet. This is variable for land and marine based ice sheets.

Upper slope massive mudstone deposited from 4.2-3.2 Ma.

Middle to inner shelf to shoreface deposits including mudstone and sandstones, deposited between 3.2-3.0 Ma.

Outer shelf massive mudstone deposited between 3.0$2.6 \mathrm{Ma}$.

The sediment core recovered in the Turakina River valley, containing the Utiku Sandstone and upper Tangahoe Mudstone ( 3.3-3.0 Ma)

The sediment core recovered near Tiriraukawa, along Watershed Road, containing the Utiku Sandstone and upper Tangahoe Mudstone ( 3.3 - 3.0 Ma) The outcrop describing the Mangaweka Mudstone ( 2.9-2.6 Ma) along Watershed Road by Sefton (2015). The outcrop describing the Utiku Sandstone and Mangaweka Mudstone ( 3.2-2.6 Ma) in the Rangitikei River valley by Journeaux et al. (1996) and Naish et al. (1998).

Outcrop described in the Turakina River valley by Patterson (2014) that contains stratigraphy recovered by the Siberia-1 core (3.1-3.0 Ma). 


\section{Literature review: Mid- to late Pliocene climate, sea level and the Whanganui Basin shallow-marine sedimentary record}

This review outlines the current understanding of orbitally-driven, mid- to late Pliocene (3.3 2.6 Ma) global sea-level changes, with specific focus on the contribution of the polar ice sheets. This review assesses how periodic changes in Earth's orbital geometry, known as Milankovitch cycles, together with changes in atmospheric concentration of carbon dioxide, influence volume changes of the polar ice sheets, and therefore the magnitude and frequency of global sea-level change (Section 2.1).

The mid-Pliocene warm period (MPWP; 3.3-3.0 Ma) is widely regarded as the most accessible and relevant paleoclimate analogue that can provide insights into how the climate system, the polar ice sheets and sea level might respond to future global warming (e.g. Naish \& Zwartz, 2012). The interval from 3.0 to 2.6 Ma (late Pliocene) is marked by the progressive expansion of ice on Northern Hemisphere continents as global climate cooled in concert with a decline in $\mathrm{pCO}_{2}$ to pre-industrial levels. Climate reconstructions for these periods are discussed in Section 2.2 , with particular focus on polar ice sheet response to such a climate.

Existing methods and proxies using geological archives to reconstruct sea-level are summarised in Section 2.3, and are often compromised by equivocal interpretations (e.g. benthic $\delta^{18} \mathrm{O}$ record), regional tectonics, dynamic topography and regional gravitational and viscoelastic responses of the crust. The high-resolution, continuous shallow-marine sedimentary record in Whanganui Basin, New Zealand, has the potential to address some of these issues in order to provide new constraints on the magnitude and frequency of global sealevel change (Section 2.4). 


\subsection{Orbital forcing of Earth's climate}

The term 'orbital forcing' refers to the incoming solar radiation (insolation) originating from long-term variations in the Earth's orbital parameters. The relationship between climate and insolation was developed by Milankovitch, building on observations from Adhmer and Croll in the early $19^{\text {th }}$ century (e.g. Milankovitch, 1941; Raymo \& Huybers, 2008). Today, precise astronomical calculations of the orbital geometry of the solar system are available for the past $\sim 50$ million years and millions of years into the future (Laskar et al., 2004). Changes in eccentricity, longitude of perihelion (related to precession) and axial tilt (obliquity) combine to affect the seasonal and latitudinal distribution and magnitude of solar energy received at the top of the atmosphere, and consequently the duration and intensity of seasons (Berger and Loutre, 1991). Obliquity also modulates annual mean insolation at any given latitude.

The eccentricity cycle (Figure 2.1) describes the departure from a circular orbit of Earth around the Sun due to gravitational interactions with other planets in the solar system, primarily Saturn and Jupiter. This influences the total amount of insolation reaching Earth's atmosphere by modulating the Sun-Earth distance on $\sim 400 \mathrm{kyr}$ and 100 kyr cycles. Eccentricity has only limited impact on global and annual mean insolation. However, changes in eccentricity affect the intra-annual changes in the Sun-Earth distance and therefore modulate the seasonal effects induced by precession.

Precession causes changes in longitude of the perihelion (shortest Sun-Earth distance) and shifts the position of the solstices and equinoxes on the orbit relative to the perihelion, which in turn modulates the seasonal cycle of insolation over 19 kyr and 23 kyr cycles (Figure 2.1). As a result, changes in the position of the seasons, strongly modulate the latitudinal and seasonal distribution of insolation. During periods of low eccentricity, seasonal insolation changes induced by precession are weaker than during periods of larger eccentricity. According to Kepler's second law of planetary motion, the duration and intensity of the summer is inversely proportional to Earth's distance from the Sun. Therefore, long summers in the Southern Hemisphere should occur when the Earth's orbit is in aphelion during austral summer, whereas the Northern Hemisphere experiences shorter more intense summers in perihelion. Thus, the influence of the precession cycle on global climate is anti-phased between the hemispheres. 
The extent of the polar circles (i.e. the latitude above which experiences $24 \mathrm{hr}$ daylight and darkness) is determined by the tilt of Earth's axis, termed obliquity, which varies between $22.1^{\circ}$ and $24.5^{\circ}$ (Figure 2.1) at a dominant frequency of $41 \mathrm{kyr}$. Obliquity controls the latitudinal gradient of insolation. This parameter also modulates annual mean insolation changes with opposite effects in low versus high latitudes (and therefore no effect on total global average insolation) and is in phase between the hemispheres.

Orbitally-driven climate cycles proposed by Milankovitch (1941) cause long-term changes in daily insolation at precession frequencies, modulated by obliquity and eccentricity, whereby the number and intensity of positive degree days at high latitudes during summer, controls variations in the size and extent of polar ice sheets, but is anti-phased between the hemispheres.

The first compelling geologic evidence that Earth's climate had been driven by orbital cycles came from stable oxygen isotope analysis of fossil foraminifera shells in deep-sea sediment cores (Emiliani, 1966; Shackleton and Opdyke, 1973; Hays et al., 1976). Growing ice sheets preferentially incorporate the light isotope ${ }^{16} \mathrm{O}$, which causes the ocean oxygen isotope ratio $\delta^{18} \mathrm{O}$ to become more positive (enriched in ${ }^{18} \mathrm{O}$ ), as global sea level falls. Additionally, temperature dependent fractionation between water and calcite causes $\delta^{18} \mathrm{O}$ to increase as ocean temperatures cool. Therefore, the $\delta^{18} \mathrm{O}$ record from foraminifera in particular deep-sea cores contains both global (ice volume) and local (temperature, evaporation /precipitation) components (Urey, 1947; Epstein, 1951; Lea, 2010).

The presence of a strong cyclicity at $\sim 100, \sim 40$ and $\sim 20$ kyrs observed in $\delta^{18} \mathrm{O}$ time series by Hays et al. (1976), was related to the influence of eccentricity, obliquity and precession, respectively, in their classic paper "Variations in Earth's Orbit: Pacemaker of the Ice Ages". While, they discussed the possibility of combinations of obliquity and precession contributing to the dominating 100 kyr cycle, they attributed it to a "yet to be understood" non-linear response to eccentricity forcing. Times of amplified response of the climate system to relatively weak eccentricity forcing during the geological past, and especially in the last 1 Myr (Imbrie et al., 1992), still confound paleoclimatology today (e.g. Crowley and Hyde, 2008; Huybers, 2009). 

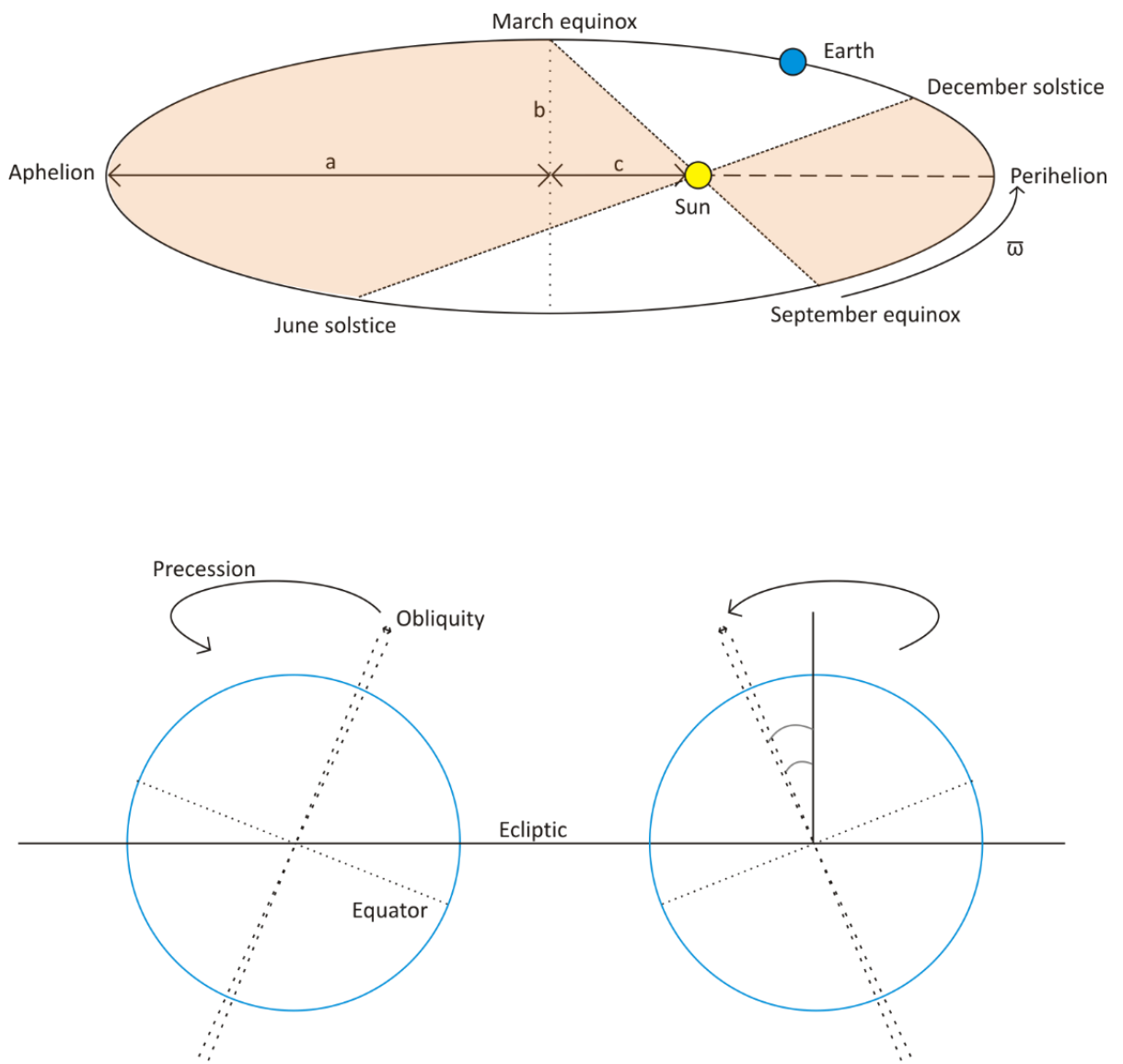

Figure 2.1 Schematic diagram illustrating parameters describing Earth's orbit about the sun, where eccentricity (e) is equal to $c / a$, climatic precession = e sin $\varpi$, and the degree of tilt (obliquity) is measured in reference to the perpendicular of the ecliptic. The orange shaded regions display the effect of Kepler's Second Law for arbitrary solstice positions.

Tuning of benthic $\delta^{18} \mathrm{O}$ ice volume proxy records to time series of the orbital parameters has provided a detailed chronology for Pliocene-Pleistocene ice volume and sea-level changes (e.g., Shackleton et al., 1995: Lisiecki and Raymo, 2005). The Antarctic ice core record indicates that greenhouse gases co-varied with Antarctic temperature over glacial-interglacial cycles during the last 800,000 years (EPICA Community Members, 2004), suggesting a close link between greenhouse gas variations and Earth's surface temperature. More recently, computer modelling using global climate models (Masson-Delmotte et al., 2013, and refs. therein) provides strong support for the Milankovitch theory, that Northern Hemisphere summer insolation is sufficiently low to initiate ice sheet growth on northern continents. The role of greenhouses gases and high-latitude ice albedo feedbacks in amplifying the initial weak insolation forcing of eccentricity is becoming clearer (e.g. Denton et al., 2010). Climate-ice sheet models forced by variations in orbital parameters and reconstructed $\mathrm{pCO}_{2}$ concentrations simulate ice volume variations and other climate characteristics during glacial- 
interglacial cycles over the last $\sim 1$ Myr that are consistent with ice core and geological paleoclimate records (Abe-Ouchi et al., 2013; Ganopolski et al., 2010; Masson-Delmotte et al., 2013; Figure 2.2). However, the drivers for changes in the dominant orbital pacing is less wellunderstood, such as the Mid-Pleistocene Transition (1.2 - $0.8 \mathrm{Ma}$ ) from $40 \mathrm{kyr}$ to $100 \mathrm{kyr}$ pacing of climate.

Therefore, according to assessment by the International Panel on Climate Change (IPCC; Masson-Delmotte et al., 2013), there is now high confidence that orbital forcing is the primary external driver of glacial-interglacial cycles and $\mathrm{pCO}_{2}$ content plays an important internal feedback role, affecting the timing and amplifying the magnitude of the climate system response (Timmermann et al., 2009; Shakun et al., 2012). Orbital-scale variability in $p \mathrm{CO}_{2}$ concentrations over the last several hundred thousand years co-varies with proxy records including Fe concentrations in dust from Southern Ocean sediment cores that regulates phytoplankton growth (e.g. Martinez-Garcia et al. 2011; Jaccard et al., 2013), reconstructions of global ice volume (Lisiecki and Raymo, 2005), climatic conditions in central Asia (Prokopenko et al., 2006), tropical (Herbert et al., 2010) and Southern Ocean sea-surface temperatures (SST; Pahnke et al., 2003; Lang and Wolff, 2011), Antarctic temperature (Parrenin et al., 2013), deepocean temperature (Elderfield et al., 2010), Arctic temperature and vegetation (Melles et al., 2012; Brigham-Grette et al., 2013), biogeochemical conditions in the North Pacific (Jaccard et al., 2010) and deep-ocean circulation and ventilation (Lisiecki et al., 2008). 


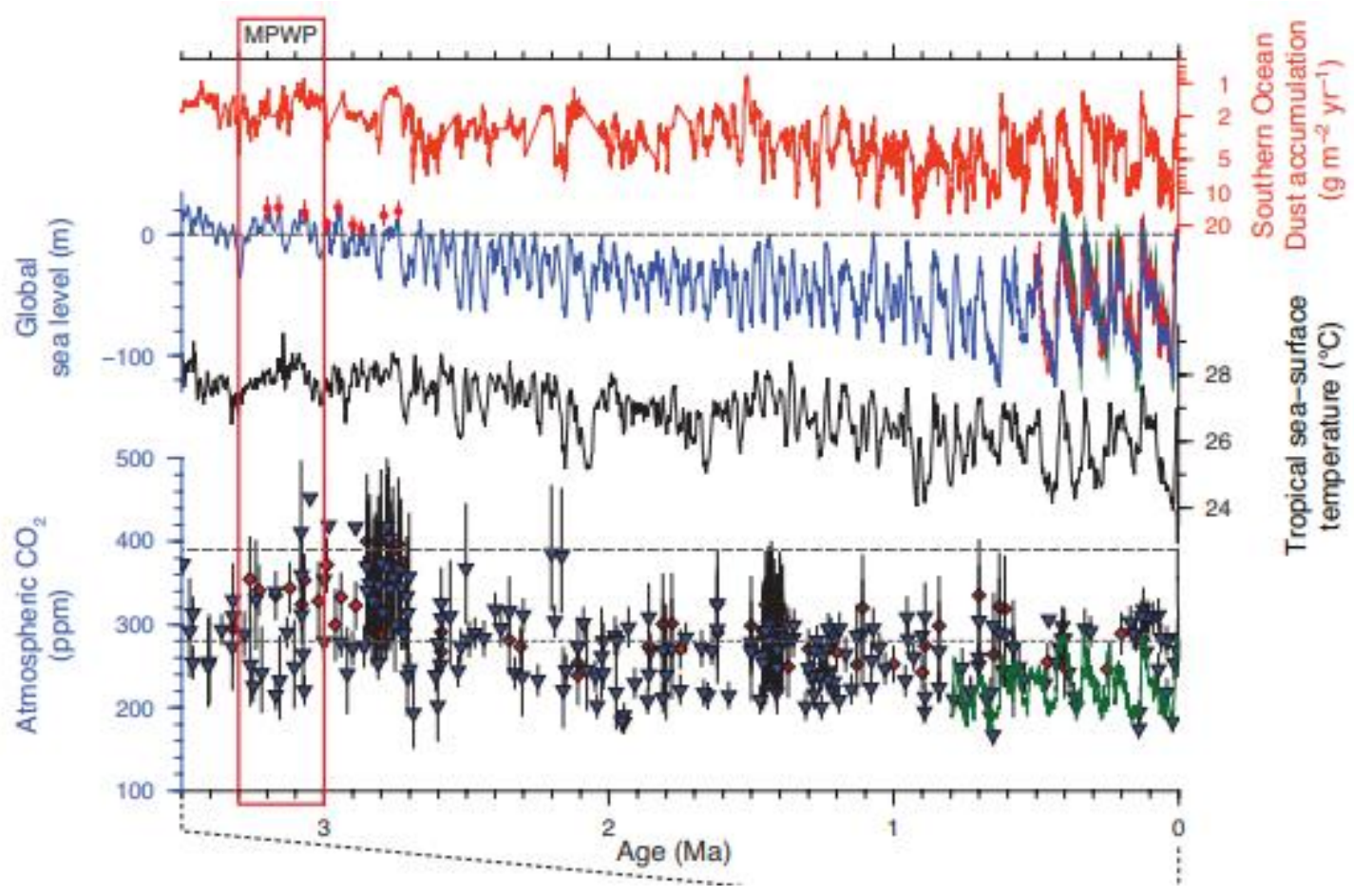

Figure 2.2 Orbital pacing and climate coupling for the last 3.5 Myr (including the MPWP 3.3-3.0 Ma) of dust mass accumulation rates (Martinez-Garcia et al., 2011) and tropical sea-surface temperature stack (Herbert et al., 2010). Global sea-level calibration of the benthic $\delta^{18} \mathrm{O}$ stack (blue line; Lisiecki and Raymo, 2005; Naish and Wilson, 2009), with estimates from Miller et al. (2012) for the mid Pliocene (red dots with 2 standard deviation of uncertainty), and Late Pleistocene reconstructions from coral terraces (green line; Waelbroeck et al., 2002) and the Red Sea (red line; Rohling et al., 2009). In comparison with background $\mathrm{pCO}_{2}$ concentration from Antarctic ice cores (green line, Petit et al., 1999; Siegenthaler et al., 2005; Lüthi et al., 2008), and estimates of $\mathrm{pCO}_{2}$ from boron isotopes $\left(\delta^{11} B\right)$ in foraminifera in marine sediments (blue triangles; Hönisch et al., 2009; Seki et al., 2010; Bartoli et al., 2011), and phytoplankton alkenone-derived carbon isotope proxies (red diamonds; Pagani et al., 2010; Seki et al., 2010), plotted with 2 standard deviation uncertainty. Present (2012) and pre-industrial pCO concentrations are indicated with long-dashed and short-dashed grey lines, respectively.

\subsubsection{Polar ice sheet response to orbital forcing}

While there seems to be reasonable consensus on the response of polar ice sheets to orbital pacing (i.e. frequency) there is much less consensus on exactly how the different physical processes influenced by insolation interact to determine the magnitude of polar ice volume change (Masson-Delmotte et al., 2013). There are a number of key questions especially relevant to the Pliocene prior to the intensification of Northern Hemisphere Ice Sheets (NHIS) $\sim 2.7 \mathrm{Ma}$, and during the Pleistocene prior to the last $1 \mathrm{Ma}$, which require explanation.

At the heart of the problem is that if the primary control on global ice volume is the intensity of summer insolation (controlled by the $\sim 20$ kyr precession cycle), then this property is anti- 
phased between the hemispheres (Milankovitch, 1941), yet the $\sim 40$ kyr obliquity cycle dominates the benthic $\delta^{18} \mathrm{O}$ stack (Figure 2.3). There are currently two predominant hypotheses on the mechanism of how long-term variations in the latitudinal distribution of insolation affect Earth's polar ice volume during the Pliocene.

One study (Raymo et al., 2006) has argued that the oceanic $\delta^{18} \mathrm{O}$ signature of an ice volume increase in the NHIS can be offset, or masked, by a small amount of melt and reduction in Antarctic Ice Sheets (AIS). Because of differing $\delta^{18} \mathrm{O}$ compositions of the polar ice sheets, this process cancels out the precession signal, allowing the residual $\sim 40 \mathrm{kyr}$ obliquity cycle to dominate the globally averaged $\delta^{18} \mathrm{O}$ record (Figure 2.4). A major problem with the hypothesis of Raymo et al. (2006), is that the geological evidence for a dominant 40 kyr obliquity control on the glacial-interglacial cycles of the last $2.7 \mathrm{Ma}$ is not just confined to the benthic $\delta^{18} \mathrm{O}$ records, but is widespread and expressed in a range of polar to equatorial depositional environments where a cancelling effect cannot be in operation, including: glacio-eustatic sealevel records in shallow-marine continental margins (Naish and Kamp, 1997a; Naish et al., 1998), ice-berg rafted debris (IBRD) records from the polar deep ocean (Maslin, 1998; Patterson et al., 2014), dust mass accumulation rates from the Southern Ocean (MartinezGarcia et al., 2011), tropical sea surface temperature reconstructions (Herbert et al., 2010), atmospheric circulation records in continental loess deposits (Ding et al., 2002), and records from lacustrine (e.g. Brigham-Grette et al., 2013) and glacio-fluvial sediments (e.g. Kukla, 1977). 


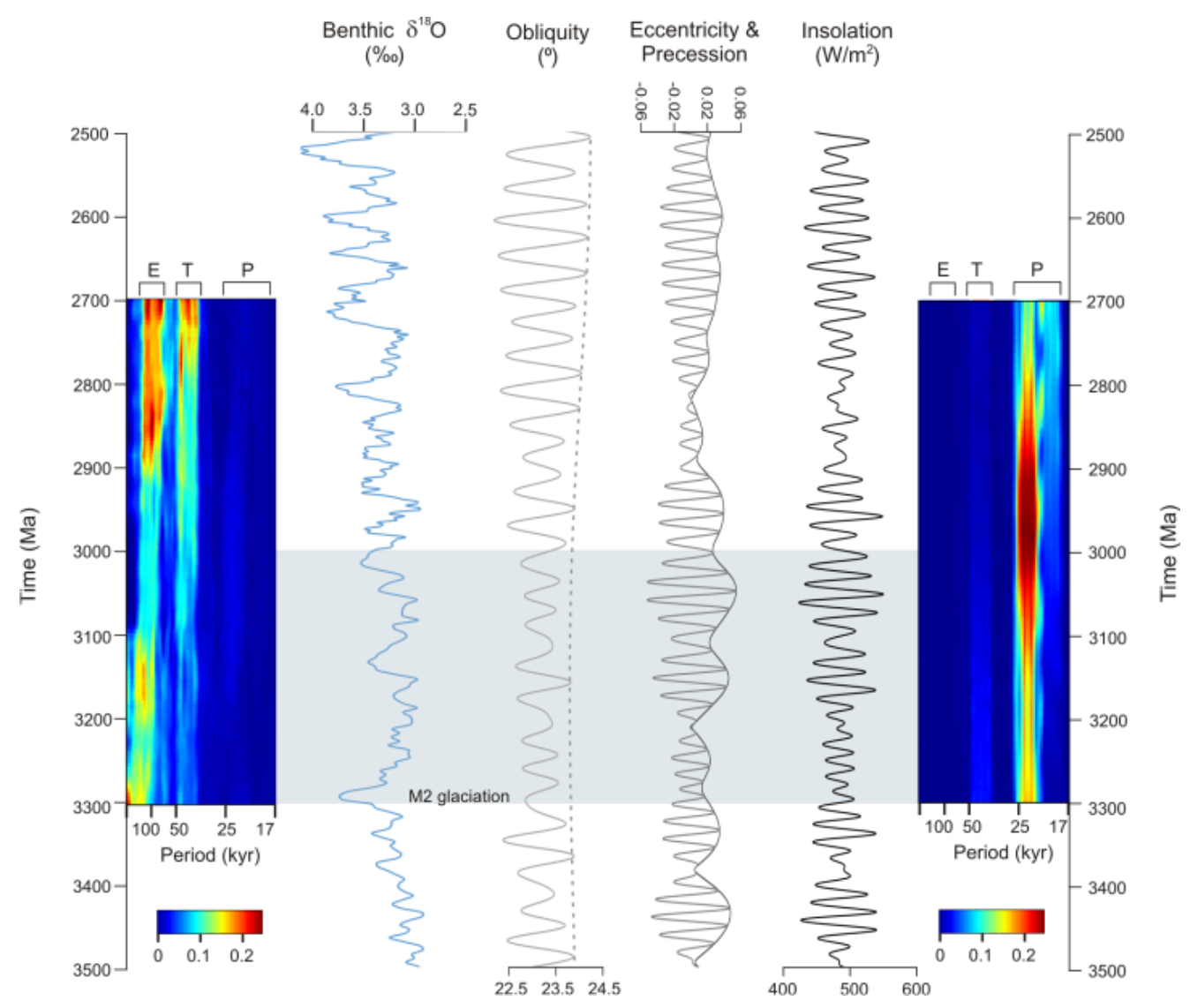

Figure 2.3 Evolutionary harmonic analysis comparing the relative influence of eccentricity (E), obliquity (T: tilt) and precession $(P)$ in the global benthic $\delta^{18} \mathrm{O}$ stack (Lisiecki and Raymo, 2005; left)) and $65^{\circ} \mathrm{S}$ Jan 1st insolation (Laskar et al., 2004; right) for $3.3-2.7 \mathrm{Ma}$ displaying the dominance of precession in the insolation spectra and its relative absence in the benthic $\delta^{18} \mathrm{O}$ spectra. Of interest is the long-term node in obliquity, while eccentricity and precession continue to fluctuate in amplitude during the MPWP, highlighted in grey.

This hypothesis also requires dynamic ice sheets in both hemispheres to provide the 'cancelling' effect on precession. Lastly, significantly different compositions of polar ice in each hemisphere can effectively decouple $\delta^{18} \mathrm{O}$ periodicity from eustatic periodicity. That is the cancelling effect on the ice volume $\delta^{18} \mathrm{O}$ proxy will be different from the cancelling effect on sea level, meaning the two records may vary at different amplitudes and frequencies.

A second study (Huybers, 2006), suggests that both the AIS and the NHIS are sensitive to integrated summer energy, that is, insolation above a melt threshold integrated over the length of summer. This is largely controlled by globally-synchronous obliquity, rather than the peak intensity of summer insolation, which is controlled by precession (Figure 2.4). For high northern latitudes there is a strong linear correlation between insolation and air temperature such that melting occurs above $60^{\circ} \mathrm{N}$ once insolation exceeds $275 \mathrm{~W} / \mathrm{m}^{2}$. Because the 
integrated summer energy is largely controlled by obliquity (when the melt threshold is 275 $\mathrm{W} / \mathrm{m}^{2}$ ) the signal is in phase between the hemispheres. Huybers and Tziperman (2008) used integrated seasonal insolation as input to an ice sheet/energy-balance model and produced $\sim 40 \mathrm{kyr}$ cycles, However, because of the Southern Ocean isolating Antarctica, $275 \mathrm{~W} / \mathrm{m}^{2}$ is insufficient to cause sustained surface melting around Antarctica today, and it remains unclear what the temperature-insolation relationship is. However, an Antarctic melt threshold may have been exceeded in the past when the background climate state was warmer, as it was during parts of the Pliocene (e.g. Patterson et al., 2014).

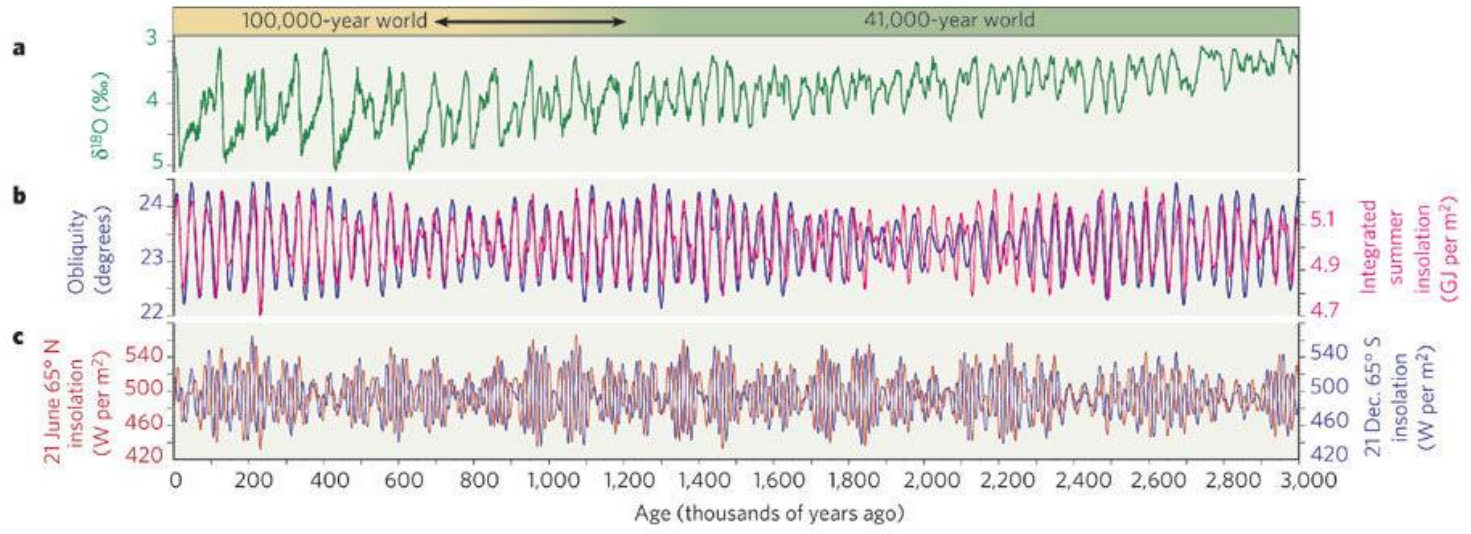

Figure $2.4 \mathrm{Global}$ benthic $\delta^{18} \mathrm{O}$ stack (Lisiecki and Raymo, 2005) showing the transition from the 41 kyr world to 100 kyr cyclicity of the Late Pleistocene in the first panel (a), with obliquity (Laskar et al., 2004) and obliquity paced integrated summer insolation (Huybers et al., 2006) in the second panel (b) and bipolar precession-paced summer insolation (Laskar et al., 2004) argued by Raymo et al. (2006) to produce a dominantly $40 \mathrm{kyr}$ world in the third panel (c).

Naish et al. (2009) appealed to this mechanism to explain the dominance of $\sim 40 \mathrm{kyr}$ cyclic fluctuations in the retreat and advance of the West Antarctic Ice Sheet (WAIS) recorded in a proximal geological Antarctic drill core (AND-1B) from the Ross Sea. Indeed, an ice sheet model simulation for the Pliocene by DeConto and Pollard (2016), showed that regional sea-surface temperatures needed to be $\sim 2^{\circ} \mathrm{C}$ warmer to initiate complete collapse of WAIS. Based on geological evidence for $5^{\circ} \mathrm{C}$ warmer Ross Sea, sea surface temperatures (McKay et al., 2012) and an absence of summer sea ice, Naish et al. (2009) argued that warm circumpolar deepwater (CDW) was upwelling onto the continental shelf with consequences for the stability of marine-based ice sheets (discussed below). They argued that Huybers' (2006) seasonal insolation hypothesis explained AIS variability either through a direct influence on local 
insolation, and/or influencing ocean circulation via the influence of obliquity on the latitudinal temperature gradient (Young and Bradley, 1984; Raymo and Nisancioglu, 2003). Toggweiller et al. (2007) and Toggweiller and Russell (2008) argue that a steepened latitudinal temperature gradient intensifies zonal atmospheric circulation and the vigour of the Antarctic circumpolar overturning circulation via its influence on the Antarctic Circumpolar Current. Export of cold fresh surface waters northwards by Ekman transport is compensated for by enhanced upwelling of warm CDW.

A high-resolution record (IODP Site U1361) of IBRD mass accumulation rates recovered adjacent to the Wilkes Land subglacial basin of the East Antarctic Ice Sheet (EAIS) was reported by Patterson et al. (2014). During the warmest Pliocene from 4.5 to 3.3 Ma, IBRD display a very strong obliquity cycle consistent with the Ross Sea record for West Antarctic Ice Sheet (WAIS) variability (Naish et al., 2009). However, following the M2 cooling event ( 3.3 Ma), evident in benthic $\delta^{18} \mathrm{O}$ stack, the U1361 IBRD record switches to precession, apparently in phase with southern high-latitude insolation. The record also shows evidence for an increase in the extent of summer sea ice, colder sea-surface temperatures and a less variable EAIS following the M2 glaciation (Figure 2.5). Importantly, the chronology of AND-1B is not sufficient to constrain to accurately determine orbital variability after 3.3 Ma, and some of the cyclic changes in lithology apparent in the drill core over this period may be precession-paced (Patterson et al., 2014). 


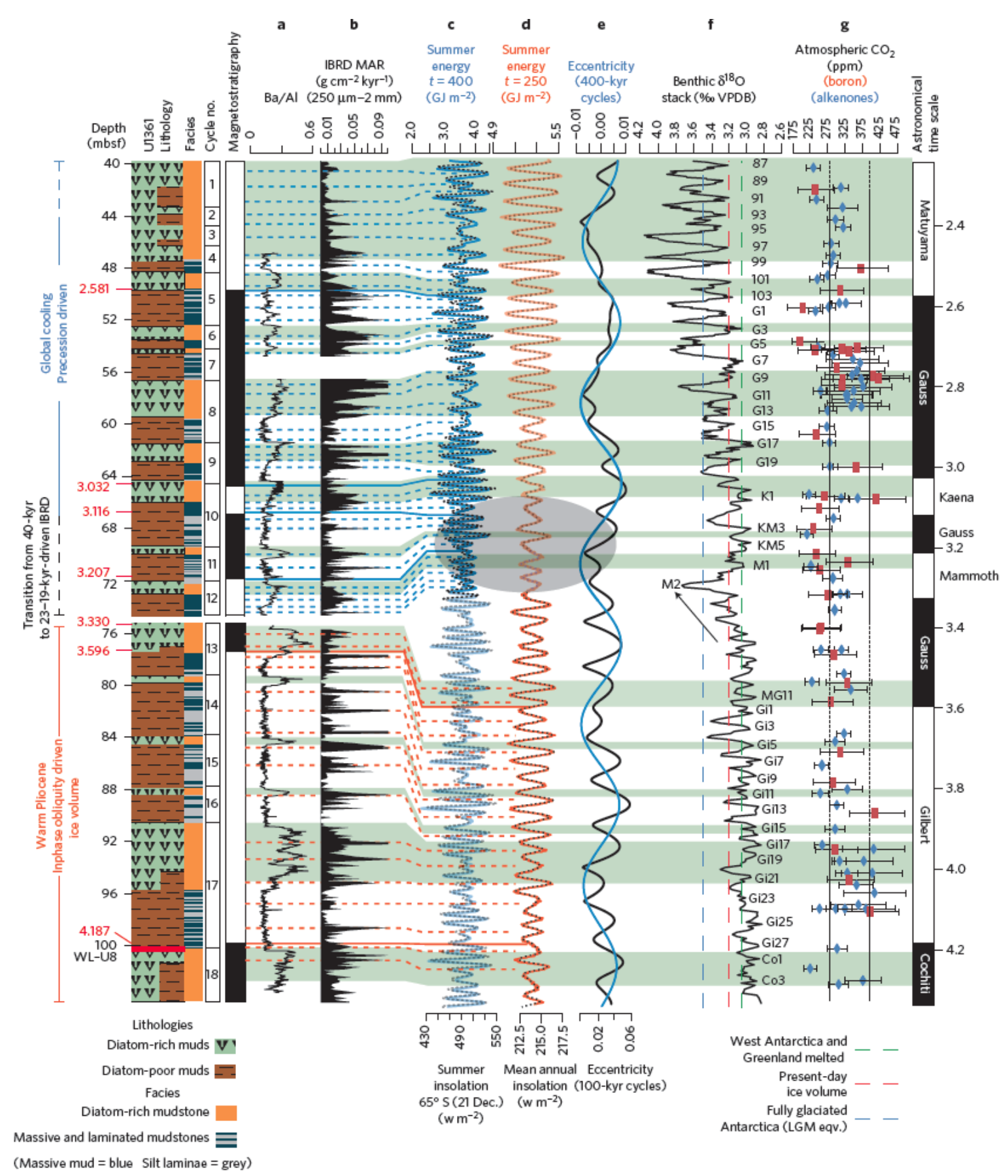

Figure 2.5 Ba/Al (a) and IBRD MAR (b) from U1361 sediment core for 4.4-2.2 Ma correlated to $65^{\circ} \mathrm{S}$ Dec 21 st summer insolation and summer energy calculated for a melt threshold $400 \mathrm{GJ} / \mathrm{m}^{2}$ (c), mean annual insolation and summer energy calculated for a melt threshold $250 \mathrm{GJ} / \mathrm{m}^{2}$ (d), eccentricity (e), and the benthic $\delta^{18} \mathrm{O}$ record (Lisiecki and Raymo, 2005) (f). Grey ellipse denotes alignment between a 1.2-Ma node in obliquity-modulated mean annual insolation and minimum in 400-kyr eccentricity and corresponds with the $\mathrm{M} 2$ event (arrow). Atmospheric $\mathrm{CO}_{2}$ reconstructions based on boron isotopes and alkenones (Pagani et al., 2010; Seki et al., 2010; Masson-Delmotte et al., 2013) (g) (Reproduced from Patterson et al. (2014).

In summary, evidence from Antarctic geological drill core data imply that during the warm Pliocene prior to 3.3 Ma Antarctica's marine-based ice sheet margins were highly variable. Furthermore, the evidence suggests they responded to obliquity forcing either via its influence 
on mean annual insolation and local summer energy, and/or its influence on the meridional temperature gradient of the southern hemisphere and attendant changes in ocean circulation. Following global cooling during the M2 glaciation at 3.3 Ma, Antarctica's marine-based ice margins were less dynamic, responding to the intensity of local summer insolation paced by precession, perhaps well into the Pleistocene (McKay et al., 2012; Patterson et al., 2014; Figure 2.5).

The emergence of a strong obliquity signal in the benthic $\delta^{18} \mathrm{O}$ stack (Lisiecki and Raymo, 2005) from 2.7-2.8 Ma and continuing into the Pleistocene could be explained by: (1) developing continental-scale NHIS responding directly to obliquity forcing via the Huybers and Tziperman (2008) mechanism overwhelming the influence of smaller Antarctic ice volume changes in response to local insolation (precession), or (2) an anti-phased hemispheric response to the precession cycle as proposed by Raymo et al. (2006), whereby polar meltwater and oxygen isotopic contributions to the global ocean are balanced, leaving the obliquity forcing to dominate, or some combination of both. Determining which mechanism is dominant, requires continuous orbital-scale sea-level reconstructions that are independent of the benthic $\delta^{18} \mathrm{O}$ record, which is one of the motivations of this thesis.

This thesis directly evaluates the leading hypotheses outlined above concerning the role of orbital forcing on the AIS immediately prior to, and during the development of NHIS and global sea-level change between 3.3-2.6 Ma.

\subsubsection{The role of climate feedbacks and polar amplification on ice sheet dynamics}

The role of climate feedbacks in amplifying the response of the polar regions on glacialinterglacial timescales to orbital forcing is important in terms of understanding ice sheet sensitivity, and therefore, the potential magnitude of global sea-level change. The strength of a number of internal feedbacks to insolation-driven surface warming is greater in the polar regions (e.g. Pithan \& Mauritsen, 2013), leading to the phenomenon of polar temperature amplification. A summary of the key feedbacks and consequences of polar amplification for polar ice sheet mass balance is provided below. 
High-resolution records from ice cores (EPICA [Lambert et al., 2008; Luthi et al., 2008]; NGRIP [Andersen et al., 2004]; Vostok [Petit et al., 1999]) utilised in combination with global climate models and ice sheet models provide the opportunity to assess the relative influence and interaction of internal climate feedbacks over glacial-interglacial timescales. Kohler et al. (2010) show that expanding ice cover and its associated reflectance of solar radiation (albedo) accounted for twice the cooling effect of $p \mathrm{CO}_{2}$ forcing on cooling for the Last Glacial Maximum (LGM) climate. Stap et al. (2014) show that equilibrium Northern Hemisphere temperatures (once fast and slow feedbacks have played out) were controlled by the waxing and waning of the ice sheets and ice-albedo feedback doubles the magnitude of the polar amplification. Stap et al. (2014) also find that atmospheric temperature is an integrated response to $p \mathrm{CO}_{2}$ and insolation, both of which serve as thresholds for glaciation in the Northern Hemisphere, while Southern Hemisphere climate is driven by ocean heat uptake, and the strength of ocean overturning (discussed in Section 2.1.1).

Other studies imply an important amplifying feedback during glacial-interglacial cycles is provided by the carbon cycle (e.g. Paillard \& Parrenin, 2004; Sigman et al, 2010) involving sequestration and release of $\mathrm{CO}_{2}$ by the deep ocean linked to the efficiency of bottom water formation, surface ocean stratification, and the upwelling of circumpolar deep water. Cooling and subsequent growth of NHIS lowers sea-level and decreases the ocean heat budget around Antarctica, encouraging the growth of sea-ice, increasing brine formation, cooling the deep sea and increasing the stratification of surface ocean, effectively storing $\mathrm{CO}_{2}$ in the deep ocean (Paillard and Parrenin, 2004). Progressive cooling leads to the AIS reaching its maximum extent at the continental slope, a few thousand years after the glacial maxima (Denton and Hughes, 2002; Anderson et al., 2002; Mackintosh et al., 2014). At this time Antarctic Bottom Water formation is reduced when the AIS reaches the continental slope, as a significantly larger water column would need to be cooled. This in turn leads to a decrease in ocean stratification and release of $\mathrm{CO}_{2}$, which along with other factors discussed previously may cause the southern high-latitudes and rest of the globe to warm. For the last deglaciation, Shakun et al. (2012) show that Antarctic temperatures initially increased about 18 kyrs ago due to orbital forcing, and that these led to the increase in $\mathrm{CO}_{2}$ recorded in the Antarctic ice cores. Then as warming continues $\mathrm{CO}_{2}$ (possibly ventilated from the Southern Ocean as described above), begins to lead the temperature signal in ice cores and the global ocean warming by up to 800 years. This 
is strong evidence for the role of $\mathrm{CO}_{2}$ as an amplifier of warming. Together with albedo feedbacks this process amplifies the rate and magnitude of global climate change in response to comparatively weak orbital forcing.

Polar amplification in both the Arctic and the Antarctic occurs with a magnitude up to 3 times the global average warming. This is a consistent feature of climate reconstructions for past warmer worlds and global climate models of future greenhosue gas scenarios run to equilibrium (Naish and Zwartz, 2012; Masson-Delmotte et al., 2013; Figure 2.6). Models (e.g. Haywood et al., 2013) and paleoclimate data (Dowsett et al., 2012) show that an amplified response of Southern Ocean sea surface temperature (SST) to global warming will emerge due to a reduction in sea ice extent, leading to reduced albedo and more surface warming. However, in contrast to the Arctic Ocean, which in parts is highly stratified, mixed-layer depths in the Southern Ocean typically exceed several hundreds of metres. This allows the ocean to take up vast amounts of heat (Böning et al., 2008; Gille, 2008; Sokolov and Rintoul, 2009) and damp the surface temperature response to external forcing. Over longer timescales of decades to centuries future Antarctic amplification occurs in models as sea-ice retreats and an albedo feedback strengthens.

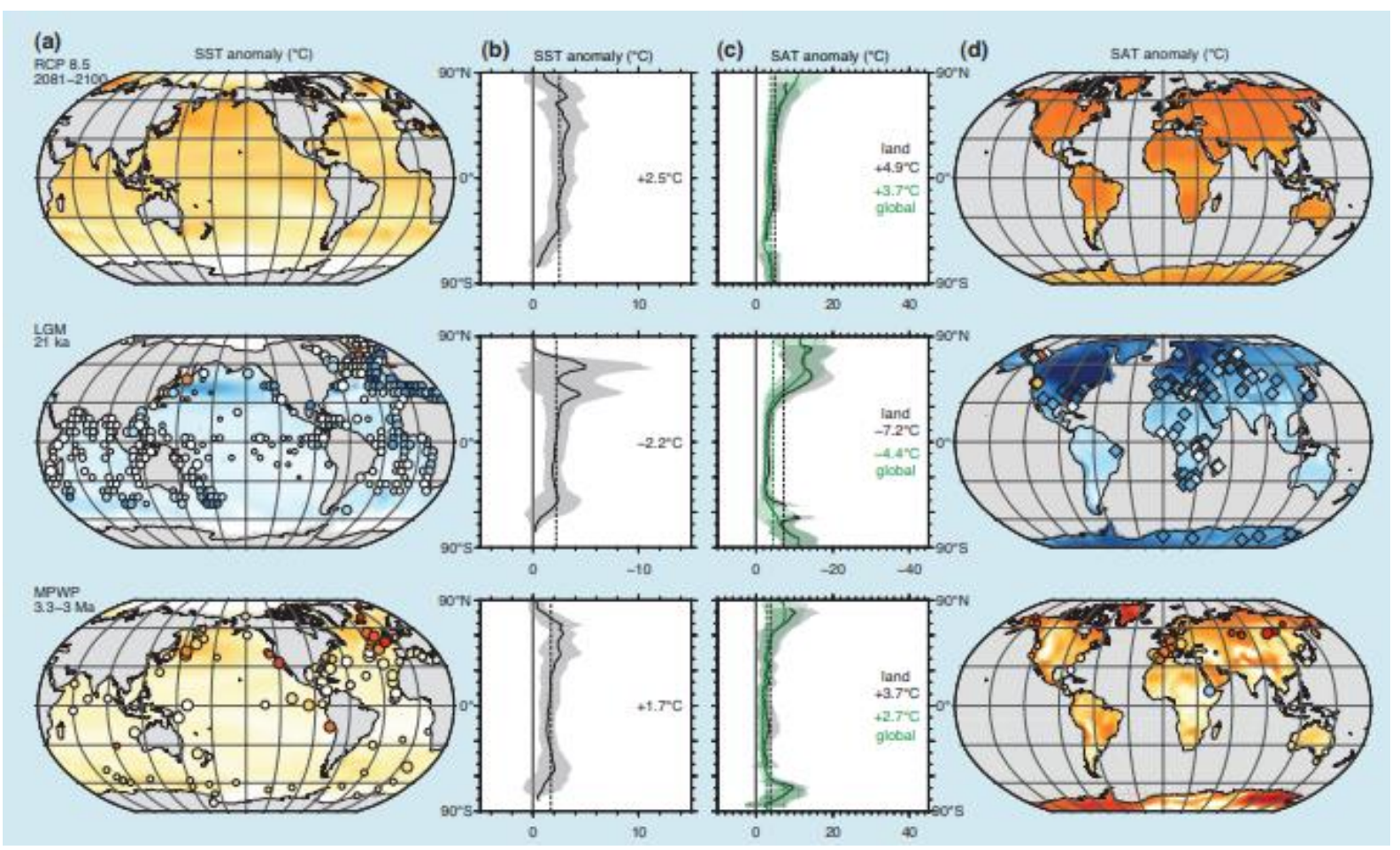

Figure 2.6 Global oceanic ( $a$ and b) and continental (c and d) temperature anomalies for Representative Concentration Pathway 8.5 (top row; $3.7^{\circ} \mathrm{C} \mathrm{global}$ warming estimated for 2081-2100 BC), the Last Glacial Maximum (20 ka; second row) and MPWP (bottom row) compiled by Masson-Delmotte et al. (2013 and references therein). 
Recent observations have yet to detect continental-wide amplified surface warming relative to the global mean, but satellite observations do show that Antarctica is still losing mass at an accelerating rate (Shepherd et al., 2018). The loss and thinning of ice shelves (Paolo et al., 2015), and retreat of marine grounding lines, particularly in the Amundsen Sea sector of WAIS and the Aurora subglacial basin of EAIS (Rignot et al., 2008; 2014; Pritchard et al., 2012), is associated with observations of warm CDW incursions reaching grounding lines in these areas (Stanton et al., 2013; Rintoul et al., 2016). This upwelling has been linked to intensification of the zonal westerly winds over the Antarctic Circumpolar Current and northward Ekman transport of cold surface waters allowing CDW to upwell onto the shelf (e.g. Toggweiller and Russell, 2008; Figure 2.7). The observed changes in atmospheric circulation are attributed to changes in the pole to equator temperature gradient. Therefore, even in the absence of surface ocean warming, the role of anthropogenic forcing on atmospheric circulation and ocean circulation is melting the marine margins of the AIS. A similar mechanism has been invoked in paleoclimate reconstructions to explain loss of marine-based sectors of the AIS during the warm periods of Pliocene (Naish et al., 2009) and Mid- Miocene (Levy et al., 2016), driven by the response of the latitudinal gradient to obliquity.

Once initiated, the retreat of marine-based sectors of the AIS have been shown theoretically (e.g. Schoof, 2007) and in paleoclimate studies (Jones et al., 2015) to occur rapidly and in a non-linear manner. This process known as marine ice sheet instability (MISI) was first described by Weertman (1974) and Thomas and Bentley (1978), and predicted by Mercer (1978) as a key factor for loss of the WAIS (Figure 2.7). The concept of MISI is important in the context of this thesis, because under past warmer climates, the circulation of warm ocean waters into ice shelf cavities may have removed the ice shelves and resulted in rapid and widespread deglaciation of marine-based parts of Antarctica, leading to a large AIS contribution to past global sea level (e.g. Naish et al., 2009; Cook et al., 2013; Pollard et al., 2015; DeConto and Pollard, 2016; Gasson et al., 2016; Levy et al., 2016; Golledge et al., 2017; Figure 2.8). 


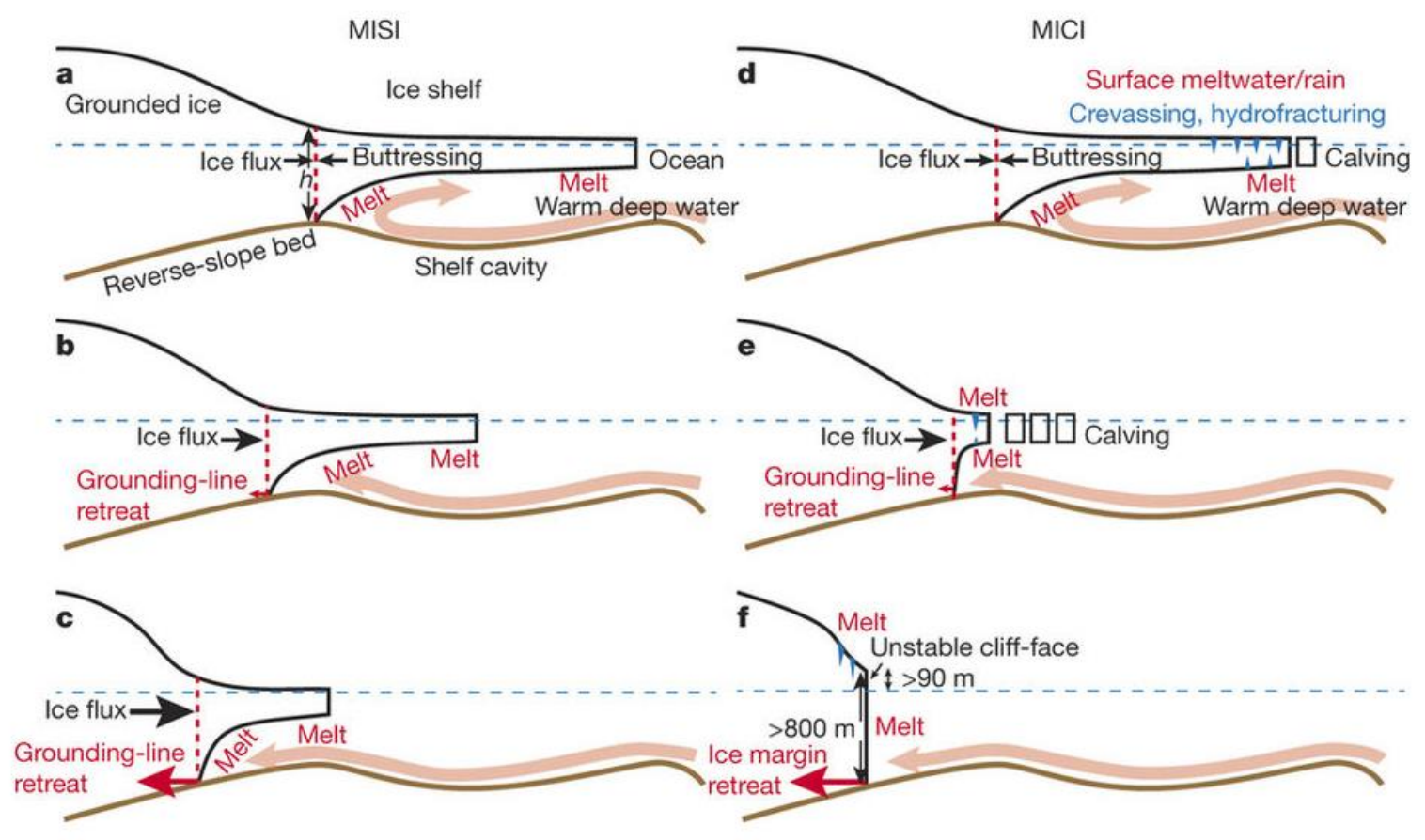

Figure 2.7 Marine Ice Shelf Instability (MISI) and Marine Ice Cliff Instability (MICI) causing collapse of ice shelves and subsequent ice margin retreat (DeConto and Pollard, 2016).

These views postulate insolation induced internal climate feedbacks as important modulators of glacial-interglacial cyclicity. Paleoclimate reconstructions from models and geological data for past warmer worlds such as the Last Interglacial ( 125 kyr) and the MPWP (3.3-3.0 Ma) imply that the polar ice sheets are highly sensitive to small changes in global mean temperature and atmospheric $\mathrm{CO}_{2}$, producing large changes in global mean sea-level (Figure 2.9; Dutton et al., 2015). On glacial - interglacial time scales, the very slow ice sheet-albedo and ice sheet height-mass balance responses to external forcing is a major contributor to equilibrium polar amplification and leads to accelerated mass loss of the Greenland (Masson-Delmotte et al., 2013). 


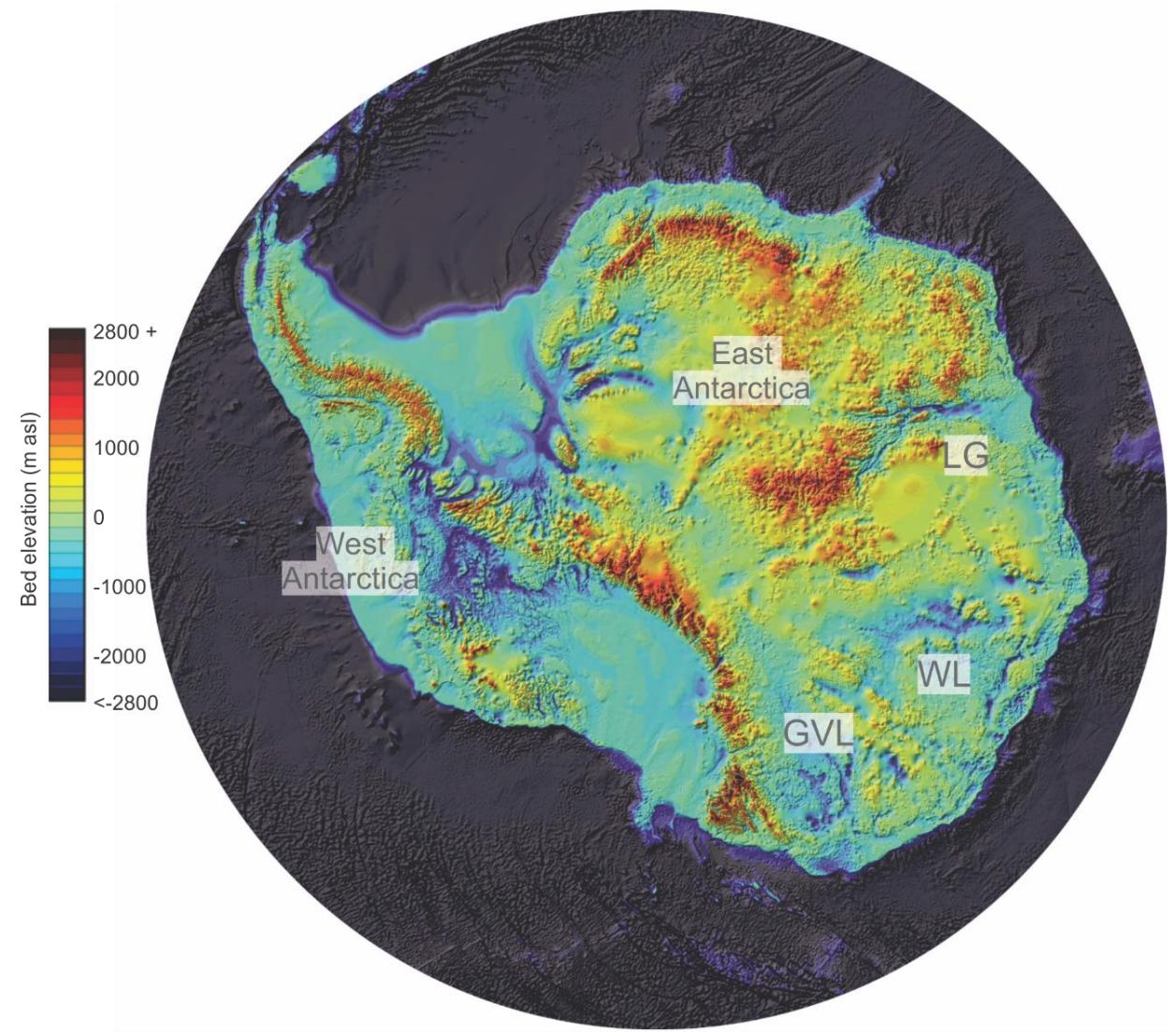

Figure 2.8 Antarctic BEDMAP2 (Fretwell et al., 2013) bed elevation ( $m$ above sea-level) displaying the marine-based West Antarctic and East Antarctic areas of subglacial basins referred to in text; George V Land (GVL), Wilkes Land (WL) and Lambert Glacier (LG).

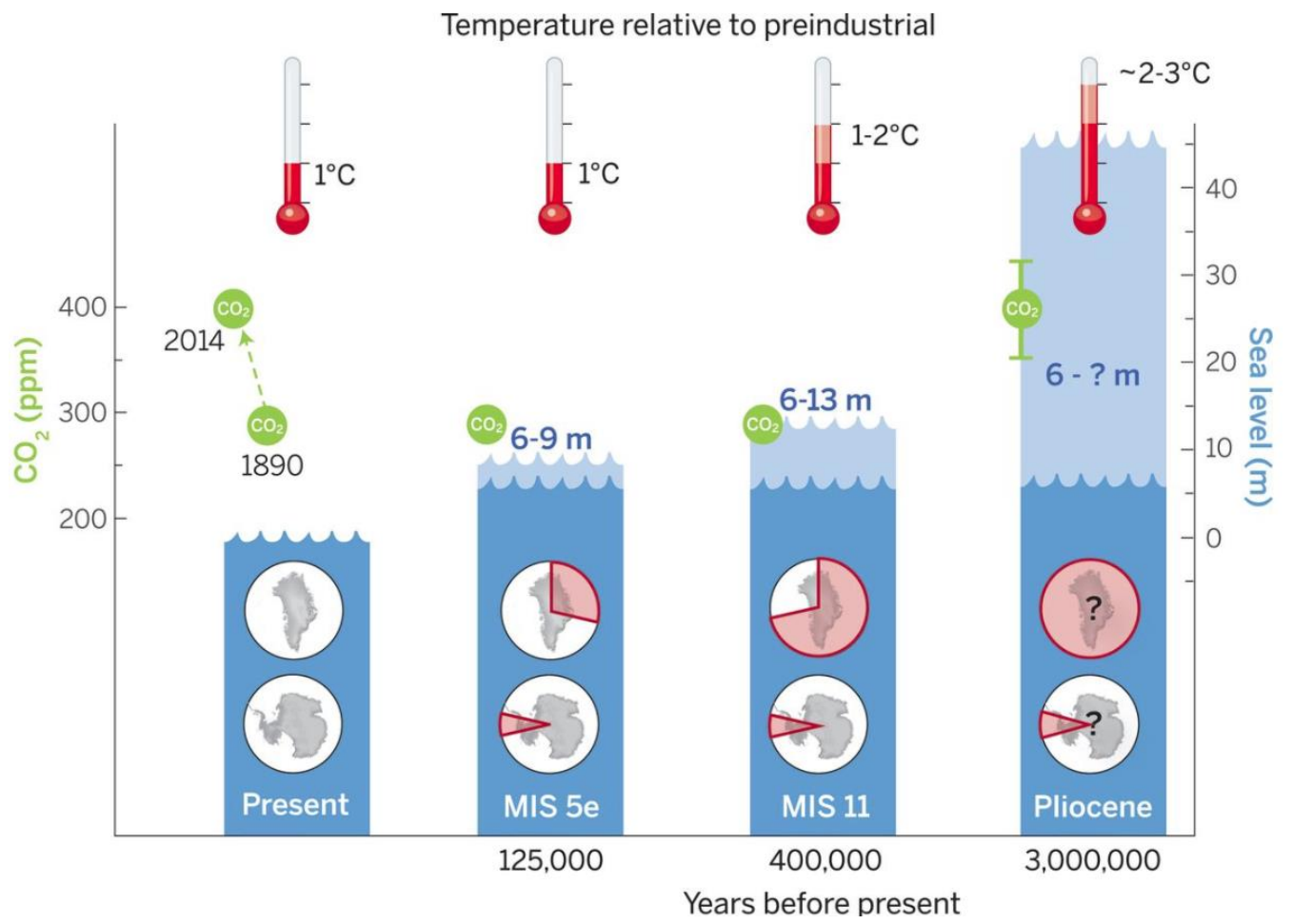

Figure 2.9 Peak global mean temperature, $\mathrm{pCO}_{2}$ and global mean sea-level estimates with estimated meltwater source for the Mid-Pliocene, MIS 11 \& 5 e and present (Dutton et al., 2015). 


\subsection{Mid- to late Pliocene global climate}

Climate reconstructions for the mid-Pliocene based on proxy measurements from geological archives reveal that $p \mathrm{CO}_{2}$ concentrations were $\sim 400$ ppm (e.g. Seki et al., 2013; Martinez-Boti et al., 2015; Figure 2.2), comparable to present-day levels, and average surface temperature was $2-3^{\circ} \mathrm{C}$ warmer than at present (e.g. Dowsett et al. 2012; Haywood et al., 2013; MassonDemotte et al, 2013; Figure 2.6). Furthermore, the configuration of the oceans, continents and ice sheets was broadly similar to today. Given the magnitude of the model-based climate projections for the end of this century and the difficulty in assessing their accuracy the Pliocene is being increasingly studied as the most appropriate recent climate analogue for understanding how the Earth system will respond to $2-3^{\circ} \mathrm{C}$ of global warming (Naish \& Zwartz, 2012).

The MPWP represents 300 kyrs of "warmer-than-present" equable global climate following transient climate cooling from the M2 glaciation at 3.3 Ma (Figure 2.2). The M2 event is a significant excursion of nearly $+0.7 \%$ in the benthic $\delta^{18} \mathrm{O}$ stack (Lisiecki and Raymo, 2005) that is interpreted to represent southern high-latitude cooling, expansion of marine-based ice margins and summer sea-ice (McKay et al., 2012) and/or continental ice sheet expansion on Northern Hemisphere continents (Dolan et al., 2015,). The ensuing MPWP, also known as the PRISM (Pliocene Research Interpretation Synoptic Mapping; Dowsett et al., 2010) and PlioMax (Pliocene Maximum; Raymo et al., 2009) intervals, ( 3.3-3.0 Ma), has been widely studied, in terms of both modelling and geological data collection, in order to understand the causes of Pliocene warmth (e.g. Lunt et al., 2012), and to establish the long-term effect (Earth system sensitivity) of increased levels of $\mathrm{CO}_{2}$ in the atmosphere (e.g. Lunt et al., 2010). Although not the warmest part of the Pliocene, the MPWP has received significant attention because it is a time slab encompassing four short-lived paleomagnetic reversal boundaries corresponding to the Kaena and Mammoth reversed polarity subchrons within the Gauss normal chron, thus allowing the identification and global correlation of glacial-interglacial climate variability in wide range of terrestrial and marine records. 
The late Pliocene $~ 3.0-2.6 \mathrm{Ma}$ is characterized in the benthic $\delta^{18} \mathrm{O}$ stack by an overall $0.7 \%$ increase in $\delta^{18} \mathrm{O}$, with a superimposed increase in the amplitude of $\sim 40 \mathrm{kyr}$ glacial-interglacial cycles. This cooling interval, which intensified from $2.8 \mathrm{Ma}$, has been associated with intensification of large continental-scale NHIS (Haug and Tiedemann, 1998) and a cooler, less variable AIS (McKay et al., 2012; Patterson et al., 2014) as pCO $_{2}$ concentration decreased from $\sim 400$ ppm to pre-industrial levels of 300 ppm (e.g. Seki et al., 2013; Martinez-Boti et al., 2015). Although more recent interglacials have had higher-than-pre-industrial $p \mathrm{CO}_{2}$ levels (285 ppm; Hönisch et al., 2009), present day levels thought to be unprecedented since the MPWP.

Global climate model simulations (Haywood et al., 2012) compared with compilations of geological proxy data (Salzmann et al, 2008; Dowsett et al., 2012) assessed by the IPCC (Masson-Delmotte et al., 2013), produce a global average surface temperature of $+2.7^{\circ} \mathrm{C}$ average peak warmth relative to pre-industrial for the MPWP (Figure 2.6). Equatorial sea surface temperatures derived from a stack of four alkenone-based reconstructions imply little to no temperature change at low latitudes (Herbert et al., 2010). However, significant bi-polar amplification of 2-3 times the global average temperature is implied by a weakened meridional surface temperature gradient (Figure 2.6), with implicit consequences for the warming and stability of the polar ice sheets and global sea level. Sea surface temperature gradients across the equatorial Pacific were also reduced, with enhanced heat transport towards the polar regions (Federov et al., 2013). Vegetation reconstructions for the Arctic, show a reduction in the extent of arid regions and the expansion of boreal forests at the expense of tundra (Salzmann et al., 2008; Brigham-Grette et al., 2013).

Temperature and precipitation reconstructions from pollen assemblages in the Siberian Lake El'gygytgyn drill core imply maximum summer temperatures $\sim 15^{\circ} \mathrm{C}$ warmer than today, and $600 \mathrm{~mm} /$ year more rainfall (Brigham-Grette et al., 2013) - a climate that would have precluded continental ice except for parts of Greenland. Mean annual (likely summer biased) sea surface temperatures of $\sim 5^{\circ} \mathrm{C}$ were derived from lipid biomarker TEX 86 proxy method applied to the Ross Sea AND-1B sediment cores for the MPWP and showed a cooling trend through the late Pliocene to cold polar conditions of $\left(\sim 1^{\circ} \mathrm{C}\right.$ sea surface temperature) by $\sim 2.5 \mathrm{Ma}$ (McKay et al., 2012). A modern analogue analysis of extant diatom assemblages in the AND-1B core showed an open ocean sub-Antarctic flora that currently lives north of the Polar Front in waters of 4- 
$8^{\circ} \mathrm{C}$, had occupied the Ross Sea during the MPWP, and by $2.5 \mathrm{Ma}$ had been replaced by a seaice tolerant polar ocean assemblage similar to today (McKay et al., 2012).

\subsubsection{Polar ice sheet response to mid- to late Pliocene global climate}

The most comprehensive well-dated geologic records proximal to the Antarctic margin resolving orbitally-paced variations in AIS extent during the mid- to late Pliocene come from three regions:

(1) The ANDRILL (AND-1B) geological drill core record of WAIS grounding line retreat and advance across the continental shelf in the south western Ross Sea (Naish et al., 2009; Mckay et al., 2012);

(2) The IODP Expedition 318, Wilkes Land margin, Site U1361 geological drill core record of ice-berg rafted debris (IBRD; Patterson et al., 2014), and a glacial erosion history based of neodymium geochemical variability (Cook et al., 2013) from the continental rise adjacent to the EAIS Wilkes subglacial basin.

(3) The terrestrial fjordal glacio-marine deposits in the Prydz Bay region of the EAIS (e.g. Hambrey and McKelvey, 2000) and IBRD and diatom assemblages from adjacent offshore deep ocean drill cores (ODP sites 1165 and 1166; Passchier, 2011; Whitehead et al., 2005).

Collectively, these records show that the marine margins and sub-glacial basins of the EAIS and the WAIS were highly dynamic, with major fluctuations in ice sheet extent occurring at orbital frequencies. Unconformity-bound sedimentary cycles of grounding-line advance and retreat in the Ross Sea provided the first evidence of a highly dynamic marine-based ice sheet in West Antarctica (Naish et al., 2009), while cycles in neodymium in fine-grained sediments eroded from the Wilkes subglacial basin provided the first evidence that ice had regularly retreated into subglacial basins of EAIS (Cook et al., 2013; Figure 2.8). The neodymium signature of fine-grained sediments delivered to the slope via turbidity currents show that sub-cropping Ferrar dolerite up to $300 \mathrm{~km}$ in land of the present ice sheet margin was being eroded.

The first dynamic continental-scale AIS models capable of simulating a marine grounding line 
and thus a marine-based ice sheet, susceptible MISI, showed that for the Pliocene glacial advance and retreat identified by Naish et al. (2009), up to $7 \mathrm{~m}$ of global sea-level rise above present day could have been contributed from Antarctica (Pollard and DeConto, 2009). At the time these model estimates were inconsistent with a far-field estimates of global mean sealevel (GMSL) for the peak warm interglacials of the Pliocene during the MPWP, compiled by Miller et al. (2012 - discussed further in the next section), which suggested GMSL was 22 \pm $10 \mathrm{~m}$ above present. Even with the Greenland Ice Sheet (GIS) completely deglaciated (adding another $7 \mathrm{~m} \mathrm{GMSL}$ ), the Antarctic model estimates appeared too low for mid to high range estimates. The discovery by Cook et al. (2013) that the Wilkes subglacial basin may have been substantially deglaciated and the ongoing suggestions that George $V$ Land, Wilkes Land and Lambert Graben regions may also have lost ice, together with the far-field sea-level estimates suggested the upper range of estimates from ice sheet models were viable (Figure 2.8). Subsequent evolution of the DeConto and Pollard (2016) model to include mechanisms of rapid ice shelf collapse (e.g. Figure 2.7) indicated that together with EAIS subglacial basins, Antarctica contributed up to +15 m SLE during the MPWP. Golledge et al. (2017) argue for +13 $\mathrm{m}$ without marine ice cliff instability ( $\mathrm{MICl}$; Figure 2.7).

Well-dated geological evidence constraining the extent of ice on northern hemisphere continents during the mid- to late Pliocene is generally lacking. The most compelling evidence comes from deep ocean records of IBRD in North Pacific and Nordic seas near Greenland (Shackleton et al., 1984; Maslin et al., 1998; Jansen et al., 2000), which show that ice berg rafting representing marine terminating glaciation begins about $\sim 2.75 \mathrm{Ma}$ and intensifies around $\sim 2.5 \mathrm{Ma}$. The vegetation and climate history reconstructed from the Siberian Lake El'gygytgyn drill core shows the development of summer lake-ice, loss of boreal forest, return of tundra, and climate conducive to glaciation from 2.6 Ma onwards (Brigham-Grette et al., 2013). Ice sheet model reconstructions for GIS are limited, but ice sheet reductions of up to 80\% have been simulated (Lunt et al., 2010; Hill et al., 2010; De Boer et al., 2017) using models perturbed by climate conditions consistent with paleoclimate reconstructions for MPWP. These models suggest continental ice beyond the GIS on North America or Eurasia during the MPWP, is unlikely. 
In summary, this assessment of the available evidence suggests ice sheet model reconstructions constrained by ice sheet proximal geological climate proxy data are consistent with the limited number of far-field sea-level reconstructions for the MPWP and show that during the warmest interglacials of the MPWP, GMSL may have been up to $+20 \mathrm{~m}$ above present day, with up to $+13 \mathrm{~m}$ from AIS, $+6 \mathrm{~m}$ from GIS, and $+1 \mathrm{~m}$ from ocean thermal expansion.

\subsection{Methods for reconstructing global sea level}

Average sea-level change as a response to variations in the mass or volume of the ocean is termed eustatic sea level (ESL), and the average height of the global sea-surface with respect to the centre of the Earth is referred to GMSL. For this thesis, ESL and GMSL are broadly similar and represent the average global expression of ocean volume change. The latter is usually registered to present day, which is not possible for the Whanganui sea-level cycles, even once corrected for GIA. While relative sea-level (RSL) is site specific sea-level change, which is corrected for local tectonic factors, but uncorrected for regional geoidal deformation, measured with respect to an arbitrary reference is referred to as RSL. There are climate and geologic factors that contribute to ESL on a range of timescales and amplitudes that result in a

uniform change to the global ocean volume. However, the response of the solid Earth to the redistribution of mass (ice, sediment or water) is spatially variable and is recorded as RSL change (Section 2.3.1), thus RSL reconstructed for a specific site must be corrected for these solid Earth adjustments to estimate GMSL or ESL.

Estimates of peak sea levels during the MPWP based on a variety of geological records far from the polar ice sheets are consistent in suggesting higher-than-present sea levels, but they range widely in amplitude from 10 to 30 m above present day (Miller et al., 2012; Figure 2.10), and each method utilised in the compilation contains large uncertainties, shown by Dutton et al. (2015) assessment (Figure 2.9). The advantages and limitations of the various methods for reconstructing Pliocene sea-level are summarised briefly in Masson-Delmotte et al. (2013), Miller et al. (2012), Dutton et al. (2015) and in more detail below (Sections 2.3.2-2.3.4). 


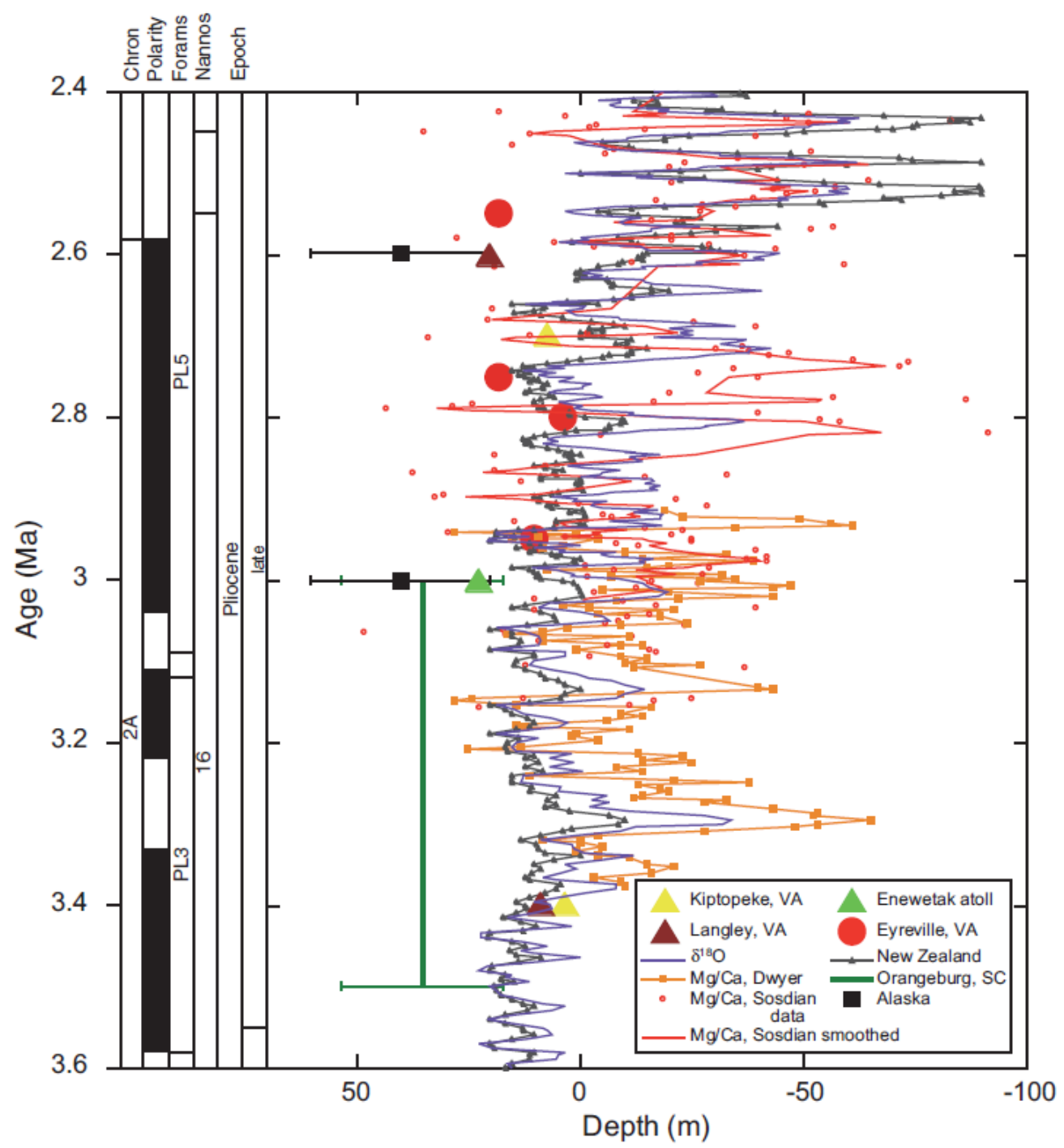

Figure 2.10 Sea-level compilation by Miller et al. (2012). Two different calibrated $\delta^{18} \mathrm{O}$ records ( $\delta^{18} \mathrm{O}$ - Miller et al., 2012; New Zealand - Naish and Wilson, 2009), Mg/Ca estimates (Mg/Ca Dwyer-Dwyer and Chandler, 2009; Mg/Ca Sosdian data-Sosdian and Rosenthal, 2009) and geological deposits of Kiptopeke and Langley, VA (Hayden et al., 2008), Enewetak Atoll (Wardlaw and Quinn, 1991), Eyreville, VA (Miller et al., 2012) and Orangeburg Scarp (Doswett and Cronin, 1990).

2.3.1 Regional sea-level variability: the influence of glacio-isostatic adjustment and dynamic topography

There are numerous processes that continental margins experience that affect the RSL in response to a ESL change. Different processes are influential on different timescales. The single most significant effect on glacial-interglacial timescales is glacio-isostatic adjustment (GIA), that is the visco-elastic response of the solid earth to the redistribution of mass (primarily ice and water) during glaciation or deglaciation (e.g. Lambeck, 2008; 2011). Proximal to the ice 
sheet margins a peripheral fore-bulge forms under loading of ice, which exacerbates the relative sea-level fall around the margin. However, in response to the concentration of mass of the ice sheets, gravitational attraction of the ocean to the ice sheet induces sea-level rise near the margin and sea-level fall in the far-field (Raymo et al., 2011; Figure 2.11). Slight uplift of the ocean basins in response to the reduced load is associated with subsidence of the continental margins (hydro-eustasy; Rovere et al., 2016). Following deglaciation, and subsequent subsidence of the peripheral fore-bulge, the inverse of these processes occurs. The effects of GIA on the RSL around the globe are predictable from solid Earth models that account for the visco-elastic, rotational and gravitational responses. By comparing the observed patterns of sea level change relative to model predictions, the contributions of ice mass from each polar region can be discerned. Figure 2.11 displays this effect on regional sealevel variability for an interglacial during the Mid-Pliocene (Raymo et al., 2011).

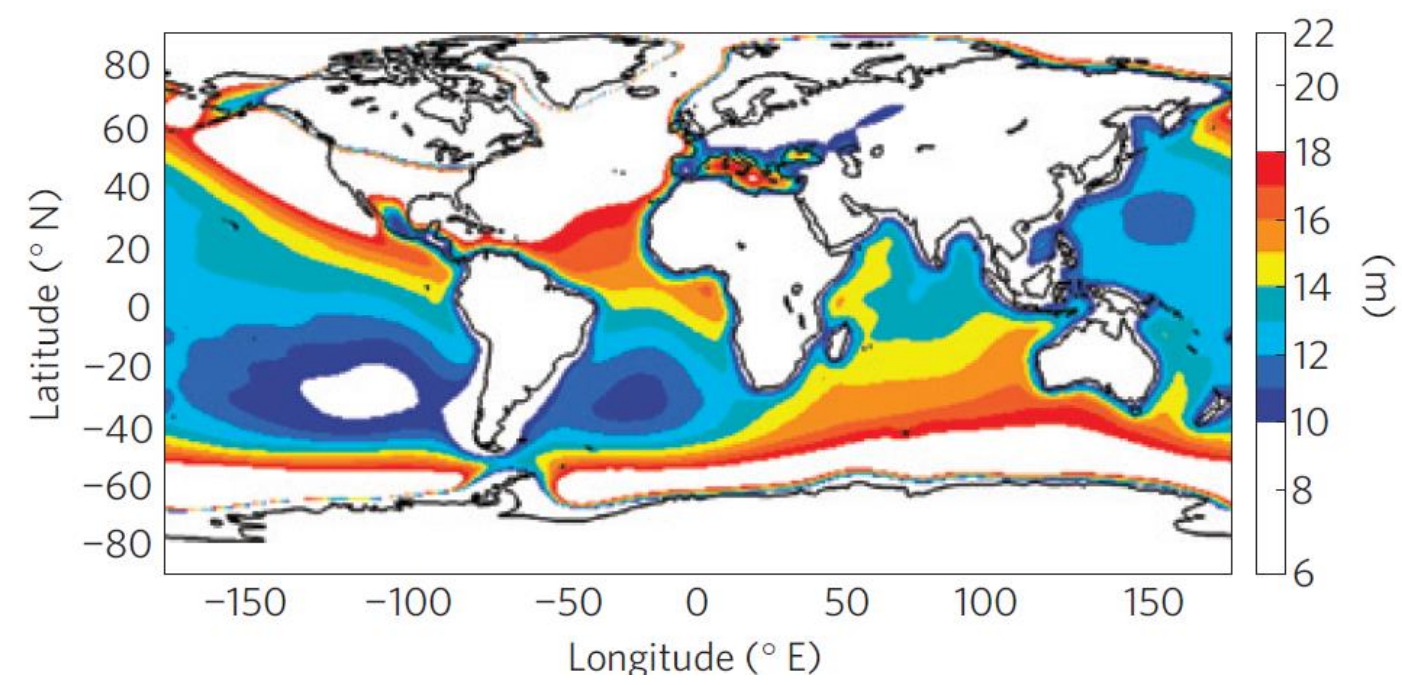

Figure 2.11 Elevation of a shoreline indicator relative to modern sea-level, representing $+14 \mathrm{~m}$ of sea-level equivalent ice melt of which $7 \mathrm{~m}$ is allocated from the Greenland Ice Sheet and $7 \mathrm{~m}$ from AIS. The coloured regions represent the shoreline within $\pm 4 m$ (Raymo et al., 2011). Note the significant departure from ESL proximal to the polar ice sheet margins, while the broader global ocean experiences variance on a much smaller scale.

Far-field records, while experiencing instantaneous gravitational effects, are far less affected than proximal sites experiencing significant visco-elastic deformation and gravitational attraction response (Figure 2.11). Tectonically stable regions were targeted for sea-level reconstructions, but the effect of mantle dynamics (dynamic topography) on million-year timescales can add or subtract ten to twenty metres to the RSL estimate (Figure 2.12; Moucha 
et al., 2008; Raymo et al., 2011; Rowley et al., 2013). This has been shown to be the case for the eastern USA passive margin since the Pliocene (Rowley et al., 2013). Furthermore, regional tectonic activity, has the ability to produce changes in RSL on the order of 10's to 100's of metres but can be corrected for if the history is well-known (Kominz and Pekar, 2001). The influence of the basin subsidence, rate of sediment supply and compaction of those sediments by subsequent deposition and water loading, can be accounted for using a technique known as backstripping (Figure 2.13; Section 2.3.3). Another relevant, but less known, or wellconstrained effect on RSL, especially near mountainous continental margins is the isostatic rebound (uplift) from denudation and erosion (e.g. Stern et al., 2010; Rovere et al., 2016).

GIA and the fingerprint of gravitational attraction, must be accounted for in determining ESL. Dynamic topography is particularly important when registering paleo sea-level to present day. However, it is not so important when assessing relative sea-level amplitude or frequency over glacial-interglacial timescales.

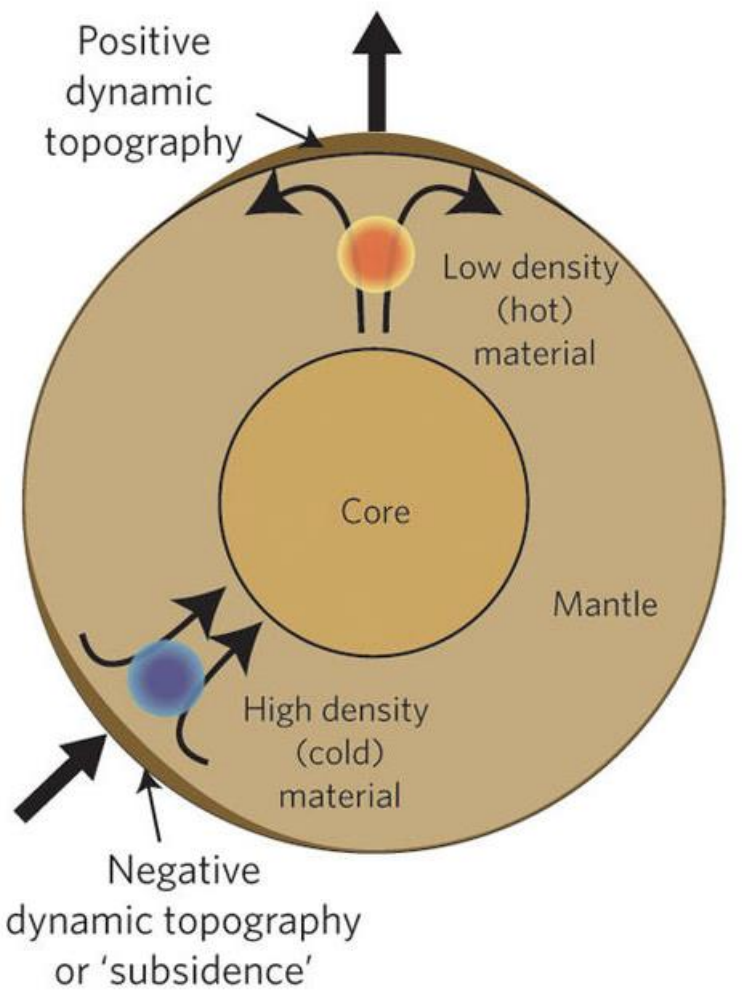

Figure 2.12 Schematic diagram illustrating the positive and negative effect of mantle convection on topography (Braun, 2010). 


\subsubsection{Sea level estimates from the benthic $\delta^{18} \mathrm{O}$ stack}

The benthic foraminiferal $\delta^{18} \mathrm{O}$ stack of Lisiecki and Raymo (2005) provides a continuous and well-dated record of climate variability, unaffected by GIA and dynamic topography, but even so cannot be considered a direct sea level record as foraminiferal $\delta^{18} \mathrm{O}$ contains both an ice volume and temperature component. As stated above, the ice volume effect relates changing $\delta^{18} \mathrm{O}$ of sea water $\left(\delta^{18} \mathrm{O}_{\text {seawater }}\right)$ to the extent of ${ }^{16} \mathrm{O}$-enriched ice on land, and thereby, provides a proxy for relative ice volume/global sea-level change. Calibration of benthic $\delta^{18} \mathrm{O}$ records against independently determined sea-level change has been accomplished for the LGM to Holocene, from studies of coral terraces (Fairbanks and Matthews, 1978; Chappell and Shackleton, 1986; Pillans et al. 1998).

During the MPWP, the small amplitude (0.1 to $0.25 \%$ ) anomalies compared to the Holocene recorded in the benthic $\delta^{18} \mathrm{O}$ stack (Lisiecki and Raymo, 2005) would translate into 12 to 31 $\mathrm{m}$ higher than present GMSL, if they reflected only ice volume (Naish and Wilson, 2009; Miller et al., 2012; Rohling et al., 2014). Conversely, these anomalies could be explained entirely by warmer deep-water temperatures (e.g. Dowsett et al., 2009).

Independent assessment of the temperature contribution to $\delta^{18} \mathrm{O}$ in deep-sea records has been attempted by $\mathrm{Mg} / \mathrm{Ca}$ paleothermometry. Magnesium incorporation in organisms with $\mathrm{CaCO}_{3}$ exoskeletons is endothermic, however a number of complications with this technique have been noted. These include possible $\mathrm{pH}$-related changes in $\mathrm{Mg}$-partitioning into calcite associated with changes in the calcium compensation depth, possible oceanic $\mathrm{Mg} / \mathrm{Ca}$ ratio changes through time, species specific offsets, and diagenesis (e.g. Lear et al., 2000). Two widely referenced studies are, Dwyer and Chandler (2009), who measured Mg/Ca ratios in seafloor dwelling ostracods and Sosdian and Rosenthal (2009), who measured Mg/Ca in two benthic foraminifera species (Cibicidoides wuellerstorfi and Oridorsalis umbonatus).

Alternatively, the independently well-constrained sea-level amplitude of the Late Pleistocene can be used to estimate $\delta^{18} \mathrm{O}_{\text {seawater }}$ and derive a $\delta^{18} \mathrm{O}_{\text {seawater }} /$ sea level calibration. Assuming a constant temperature contribution to benthic $\delta^{18} \mathrm{O}$ of 20 and $33 \%$ a resulting $\delta^{18} \mathrm{O}_{\text {seawater }}$ calibration of $0.011 \%$. $\mathrm{m}^{-1}$ and $0.01 \%$. $\mathrm{m}^{-1}$ respectively was determined (Naish and Wilson, 
2009; Miller et al., 2012). Application of the Holocene-LGM calibration to Pliocene glacialinterglacial benthic $\delta^{18} \mathrm{O}$ cycles assumes that the isotopic composition of the modern ice sheets has not changed through time and does not account for changes in the relative contributions of NHIS and AIS meltwater (e.g. Miller et al., 2005; Naish and Wilson, 2009). However, modern ice sheets are documented to have varying $\delta^{18} \mathrm{O}$ compositions resulting in different sea-level equivalent calibrations (Table 2-1), supporting well-understood physical processes controlling $\delta^{18} \mathrm{O}$-precipitation with temperature and distance travelled from source (Lhomme et al., 2005; Winnick and Caves, 2015; Gasson et al., 2016).

Recent studies have utilised oxygen isotope mass-balance equations to assess the significance of varying ice sheet composition and meltwater contributions to $\delta^{18} \mathrm{O}_{\text {seawater }}$ (Winnick and Caves, 2015; Gasson et al., 2016). Winnick and Caves (2015) estimate that GMSL was 9-13.5 m above modern, with a 2-4.5 m contribution from EAIS for the warmest, mid-Pliocene interglacials in the benthic $\delta^{18} \mathrm{O}$ stack. Gasson et al. (2016) model the Antarctic ice $\delta^{18} \mathrm{O}$ composition for a variation of previously proposed mid-Pliocene AIS configurations and suggest a maximum contribution of up to $13 \mathrm{~m}$ to GMSL. These studies highlight the non-linear relationship between $\delta^{18} \mathrm{O}_{\text {seawater }}$ and sea-level in response to melting of EAIS subglacial basins, and marine-based WAIS (Figure 2.8) that contribute to $\delta^{18} \mathrm{O}_{\text {seawater }}$ but not to sea-level. This raises questions around the suitability of a $\delta^{18} \mathrm{O}_{\text {seawater }}$ sea level calibration, excluding the uncertainty of constraining the temperature component, for periods such as the mid-Pliocene when large portions of marine-based ice are a source of meltwater (Cook et al., 2013).

Pollard et al. (2015) incorporated marine ice shelf and ice cliff instability in their AIS model, which produced up to $17 \mathrm{~m}$ contribution to GMSL from Antarctica for a generic mid-Pliocene interglacial. In the most recent publication on this topic, DeConto and Pollard (2016) reduced their Pliocene Antarctic ice sheet model to contribute $~ 13 \mathrm{~m}$ to GMSL during interglacials of the MPWP. An independent continental-scale ice sheet model that accounts for MISI and that better resolves the grounding line but does not require ice shelf hydro-fracturing and cliff collapse also produces up to $13 \mathrm{~m}$ above present day contribution to GMSL during the warmest interglacials of the Pliocene (Golledge et al., 2017). 
Table 2.1 Comparison of modern $\delta^{18} \mathrm{O}$ ice sheet composition(Lhomme et al., 2005) and the respective, sea-level equivalent (Fretwell et al., 2013), linear $\delta^{18} \mathrm{O} / \mathrm{sea-level} \mathrm{calibrations}$ and the total possible contribution to $\delta^{18} \mathrm{O}_{\text {seawater }}$ (after Winnick and Caves, 2015). Note the modern calibration for all ice sheets is much higher than that suggested for the Late Pleistocene $\left(0.011 \% . \mathrm{m}^{-1}\right)$ because of the absent Northern Hemisphere Ice Sheets.

\begin{tabular}{|c|c|c|c|c|c|c|}
\hline & $\delta^{18} \mathrm{O}(\%)$ & $\operatorname{SLE}(\mathrm{m})$ & $\begin{array}{l}\text { Mass } \\
\left(.10^{16} \mathrm{~kg}\right)\end{array}$ & $\begin{array}{l}\text { Relative } \\
\text { mass } \\
(\%)\end{array}$ & $\begin{array}{l}\text { Calibration } \\
\left(\% \circ \mathrm{m}^{-1}\right)\end{array}$ & $\begin{array}{l}\text { Total } \\
\text { equivalent } \\
\Delta \delta^{18} \mathrm{O}(\%)\end{array}$ \\
\hline EAIS & -56.5 & 53.3 & 21.55 & 0.0156 & -0.0165 & -0.8791 \\
\hline GIS & -35 & 7.3 & 2.66 & 0.0019 & -0.0092 & -0.0672 \\
\hline $\begin{array}{l}\text { WAIS } \\
\text { (grounded) }\end{array}$ & -41 & 0.9 & 0.322 & 0.0002 & -0.0106 & -0.0095 \\
\hline $\begin{array}{l}\text { WAIS } \\
\text { (marine) }\end{array}$ & -41 & 3.4 & 2.43 & 0.0018 & -0.0212 & -0.0719 \\
\hline Ocean & & & 1358 & & & \\
\hline & & & \multicolumn{3}{|c|}{ Modern calibration \%o m-1 } & -0.0158 \\
\hline
\end{tabular}

\subsubsection{Preserved paleoshoreline records}

Morphological features such as wave-cut platforms and relict coastlines may also be used to infer past sea level. The Orangeburg Scarp in South Carolina, USA is an uplifted wave-cut paleoshoreline, dated to 3.5 -3 Ma by biostratigraphy. This paleoshoreline is interpreted to represent high stand sea-level of $35 \pm 18 \mathrm{~m}$ above present sea-level (ASL; Dowsett and Cronin, 1990). Similar scarps are found in southern Australia and South Africa describing paleo sealevel heights of 20-30 m and 24-30 m ASL, respectively (James et al., 2006; Malan, 1991, see also Rovere et al., 2014). Three marine transgressions bounded by erosional surfaces, located in the Alaskan coastal plains have been dated by stratigraphic correlation and biochronology, the oldest of which represents a high stand at $3 \mathrm{Ma}$, shown by lithofacies analysis to represent 
40 m ASL (Brigham-Grette and Carter, 1992).

The GIA and gravitational attraction effect was modelled for the paleoshorelines of Australia, US and Africa to investigate the magnitude of dynamic topography at each location, resulting in estimates of vertical displacement of tens of metres (Rovere et al., 2014), with the potential deviation due to dynamic topography as large as the reconstructed sea-level signal for Pliocene paleoshorelines. Attempts to determine the relative elevation of eustatic sea-level in response to deglaciation of present-day values for WAIS and GIS and accounting for GIA, suggest that paleoshorelines on land today, would be over $\pm 4 \mathrm{~m}$ in error (Figure 2.11; Raymo et al., 2011). This does not include the additive or subtractive influence of dynamic topography.

The subsiding Enewetak Atoll in the Pacific Ocean, was cored to recover lagoonal deposits of the mid Pliocene. Biostratigraphic constraints were used to correlate six highstands to the locally-derived $\delta^{18} \mathrm{O}$ record which determined a sea level peak at $3 \pm 0.5 \mathrm{Ma}$ of $20-26 \mathrm{~m} \mathrm{ASL}$ (Wardlaw and Quinn, 1991). Errors in these records are primarily due to uncertainty in post depositional Earth deformation processes and subsidence estimates.

While paleoshorelines, provide direct records of past sea-level, they also represent a single (or at best, multiple similar magnitude) interglacial record. Poor age constraints and the effects of dynamic topography, tectonics, and GIA, add uncertainty with respect to registering these records to present day sea level. Furthermore, registering sea-level to present day does not provide constraints on total meltwater contribution and thus fully address the sensitivity of ice sheets to warmer climates of the past.

\subsubsection{Backstripped shallow-marine continental margin records}

Sea level reconstruction from continental margin shallow marine sedimentary deposits are established through: (1) analysis of extant mollusc and foraminifera to identify sample associations and species assemblages for comparison with modern abundances in known water depths (Browning et al., 2009; Hayward et al., 1999), and (2) well-documented lithology and sedimentary structures in modern and paleo continental shelf environments to constrain 
depositional environment, in association with ichnofacies and levels of bioturbation (e.g. Naish and Kamp, 1997b).

Backstripping describes a quantitative approach of removing the influence of subsidence induced by sediment, water loading and tectonics (while also correcting for sediment compaction) from the paleowater depth estimate of a continental margin sea-level record (e.g. Kominz and Pekar, 2001; Hayden et al., 2008; Kulpecz et al., 2009; Figure 2.13). Thus, backstripping enables the RSL change recorded in a shallow marine sedimentary succession to be extracted (including non-tectonic subsidence). Backstripping also requires the estimation of the amount of sediment exhumation/erosion. This is achieved through applying a wellestablished porosity-burial depth relationship to determine the original pre-burial thickness of the sedimentary succession from basement (Kominz et al., 2011). Well-constrained paleobathymetry and depositional ages are necessary to develop the complete basin sequence in order to accurately apply the backstripping technique.

Sediment deposition and tectonic subsidence

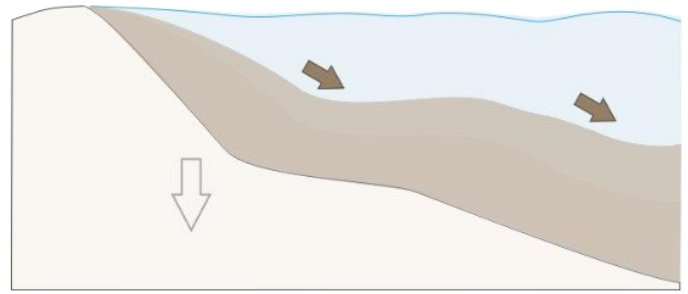

Deposition>subsidence - shallowing facies

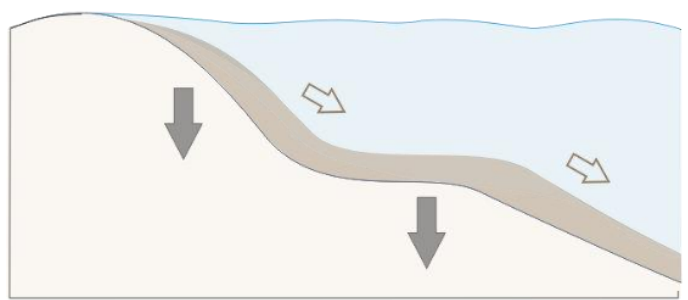

Deposition < subsidence - deepening facies
Eustatic sea level

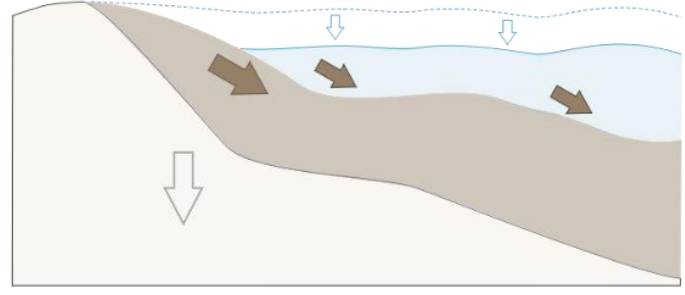

Sea level fall + sed deposition > subsidence exaggerated shallowing

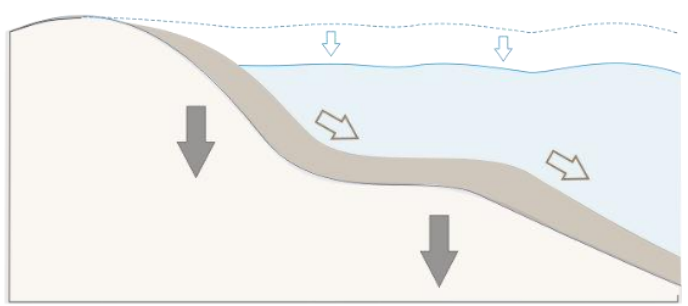

Sea level fall + sed deposition < subsidence dampened shallowing

Figure 2.13 Schematic diagram displaying the response of a shallow-marine depositional environment to the relative effects of local tectonics (subsidence), sediment supply and eustatic sea-level variation. These combined influences determine the paleobathymetry and can be accounted for by using a sediment backstripping technique allowing the RSL to be estimated from a continental margin record. 
While a number of studies have attempted to backstrip "eustatic" sea-level (ESL) out of the New Jersey margin for the Cretaceous-Paleogene and Miocene (Kominz and Pekar, 2001; Hayden et al., 2008; Kulpecz et al., 2009), there are only two studies from backstripped shallow marine margins used in the Miller et al. (2012) compilation of mid-Pliocene peak eustatic sealevel estimates. The first study, from the Whanganui Basin, was used to calibrate to the benthic $\delta^{18} \mathrm{O}$ stack between 3.3 and $2.7 \mathrm{Ma}$. Cyclic unconformity bound strata, representing glacialinterglacial sea-level cycles spanning the Plio-Pleistocene are located in the Whanganui Basin, New Zealand (containing the record studied in this thesis; Naish et al., 1998). The cyclothems represent alternating continental shelf to shoreline environments and throughout the Pleistocene contain subaerial exposure and transgressive surfaces of erosion corresponding to the lowstand and early phases of the sea-level cycle, thus does not resolve the full amplitude of sea level. Paleobathymetry was interpreted through extant molluscan and benthic foraminifera assemblage analysis and quantitative grain size-water depth estimates prior to qualitative attempt at 1-D backstripping (Naish and Wilson, 2009). Well-constrained dating and correlation to the benthic $\delta^{18} \mathrm{O}$ stack enabled a glacial-interglacial resolution record of sealevel fluctuations from Whanganui Basin. This resulted in glacial-interglacial amplitudes of up to $30 \mathrm{~m}$ in the mid-Pliocene, which should be considered a maximum as cooling temperatures over the Pliocene were not accounted for. The glacial-interglacial amplitudes were still lower than those estimated from Mg/Ca derived estimates (Dwyer and Chandler, 2009; Sosdian and Rosenthal, 2009).

In the second study, shallow marine sequences accumulated in the Chesapeake impact crater (Virginia, USA), were analysed using lithofacies, ichnofacies and extant benthic foraminiferal analysis, to identify four high-stands following the MPWP (Browning et al., 2009; Miller et al., 2012). Limited active tectonic influence during the Pliocene on the Chesapeake structure meant one-dimensional backstripping was considered sufficient to determine the evolution of the basin (Kulpecz et al., 2009), and constrain the magnitude of mid-Pliocene sea-level with respect to present day. The errors in RSL calculated from backstripping are not easy to estimate, but include paleobathymetry, the porosity depth relationship of preserved and eroded sediments, precision of age control points and estimates of sediment thickness. Miller et al. (2012) estimates a typical backstripping uncertainty of $20 \%$. 
Miller et al. (2012) compiled the full range of glacial-interglacial sea-level estimates including $\delta^{18} \mathrm{O}$ calibration by backstripping and $\mathrm{Mg} / \mathrm{Ca}$, including estimated ages of paleoshorelines within a probabilistic framework. From this, they calculated an average mid-Pliocene interglacial sea-level highstand during 3.2-2.7 Ma of $22 \pm 10 \mathrm{~m}$ with 95\% confidence. Raymo et al. (2011) and Masson-Delmotte et al. (2013) highlight a number of uncertainties and assumptions in the Miller et al. (2012) compilation including the lack of correction for dynamic topography, GIA and inability to register some sea-level magnitudes back to present day sea level. Notwithstanding this, the relative agreeance of certain sites in the far-field of ice sheets and calibrated proxy records not affected by dynamic topography, suggests the mean estimate and associated error may be considered reasonable.

\subsection{The Whanganui Basin shallow-marine sedimentary record as an archive of Pliocene-Pleistocene global sea-level change}

The western North Island of New Zealand comprises three back-arc basins; King Country Basin (previously northern Whanganui Basin), Whanganui Basin to the south, which is separated from the Taranaki Basin by the Taranaki Fault to the west and onlapping basement of the axial ranges at the eastern margin (Kamp et al., 2002; Figure 2.14 A). The Whanganui Basin developed behind the Hikurangi subduction zone over the last $\sim 5 \mathrm{Ma}$ as a broad flexural downwarp of the Indo-Australian Plate overriding the subducted Pacific Plate, south of the extensional back-arc basin of the Central Volcanic Region to the north (Figure 2.14 B; Stern and Davey, 1989). The basin depocentre has migrated southward by $30 \mathrm{~mm} / \mathrm{yr}$ from the King Country to the presently drowned river valleys in the North Marlborough region, and is suggested to be the result of a topographic wave formed by the redistribution of lithosphere over the mantle (Stern et al., 2013; Figure 2.14 C).

The nature of the basin deposition is spatially variable and formation names and depositional environments discussed in this thesis are representative of the eastern Whanganui Basin. The accumulation of marine sediments describes the paleogeographic evolution of the basin, with 
the shelf deposits of the Matemateonga Formation onlapping slope deposits to the north and basement within the Whanganui Basin from 5.6 Ma. A significant regional flooding event at 4.7 Ma, defines the boundary to the Rangitikei Supergroup (Kamp et al., 2004) when the depocentre moved into the Whanganui Basin, which is overlain by a $2 \mathrm{~m}$ thick condensed glauconitic mudstone representing 500 kyrs (Hayton, 1998). The overlying Tangahoe Mudstone represents a basin-wide continental slope environment from $4.2 \mathrm{Ma}$, deposited in equilibrium with subsidence, represented by a relatively stable depositional environment. This is followed by an uplift event on the axial ranges, resulting in a shallowing over $\sim 200 \mathrm{kyr}$ culminating in the $\sim 300$ m-thick deposition of the Utiku Group at $3.2 \mathrm{Ma}$, representing inner to outer shelf depositional environments from east to west. Renewed subsidence at $3 \mathrm{Ma}$ when the depocentre of the basin is situated in the central region is marked by the deposition of the Mangaweka Mudstone, a 500 m-thick outer shelf to upper slope deposit described by very fine sandy massive mudstone. A series of alternating inner to mid shelf marine sediments were deposited during the late Pliocene as sea-level cycles increase in amplitude.

During deposition of the Rangitikei Supergroup in the Whanganui Basin, the shoreline migrates southward in a general east-west orientation, arcing around to lap onto the foothills of the eastern axial ranges in a north-south orientation (Figure 2.15). Paleogeographic reconstructions describe an open bay exposed principally to the west, with significant topography to the east, reaching over $1000 \mathrm{~m}$ altitude in the south. Two seaways through the axial ranges to the north and south, developed between 4 and $3 \mathrm{Ma}$. As the tectonic hingeline migrated southwestward, uplift of Pliocene strata progressively occurred and intensified in the last 1 million years at a rate of $\sim 30 \mathrm{~m} / \mathrm{kyr}$ at the axial ranges to $\sim 10 \mathrm{~m} / \mathrm{kyr}$ at the coast. This has resulted in tilting of the Plio-Pleistocene strata by $5-3^{\circ}$ to the south and southwest (Stern et al., 2013). Additional effects of local isostatic rebound from the subsequent erosion of over 2000 m of exhumed material contributes to the uplift of the basin (Pulford, 2002). 

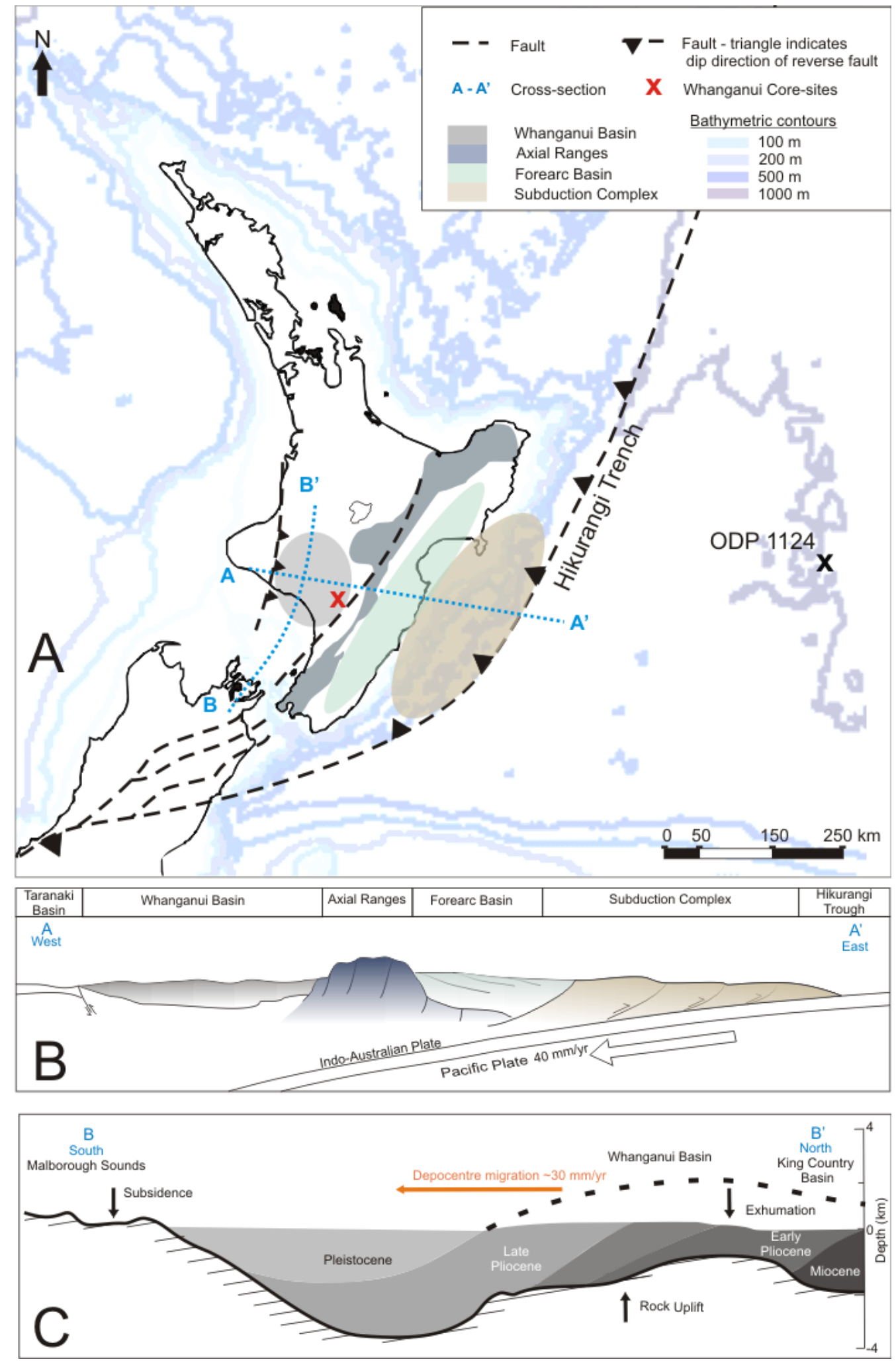

Figure 2.14 a) Location of Whanganui Basin in relation to the Pacific and Indo-Australian Plate boundary (Hikurangi Trench). b) The subducting Pacific Plate coupled to the Indo-Australian Plate forming the Whanganui backarc basin is shown by the A$A^{\prime}$ cross-section. c) The $B-B^{\prime}$ schematic cross-section conceptually illustrates the southward migration of the depocentre and contemporaneous uplift in the north, exposing the geological units onshore (after Stern et al., 2013). 


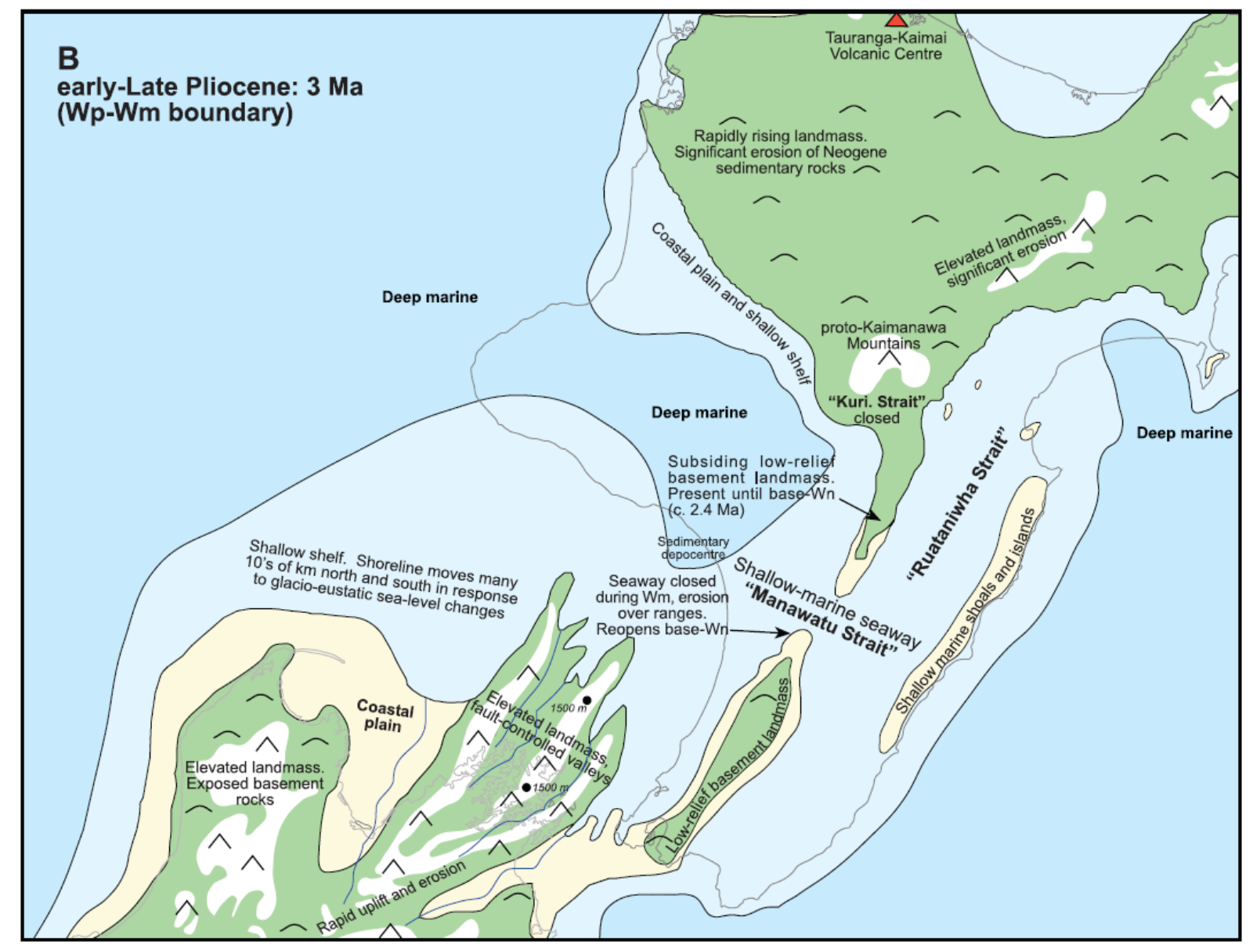

Figure 2.15 Paleogeographic map of the Whanganui Basin showing the deep marine (>200 $\mathrm{m}$ water depth) and shallow marine (<200 $\mathrm{m}$ water depth) of the Whanganui embayment for 3 Ma (Trewick and Bland, 2014).

The Whanganui Basin thus provides outcrop of ca. $5 \mathrm{~km}$ of marine sediments deposited at a rate coeval with subsidence, resulting in arguably the highest resolution, near-continuous, shallow-marine stratigraphic record for the Plio-Pleistocene, globally. A well-constrained chronostratigraphic framework has been developed for this succession from paleomagnetic, biostratigraphic datum, and numerous dated silicic tephra horizons associated with the backarc volcanism in the Coromandel Region (active ca. $10-2 \mathrm{Ma}$ ), enabling astronomical calibration of the sequences (Naish et al., 1996; 1998). Deposition of shelf sediments provide an environment sensitive to water depth changes, allowing assessment of eustatic sea-level through the Plio-Pleistocene.

The recognition of sea-level cyclicity in Whanganui strata by Fleming (1953) was initially argued to be the result of regional tectonic movements. High-resolution studies of cyclical lithofacies have identified the stratigraphic sequences as a response to the 41 kyr eustatic sea-level cycles 
of the Early to mid-Pleistocene (Figures 2.16 \& 2.17; Beu and Edwards, 1984; Kamp and Turner, 1990; Abbott and Carter, 1994; Pillans et al., 1994; Naish and Kamp, 1997b; Journeaux et al., 1996; Kamp et al., 1998; Saul et al., 1999). Each 41 kyr sea-level cycle is represented by an individual depositional sequence comprising transgressive (TST), highstand (HST) and regressive (RST) systems-tracts (e.g. Naish and Kamp, 1997a) and are generally bound by unconformities formed through aerial exposure during glacial lowstands (Figure 2.16).

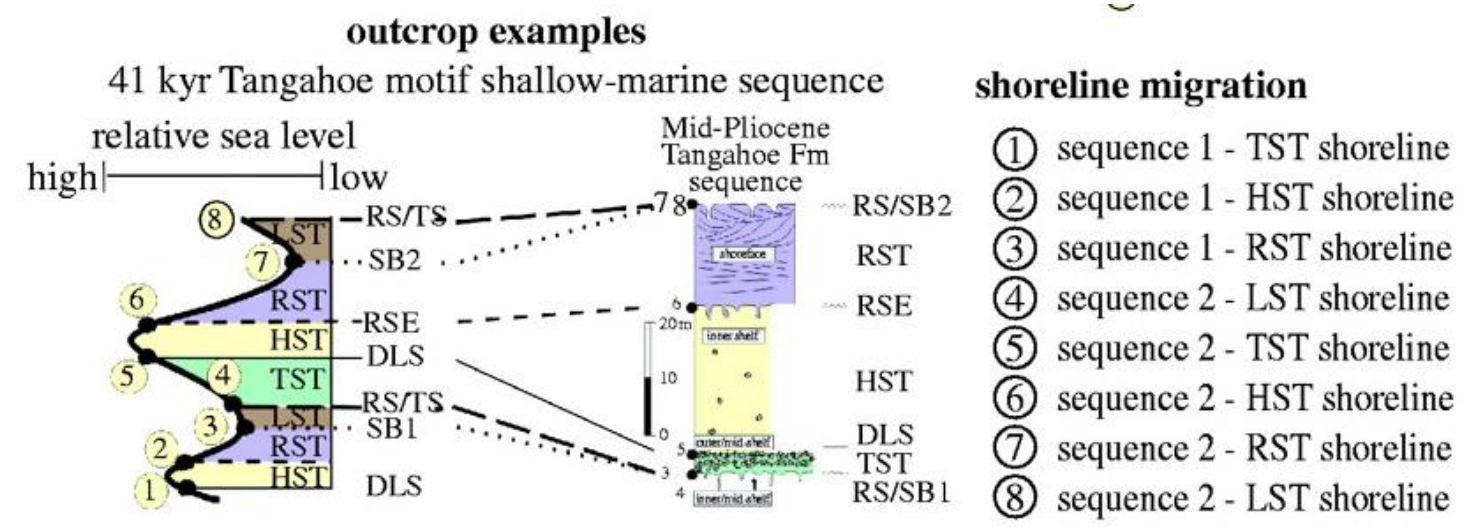

Figure 2.16 Sequence stratigraphic interpretation of a how a relative sea-level cycle is recorded in a typical Whanganui outcrop motif (Naish et al., 2005).

The development of integrated and well-constrained chronology utilising tephrochronology, paleomagnetism and biostratigraphic markers permit correlation to the global benthic $\delta^{18} \mathrm{O}$ stack (Figure 2.17; Naish et al., 1996; Pillans et al., 2005; Turner et al., 2005). Constraints on the amplitude of RSL were developed through water-depth sensitive extant foraminiferal assemblages in association with lithofacies (Naish and Kamp, 1997b; Kamp et al., 1998; Naish et al., 2005), then calibrated to the global benthic $\delta^{18} \mathrm{O}$ stack for the Pliocene to present (Naish and Wilson, 2009). 


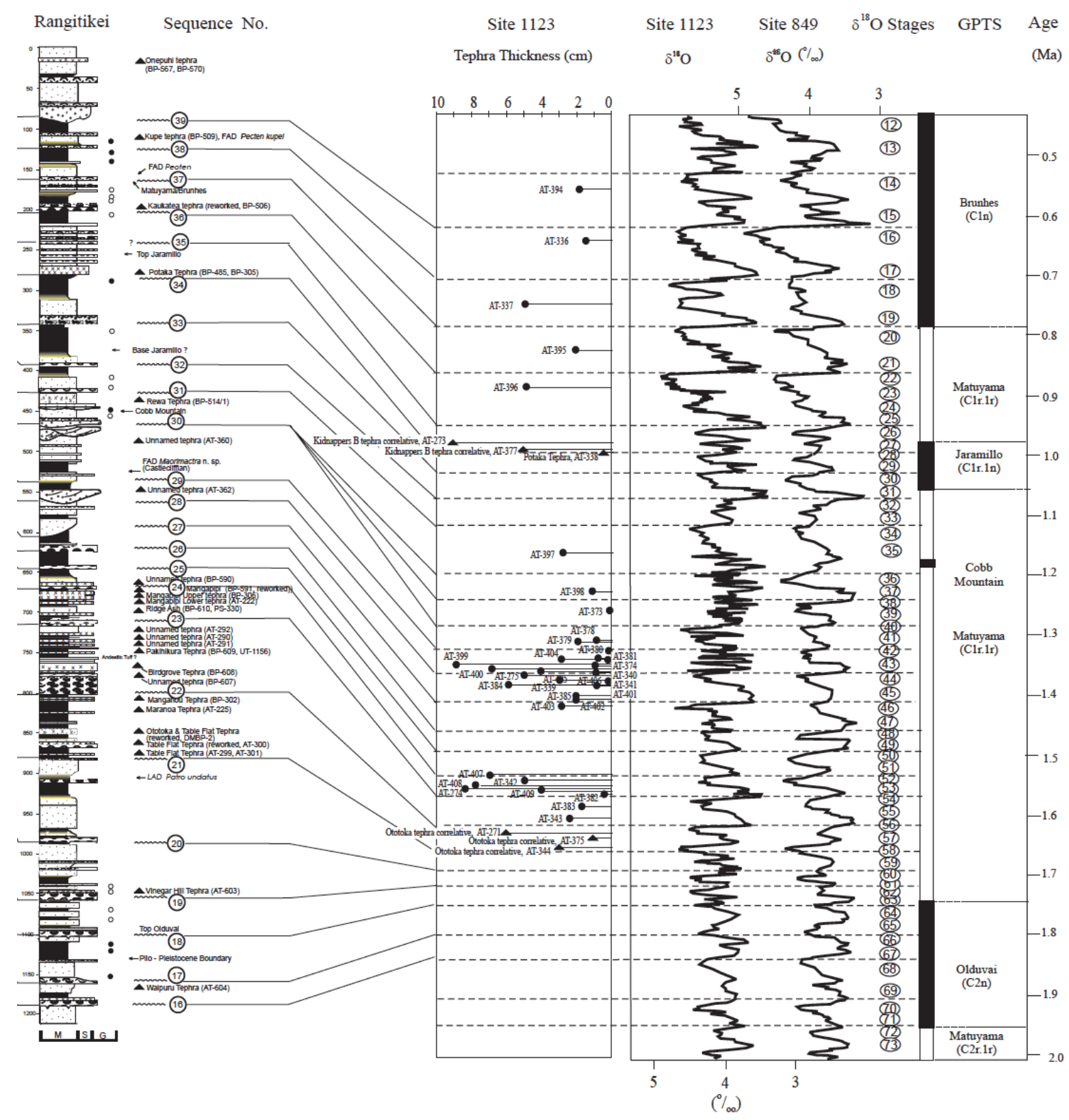

Figure 2.17 Onshore cyclostratigraphic record from Rangitikei and correlation to offshore $\delta^{18} \mathrm{O}$ records within paleomagnetic, biostratigraphic and tephrostratigraphy age constraints (Pillans et al., 2005).

This study focuses on improving sea-level estimates in the MPWP by integrating methods of water depth estimates, and targeting laterally equivalent shelf depositional environments represented in the Utiku Group (Figure 2.18 A). A preliminary study was carried out on outcrop in the Turakina Valley (Patterson, 2014; Figure 2.18 A) to constrain the location of a tephra in the Utiku Group and to confirm the lithology. A second study was carried out on outcrop of 
the overlying Mangaweka Mudstone (Sefton, 2015; Figure 2.18 A) on Watershed Road to test parts of the methodology used in this study.

The two new cores were drilled in proximity to the outcrop studies (Figure 2.18) and recovered laterally adjacent, contemporaneous depositional environments of the Utiku Group. The Siberia-1 core site in the Turakina Valley, represents middle to outer shelf environments, characterised by alternating very fine sandy mudstones and sandy mudstones. While the Tiriraukawa-1 core site to the east, represents middle to inner shelf environments, characterised by sandy mudstones to muddy sandstones. The previously described Utiku Group in the Rangitikei River Section represents the innermost shelf, with unconformities denoting aerial exposure during significant sea level lowstands (Figure 2.18 B; Kamp et al., 1998). 


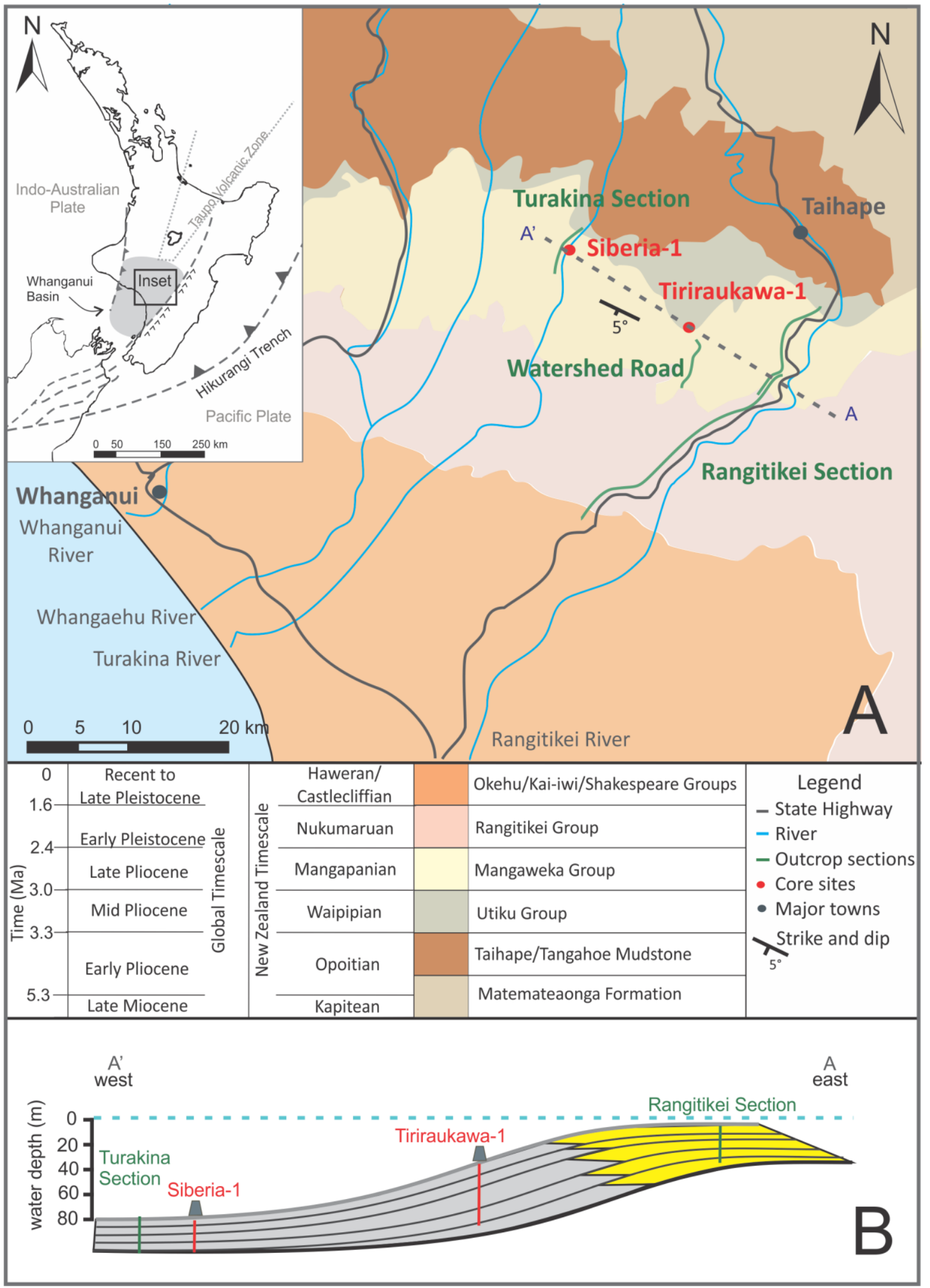

Figure 2.18 Simplified geologic map of Wanganui Basin based on Townsend et al. (1972), with the core sites (Siberia-1 and Tiriraukawa-1) and outcrop sections (Turakina [Patterson et al., 2014], Watershed Road [Sefton, 2015] and Rangitikei [Journeaux et al., 1996; Naish and Kamp, 1997a]) referred to in text. The schematic A-A' cross section (B) describes the westward deepening shelf during the deposition of the Utiku Group, and the location of core and outcrop across that transect. 


\section{Data collection}

This chapter contains a brief description of core recovery and processing. It includes the collection of physical property logs, core logging and sampling and sample processing procedures for grain size and foraminifera abundance and cluster analysis. More evolved data analysis (e.g. foraminiferal paleowater depth modern analogue analysis) will be explained within the relevant results chapters.

\subsection{Core Recovery}

Sediment cores were recovered from Siberia-1 and Tiriraukawa-1 sites during the months of July to October 2014. Webster Drilling \& Exploration Ltd supplied the crew and a rotary drill rig coring system, while operations were supervised by the Science Drilling Office, Antarctic Research Centre, Victoria University of Wellington. Appendix A contains the core recovery details. The Siberia-1 core was drilled to a depth of $351.2 \mathrm{~m}$ with a recovery of $\sim 95 \%$ from 40 $\mathrm{m}$ depth. The upper $40 \mathrm{~m}$ of core was considered to represent a slump deposit on the basis of its brecciated fabric and was not included in further analyses. The Tiriraukawa-1 site was drilled to $382.54 \mathrm{~m}$ with a recovery of $100.6 \%$ from $40 \mathrm{~m}$ depth. The greater than $100 \%$ core recovery is due to post exhumation core expansion (Table 3.1).

There were recurring issues at the Siberia-1 site with breaking off and securing the core in the core barrel following each 3 m coring run. Tungsten 'claws' were welded on to the core catcher in an attempt to remedy this. This appeared to improve recovery but resulted in two scours up to $1 \mathrm{~cm}$ wide and $5 \mathrm{~mm}$ deep on the core surface as the claws attempted to grip the surface of the core. The same system was also used at the Tiriraukawa-1 site. The reduced quality of the core caused difficulties during core scanning, specifically in maintaining electrical conductivity for velocity measurements and with estimation of core thickness used to calculate other physical property parameters.

Upon recovery, cores were cleaned to remove drilling mud, cut into metre lengths, assigned depths, briefly described and packaged into heat sealed plastic sleeves for later processing. On 
completion of the drilling programme, down-hole wireline logging of density, natural gamma radiation, resistivity and sonic velocity were collected by RDCL LTD.

Table 3.1 Core recovery for PQ coring (81 mm diameter) and HQ coring (61 mm diameter) for Tiriraukawa-1 and Siberia-1 cores.

\begin{tabular}{llll}
\hline Tiriraukawa-1 & Core Recovery & Siberia-1 & Core Recovery \\
\hline Slump 0-41.99 m & $79.8 \%$ & Slump 0-39.56 m & $60 \%$ \\
PQ core 0-173.3m & $100.3 \%$ (exc. & PQ core 0 - 263.75 m & $93.3 \%$ \\
& Slump) & & (exc. Slump) \\
HQ core 173.26 - & $100.9 \%$ & HQ core 263.75 - & $97.4 \%$ \\
$282.63 \mathrm{~m}$ & & $351.21 \mathrm{~m}$ & \\
\hline
\end{tabular}

\subsection{Core processing}

The cores were returned to Victoria University of Wellington and processed as outlined below.

- Whole core scanning of physical properties (gamma ray attenuation/bulk density, compressional (p)-wave velocity, magnetic susceptibility and non-contact resistivity).

- Discrete samples collected at $1 \mathrm{~m}$ intervals from the whole core for paleomagnetic studies and grain size

- Core splitting

- Detailed visual core description

- Sampling

\section{Physical Properties Logs}

P-wave velocity, magnetic susceptibility (MS) and gamma-ray attenuated density (bulk density) were measured on whole-core sections using the Alfred Wegener Institutes GEOTEK multisensor core logger (MSCL). Instrument drift and issues with software communication cables generated discontinuous and inconsistent results from the non-contact resistivity (NCR) sensor and were not further processed. P-wave velocity also provided inconsistent results for two reasons; 1 ) due to inability to maintain a good acoustic coupling between the transducers and 
core surface; and 2) the high permeability of the sediment allowed it to drain sufficiently that allowed enough air into the core to greatly attenuate sound waves. These data were not processed further. Standards for calibration were logged at the beginning and end of every 912 m run (Appendix B contains detailed methodology and instrument calibration parameters).

Measurements were usually made at an interval of $4 \mathrm{~cm}$. However, in the case of very poorquality core where it was unlikely that accurate core diameter would be obtained (and therefore associated measurements would not be corrected for core thickness) a sampling interval of $8 \mathrm{~cm}$ was taken or more often, the core sections were removed from the run. The data were then collated and assigned depths.

Borehole geometry (calliper tool), resistivity, Natural Gamma-ray (NGR) activity and density wireline logs were provided by RDCL LTD as compiled standardised raw datasets. The data were consolidated and resampled at a coarser sampling resolution, as the original sampling interval of $1 \mathrm{~cm}$ resulted in a highly variable dataset. Measurement of density required the borehole wall to be even so that the instrument is secured against the side. The calliper measurement identified numerous depth intervals where this was not the case. As a result, the down-hole density logs were discarded in favour of the whole-core MSCL density log. As resistivity and NGR measurements are not sensitive to instrument distance from the side wall, the logs are considered reliable.

In summary, MS and density logs measured on the MSCL, and the resistivity and NGR wireline logs were used in this study. All data were processed in a similar manner to reduce outliers and smooth instrumental error (Appendix B). The mean of a selected number of data points (binning) is taken to reduce variation in measurements within instrument error. Outliers still present were identified and removed if they were geologically unreasonable, for example density measurements below $2 \mathrm{~g} \cdot \mathrm{cm}^{-3}$ represented gaps in the core. Detrending was only required for the down hole resistivity logs, which are sensitive to temperature. A further smoothing of the data was then applied using the LOESS smooth function available in $\mathrm{R}$, a statistical software package. This function uses overlapping windows of a chosen number of sample points to average at a selected spacing. The windows were variable for each dataset depending on the number of samples in each dataset and the range of outliers (Appendix B). 


\section{Core logging and sampling}

Cores were split lengthways to provide a clean surface to describe and sample, and an archive half was retained. This included describing the colour and hardness, classifying lithology following the classification scheme of Mazzulllo and Graham (1988), identifying sedimentary structures, giving a bioturbation index after Droser and Bottjer (1986), describing types of bioturbation and estimating the abundance and macrofossil type. The type and frequency of samples collected is outlined in Table 3-2. Samples were annotated as follows; the first letter represents the core site name (S for Siberia-1; T for Tiriraukawa-1), the second letter refers to the sample type (see Table 2; with the exclusion of grain size which had no notation), followed by the core depth expressed as three digits for the metres and two digits for centimetres downhole. An initial core description and location of samples taken can be found in Appendix C.

Table 3.2 Sample type, size and frequency of sampling for Siberia-1 and Tiriraukawa-1 cores.

\begin{tabular}{|c|c|c|}
\hline Sample Type & Sample Size and Method & Sample Label \\
\hline Microfossils & $\begin{array}{l}\text { 200-400g near the grain size sample } \\
\text { site. Sample depth from noted as the } \\
\text { centre of sample with the range to be } \\
\text { noted. Sampled every } 2 \mathrm{~m} \text {. }\end{array}$ & $\begin{array}{l}\text { e.g. Tf06545 } \\
\text { Tiriraukawa; foraminifera; } 65.35 \text { - } \\
65.55 \mathrm{~m}\end{array}$ \\
\hline Porosity & $\begin{array}{l}\text { 2cc, } 2 \mathrm{~cm} \text { wide. } \\
\text { Sampled every } \sim 10 \mathrm{~m}\end{array}$ & $\begin{array}{l}\text { e.g. Tp06645 } \\
\text { Tiriraukawa-1; porosity; 66.44- } \\
66.46 \mathrm{~m}\end{array}$ \\
\hline $\begin{array}{l}\text { Macro } \\
\text { Fossils }\end{array}$ & $\begin{array}{l}\text { A range of sizes, range of depth to be } \\
\text { noted. Sampled when applicable. }\end{array}$ & $\begin{array}{l}\text { e.g. Tm06743 } \\
\text { Tiriraukawa; macro; 67.40-67.46 } \\
\text { m }\end{array}$ \\
\hline Grain size & $\begin{array}{l}\sim 10 \mathrm{~g} \text { and briefly rinsed to remove } \\
\text { drilling mud. Sampled every } 2 \mathrm{~m} \text {. }\end{array}$ & $\begin{array}{l}\text { e.g. T06545 } \\
\text { Tiriraukawa; (grain size); } \\
65.45 \mathrm{~m}\end{array}$ \\
\hline Organics & $\sim 50 \mathrm{~g}, 1 \mathrm{~cm}$ wide. Sampled every $\sim 10 \mathrm{~m}$ & $\begin{array}{l}\text { e.g. To06556 } \\
\text { Tiriraukawa-1; organics; } 65.55 \text { - } \\
65.56 \mathrm{~m}\end{array}$ \\
\hline
\end{tabular}




\subsection{Grain size}

In order to determine the grain size of sediment deposited from wave dominated processes, sediment components not likely to be in hydraulic equilibrium were removed. This includes organic and calcium carbonate $\left(\mathrm{CaCO}_{3}\right)$ material. Hydrochloric acid $(\mathrm{HCl})$ dissolves any biogenic $\mathrm{CaCO}_{3}$ or $\mathrm{CaCO}_{3}$ cement and hydrogen peroxide $\left(\mathrm{H}_{2} \mathrm{O}_{2}\right)$ oxidises organic material. The preferred method for removing organic matter was to use a high concentration of $\mathrm{H}_{2} \mathrm{O}_{2}$ at moderate temperatures since previous studies have shown there was a swelling effect on clays particularly in the presence of mica in response to high temperatures and lengthy treatments (Mikutta, 2005). A test of two different peroxide treatments and the addition of $\mathrm{HCl}$ was undertaken to determine the best treatments for the removal of $\mathrm{CaCO}_{3}$ and organic matter and how it affected the resulting grain size (Appendix D). There was a consistent increase in percent mass loss with the use of $\mathrm{HCl}$ treatments, indicating $\mathrm{CaCO}_{3}$ was present in moderate abundance (Appendix D). The $\mathrm{HCl}$ treatment also assisted in disaggregating rare $\mathrm{CaCO}_{3}$ cemented samples. There was a limited variance on grain size distribution between different treatments as displayed in Figure 3.1. 

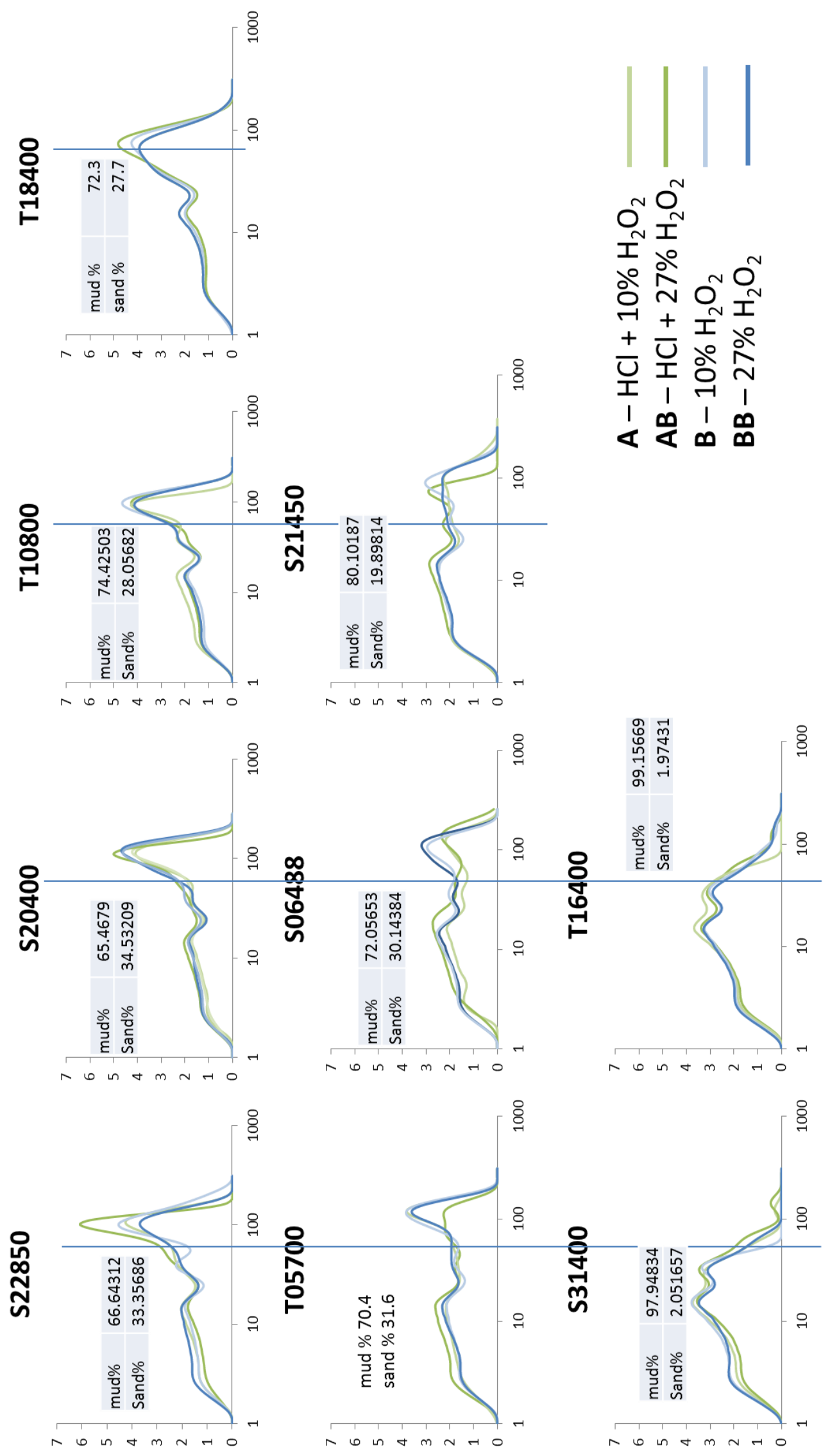

Figure 3.1 Comparison of grain size distribution for selected samples for the variable $\mathrm{CaCO}_{3}$ and organic treatments (discussed in Appendix D). 
The processing of grain size samples was undertaken as outlined below.

1. Sample dried at $50^{\circ} \mathrm{C}$

2. Crushed with wooden blocks

3. Split taken of $2 \mathrm{~g}$

4. Sample wetted before adding $5 \mathrm{~mL}$ of $\mathrm{HCl}$ and left for $30 \mathrm{~min}$

5. $\sim 40 \mathrm{~mL}$ of distilled water added

6. Placed in centrifuge for $10 \mathrm{~min}$ at $4000 \mathrm{rpm}$

7. Water decanted, $\sim 40 \mathrm{~mL}$ of distilled water added and sonicated for $2 \mathrm{~min}$

8. Repeat step 6 and 7 for a second and third time.

9. Decant water and add $5 \mathrm{~mL}$ of $\mathrm{H}_{2} \mathrm{O}_{2}$ at $10 \%$ concentration

10. Leave for $48 \mathrm{hrs}$ at room temperature

11. Repeat step 6 and 7 three times

12. Freeze sample for $24 \mathrm{hrs}$

13. Freeze dry sample until dry

14. Run in laser-based particle size analyser

The treated samples were subsampled at 0.15-0.2 g (muddier samples have a greater surface area per unit mass and therefore a lower weight per sample is required for laser diffraction) and added to $\sim 50 \mathrm{~mL}$ of $0.5 \mathrm{~g} . \mathrm{L}^{-1}$ sodium hexametaphosphate surfactant (Calgon) before being stirred and sonicated for $\sim 30 \mathrm{~min}$. These were then placed in the Aqueous Liquid Module of the Beckman-Coulter LS 13320 Laser Diffraction Particle Size Analyser that translates the pattern of scattered light to the particle size distribution of a sample. The grain size distribution was calculated based on an optical model (refractive index) for quartz, that is, assuming that the diffraction of all particles in the sample is the same as that of quartz. Standard soda-glass beads with modes at $250 \mu \mathrm{m}$ and $68 \mu \mathrm{m}$ were run 3 times a day (Figure 3.2) to ensure instrument performance. To test consistency of the treatment and sub-sampling, six samples of varying lithologies were selected and run with each of the five batches of samples treated. The standard deviation was taken for each set of sub-samples at each grain size bin before taking the mean standard deviation of all grain size bin (Table 3.3). Grain size results can be found in Appendix E. 


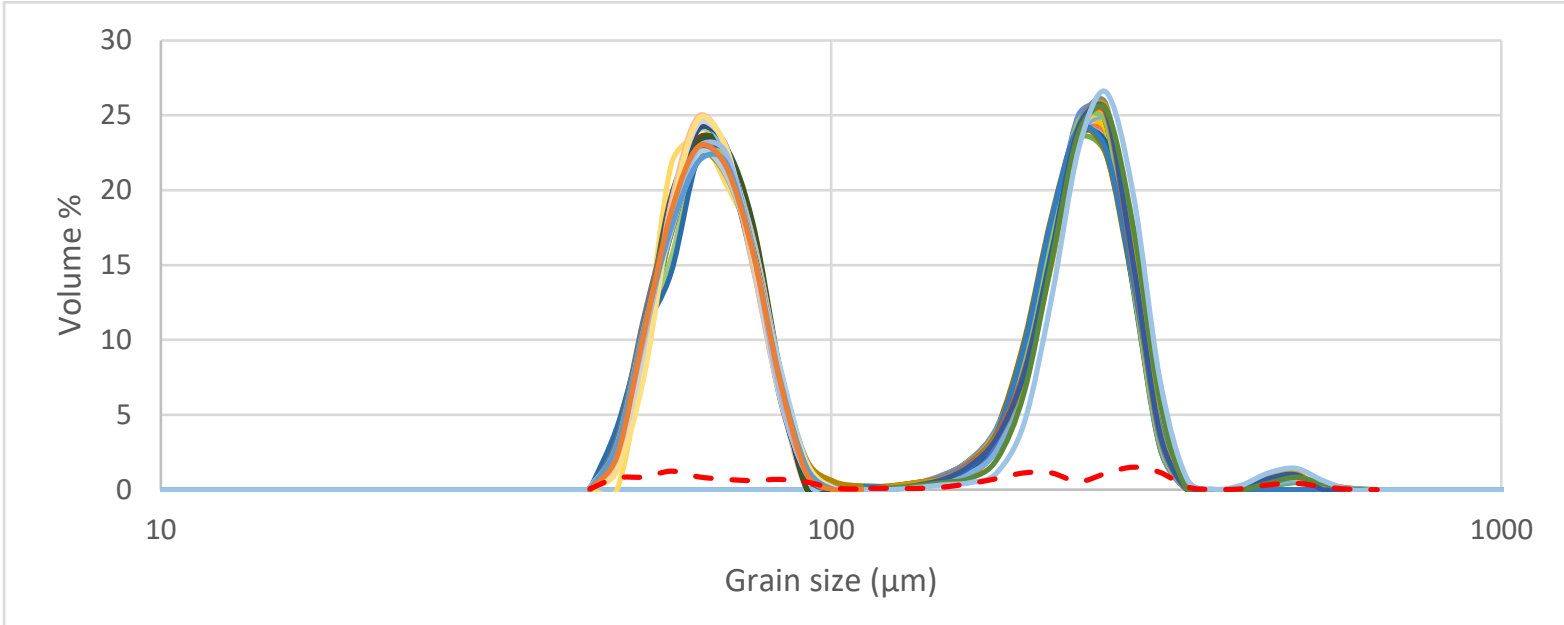

Figure 3.2 Standard deviation (red dashed line) of $250 \mu \mathrm{m}$ and $68 \mu \mathrm{m}$ standards run during sample analysis of grain size distribution.

Table 3.3 Average standard deviation in volume \% (from standard deviation of each size bin) of repeat grain size distribution samples.

\begin{tabular}{ll}
\hline Repeat Samples & Average St. Dev $1 \sigma$ \\
\hline T08500 & 0.13 \\
T10500 & 0.14 \\
T11500 & 0.13 \\
T16500 & 0.11 \\
T17500 & 0.09 \\
T18500 & 0.13 \\
T19500 & 0.11 \\
T24500 & 0.13 \\
T26500 & 0.12 \\
T28500 & 0.10 \\
T29500 & 0.18 \\
\hline
\end{tabular}




\subsection{Foraminifera}

Sample preparation for foraminiferal analysis included drying samples at no more than $50^{\circ} \mathrm{C}$ before crushing the samples with wooden blocks and sub sampling $200 \mathrm{~g}$ of material, which was then wet sieved at $63 \mu \mathrm{m}$ and dried, with the coarse fraction retained for microscope analysis. Samples were then selected for census counts or picked for later stable isotope analysis.

\section{Census Counts}

Samples selected for census counts were split using a riffle splitter, until an estimated $\sim 200$ specimens were present in the sample. The split to be counted was then dry sieved at $125 \mu \mathrm{m}$ and all specimens $>125 \mu \mathrm{m}$ were counted. Benthic foraminifera were identified and counted at species level while planktic specimens were not differentiated (Appendix F). Counts for both cores were normalised to sample totals as percent abundance. Census counts used in this study from the Rangitikei outcrop (Kamp et al., 1998) and Watershed Road (Sefton, 2015), were processed in a similar manner to this study but counts were undertaken on the $>150 \mu \mathrm{m}$ fraction. Samples containing less than 200 specimens were excluded from further analysis.

\section{Stable isotope analysis}

Samples for stable isotope analysis were taken every $2 \mathrm{~m}$ down core. Up to 25 specimens of Cibicides deliquatus from the $>180 \mu \mathrm{m}$ size fraction were picked for analysis. Foraminifera were cleaned by sonicating the tests in a glass vial with distilled water, two times for $15 \mathrm{~s}$, decanting the water and suspended contaminants between treatments. Five samples were selected from a Siberia-1 grain size cycle down core and a sixth sample were selected from the muddiest interval in the Tiriraukawa-1 core to investigate possible equilibrium offsets in stable oxygen isotope ratios between two benthic species (Cibicides deliquatus and Uvigerina peregrina/pliozea) and one planktic species Globigerina bulloides. Selected specimens for each species and sample were imaged by a Scanning Electron Microscope to determine if any postdepositional recrystallisation of $\mathrm{CaCO}_{3}$ was evident, but none was observed (Figure 3.3). Results of the oxygen isotope analysis displayed a documented offset between the benthic 
species (Figure 3.3; Marchitto, 2014) of $0.6 \%$ and an expected offset between the benthic and planktic species due to the temperature difference of sea surface to sea floor (Figure 3.4).

The stable isotope analysis was undertaken at the Stanford Stable Isotope Biogeochemistry Laboratory, Stanford University, United States of America. The specimens in each sample were counted then gently crushed before weighing out $50-100 \mu \mathrm{g}$. The samples were run in batches of 46, including six standards of NBS-19 (Friedman et al., 1982) and analysed with a Finnigan MAT252 coupled to a Kiel III carbonate device. Results were processed for any instrument drift, deviation from recorded standard values and reported relative to the international PDB standard by the laboratory manager David Mucciarone.

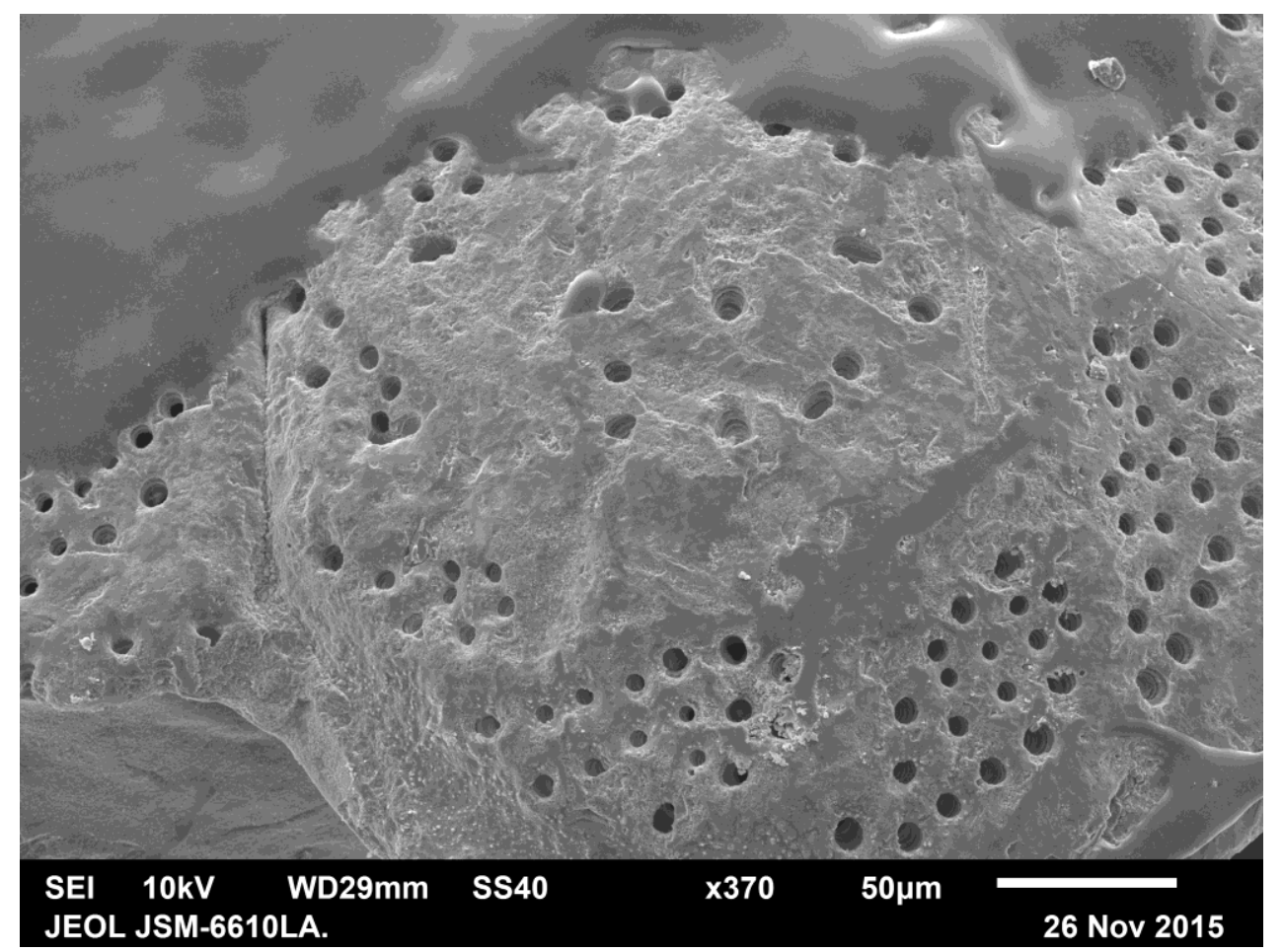

Figure 3.3 SEM image of Cibicides deliquatus, that shows evidence of abrasion but no recrystallization. The black adhesive on the margins of the image is carbon tape. 


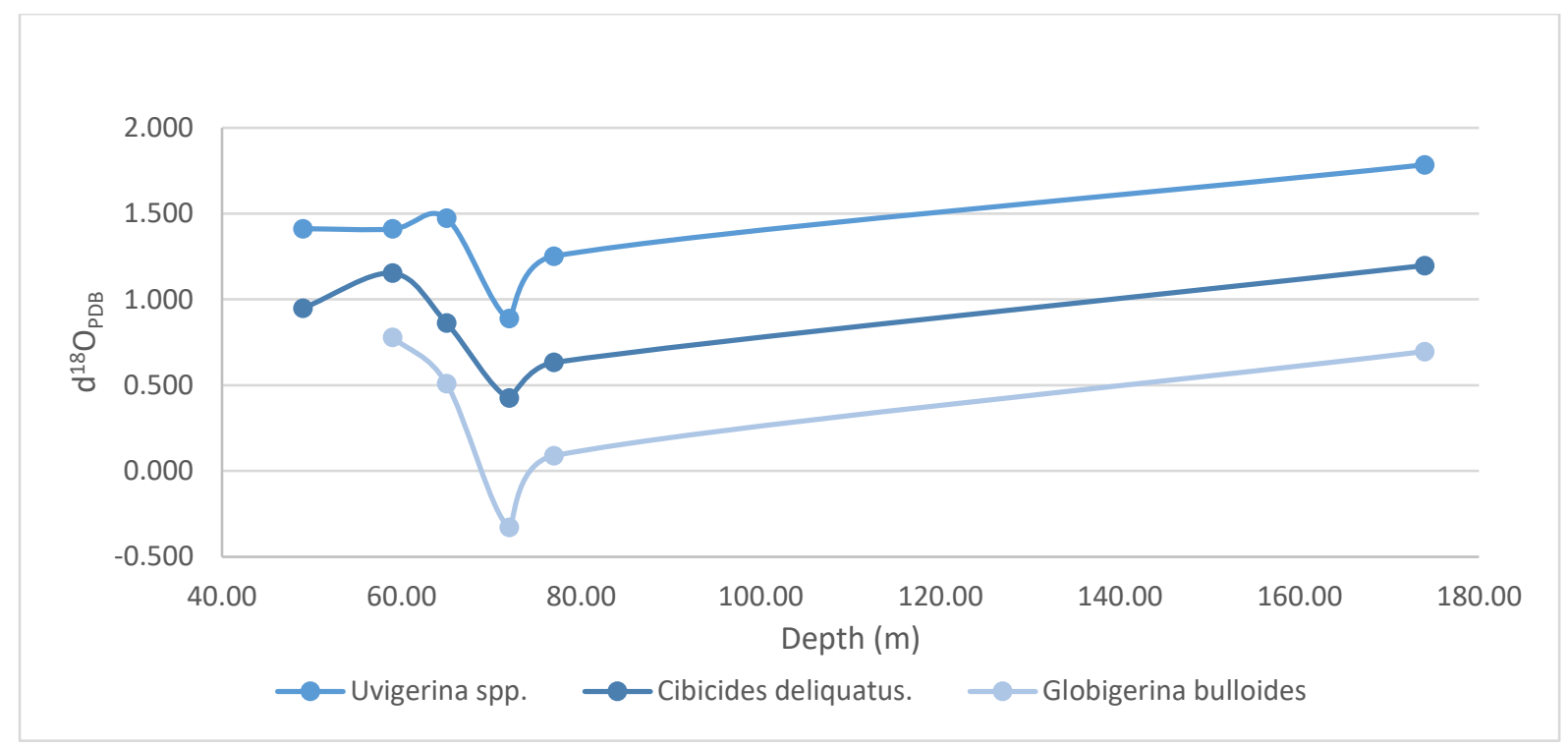

Figure 3.4 Comparison of $\delta^{18} \mathrm{O}$ values for benthic (Uvigerina spp. and Cibicides deliquatus) and planktic (Globigerina bulloides) foraminifera from the Tiriraukawa-1 core. 


\section{Mid- to late Pliocene (3.3-2.6 Ma) global sea-level fluctuations}

recorded on a continental shelf transect, Whanganui Basin, New Zealand.

This manuscript, "Mid- to late Pliocene (3.3-2.6 Ma) global sea-level fluctuations recorded on a continental shelf transect, Whanganui Basin, New Zealand" was submitted for a special issue (PALSEA2) of Quaternary Science Reviews. This includes the sedimentological analysis, paleoecology, paleoenvironment interpretation and a sequence stratigraphic model, set within a high-resolution chronostratigraphic framework. The Introduction of this manuscript is brief, however by necessity, it does overlap with that detailed in Chapter 2 of this thesis. The manuscript has been reformatted to match the rest of the thesis.

Author contributions are as follows: Georgia Grant wrote the first draft, undertook the analyses and interpretation of the data. Juliet Sefton and Dr. Molly Patterson provided secondary outcrop datasets as part of post graduate thesis research. Prof. Tim Naish helped conceptualise the manuscript, contributed to writing and aided in data interpretation. Dr. Hugh Morgans assisted in foraminiferal census counts and identification, while Dr. Bruce Hayward provided methods and assistance in the interpretation of foraminiferal paleoecology. Dr. Brent Alloway and Prof. Diane Seward provided analysis and interpretation of the various tephrochronology and tephrostratigraphy. Dr. Claudio Tapia, Dr. Christian Ohneiser and Prof. Gillian Turner undertook the paleomagnetic analysis and magnetostratigraphy interpretation. The magnetostratigraphy has been submitted for publication as a specialist paper to Geophysical Journal International and a copy of the paper "High-resolution magnetostratigraphy of midPliocene warm period ( 3.6-3.0 Ma) shallow-marine sediments, Whanganui Basin, New Zealand" by Claudio A. Tapia, Georgia R. Grant, Gillian M. Turner, Christian Ohneiser, Tim R. Naish, Gavin Dunbar, is included in Appendix G.

Dr. Joe Prebble carried out the palynological analyses and interpretation. Dr. Gavin Dunbar, Prof. Peter Kamp and Dr. Rob McKay contributed to fieldwork and writing of the manuscript. Datasets collected and processed as a part of this thesis that are associated with this manuscript, include foraminiferal census counts (Appendix F), genus abundance used for 
Modern Analogue Technique from the core and outcrop foraminiferal samples (Appendix $\mathrm{H}$ ) and the Supplementary Material submitted with the publication can be found in Appendix I. Stable isotope $\left(\delta^{18} \mathrm{O}\right.$ and $\left.\delta^{13} \mathrm{C}\right)$ data undertaken as a part of this thesis, is most suited to interpretation within the context of this manuscript, but was excluded from publication as the results need further investigation (data and discussion can be found in Appendix J). 
Mid- to late Pliocene (3.3-2.6 Ma) global sea-level fluctuations recorded on a continental shelf transect, Whanganui Basin, New Zealand.

Grant, G.R. ${ }^{1}{ }^{*}$, Sefton, J.P. ${ }^{2}$, Patterson, M.O. ${ }^{3}$, Naish, T.R. ${ }^{1}$, Dunbar, G.B. ${ }^{1}$, Hayward, B.W. ${ }^{4}$, Alloway, B.V. ${ }^{5,6}$, Kamp, P.J.J. ${ }^{7}$, McKay, R. ${ }^{1}$, Morgans, H.E.G. ${ }^{8}$, Ohneiser, C. ${ }^{9}$, Prebble, J.G. ${ }^{8}$, Seward, D. ${ }^{10}$, Tapia, C.A. ${ }^{11}$, Turner, G.M. ${ }^{12}$

1. Antarctic Research Centre, Victoria University of Wellington, PO Box 600, Wellington 6012, New Zealand.

2. Department of Geography, Durham University, South Road, Durham, DH1 3LE United Kingdom.

3. Binghamton University, State University of New York, 4400 Vestal Parkway East, Binghamton, New York 13902, United States of America.

4. Geomarine Research, 19 Debron Ave, Remuera, Auckland, New Zealand.

5. School of Environment, University of Auckland, Private Bag 92019, Auckland 1142, New Zealand.

6. Centre for Archaeological Science (CAS), University of Wollongong, Wollongong, NSW 2522, Australia.

7. School of Science, University of Waikato, Hamilton 3240, New Zealand.

8. GNS Science, 1 Fairway Drive, Avalon 5010, PO Box 30-368, Lower Hutt 5040, New Zealand.

9. Department of Geology, University of Otago, PO Box 56, Dunedin, 9054, New Zealand.

10. School of Geography, Environmental and Earth Sciences, Victoria University of Wellington, P.O. Box 600, Wellington 6012, New Zealand.

11. Department of Civil Works and Geology, Faculty of Engineering, Catholic University of Temuco, Avenida Alemania No. 0211, Casilla 15-D, Temuco, Chile.

12. School of Chemical and Physical Sciences, Victoria University of Wellington, P.O. Box 600, Wellington 6012, New Zealand.

*Corresponding author email: georgia.grant@vuw.ac.nz 


\section{Abstract}

We present a 900 m-thick, mid- (3.3-3.0 Ma) to late Pliocene (3.0-2.6 Ma), shallow-marine, cyclical sedimentary succession from Whanganui Basin, New Zealand that identifies paleobathymetric changes. Our approach applies lithofacies, sequence stratigraphy and benthic foraminiferal analyses to two continuously-cored drillholes integrated with new and existing outcrop studies. We construct a depositional model of orbitally-paced global sea-level changes on a wave-graded continental shelf. Unlike previous studies, these shelf sediments were not eroded during sea-level lowstands and thus provide the potential to reconstruct the full amplitude of glacial-interglacial sea-level change. Paleobathymetric interpretations are underpinned by analysis of extant benthic foraminiferal census data and a statistical correlation with the distribution of modern taxa. In general, water depths derived from foraminiferal Modern Analogue Technique, are consistent with variability recorded by lithofacies.

The inferred sea-level cycles co-vary with a qualitative climate record reconstructed from a census of extant pollen and spores, and a modern temperature relationship. A high-resolution age model is established using magnetostratigraphy constrained by biostratigraphy, and the dating and correlation of tephra. This integrated chronostratigraphy allows the recognition of 23 individual sedimentary cycles, that are correlated "one-to-one" across the paleo-shelf and are compared to the deep-ocean benthic oxygen isotope $\left(\delta^{18} \mathrm{O}\right)$ record. In general water depth changes were $\sim 20$ kyr-paced duration between 3.3-3.0 Ma, after which cycle duration is $\sim 40$ kyr during the late Pliocene (3.0-2.6 Ma). This record provides a future opportunity to evaluate the amplitude and frequency of global, Pliocene glacio-eustatic sea-level change, independent of the global $\delta^{18} \mathrm{O}$ benthic record.

\subsection{Introduction}

\subsubsection{Pliocene climate and sea-level change}

The mid- to late Pliocene (3.3-2.6 Ma) spans one of the most significant climatic transitions of the Cenozoic. It is characterised by global cooling from a climate with an atmospheric $\mathrm{CO}_{2}$ 
concentration of $\sim 400 \mathrm{ppm}$ and temperature of $2-3^{\circ} \mathrm{C}$ warmer-than-present (summarised in Masson-Delmotte et al., 2013), to one marked by the progressive expansion of ice sheets on northern hemisphere continents (e.g. Raymo, 1994) as $\mathrm{CO}_{2}$ fell below 300 ppm (DeConto et al., 2008). Consequently, the mid-Pliocene warm period (3.3-3.0 Ma) provides the most accessible and recent geological analogue for global sea-level variability relevant to future warming.

Pliocene sea-level changes have been reconstructed using a variety of geological techniques, including benthic $\delta^{18} \mathrm{O}$ records and $\mathrm{Mg} / \mathrm{Ca}$ paleothermometry, submerged coral reefs and backstripped continental margins (Miller et al., 2012 and refs. therein). Although there are considerable uncertainties with all these techniques, a central value for peak global mean sealevel (GMSL), during the mid-Pliocene centred on +20 $\pm 10 \mathrm{~m}$ (above present day), has become widely accepted (Miller et al., 2012; Dutton et al., 2015).

However, it now appears that estimating the absolute magnitude of peak Pliocene GMSL, with respect to present day, is beyond our current capability due to Earth deformation processes. Global mantle dynamic processes (Moucha et al., 2008; Müller et al., 2008) could contribute more than $\pm 10 \mathrm{~m}$ to the uncertainty when reconstructing paleo sea-level. Visco-elastic response of the crust and gravitational changes (glacio-isostatic adjustment; GIA) associated with the redistribution of water between ice sheets and the oceans can cause deviations from GMSL of the order of 5 to $30 \mathrm{~m}$ for sites in the far and near fields of ice sheets respectively (Raymo et al., 2011). Consequently, both GIA and dynamic topography signals can be as large as the sea-level estimate itself and current estimates of their amplitudes carry large uncertainties.

While benthic $\delta^{18} \mathrm{O}$ records provide the most detailed and well-dated proxy of climate variability during the Pliocene and Pleistocene (e.g. Lisiecki and Raymo, 2005), their signal reflects ocean temperature and ice volume. Calibration of the ice volume component of the $\delta^{18} \mathrm{O}$ record using sea-level reconstructions from far-field shallow-marine continental margins (Naish, 1997; Miller et al. 2005; Naish and Wilson, 2009; Miller et al., 2012) is also complicated by uncertainties and assumptions. Backstripping approaches to date have uncertainties 
resulting from the broad depth ranges inherent to faunal paleodepth indicators. An additional impediment is that in many cases sea-level lowstand unconformities result in incomplete records which hinders determination of full amplitude sea-level variability.

Notwithstanding this, far-field shallow-marine continental margins are less affected by GIA, and have the potential to capture the full amplitude of global sea-level changes on glacialinterglacial time-scales (e.g. Naish and Wilson, 2009; Miller et al., 2012). Moreover, mantle dynamic processes are negligible at orbital timescales. If a more precise paleobathymetry can be reconstructed (e.g. Dunbar and Barrett, 2005), then a backstripping approach would produce a sea-level curve. Such a curve would be independent of the $\delta^{18} \mathrm{O}$ record that will allow the assumptions and uncertainties in the $\delta^{18} \mathrm{O}$ record to be assessed.

Suitable continental margins require shallow-marine, sedimentary basins with high sedimentation rates ( $>1 \mathrm{~m} / \mathrm{kyr}$ ), where accommodation space (subsidence rate) has been sufficient to prevent shallow-marine or subaerial erosion during sea-level lowstands. This type of depositional setting can be a very sensitive recorder of multi-metre-amplitude, cyclic changes in water depth.

Such sedimentary basins are rare, but do occur on convergent plate margins (e.g. Italy, Japan, New Zealand). Whanganui Basin, New Zealand, comprises one of the highest-resolution, shallow-marine records of orbitally-paced, late Neogene global sea-level change (e.g. Naish et al., 1998). Its $\sim 5 \mathrm{~km}$ thick, composite sedimentary-fill (Fleming, 1953; Anderton, 1981) accumulated as a consequence of relatively linear basin subsidence due to plate boundary interactions behind the Hikurangi subduction zone off eastern New Zealand (Stern et al., 1992; Figure 1). Sediment deposition in the basin has more-or-less kept pace with the rate of accommodation creation through the past 5 Ma (e.g. Naish et al., 1998). 


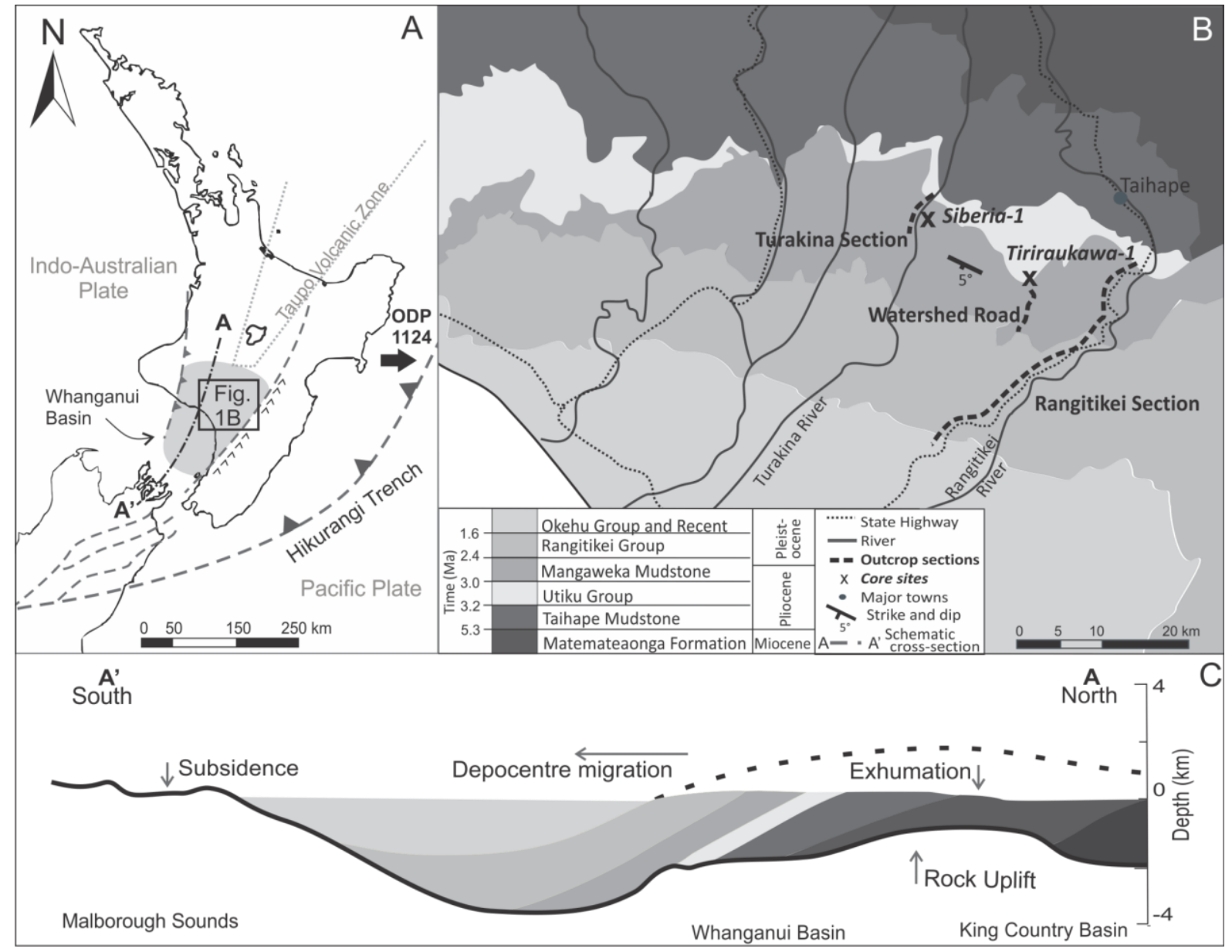

Figure 4.1 a) Location map of Whanganui Basin in relation to the Pacific and Indo-Australian Plate boundary (Hikurangi Trench). ODP Site 1124 lies $500 \mathrm{~km}$ offshore to the southeast of Wellington. B) The location of the cores (Siberia-1 and Tiriraukawa-1; this study) and outcrop sections (Turakina: Patterson, 2014, Watershed Road: Sefton, 2015 and Rangitikei: Journeaux et al., 1996; Kamp et al., 1998) are shown on the geological map. Strata generally dip at $5^{\circ}$ southwest. C) The A - A' schematic crosssection conceptually illustrates the southward migration of the depocentre and contemporaneous uplift in the north, exposing the geological units onshore (after Stern et al., 2013).

\subsubsection{Aims of this paper}

In this paper, we report on two new sediment cores (Siberia-1 and Tiriraukawa-1) that recovered a continuous and high-resolution ( $1 \mathrm{~m} / \mathrm{kyr}$ sedimentation rate) succession of cyclical environmental change from laterally adjacent outer to middle shelf environments, in Whanganui Basin, New Zealand. In contrast to Pleistocene-age cycles from Whanganui Basin, these have not been eroded during sea-level lowstands (Figure 4.1). These cores, together with regional outcrop stratigraphy, provide the opportunity to fully resolve glacial-interglacial sealevel changes between 3.3 and $2.6 \mathrm{Ma}$. 
The approach applied here involves a sedimentological description, down-core physical property measurements, and grain size analysis to support a sedimentary facies interpretation of environmental change. We establish water depth changes using statistical analysis of extant benthic foraminiferal census data and Modern Analogue Technique to reconstruct paleobathymetry of the continental shelf transect (e.g. Hayward et al., 1999; Hayward and Triggs, 2016). Sequence architecture across the SE-NW deepening wave-graded paleo-shelf transect allows the lateral sedimentary expression of cyclical bathymetric changes to be evaluated in the context of changes in sediment supply, basin subsidence and sea-level change.

Finally, we present an integrated age model, developed from magnetostratigraphy (Tapia et al., submitted), biostratigraphy and tephrochronology. Correlation of the sedimentary cycles identified within the two drill cores with cycles in other regional outcrop successions (Figure 4.1) in the Rangitikei River Section (Kamp et al., 1998; Turner et al., 2005), Turakina River Section (Turner et al., 2005; Patterson, 2014) and Watershed Road Section (Sefton, 2015), constrained by the new chronostratigraphic framework, enables orbital-scale, glacialinterglacial changes of water depth to be determined. We discuss the potential of the new drill cores for quantitative reconstruction of the frequency and amplitude of global mean-sea-level change between 3.3-2.6 Ma, independent of the global $\delta^{18} \mathrm{O}$ benthic stack (Lisiecki \& Raymo, 2005).

\subsection{Geologic and stratigraphic setting}

The Whanganui Basin (Figure 4.1) in western North Island is located southwest of an active volcanic arc (Taupo Volcanic Zone), and west of the accretionary prism that forms the leading edge of the overriding part of the Hikurangi Margin, where the oceanic Pacific Plate is subducting below continental crust of the Indo-Australian Plate (e.g., Kamp et al. 2004). The basin's depocentre has progressively migrated southwards since the Miocene at $30 \mathrm{~mm} / \mathrm{yr}$ from the King Country to the presently subsiding river valleys in the North Marlborough region (Figure 4.1c), as a topographic wave in response to redistribution of lithosphere over the 
mantle (Stern et al., 2013). Consequently, the position of the paleo-shoreline during deposition of the mid- to late Pliocene sediments was controlled by the southwest passage of the eastwest trending tectonic hinge line. Paleogeographic reconstructions (Bunce et al., 2009; Trewick and Bland, 2012) describe a broad west-facing marine embayment with an arcuate shoreline running along the north and western boundary, and exposed basement forming the ranges along its eastern margin (Figure 4.2). Progressive uplift to the northeast and subsidence to the southwest has resulted in tilting of the strata on the order of $3-15^{\circ}$ to the southwest (Naish and Kamp, 1995; Journeaux et al., 1996; Stern et al., 2013). Additional influences due to local isostatic rebound from subsequent erosion of over $2000 \mathrm{~m}$ of exhumed material, exacerbated the uplift of the basin to the north (Pulford and Stern, 2004).

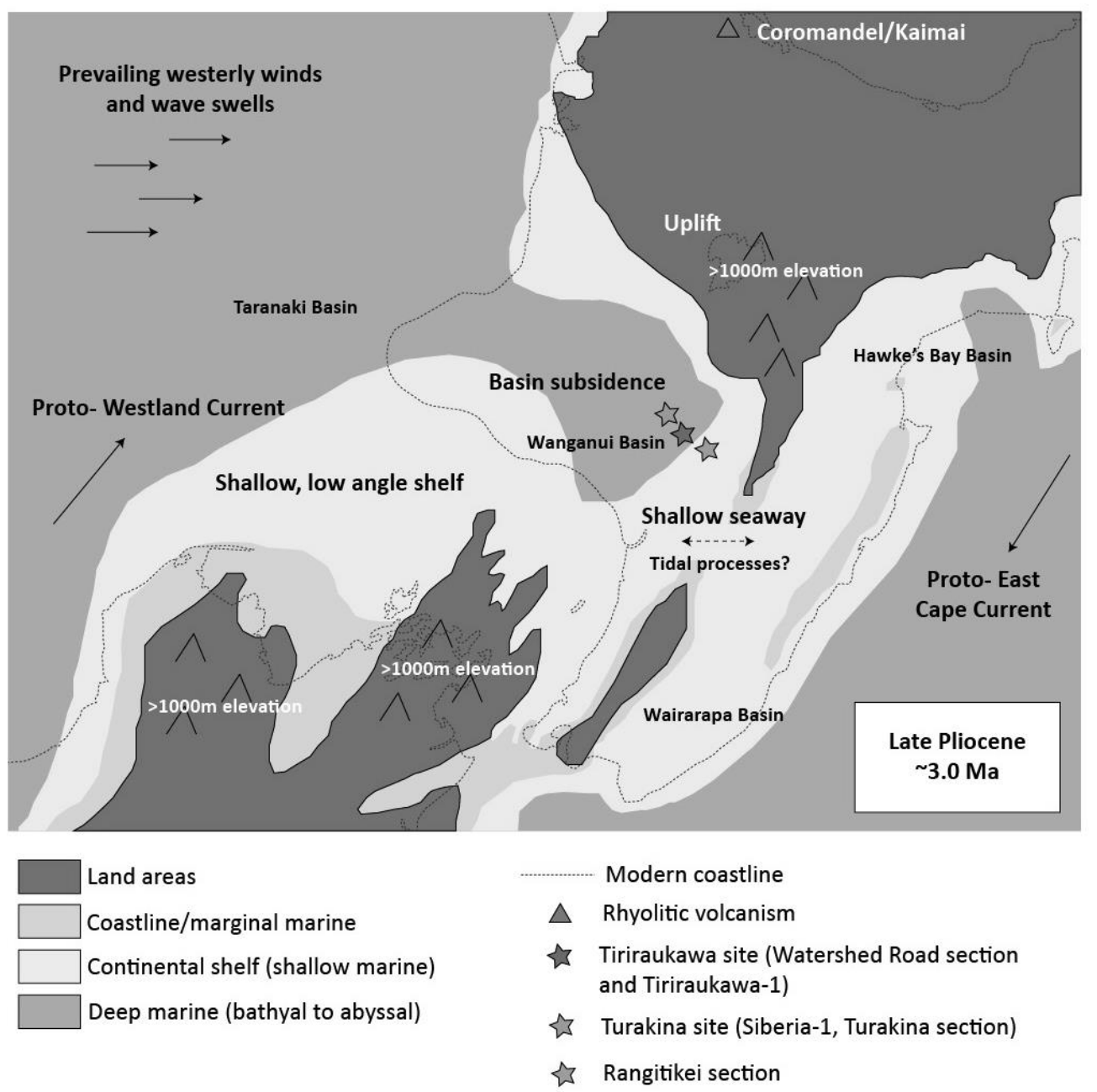

Figure 4.2 A paleogeographic reconstruction after Bunce et al., (2009) and Trewick and Bland (2012), displaying an open semienclosed broad embayment open to the dominant westerly wind, with an arcuate shoreline forming a west-east to north-south orientation, with a deepening shelf westward. The locations of outcrop sections and cores shown in Figure1 are denoted by stars and signify (west to east) Turakina Valley, Tiriraukawa and Rangitikei Valley. 
Previous attempts to reconstruct the amplitude of sea-level changes from Pliocene shallowmarine cycles have been made from outcrops in the shallower eastern margin of the basin (Rangitikei River Section). However, these sediments accumulated in inner shelf to shoreline water depths, punctuated by erosional unconformities formed during glacial sea-level lowstands (Naish, 1997; Naish and Wilson, 2009). Accordingly, the sea-level estimates could only constrain minimum amplitudes.

This paper addresses the mid- to late Pliocene (3.3-2.6 Ma) part of the stratigraphic succession exposed in the basin between the Rangitikei and Turakina Rivers (Figure 4.1).

The Pliocene succession has been subdivided into three broad lithostratigraphic units, which display higher order sedimentary cyclicity (Naish and Kamp, 1995; Journeaux et al., 1996;):

(i) upper part of the Tangahoe Formation deposited on the upper slope and outer shelf during the earliest part of the Waipipian Stage (early Pliocene, 3.7-3.2 Ma);

(ii) The Utiku Group deposited on the outer to inner shelf during the late Waipipian Stage (mid-Pliocene; 3.2-3.0 Ma);

(iii) Mangaweka Mudstone deposited on the outer to middle shelf during the Mangapanian Stage (late Pliocene, 3.0-2.6 Ma).

Sediments forming the $\sim 350$ m-thick Utiku Group deepen laterally to the west across the basin starting at middle and inner shelf depths in the Rangitikei River Section and deepening to outer and middle shelf depths in the Turakina River Section. A regional subsidence event marks an abrupt deepening in the Rangitikei River Section at the top of the Utiku Group from inner shelf (50 $\mathrm{m}$ ) to outer shelf ( $\sim 150 \mathrm{~m})$ depths, possibly in response to southward migration of the depocentre (Kamp et al., 1998). The overlying Mangaweka Mudstone was deposited in outer to middle shelf depths in the Rangitikei River Section and deepens west across the study area where it was deposited in an outer shelf to upper slope environment.

The two drill sites were targeted to recover age-equivalent, continuous records of midPliocene strata, from different locations on a westward deepening paleo-shelf transect. This was in order to avoid missing section due to lowstand erosion that characterises the Rangitikei River Section. 


\section{Siberia-1 drill core}

Siberia-1 drillcore was spudded in July 2014, at Siberia Station 300 m east of the Turakina River $\left(\mathrm{S} 39.6964^{\circ} \mathrm{E} 175.5241^{\circ}\right)$ into the lowermost part of the Mangaweka Mudstone (Figure 4.1). It was cored continuously to a depth of $352 \mathrm{~m}$ with the exception of the upper $40 \mathrm{~m}$, which was poorly-recovered unconsolidated recent colluvium. The recovered stratigraphic record contains 13 full sedimentary cycles, ranging from 10 to $50 \mathrm{~m}$ in thickness, within the Utiku Group spanning 40-276 m. The cycles are characterised by oscillations in grain size from 10$60 \%$ sand, displayed by lithologic changes ranging from clay-rich mudstone and mudstone to fine-sandy mudstone/muddy sandstone (Figure 4.3a). Cycle boundaries are conformable and correspond to the inferred shallowest paleobathymetry as expressed by maximum sand percentage (see below). Physical properties logs of the borehole and the core also co-vary cyclically with grain size, lithology and lithofacies variations (Figure 4.3a). Natural gammaradiation (NGR) maxima associated with increased uranium, potassium and thorium in clayrich sediments typically correspond to fine-grained lithologies. Likewise, magnetic susceptibility is stronger in finer-grained sediments containing a higher proportion of submicron ferromagnetic grains in the superparamagnetic state (Hunt, 1995). Sandier sediments in the core are characterised by relatively high resistivity and density, and low magnetic susceptibility and NGR activity. 
SIBERIA-1

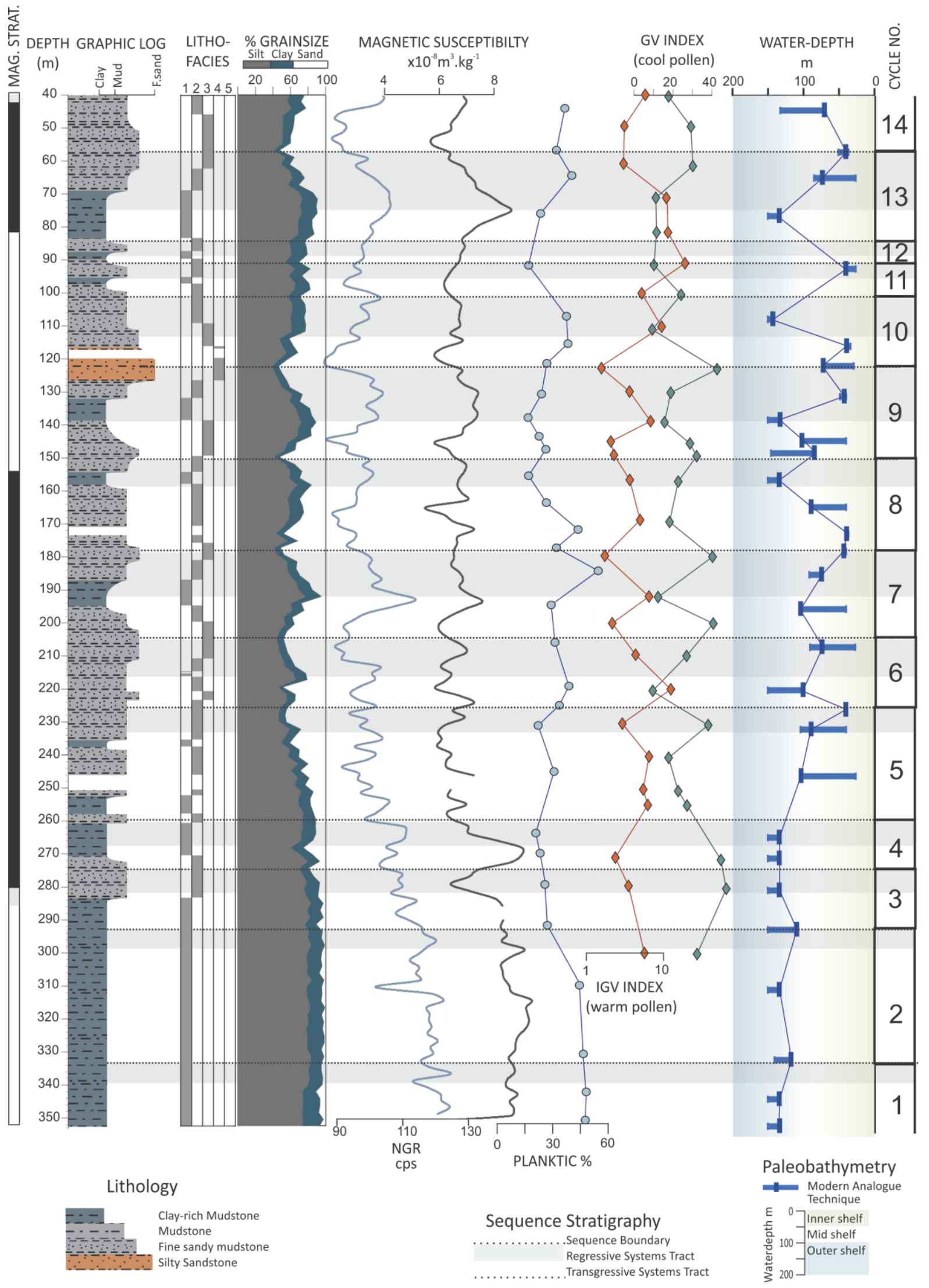




\section{TIRIRAUKAWA-1}

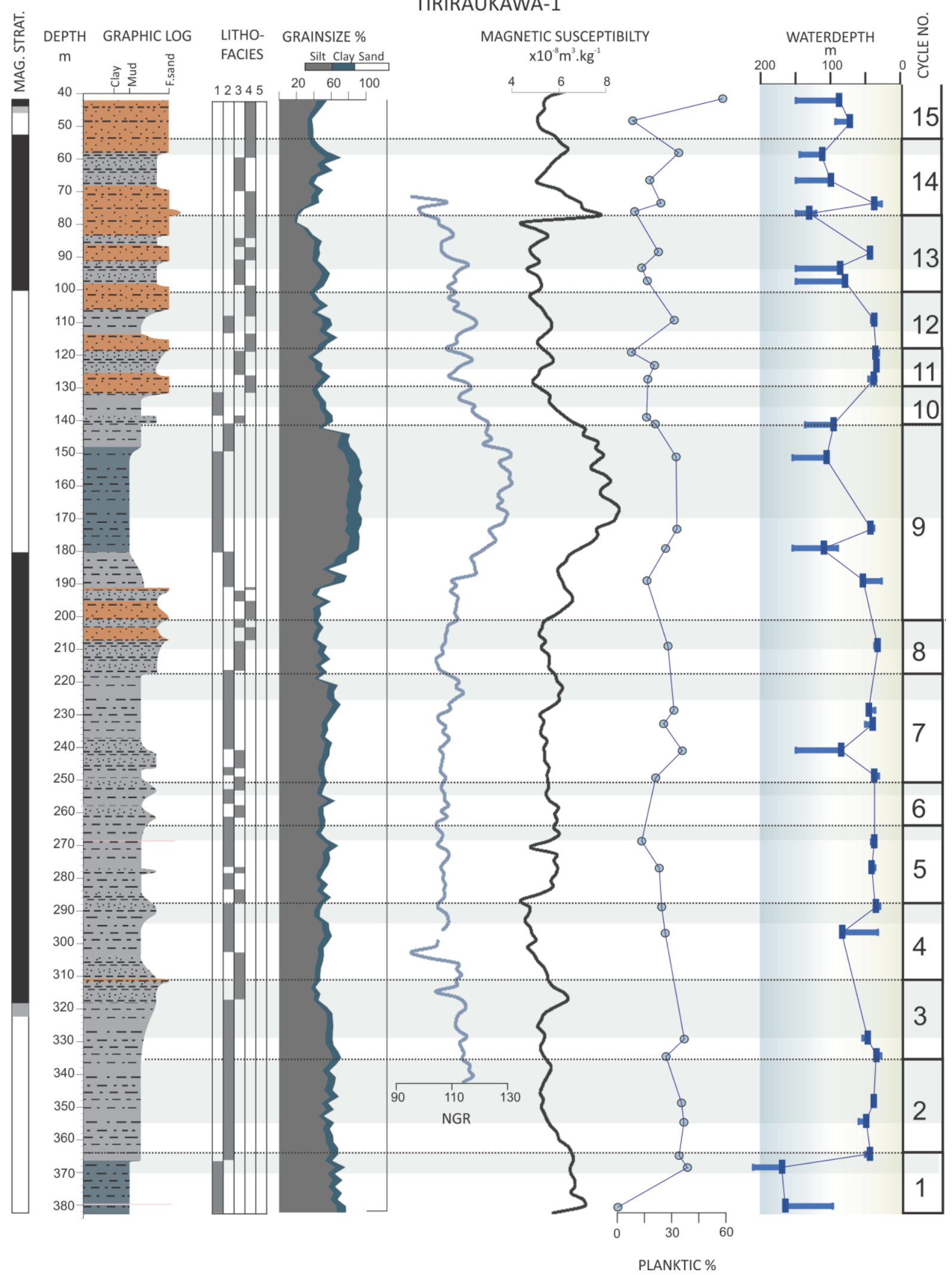

Figure 4.3 (a) Siberia-1 and (b) Tiriraukawa-1 drill core showing core magnetostratigraphy and stratigraphy, lithofacies, clay/silt/sand percentage, natural gamma-ray (NGR) and mass-corrected magnetic susceptibility physical property logs, planktic foraminiferal percentage and palynological glacial-interglacial indices (for Siberia-1 only). Water depths derived by the Modern Analogue Technique are displayed as mean values (dark blue rectangle) and minimum and maximum values (light blue bar), as discussed in text (also displayed in Figure 4.4) and sequence stratigraphy (Figure 4.5 \& 4.6). 
Tiriraukawa-1 drillcore was spudded in August 2014, at Watershed Road, near Tiriraukawa, approximately $18 \mathrm{~km}$ southeast of Siberia-1 and roughly halfway between the Rangitikei and Turakina rivers (S39.7625 E175.6689 ; Figure 4.1). It was cored continuously to a depth of 384 $\mathrm{m}$ with the exception of the upper $43 \mathrm{~m}$, which also contained poorly-recovered unconsolidated recent colluvium. The recovered stratigraphic record contains 14 full sedimentary cycles, ranging from 10-60 m in thickness, within the Utiku Group spanning 43$376 \mathrm{~m}$. The cycles are generally sandier than in Siberia-1, reflecting a more shoreline-proximal location, and are characterised by oscillations in grain size from $20-80 \%$ sand, and lithologic changes ranging from clay-rich mudstone/mudstone to fine-sandy mudstone/muddy sandstone/sandstone (Figure 4.3b). Cycle boundaries are all conformable and correspond to the inferred shallowest points as expressed by maximum sand percentage (see below). Physical properties logs of the bore hole and the core also co-vary cyclically with grain size, lithology and lithofacies variations (Figure 4.3b) and display a similar relationship to that described for the Siberia-1 core.

\section{Rangitikei River Section}

Rangitikei River Section in eastern Whanganui Basin contains a well-exposed $750 \mathrm{~m}$ thick Pliocene sedimentary succession that accumulated between 3.3-2.6 Ma (Journeaux et al., 1996; Figure 4.1). Lithofacies analysis, including laboratory grain-size determinations, and benthic foraminiferal paleowater depth estimates show that the lower $350 \mathrm{~m}$ (Utiku Group) accumulated predominantly in a shoreface to inner shelf environment; while the overlying 400 $m$ thick Mangaweka Mudstone accumulated in a middle to outer shelf environment (Kamp et al., 1998). Combined with the identification of sequence stratigraphic boundaries, 14 sedimentary cycles were identified in the Utiku Group. In the outwardly massive Mangaweka Mudstone, there is no outcrop evidence for sedimentary cyclicity. However, 9 sedimentary cycles are defined by changes in grain size, lithofacies and foraminiferal faunas (Figure 4.4; Journeaux et al., 1996). Rapid deepening of greater than $100 \mathrm{~m}$ across the Utiku GroupMangaweka Mudstone boundary at ca 3 Ma occurs within a $30 \mathrm{~m}$ thick stratigraphic interval. 


\section{Watershed Road Section}

Late Pliocene Mangaweka Mudstone is exposed in a semi-continuous $672 \mathrm{~m}$ thick road section south of Tiriraukawa, on the Watershed Road between the Rangitikei and Turakina River valleys (Figure 4.1). A recent study by Sefton (2015) using lithofacies and benthic foraminiferal paleoecology show that the section is dominated by clay-rich mudstone and mudstone with 10-30\% sand deposited in outer shelf to upper slope water depths (Figure 4). A silty sandstone occurs at the top of the section near the boundary with the overlying Rangitikei Group (Naish and Kamp, 1995). While not continuously exposed, 7 cycles of grain size and benthic foraminiferal depth assemblages have been identified.

\section{Turakina River Section}

We present new detailed stratigraphy based on river valley outcrop description and sedimentological analyses by Patterson (2014) at Siberia Station in the Turakina Valley south of Papanui Junction (Figure 4.1; S39.69425 E175.52151). The stratigraphy provides a higherresolution description and grain size measurements in the context of broad regional mapping by McGuire (1989). The 140 m-thick composite section fines upwards from $60 \%$ to $10 \%$ sand and is dominated by 6 cyclic-alternations of clay-rich mudstone and mudstone interpreted to be deposited on the middle to outer shelf. The succession includes the Kaena reversed geomagnetic polarity subchron and spans 3.15-3.0 Ma (Turner et al., 2005). The stratigraphy and grain-size curve (sand percentage curve) can be readily correlated with Siberia-1 due to their close proximity and overlapping stratigraphy (Figure 4.4). 


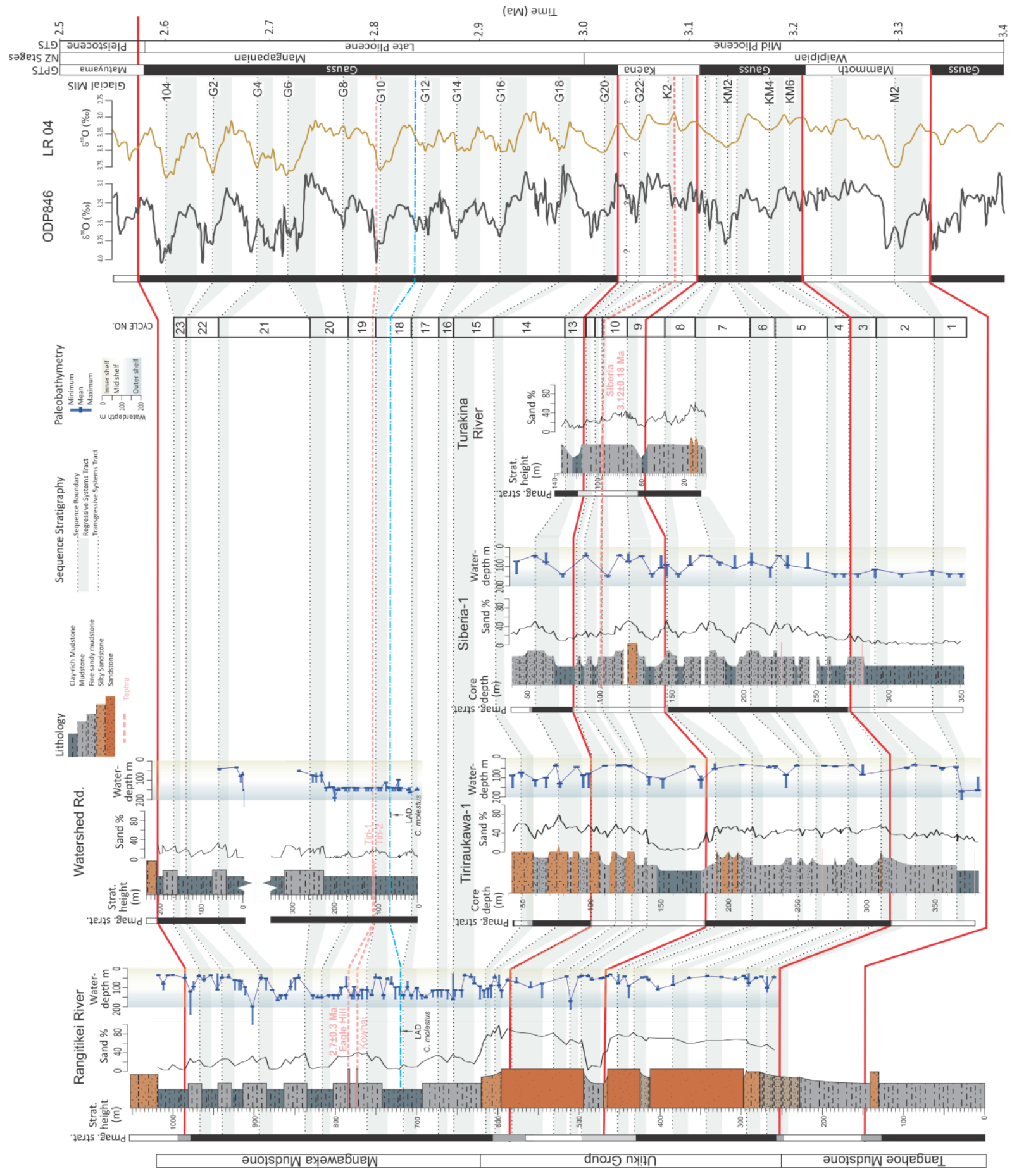

Figure 4.4. Figure showing correlation of sedimentary cycles, tephra positions and mid- to late Pliocene chrons identified in outcrop sections of the Utiku Group and Mangaweka Mudstone (Rangikikei River, Watershed Road and Turakina River Sections) and drillcores (Tiriraukawa-1; Siberia-1) with published oxygen isotope records (ODP846, Shackleton et al., 1995 and LRO4, Lisiecki and Raymo, 2005) giving the Whanganui Basin stratigraphy a sound chronostratigraphic framework. Sand percentage provides a high resolution signature for lithologic cycles, which are numbered 1 to 23. Water depths have been derived by application of the benthic foraminifera modern analogue technique (MAT). The paleomagnetic stratigraphy is after Naish et al., (1997) and Turner et al., (2005) for the Rangitikei River Section, Turner et al., (2005) for the Turakina section and Tapia et al., (submitted) for the drill cores. Biostratigraphic datums are after Cooper et al., (2004) and Raine et al., (2015). Tephra correlation and numeric ages discussed in the text are shown. This integrated chronostratigraphic framework allows correlation of Whanganui cycles 1-23 with the high-resolution, deep sea benthic $\delta^{18} O$ record of ODP Site 846 (Shackleton et al., 1995; using the age model provided by Lisiecki and Raymo, 2005) and the benthic $\delta^{18}$ O stack (LR04; Lisiecki and Raymo, 2005). 


\subsection{Lithofacies analysis and sequence stratigraphy}

The twenty-three cycles identified within the Utiku Group (Cycles 1-14) and the Mangaweka Mudstone (Cycles 15-23) display continuous, recurrent vertically-stacked cyclical facies successions, whose identification, is augmented by continuous grain-size analyses (summarised as sand percentage; Figure 4.4). Each sequence or sedimentary cycle is bounded by conformable boundaries (correlative conformities: CC) marking the shallowest point as shown by sand percentage. However, erosional unconformities mark some sequence boundaries in the shallow water Utiku Group facies cycles described in the Rangitikei River Section (e.g. Figure 4.4; Kamp et al., 1998). Five lithofacies, identified on the basis of lithology, bioturbation and sedimentary structures, and their interpreted depositional environments, are used to highlight recurring cyclicity up-core (Table 4.1). The vertical occurrence of the facies in each of the 23 sedimentary cycles in shown in Figure 4.4. Later in this paper we provide a highresolution age model that allows individual sedimentary cycles to be mapped from the shallow eastern margin (Rangitikei River Section) across the basin to the deeper water Turakina River Section/Siberia-1 drillcore further west, and correlated with orbital scale, glacial-interglacial cycles in the benthic oxygen isotope curve (Figure 4.4). 
Table 4.1 Lithofacies codes, description and depositional environments for the Utiku Group recovered by the cores (Facies 14) and described in outcrop for the Rangitikei River Section (Facies 5) by Journeaux et al., 1996. These facies were also applied to the Mangaweka Group outcrop sections.

\begin{tabular}{|c|c|c|c|c|}
\hline Code & Facies & Description & Lithology & $\begin{array}{l}\text { Depositional } \\
\text { Environment }\end{array}$ \\
\hline 5 & $\begin{array}{l}\text { Well sorted } \\
\text { Sandstone }\end{array}$ & $\begin{array}{l}\text { Fine Sandstone, brown, moderately } \\
\text { to highly bioturbated, sparsely } \\
\text { fossiliferous, massive to crudely } \\
\text { bedded } \mathrm{m} \text {-scale. }\end{array}$ & Fine Sandstone & $\begin{array}{l}\text { Shoreface } \\
\text { Inner shelf }\end{array}$ \\
\hline 4 & $\begin{array}{l}\text { Muddy } \\
\text { Sandstone }\end{array}$ & $\begin{array}{l}\text { Silty-Sandstone, green grey to grey } \\
\text { brown, moderately bioturbated, } \\
\text { burrowed. Sparsely to moderately } \\
\text { fossiliferous, } \mathrm{cm} \text {-scale bivalve } \\
\text { fragments <15mm and dm-scale } \\
\text { disarticulate and articulate bivalves } \\
\text { up to } 40 \mathrm{~mm} \text {. Common discontinuous } \\
\mathrm{mm} \text {-scale lenticular laminae and } \\
\text { sand-silt } \mathrm{cm} \text {-scale lenses. }\end{array}$ & $\begin{array}{l}\text { Muddy } \\
\text { Sandstone }\end{array}$ & Inner shelf \\
\hline 3 & $\begin{array}{l}\text { Fine sandy } \\
\text { Mudstone }\end{array}$ & $\begin{array}{l}\text { Sandy Mudstone, green-grey, firm, } \\
\text { moderately to highly bioturbated, } \\
\text { discontinuous mm-scale very fine } \\
\text { sand laminae, cm-scale bivalve } \\
\text { fragments }<15 \mathrm{~mm}\end{array}$ & $\begin{array}{l}\text { Fine Sandy } \\
\text { Mudstone }\end{array}$ & Middle shelf \\
\hline 2 & $\begin{array}{l}\text { Weakly } \\
\text { Stratified } \\
\text { Mudstone }\end{array}$ & $\begin{array}{l}\text { Sandy- Siltstone, grey-brown, firm, } \\
\text { moderately bioturbated and } \\
\text { occasional burrows. Moderately } \\
\text { fossiliferous, bivalve fragments } \\
<5 \mathrm{~mm} \text { on } \mathrm{mm} \text { to } \mathrm{cm} \text {-scale. Weakly } \\
\text { stratified with } \mathrm{mm} \text {-scale silt } \\
\text { horizontal lenses. }\end{array}$ & $\begin{array}{l}\text { Very fine sandy } \\
\text { Mudstone }\end{array}$ & $\begin{array}{l}\text { Outer to } \\
\text { middle shelf }\end{array}$ \\
\hline 1 & $\begin{array}{l}\text { Massive } \\
\text { Mudstone }\end{array}$ & $\begin{array}{l}\text { Clay-rich Siltstone, blue grey, firm, } \\
\text { moderately to highly bioturbated, } \\
\text { chondrites, rare wispy silt-sand } \\
\text { lenses. Sparsely fossiliferous, dm- } \\
\text { scale frequency of disarticulate } \\
\text { bivalves and gastropoda. }\end{array}$ & $\begin{array}{l}\text { Clay-rich } \\
\text { Mudstone }\end{array}$ & Outer shelf \\
\hline
\end{tabular}

We have developed a simplified sequence stratigraphic model (Figure 4.5) based on the identification of fining- (deepening) upwards facies successions assigned to the transgressive systems tract (TST), and coarsening- (shallowing) upwards facies successions assigned to the 
regressive systems tract (RST; e.g. Naish and Kamp, 1997a). Given the lack of erosional unconformities and the relatively low amplitude of sea-level change implied by our data, our sequence model has more similarities to the two-systems tract, transgressive-regressive model of Embry (1993), rather than the traditional, four-systems tract Exxon sequence stratigraphic model (e.g. Van Wagoner et al., 1988). The boundary between the TST and RST is the maximum flooding surface (MFS) and marks the deepest part of each cycle corresponding to minimum percentage sand. The sequence boundary is defined by the maximum sand percentage and corresponds to the deep-water correlative conformity coincident with relative sea-level lowstand. We have identified five characteristic sequence motifs (Figure 4.6) representing deposition on different parts of a shoreline to outer shelf continuum, during a cycle of relative sea-level change (Figure $4.5 \& 4.6$ ). While we acknowledge they are laterally-grading variants along a depositional transect, these motifs are distinguished on the basis of the regular vertical recurrence. Our interpretation of water depth is based on both sedimentological and benthic foraminiferal indicators, described in more detail below. The model substitutes time for space based on cycle correlations and time-depth relationships shown in Figure 4.4. The idealised sequence architecture therefore results from a combination of descriptive facies analysis and the overlying chronostratigraphic template provided by the correlation of distinctive surfaces (sequence boundaries and maximum flooding surfaces, defined by sediment grain size) within the constraints of our age model. In the following section, the characteristics of each sequence motif are described from shallowest to deepest. 

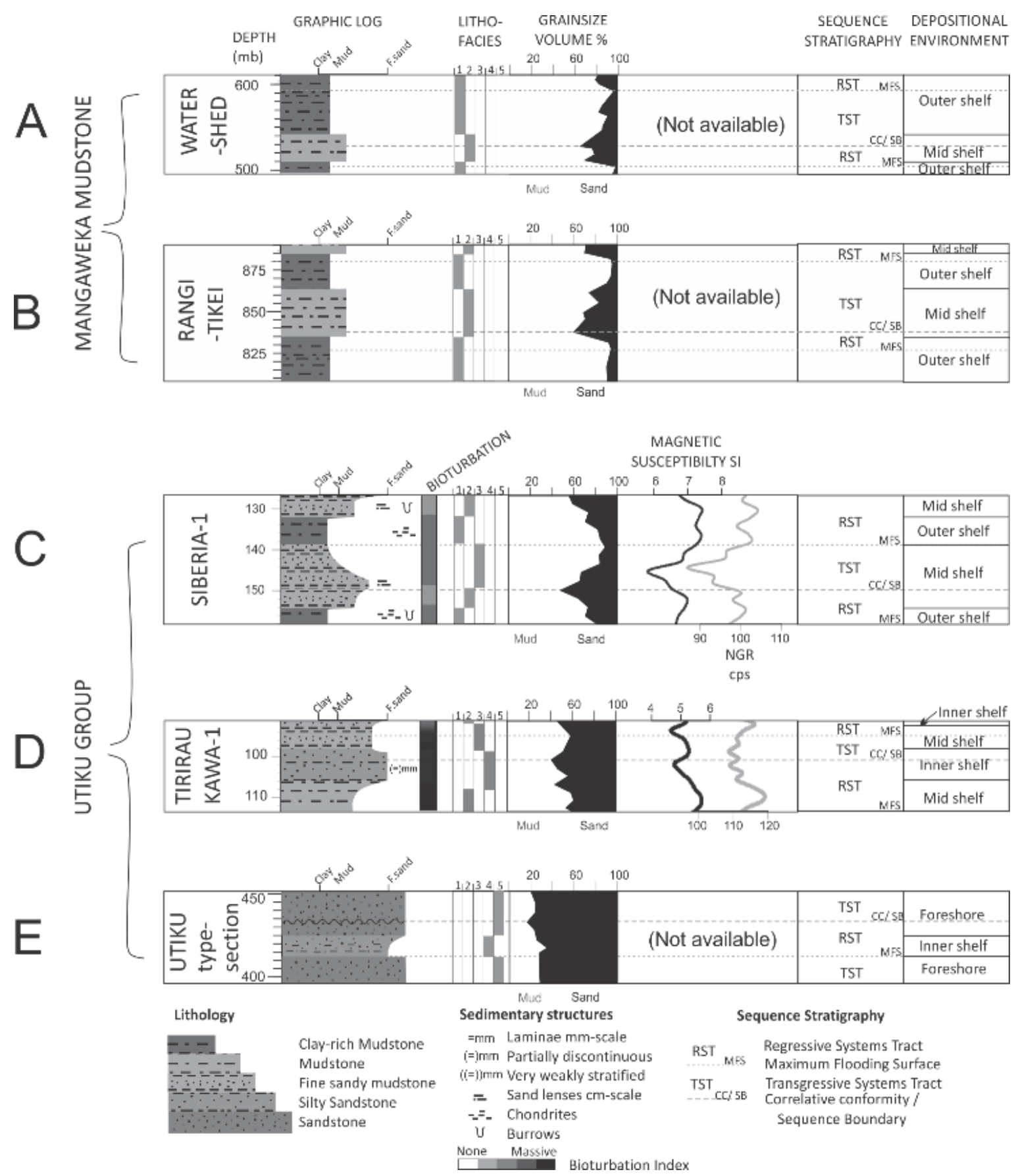

Figure 4.5 Conceptual model developed chiefly from lithofacies and sequence stratigraphic analysis of the mid- to late Pliocene outcrop sections and drillcore illustrated in Figure 4.4. Five representative sedimentary motifs (A-E), named after the sections from which they have been synthesised, show the inferred stratigraphic position of sequence boundaries and intervening flooding surface. This helps infer onlap and offlap in a cycle of sea-level change. 


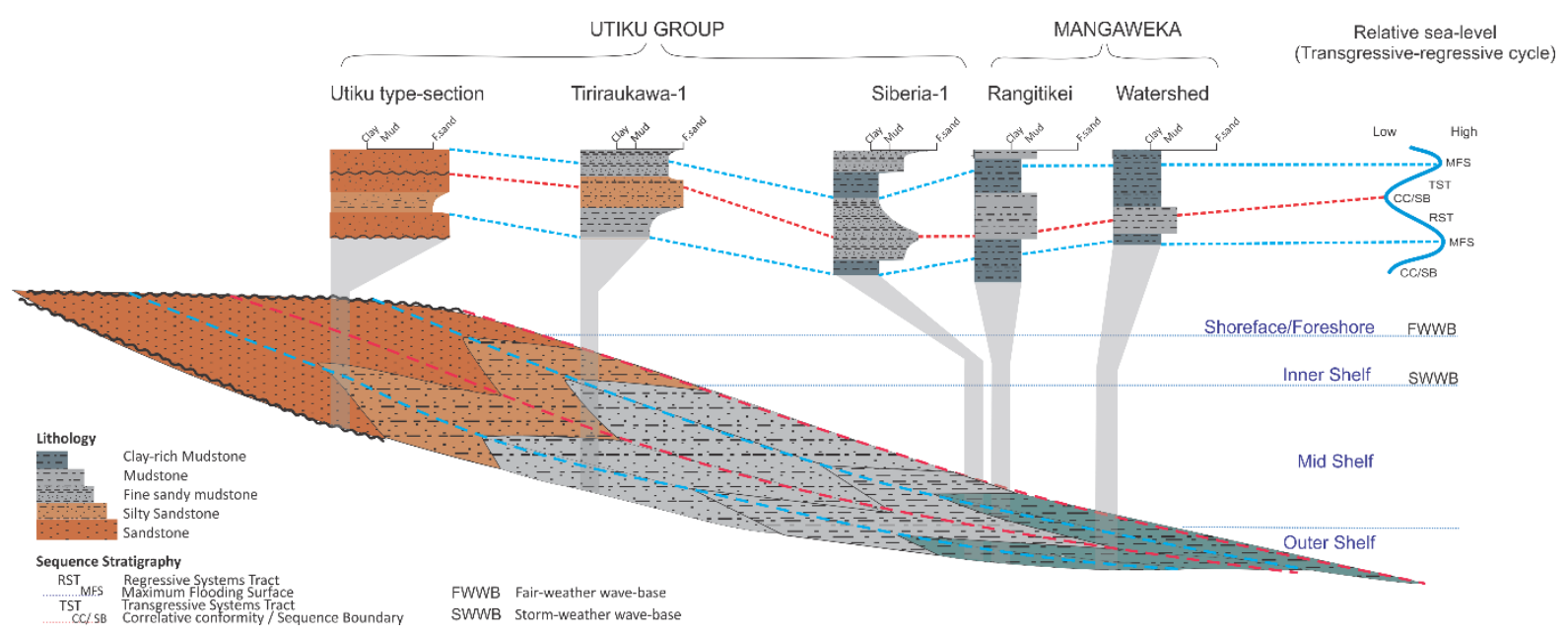

Figure 4.6 Figure showing five sedimentary motifs (Figure 4.5) arranged at increasing paleobathymetry across a shorenormal shelf cross-section to characterise the changes in lithofacies character and relative height of sequence stratigraphic surfaces in a typical mid- to late Pliocene Whanganui Basin sedimentary record of a sea-level cycle in the Utiku Group and Mangaweka Mudstone. Note how the sequence surfaces correspond to the relative sea-level cycle shown on the right.

Utiku cycle

Utiku cycles occur in the Utiku Group exposed in the Rangitikei river section. They are up to 60 m-thick and contain the shallowest facies alternating between shoreface sandstone (Facies 5) and inner shelf silty sandstone (Facies 4). In some cases the lower boundary of the TST is unconformable and interpreted as erosion during subaerial exposure at sea-level lowstands and subsequent shoreline transgression (e.g. Kamp et al., 1998).

\section{Tiriraukawa cycle}

Tiriraukawa cycles typically occur in the Utiku Group in the Tiriraukawa-1 drillcore. They are up to $50 \mathrm{~m}$ thick and display alternations between inner shelf silty-sandstone (Facies 4) and middle shelf fine sandy-mudstone (Facies 3). They are laterally equivalent to Utiku cycles and bounded by correlative conformities (no lowstand erosion). Both magnetic susceptibility and NGR logs are markedly cyclic with finer grained clay-rich facies displaying higher values compared to clay-poor sandy facies (as described above). 
Siberia cycles typically occur in the Utiku Group in the Siberia-1 drillcore. They are up to $20 \mathrm{~m}$ thick and display alternations between fine sandy-mudstone and mudstone (Facies 3/2;) deposited on the middle shelf and clay-rich mudstone deposited (Facies 1) on the outer shelf. They are laterally equivalent to Utiku and Tiriraukawa cycles and are bounded by correlative conformities (no lowstand erosion) further out on the shelf. Both magnetic susceptibility and NGR logs are markedly cyclic, as described above.

\section{Rangitikei and Watershed cycles}

Rangitikei cycles are exposed in outcropping Mangaweka Mudstone in the Rangitikei River section. Finer-grained, marginally deeper-water laterally-equivalent Watershed cycles are exposed in outcrop on the Watershed Road south of Tiriraukawa. Both sets of cycles are up to 60 m-thick and display alternations between middle shelf mudstone (Facies 2) and outer shelf clay-rich mudstone (Facies 1). While younger than the Utiku, Tiriraukawa and Siberia cycles, Rangitikei and Watershed cycles represent the deepest water sedimentary cycles in our model. They are generally thicker than the other inner to middle shelf cycle motifs, reflecting higher sedimentation rates during accumulation of the Mangaweka Mudstone, or a longer cycle duration (discussed below).

\subsection{Reconstructing paleoenvironment, water depth and climate}

The relative abundance of benthic foraminifera species preserved in marine sediments provides an environmental proxy sensitive to changes in wave and current energy, light penetration in the euphotic zone, bottom oxygenation and food availability. These environmental variables are often a function of water depth (e.g. Hayward, 1986; Hayward et al., 1999). Extant benthic foraminifera can be used to reconstruct broad changes in paleoecology, and thus determine water depth ranges. Cluster analysis of extant benthic foraminiferal faunas from the New Zealand continental shelf and shoreline, based on the 
relative abundance of species, has enabled the recognition of characteristic faunal associations having documented water depth ranges (summarised in Hayward et al., 1999). Comparison of these modern assemblages with the presence and relative abundance of extant foraminifera in the Whanganui Basin Plio-Pleistocene sediments, has allowed the semi-quantitative reconstruction of water depth changes through the Pliocene and Early Pleistocene (Naish and Kamp, 1997b; Kamp et al., 1998; Naish and Wilson, 2009).

\subsubsection{Depth estimates from extant benthic foraminiferal associations}

Samples selected for census counts were split before dry sieving at $150 \mu \mathrm{m}$ (Rangitikei and Watershed Road Sections) and $125 \mu \mathrm{m}$ (drill cores), from which a minimum of 200 specimens were counted and identified at species level. We have grouped these counts at genus level because of evolutionary changes and ambiguities with nomenclature. This allows comparison of our drillcore census data with those from the Rangitikei River Section (Journeaux, 1995; Journeaux et al., 1996; Kamp et al., 1998) and the Watershed Road Section (Sefton, 2015) which use a different species terminology.

Q-mode cluster analysis using PAleontolgical STatistics software (PAST; Hammer et al., 2001) was undertaken on 221 samples, from the two drill cores (65 samples) and outcrops in the Rangitikei (104 samples; Kamp et al., 1998) and Watershed Road sections (47 samples; Sefton, 2015). PAST uses an unweighted, pair group average algorithm where clusters are joined on the basis of the chord distance between normalised vectors to produce a dendrogram from which associations were selected (Figure 4.7). Six broad clusters were recognised, differentiated by a threshold of 0.9 on the chord distance scale, where branching occurs. Following Hayward and Triggs (2016), our chord distance was chosen to reduce the importance of highly abundant depth-insensitive (eurybathyal) genera (Hammer et al., 2009), such as Uvigerina, that while extant are not present in such large relative abundances today (Hayward, et al., 1999). In Table 2, we list abundant extant genera (> 5\%) in each cluster, calculated after removing extinct genera. 
Table 4.2 Extant genus abundant over $10 \%$ and $5 \%$ (in brackets) for the six clusters identified in Figure 7 with interpreted depositional environments.

\begin{tabular}{|c|c|c|}
\hline & Genus $>10 \%$ and $(5 \%)$ abundance & $\begin{array}{l}\text { Depositional } \\
\text { environment }\end{array}$ \\
\hline Cluster 1 & Anomalinoides, Uvigerina, Astrononion, (Elphidium) & Inner to middle shelf \\
\hline Cluster 2 & $\begin{array}{l}\text { Anomalinoides, Uvigerina, Bulimina, Cibicides, } \\
\text { (Notorotalia, Lenticulina) }\end{array}$ & Outer shelf \\
\hline Cluster 3 & Notorotalia, Uvigerina, Astrononion, (Elphidium) & $\begin{array}{l}\text { Mainly middle shelf, } \\
\text { extending to inner } \\
\text { shelf }\end{array}$ \\
\hline Cluster 4 & $\begin{array}{l}\text { Uvigerina, Notorotalia, Astrononion, Epistomina, } \\
\text { (Anomalinoides, Bulimina, Cibicides) }\end{array}$ & $\begin{array}{l}\text { Mainly middle shelf, } \\
\text { extending to inner } \\
\text { shelf }\end{array}$ \\
\hline Cluster 5 & $\begin{array}{l}\text { Uvigerina, Cibicides, (Notorotalia, Astrononion, } \\
\text { Anomalinoides) }\end{array}$ & $\begin{array}{l}\text { Mainly middle shelf, } \\
\text { extending to inner } \\
\text { shelf }\end{array}$ \\
\hline Cluster 6 & $\begin{array}{l}\text { Bulimina, Notorotalia, Cassidulina, (Astrononion, } \\
\text { Uvigerina, Nonionellina) }\end{array}$ & Outer shelf \\
\hline
\end{tabular}


Chord Distance

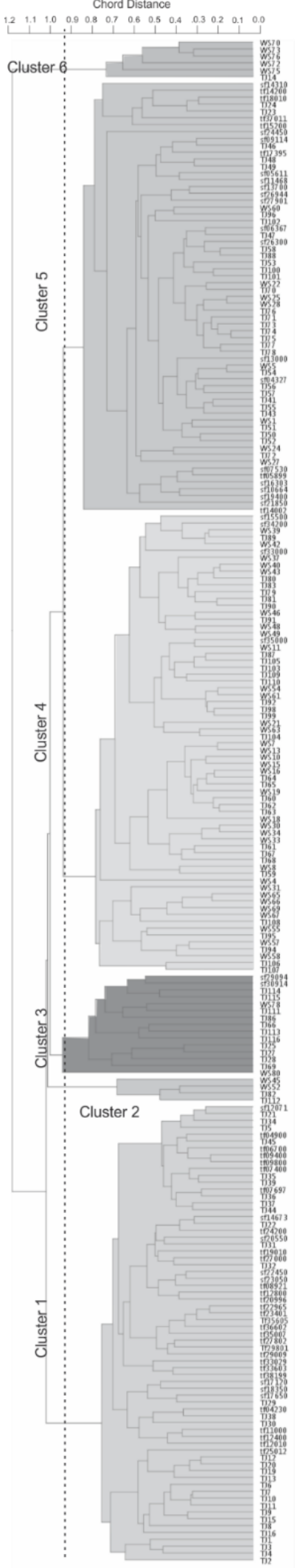

Figure 4.7 Dendrogram classification of the 221 samples referred to in the text (Rangitikei River Section, Journeaux et al., 1996; Watershed Road Section, Sefton, 2015; Siberia-1 and Tiriraukawa-1 cores, this study) for which six clusters are identified. Samples denoted TJ are for the Rangitikei River Section (Journeaux et al., 1996), WS apply to the Mangaweka Mudstone samples at the Watershed Road location (Sefton, 2015) and Tf (Tiriraukawa-1) or Sf (Siberia-1) samples were specifically collected for this investigation. 
While benthic foraminifera that favour shallow marine environments $(<100 \mathrm{~m})$ are typically viewed as more sensitive to changes in water depth than deep marine species, the minimum range of water depths inhabited by the majority of species is on the order of $50 \mathrm{~m}$ (Figure 4.6; Hayward et al., 1999). Most studies using paleoenvironmental information derived from foraminiferal assemblages have assessed changes of large-scale water depths on the shelf ( 20-150 m; e.g. Naish and Kamp, 1997b; Hayward and Triggs, 2016). Many of these studies identified foraminiferal assemblages that could not be discriminated conclusively in this study, as most genera were common to many samples (Table 4.2), suggesting that mid- and late Pliocene water depth changes were of smaller amplitude, than previous studies investigating Pleistocene sequences.

Canonical Correspondence Analysis (CCA; Figure 8) shows that the faunal pattern represented by the clusters/associations is most strongly correlated with percentage sand, interpreted as reflecting water depth on a wave-graded shelf, for which the vector is aligned with the first $(x)$ axis, accounting for $62 \%$ of the variability. Known deep-water taxa such as Epistomina elegans (previously Hoeglundina elegans), Sphaeroidina bulloides and Hauslerella parri are positioned at the opposite end of the $x$-axis to genera of shallow-water affinity such as Zeaflorilus, Elphidum and Ammonia, consistent with the x-axis representing changes in water depth (Figure 4.8). The sand percentage vector, supports the general observation that changes in grain size and benthic foraminiferal associations, and therefore sedimentary facies, reflect changes in water depth. 


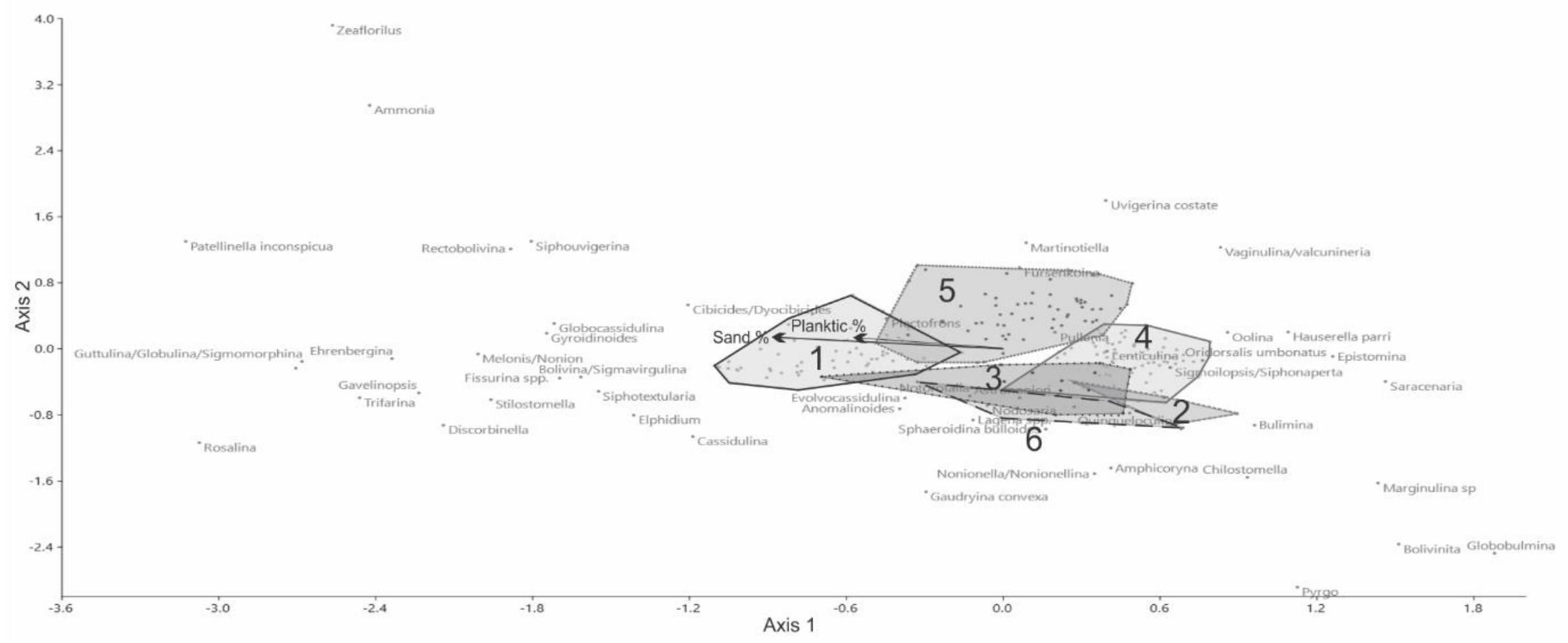

Figure 4.8 Two-dimensional Canonical Correspondance Analysis (PAST; Hammer et al., 2001) of Pliocene foraminiferal census data, with the genus, six clusters (identified in Figure 4.7) and vector arrows of the proxy environmental factors: sand and planktic foraminiferal percentage, for the two primary axes. 
While systematic up-core or up-section cycles in clusters do occur and broad water depth ranges can be defined, deepening and shallowing cycles were not readily identifiable using this approach, which is relatively insensitive as a quantitative method for identifying small changes in water depth $(<50 \mathrm{~m})$ at shelf depths.

Based on the clusters and CCA, Cluster 1 represents the shallowest environment of the inner to middle shelf. Clusters 2 and 6, suggest relatively deeper outer shelf environment, and Clusters 3, 4 and 5 suggest middle shelf depth ranges, extending into the inner shelf. We conclude from the census data and cluster analysis that the sediments were deposited within a broad inner to outer shelf depositional setting $(0-200 \mathrm{~m})$ and the cluster analysis does not systematically distinguish between inner to middle or middle to outer shelf environments.

\subsubsection{Depth estimates from foraminiferal modern analogue technique}

Modern Analogue Technique was applied to the extant benthic foraminiferal genera in the core and outcrop samples. This utilised a database of 240 samples of the available 626 samples (<300 m water depth) from estuarine to deep marine environments around New Zealand (Hayward et al., 1987; Hayward et al., 1999; Hayward and Triggs, 2016). The Modern Analogue Technique determines the squared chord correlation coefficient between the Pliocene samples and modern database with known water depths (Hayward and Triggs, 2016). The taxa selected for statistical comparison, were reduced from the 38 to 11 extant genera, using only those that showed a significant positive or negative correlation $(>0.3)$ with sand percentage in the samples considered as most depth-sensitive (Table 4.3). Uvigerina was excluded due to the anomalously high counts, which are unprecedented in modern waters, leading to overestimated water depths in the Pliocene samples. Quinqueloculina was also excluded as it showed a strong negative correlation with sand percentage whereas the modern environment shows a positive correlation. 
Table 4.3 Genus used in Modern Analogue Technique determined by a significant correlation distance (1-r of Pearson's r; Hammer et al., 2001) of more than \pm 0.3 where 1 is a total positive correlation and -1 is a total negative correlation. Bold genus were excluded for reasons outlined in text.

\begin{tabular}{ll}
\hline Genus & Correlation \\
\hline Cibicides/Dyocibicides & 0.73 \\
Elphidium & 0.70 \\
Epistomina & -0.66 \\
Gavelinopsis & 0.53 \\
Ehrenbergina & 0.48 \\
Zeaflorilus & 0.38 \\
Nonionella/Nonionellina & 0.36 \\
Cassidulina & 0.36 \\
Gyroidinoides & 0.35 \\
Sphaeroidina & -0.35 \\
Trifarina & 0.32 \\
Uvigerina & -0.48 \\
Quinqueloculina & -0.45 \\
\hline
\end{tabular}

A running weighted mean of the nearest three modern samples to the Pliocene samples (determined by the chord distance) was used, with the lowest and highest estimates used as the error in the method. Paleo-water depth estimates based on Modern Analogue Technique from the foraminiferal census data are plotted against grain size in Figure 4.4 for all drillcore and outcrop stratigraphic sections and confirm a consistent relationship between percentage sand, facies and water depth.

The Utiku Group described at the Rangitikei and Tiriraukawa-1 sites does not display sufficient sensitivity of the foraminiferal-derived paleobathymetry to resolve individual sedimentary cycles identified by the grain size, lithofacies and sequence stratigraphy (Figure 4.4). Siberia-1 appears to represent a "sweet-spot" on the paleo continental shelf where the MAT is sensitive to glacial-interglacial fluctuations between middle and outer shelf water depths, and covaries closely with facies and grain size cycles. This likely reflects the presence and absence of key outer shelf genera (e.g. Epistomina, Sphaeroidina; Hayward et al., 1999). 
The Mangaweka Mudstone, described in the Rangitikei and Watershed Road Sections, represents a significant deepening from the Utiku Group, and as such, the Rangitikei River Section records middle and outer shelf environments, while the Watershed Road Section, westward on the shelf transect, records outer to upper slope environments (Figure 4.5). Thus, the Mangaweka Mudstone of the Rangitikei River Section is comparable to the water depths of Siberia-1 throughout the deposition of the Utiku Group.

The water depths determined by the Modern Analogue Technique regularly display changes of $\sim 100 \mathrm{~m}$ in the Siberia-1, between minimum and maximum percent sand. This range of water depths is not supported by the paleoenvironmental interpretation of the lithofacies and sequence stratigraphy. However, they do match the phase and frequency of the shallowing and deepening cycles previously identified (Figure 4.4).

\subsubsection{Climate variability from terrestrial palynology from Siberia-1 drill core}

Twenty-seven samples between $39.89 \mathrm{~m}$ and $299.99 \mathrm{~m}$, with a sample resolution of approximately $10 \mathrm{~m}$, from Siberia-1 were analysed for palynology. Pollen and spore census counts were continued until one hundred pollen grains were counted on each slide and identified following the taxonomic groupings used in a comparable Pliocene marine study from ODP Site 1123, east of New Zealand (Mildenhall, 2003; Mildenhall et al., 2004). At ODP Site 1123, glacial-interglacial climate cycles are recorded as variations in carbonate percentage and show a strong correlation with two pollen indices:

- Interglacial Vegetation (IGV) index, a warm climate index: (Podocarpidities species + Dacrydiumites praecupressinoides [Dacrydium]+ Araucariacites australis [Agathis]) / (Parvisaccites catastus [Halocarpus] + Microalatidites paleogenicus [Phyllocladus] + Nothofagidites lachlaniae [Fuscospora]+ Palaeocoprosmadites zelandiae [Coprosma]).

- Glacial Vegetation (GV) index, a cool climate index, but with the possible bias from more easily transported bisaccate grains removed: (Parvisaccites catastus + Microalatidites paleogenicus + Nothofagidites lachlaniae +Palaeocoprosmadites zelandiae) / (total pollen-Podocarpidities species) 
Pollen preservation was frequently poor, and assemblages were of low diversity. Spores were approximately twice as abundant as pollen and were dominated by Cyathidites species (Cyathea). Pollen assemblages were dominated by Podocarpidites species., with common Dacrydiumites praecupressinoides and Nothofagidites lachlaniae.

Variation in pollen assemblages were positively correlated with water depth changes inferred from the other environmental datasets, such that warm climate pollen assemblages (IGV) coincided with finer grained sediment and deeper water facies, and colder climate pollen assemblages corresponded with sandier sediments, and shallower facies (Figure 4.3b). Although the depositional environment of the Siberia-1 core is considerably more proximal to land than ODP Site 1123, these ratios confirm climatically-driven vegetation changes were associated with our reconstructions of mid- to late Pliocene glacial-interglacial water depth variability.

The variability of palynology index values on glacial-interglacial timecales is generally less than reported for the Middle and Late Pleistocene from ODP Site 1123 (Mildenhall et al., 2004). There, IGV index values typically vary 18-20 units, between -10 and +10 . In contrast, IGV variation in the Siberia-1 core was in most cases $<10$ IGV units. For the GV index, the glacialinterglacial variation at ODP Site 1123 was $\sim 50$ units, again about twice as large as the glacialinterglacial in GV index values in the Siberia core. This may reflect relatively muted vegetation change on glacial-interglacial scales during the mid-Pliocene (this study) compared to those driven by Pleistocene glacial-interglacial climate variability.

\subsection{Chronostratigraphy}

A chronostratigraphic framework for the mid- to late Pliocene sedimentary cycles is presented in Figure 4.4. It allows recognition and correlation of 23 individual glacial-interglacial sedimentary cycles within drill core and outcrop data sets with individual cycles in benthic $\delta$ ${ }^{18} \mathrm{O}$ oxygen isotope record between 3.3 and $2.6 \mathrm{Ma}$. Our age model is based on the integration 
of previously published chronologies for the Rangitikei and Turakina river sections (Journeaux et al., 1996; Kamp et al., 1998; Naish et al., 1998; Turner et al., 2005) with a new highresolution magnetostratigraphy for the Siberia-1 and Tiriraukawa-1 drill cores and the Watershed Road outcrop section (Tapia et al., submitted). It is constrained by biostratigraphy, numeric ages on rhyolitic tephra and their correlation to well-dated IODP Site 1124 record off eastern New Zealand (Figure 4.4).

\subsubsection{Tephrostratigraphy and Tephrochronology}

Silicic arc volcanism, associated with the evolution of subduction of the Pacific Plate under western North Island, has regularly contributed both primary and secondary silicic volcaniclastic deposits to Whanganui Basin (Naish et al., 1996; 1998; Pillans et al., 2005) over the last $5 \mathrm{Ma}$. The well-dated ODP Site 1124 core, located east of New Zealand and downwind from onshore eruptive centres (Figure 4.1), preserves a detailed eruption history of distal airfall deposits from both the Coromandel and Taupo volcanic centres over the last 10-2 Ma and <2 Ma years, respectively (Carter et al., 2003, 2004). Many of these ODP Site 1124 tephra have been geochemically characterised using glass shard major and trace element chemistry and correlated to equivalent-aged tephra preserved within Whanganui Basin (e.g. Alloway et al., 2004, 2005).

\section{Siberia Tephra}

An $\sim 40 \mathrm{~cm}$ thick, laterally-discontinuous, white-grey vitric-rich lapilli and ash bed, outcrops within fine-sandy mudstone of the Utiku Group in the Turakina River Section (McGuire, 1989; Patterson, 2014), and occurs stratigraphically within Kaena Subchron (33 m above the base; Figure 4.4; Turner et al., 2005). Its type section is located on the true right bank of the river (S $39.69576^{\circ} \mathrm{E} 175.52099^{\circ}$ ) near a farm track bridge. Its base is marked by a sharp and wavy erosional lower contact with mudstone containing fine to medium pumiceous lapilli, grading upwards to fine vitric sand and silt that typically exhibit $\mathrm{cm}$-thick parallel and planar cross- 
stratification. Increased bioturbation towards the upper gradational contact is indicated by distinctive $10 \mathrm{~cm}$-long burrows backfilled with marine mudstone.

Siberia Tephra resembles a shelf turbidite occurring within fine sandy-mudstone (Facies 3) at its type locality. Based on both the sedimentological architecture of this unit together with glass-shard geochemistry, which indicates a homogeneous composition (see below), we interpret this deposit as a submarine non-cohesive mass flow that likely originated as remobilised silicic volcaniclastic material that was channelised in the aftermath of a large onshore eruption and then transported offshore. Presently it is unknown if the Siberia Tephra at this occurrence represents the distal end-member of a proximal gas- (i.e. pyroclastic flow) to distal water- (i.e. hyperconcentrated- to flood-flow) supported continuum.

While this channelised tephra was not identified in the Siberia-1 drillcore, located only $300 \mathrm{~m}$ to the east of the type locality, its stratigraphic position was established on the basis of the similarity of grain size curves, which allows accurate correlation of the sedimentary cycles described in outcrop with the drill core (Figure 4.4).

Major and trace element compositions of individual glass shards from both the Siberia tephra, at its type locality, and potential correlatives in the ODP Site $1124 \mathrm{C}$ core were characterised utilizing electron microprobe and Laser Ablation-ICPMS techniques (see Supplementary Material). Selected major element bivariate plots (Figure 4.9) and a similarity coefficient of $>0.92$ establishes a strong correlation between Siberia Tephra and an equivalent-aged tephra (M12-upper and M12-lower; see Figure 4.9) occurring within a paleomagnetic interval of ODP Site $1124 \mathrm{C}$ ascribed as the Kaena subchron (3.116-3.032). ODP Site 1124 tephra beds have been dated by linear interpolation of sedimentation rates between astronomically-tuned key paleomagnetic polarity boundaries and ITPFT-dated tephra (Carter et al., 2003, 2004; Alloway et al., 2005). Consequently, the base of M12 tephra has an estimated age of $3.090 \mathrm{Ma}$. Originally, the M12-upper (this study) was previously named M11 (Stevens, 2010) and occurred at the base of core section $1124 \mathrm{C}-9 \mathrm{H}-2 \mathrm{~W}-145$ at mbsf $87.10 \mathrm{~m}$. However, this tephra layer is now recognised as a continuation of M12 occurring within the uppermost part of the immediately underlying core section (1124C-9H-3W-20 at mbsf $87.40 \mathrm{~m}$ ) and therefore is regarded in this study as a discrete layer representing the same eruptive event. Correlation 
between Siberia tephra and M12 is further supported by selected trace element bivariate plots (i.e. Sr v's Nd, Zr, Zr v's Nd, Y and Nd v's Th; Figure 4.10; SI Table 1).

An age for the Siberia Tephra of $3.12 \pm 0.18 \mathrm{Ma}$ was established from $\mathrm{U}-\mathrm{Th}-\mathrm{Pb}$ analyses of zircon at Victoria University of Wellington, New Zealand, following the methods of Sagar and Palin (2011). This age confirms the more precise stratigraphic age established on the basis of tephrostratigraphy, but more importantly constrains the magnetostratigraphic interpretation (SI Figure 1). 

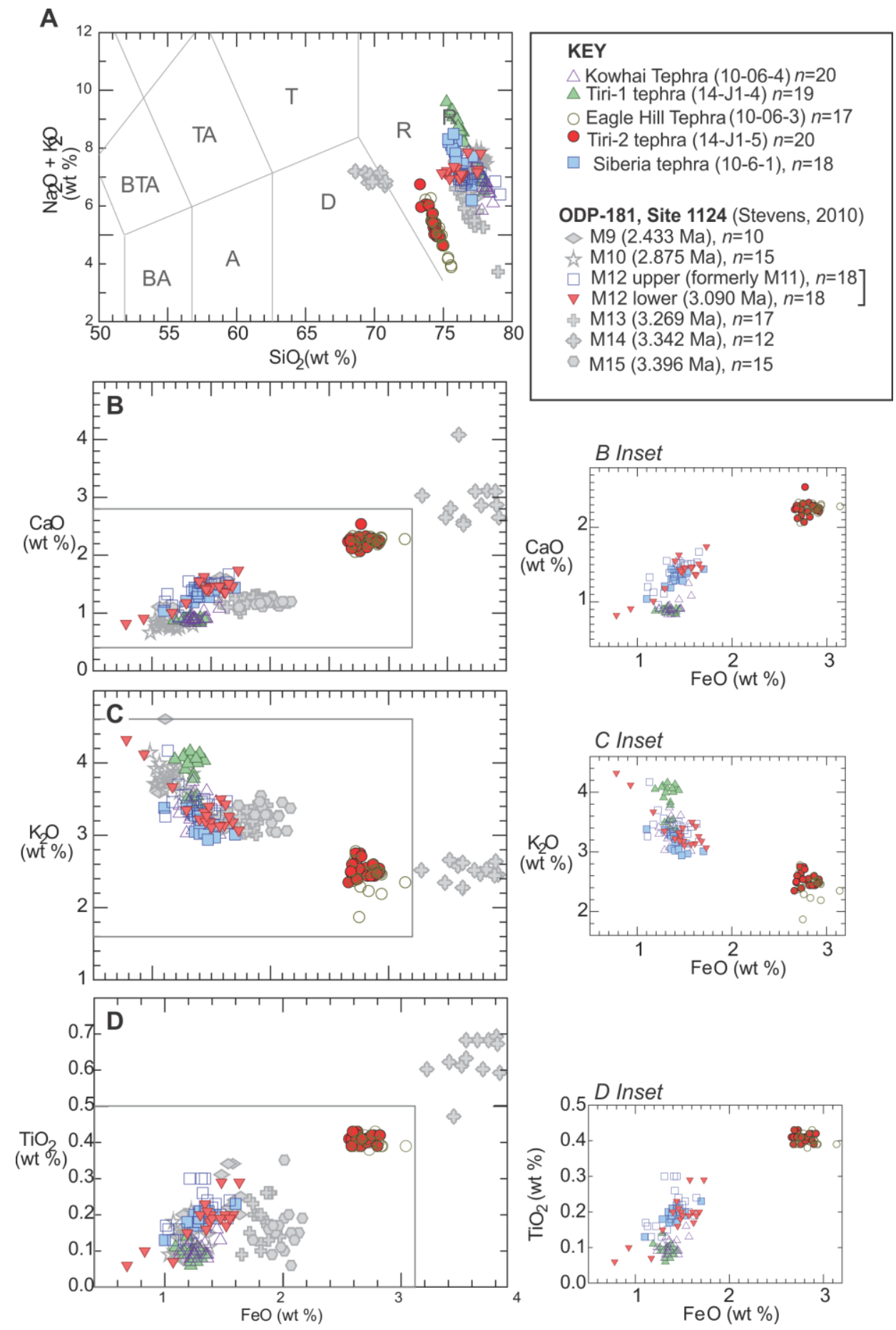

Figure 4.9. A. Plots of $\mathrm{SiO}_{2}$ vs $\mathrm{Na}_{2} \mathrm{O}+\mathrm{K}_{2} \mathrm{O}$ (wt. \%) compositions of glass shards from mid- to late Pliocene tephra beds exposed in Whanganui Basin compared with similar aged tephra from ODP Site 1124C. All tephra are rhyolitic in composition (after Le Maitre, 1982) except for M14 (ODP Site 1124C), which straddles the rhyolite-dacite domains; B-D. Selected major element compositions (weight percent $\mathrm{FeO}$ vs $\mathrm{CaO}, \mathrm{K}_{2} \mathrm{O}$ and $\mathrm{TiO}_{2}$ ) of glass shards from Kowhai, Tiri-1, Eagle Hill, Tiri-2, and Siberia tephra (Sefton, 2015) in comparison with seven tephra (M9, M10, M12 (upper; formerly M11), M12 (lower), M13, M14 and M15) of broadly similar age analysed from ODP Site 1124 C (Stevens, 2010). The ODP-tephra beds have been dated by linear interpolation of sedimentation rates between astronomically-tuned key paleomagnetic polarity boundaries and ITPFT-dated tephra (Carter et al., 2003, 2004; Alloway et al., 2005). Insets highlight those tephra that are correlated in this study. 
Table 4.4 Summary of individual glass shard major-element compositions of tephra beds from the Mangaweka Mudstone at the Watershed Road section (Tiri-1 and -2 tephra), Ruahine Road Section, Mangaweka (Eagle Hill and Kowhai tephra), and the Siberia tephra located in Utiku Group in the Turakina Valley (Sefton, 2015). Seven tephra (M9, M10, M12-upper, M12-lower, M13, M14, M15) analysed from ODP-1124C (Stevens, 2010) are included for comparison. Data displayed are weight percent means calculated on a water-free basis. Standard deviation ( \pm 1 SD) is indicated in brackets below mean values.

\begin{tabular}{|c|c|c|c|c|c|c|c|c|c|c|c|c|c|}
\hline & $\begin{array}{l}\text { Mount position } \\
\text { probe run }\end{array}$ & $\mathrm{SiO}_{2}$ & $\mathrm{Al}_{2} \mathrm{O}_{3}$ & $\mathrm{TiO}_{2}$ & $\mathrm{FeO}$ & $\mathrm{MgO}$ & $\mathrm{MnO}$ & $\mathrm{CaO}$ & $\mathrm{Na}_{2} \mathrm{O}$ & $\mathrm{K}_{2} \mathrm{O}$ & $\mathrm{Cl}$ & $\mathrm{H}_{2} \mathrm{O}$ & $n$ \\
\hline Kowhai Tephra & $\begin{array}{l}\text { 10-06-04 } \\
\text { (Aug. 21, 2014) }\end{array}$ & $\begin{array}{l}77.77 \\
(0.58)\end{array}$ & $\begin{array}{l}12.67 \\
(0.19)\end{array}$ & $\begin{array}{l}0.10 \\
(0.02)\end{array}$ & $\begin{array}{l}1.37 \\
(0.09)\end{array}$ & $\begin{array}{l}0.08 \\
(0.06)\end{array}$ & $\begin{array}{l}0.03 \\
(0.01)\end{array}$ & $\begin{array}{l}0.92 \\
(0.10)\end{array}$ & $\begin{array}{l}3.55 \\
(0.37)\end{array}$ & $\begin{array}{l}3.33 \\
(0.19)\end{array}$ & $\begin{array}{l}0.18 \\
(0.01)\end{array}$ & $\begin{array}{l}3.91 \\
(0.92)\end{array}$ & 20 \\
\hline Tiri-1 tephra & $\begin{array}{l}\text { 14-J1-4 } \\
\text { (Aug. 21, 2014) }\end{array}$ & $\begin{array}{l}76.42 \\
(0.90)\end{array}$ & $\begin{array}{l}12.60 \\
(0.12)\end{array}$ & $\begin{array}{l}0.09 \\
(0.02)\end{array}$ & $\begin{array}{l}1.34 \\
(0.06)\end{array}$ & $\begin{array}{l}0.08 \\
(0.06)\end{array}$ & $\begin{array}{l}0.03 \\
(0.02)\end{array}$ & $\begin{array}{l}0.88 \\
(0.02)\end{array}$ & $\begin{array}{l}4.51 \\
(0.74)\end{array}$ & $\begin{array}{l}3.87 \\
(0.27)\end{array}$ & $\begin{array}{l}0.18 \\
(0.01)\end{array}$ & $\begin{array}{l}4.83 \\
(1.23)\end{array}$ & 19 \\
\hline Eagle Hill Tephra & $\begin{array}{l}\text { 10-06-03 } \\
\text { (Aug. 21, 2014) }\end{array}$ & $\begin{array}{l}74.74 \\
(0.53)\end{array}$ & $\begin{array}{l}14.20 \\
(0.12)\end{array}$ & $\begin{array}{l}0.40 \\
(0.02)\end{array}$ & $\begin{array}{l}2.84 \\
(0.11)\end{array}$ & $\begin{array}{l}0.37 \\
(0.07)\end{array}$ & $\begin{array}{l}0.05 \\
(0.01)\end{array}$ & $\begin{array}{l}2.24 \\
(0.07)\end{array}$ & $\begin{array}{l}2.57 \\
(0.69)\end{array}$ & $\begin{array}{l}2.42 \\
(0.20)\end{array}$ & $\begin{array}{l}0.15 \\
(0.02)\end{array}$ & $\begin{array}{l}6.68 \\
(1.66)\end{array}$ & 17 \\
\hline Tiri-2 tephra & $\begin{array}{l}\text { 14-J1-5 } \\
\text { (Aug. 21, 2014) }\end{array}$ & $\begin{array}{l}74.22 \\
(0.41)\end{array}$ & $\begin{array}{l}14.26 \\
(0.13)\end{array}$ & $\begin{array}{l}0.41 \\
(0.01)\end{array}$ & $\begin{array}{l}2.78 \\
(0.08)\end{array}$ & $\begin{array}{l}0.40 \\
(0.07)\end{array}$ & $\begin{array}{l}0.06 \\
(0.02)\end{array}$ & $\begin{array}{l}2.24 \\
(0.10)\end{array}$ & $\begin{array}{l}2.93 \\
(0.43)\end{array}$ & $\begin{array}{l}2.54 \\
(0.11)\end{array}$ & $\begin{array}{l}0.16 \\
(0.01)\end{array}$ & $\begin{array}{l}6.55 \\
(1.02)\end{array}$ & 20 \\
\hline Siberia tephra & $\begin{array}{l}\text { 10-06-01 } \\
\text { (Aug. 21, 2014) }\end{array}$ & $\begin{array}{l}76.06 \\
(0.54)\end{array}$ & $\begin{array}{l}12.94 \\
(0.22)\end{array}$ & $\begin{array}{l}0.19 \\
(0.02)\end{array}$ & $\begin{array}{l}1.42 \\
(0.12)\end{array}$ & $\begin{array}{l}0.20 \\
(0.06)\end{array}$ & $\begin{array}{l}0.04 \\
(0.10)\end{array}$ & $\begin{array}{l}1.33 \\
(0.10)\end{array}$ & $\begin{array}{l}4.47 \\
(0.52)\end{array}$ & $\begin{array}{l}3.16 \\
(0.13)\end{array}$ & $\begin{array}{l}0.19 \\
(0.01)\end{array}$ & $\begin{array}{l}3.68 \\
(1.03)\end{array}$ & 18 \\
\hline M12 (upper) \# & & $\begin{array}{l}77.00 \\
(1.77)\end{array}$ & $\begin{array}{l}12.70 \\
(0.88)\end{array}$ & $\begin{array}{l}0.21 \\
(0.11)\end{array}$ & $\begin{array}{l}1.40 \\
(0.38)\end{array}$ & $\begin{array}{l}0.21 \\
(0.12)\end{array}$ & - & $\begin{array}{l}1.40 \\
(0.38)\end{array}$ & $\begin{array}{l}3.50 \\
(0.47)\end{array}$ & $\begin{array}{l}3.44 \\
(0.45)\end{array}$ & $\begin{array}{l}0.18 \\
(0.09)\end{array}$ & $\begin{array}{l}4.71 \\
(2.51)\end{array}$ & 18 \\
\hline $\begin{array}{l}\text { M12 (lower) \# } \\
3.090 \mathrm{Ma}\end{array}$ & & $\begin{array}{l}76.10 \\
(1.72)\end{array}$ & $\begin{array}{l}13.30 \\
(1.03)\end{array}$ & $\begin{array}{l}0.18 \\
(0.12)\end{array}$ & $\begin{array}{l}1.43 \\
(0.50)\end{array}$ & $\begin{array}{l}0.23 \\
(0.14)\end{array}$ & - & $\begin{array}{l}1.37 \\
(0.48)\end{array}$ & $\begin{array}{l}3.84 \\
(0.32)\end{array}$ & $\begin{array}{l}3.38 \\
(0.69)\end{array}$ & $\begin{array}{l}0.19 \\
(0.07)\end{array}$ & $\begin{array}{l}5.45 \\
(1.36)\end{array}$ & 18 \\
\hline $\begin{array}{ll}\text { Glass } & \text { Standard } \\
\text { ATHO-G } & \end{array}$ & (Aug. 21, 2014) & $\begin{array}{l}75.61 \\
(0.54)\end{array}$ & $\begin{array}{l}12.20 \\
(0.09)\end{array}$ & $\begin{array}{l}0.26 \\
(0.02)\end{array}$ & $\begin{array}{l}3.27 \\
(0.11)\end{array}$ & $\begin{array}{l}0.10 \\
(0.06)\end{array}$ & $\begin{array}{l}0.11 \\
(0.02)\end{array}$ & $\begin{array}{l}1.70 \\
(0.05)\end{array}$ & $\begin{array}{l}3.73 \\
(0.28)\end{array}$ & $\begin{array}{l}2.64 \\
(0.05)\end{array}$ & $\begin{array}{l}0.05 \\
(0.03)\end{array}$ & $\begin{array}{l}99.66 \\
(0.76)\end{array}$ & 73 \\
\hline
\end{tabular}



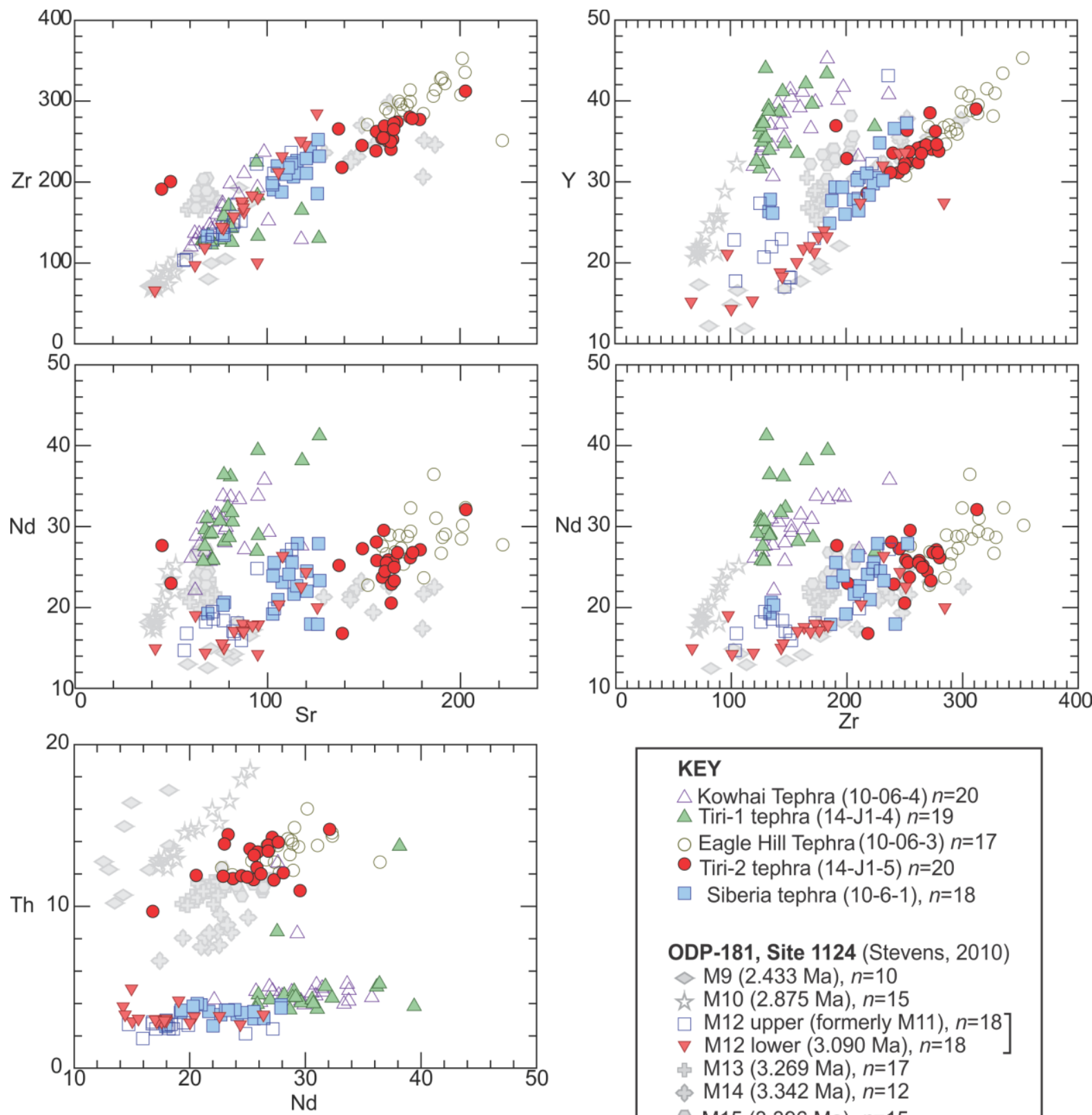

\section{KEY}

$\triangle$ Kowhai Tephra (10-06-4) $n=20$

$\triangle$ Tiri-1 tephra (14-J1-4) $n=19$

Eagle Hill Tephra(10-06-3) $n=17$

- Tiri-2 tephra (14-J1-5) $n=20$

$\square$ Siberia tephra (10-6-1), $n=18$

ODP-181, Site 1124 (Stevens, 2010)

$\diamond \mathrm{M} 9(2.433 \mathrm{Ma}), n=10$

M10 (2.875 Ma), $n=15$

$\square$ M12 upper (formerly M11), $n=18]$

$\checkmark$ M12 lower (3.090 Ma), $n=18$

M13 (3.269 Ma), $n=17$

M14 (3.342 Ma), $n=12$

M15 (3.396 Ma), $n=15$

Figure 4.10 Selected trace element bivariate plots (Sr v's Nd, Zr, Zr v's Nd, Y and Nd v's Th) determined by grain discrete LA-ICP-MS analysis (SI Table 1). Here, Kowhai, Tiri-1, Eagle Hill, Tiri-2 and Siberia tephra (Sefton, 2015) are plotted with respect to seven tephra (M9, M10, M12-upper, M12-lower, M13, M14 and M15) of similar age analysed from ODP Site 1124C (Stevens, 2010). Tephra symbols are the same as those listed in Figure 4.9. 
Two thin (<5 cm-thick), white, heavily-bioturbated and discontinuous vitric-rich tephra horizons, stratigraphically separated by 8 m of mudstone, outcrop on Watershed Road (S39.7726 $\left.{ }^{\circ} 175.6755^{\circ}\right) 150 \mathrm{~m}$ above the base of the Mangaweka Mudstone within clay-rich outer shelf mudstone (Facies 1). The lower and upper tephra are named Tiri1 and Tiri-2 respectively. Glass shards from both Tiri tephra as well as two potential correlatives, Kowhai and Eagle Hill tephra previously described in sections along Ruahine Road, Mangaweka; (Naish et al., 1996), were geochemically characterised by EMP and LA-ICP-MS techniques.

While all tephra can be classified as rhyolitic (Le Maitre, 1984), the Eagle Hill tephra and Tiri-2 are noticeably distinctive from Kowhai and Tiri-1 tephra on the basis of their glass shard major element chemistry (i.e. FeO v's $\mathrm{CaO}, \mathrm{K} 2 \mathrm{O}$, $\mathrm{TiO}_{2}$; Figure 4.9; Table 4.4). Similarly, these same tephra can be clearly distinguished by glass shard trace element concentrations (i.e. Sr v's Nd, Zr, Zr v's Nd, Y and Nd v's Th; Figure 4.10; SI Table 1), which confirms tephra correlation indicated from major element chemistry.

In this study, we have derived a zircon fission-track age of $2.7 \pm 0.3 \mathrm{Ma}$ (SI Figure 2) for Eagle Hill Tephra (Tiri-2 correlative) at its type locality in the Rangitikei River section (Naish et al., 1997). While the error is large, the weighted mean is statistically indistinguishable from a stratigraphic age of 2.88 Ma derived using sedimentation rates (Naish et al., 1996) and U/Pb age of $2.85 \pm 0.2$ Ma reported by Mclntyre (2002).

The correlation of the Eagle Hill and Kowhai to Tiri-2 and Tiri-1 tephra constrains the magnetostratigraphic interpretation of the Watershed Road section (see below), which supports the one-to-one correlation of sedimentary cycles within the Mangaweka Mudstone between the Watershed and Rangitikei River Sections. This correlation suggests that the Eagle Hill and Kowhai (Tiri-2 andTiri-1) tephra were deposited between marine isotope stage G10-G9 ( 2.8 Ma; Figure 4). 


\subsubsection{Biostratigraphy}

Key biostratigraphic constraints include:

(i) The occurrence throughout Tiriraukawa-1 core and Rangitikei River Section of the scallop Mesopeplum crawfordi within the Utiku Group, which is restricted to the Waipipian New Zealand biostratigraphic stage (3.7-3 Ma; Beu and Maxwell, 1990; Raine et al., 2015).

(ii) The Last Appearance Datum (LAD) of the benthic foraminifera Cibicides molestus toward the base of the Mangaweka Mudstone in the Rangitikei River (Journeaux et al., 1996), Watershed Road, and Turakina River Sections (McGuire, 1989) has previously been assigned to the base of the Mangapanian Stage dated to ca. 3 Ma (Cooper et al., 2004). However, this datum has been demonstrated to be diachronous across Whanganui Basin due to the restricted depositional environment of $C$. molestus (Cooper et al., 2004). A linear sedimentation rate of $0.89 \mathrm{~m} / \mathrm{kyr}$ (for the first Gauss Normal subchron 3.032-2.58 Ma) dates the LAD to $2.88 \mathrm{Ma}$, while the oneto-one correlation of sequence stratigraphic cycles to the benthic $\delta^{18} \mathrm{O}$ record dates the LAD between marine isotope stage G12 and G11 ( 2.85$2.83 \mathrm{Ma})$.

\subsubsection{Magnetostratigraphy and correlation to the Geomagnetic Polarity Timescale}

Metre-spaced sampling resolved a R-N-R-N-R (upward) polarity zonation for the Siberia-1 drill core and a R-N-R-N-R-N (upward) polarity zonation for the Tiriraukawa-1 drill core (Figure 4.4; Tapia et al., submitted). The R-N-R-N (upward) polarity zonation previously described for the Utiku Group strata in Rangitikei and Turakina sections, was interpreted as the Mammoth (3.330-3.207 Ma) and Kaena (3.116-3.032 Ma) reversed polarity subchrons within the Gauss normal chron (3.580 - $2.581 \mathrm{Ma}$ ) based on their positions within much longer polarity zonations and biostratigraphic constraints 
(Turner et al., 2005) and the age of the younger basin-fill (Naish et al., 1998). The presence of a short reversed polarity interval in the top of both drill cores is suggested to be a previously undocumented short-lived polarity interval or cryptochron within the Gauss Normal Chron, recorded because of very high sedimentation rates (1-2m/kyr) and the highly-resolved sampling (Tapia et al., submitted). It is unlikely to correspond to the Gauss/Matuyama N-R transition (2.58 Ma), as, in the Rangitikei and Turakina, this occurs in the upper part of the Mangaweka Mudstone, some $400 \mathrm{~m}$ and $700 \mathrm{~m}$ above the Kaena respectively (Naish et al., 1998; Turner et al., 2005). An N-R transition just above the Mangaweka Mudstone in Watershed Road section was also interpreted as the Gauss-Matuyama boundary in the lower-resolution study of Sefton (2015). This is supported by previous mapping of the Rangitikei Group strata in the region (Naish and Kamp, 1995), biostratigraphic constraints, and the age and occurrence of the Eagle Hill Tephra (Tiri-2 correlative) in the lower part of the Watershed Road section (see above).

The established magnetostratigraphy of the Turakina section also identifies the GilbertGauss (3.58 Ma) R-N transition in the underlying Tangahoe Mudstone, $300 \mathrm{~m}$ below the Mammoth subchron (Turner et al., 2005).

The correlation of the polarity stratigraphy in the two drillcores with the GPTS (Ogg, 2012) as proposed by Tapia et al., (submitted) is further strengthened by the U-Pb age of 3.12 $\pm 0.18 \mathrm{Ma}$ obtained for the Siberia Tephra which occurs in Kaena Subchron in both the Turakina River section and ODP Site 1124 (see above).

\subsection{Concluding remarks}

\subsubsection{Orbitally-paced, glacial-interglacial shallow marine sedimentary cycles}

We have established a cyclostratigraphic framework for the mid- to late Pliocene strata, and have identified 23 individual shallow-marine sedimentary cycles within the 
integrated drill core and outcrop data set. These can be correlated with individual cycles in the benthic $\delta^{18} \mathrm{O}$ oxygen isotope record between 3.3 and 2.6 Ma (Figure 4.4). While the water depths derived from the benthic foraminiferal modern analogue technique generally display shallowing and deepening cycles that are synchronous with those based on lithofacies analysis, sequence stratigraphy and grain size variations, they do not accurately estimate relative amplitude of water depth changes suggested by the depositional environments interpreted from variations in lithofacies. The cycles themselves progressively deepen across a broad west-facing, wave-graded paleo-shelf transect from inner to outer shelf water depths, from the Rangitikei River section to the Turakina section, respectively.

While one-to-one correlations can be made between the sedimentary cycles and the high-resolution ODP Site 846 benthic $\delta^{18} \mathrm{O}$ record (Shackleton et al., 1995) through the mid-Pliocene interval ( 3.3-3.0 Ma; with one exception), this is not possible for the same interval in the benthic $\delta^{18} \mathrm{O}$ stack (Lisiecki \& Raymo, 2005; Figure 4.4), implying the stack is of lower-resolution and/or smoothed over this interval. Cycles 1-14 within the mid-Pliocene Utiku Group appear to correspond to dominantly 20-kyr-duration glacial-interglacial fluctuations in global sea-level (e.g. Meyers and Hinnov, 2010). Cycles $15-23$ in the late Pliocene Mangaweka Mudstone by contrast, correspond to dominantly $\sim 40$ kyr-duration glacial-interglacial fluctuations in sea-level (Lisiecki and Raymo, 2005), perhaps in response to the development of continental ice sheets in the Northern Hemisphere after 2.9 Ma (e.g. Raymo, 1994; Maslin et al., 1998).

\subsubsection{Implications for reconstructing glacial-interglacial sea-level change}

The continuous record of orbitally-paced water depth changes recorded by the Whanganui shallow-marine sedimentary cycles, described here, provides a unique opportunity to reconstruct the amplitude of glacial-interglacial fluctuations in GMSL during the warmer than present mid-Pliocene (3.3-3.0 Ma) and the late Pliocene (3.02.6 Ma), independent of the oxygen isotope record (c.f. Naish and Wilson, 2009; Miller et al., 2012). 
A complex history of long-term tectonic subsidence during deposition of the Pliocene sediments, followed by uplift and exhumation during the late Quaternary, means it is not possible to register GMSL during interglacial highstands of the mid-Pliocene from Whanganui Basin with respect to the present. Moreover, as outlined in the introduction of this paper, the influence of mantle dynamics on vertical land movement over the past 3 My renders peak Pliocene GMSL unknowable (Rovere et al., 2014).

Mantle dynamics have significantly less influence on glacial-interglacial timescales (Austermann et al., 2015). Therefore, by using a backstripping approach to remove the influence of sediment compaction and tectonic subsidence on relative sea-level changes (e.g. Kominz and Pekar, 2001; Miller et al., 2012), combined with correction for GIA (e.g. Raymo et al., 2011), it may be possible to reconstruct the amplitude of glacial-interglacial GMSL changes during the mid- to late Pliocene from the Whanganui Basin record. This approach, together with an understanding of the frequency of sealevel change, could provide important insights to the relative contribution of polar ice sheets to GMSL and thus ice sheet sensitivity under past climate conditions that were similar to those predicted for the coming centuries.

\section{Acknowledgements}

The Royal Society of New Zealand, Marsden Grant 13 VUW 112, funded this research. The authors would like to acknowledge Webster Drilling and Exploration Ltd for the drilling operations and Alex Pyne and Darcy Mandeno of the Antarctic Research Centre, Science Drilling Office for logistics support. Nick Pearce, Department of Geography \& Earth Sciences, Aberystwyth University, UK, is thanked for his assistance in the acquisition of glass shard LA-ICP-MS data. 


\section{Quantifying water depth changes and relative sea level for the}

mid- to late Pliocene

In this chapter, a relative sea level record is developed from the cores and adjacent outcrops, initially by quantifying the paleobathymetry - that is the local water depth of sediment deposition (Section 5.1). The previous chapter uses sedimentology and foraminiferal paleoecology as a basis for interpreting lithofacies variations in the Utiku Group sandstone and Mangaweka Mudstone in response to changes in water depth. Paleobathymetry is further developed here through a quantitative relationship between wave energy, water depth and grain size. Grain size-derived estimates are independently supported by benthic foraminiferal paleoecology (see Section 4.4 above for details).

Secondly, a backstripping technique is applied to the paleobathymetric record to determine the contribution of tectonic subsidence and sediment compaction which results in a relative sea-level (RSL) record (Section 5.2). The RSL record, is site-specific, and is not registered to present-day sea-level, but does resolve the amplitude of glacialinterglacial sea-level changes for the mid- to late Pliocene in New Zealand.

Eustatic sea-level (ESL) height, referred to here as the sea-level equivalent of meltwater contribution, is variable over the ocean surface because of visco-elastic changes in the Earth's crust and instantaneous gravitational adjustments, collectively known as glaciohydro-isostatic adjustment (GIA). This occurs due to redistribution of mass as polar ice sheets grow or melt. Modelling the Earth surface response to changes in polar ice sheet volume change is necessary to correct for this effect and to understand how the RSL, estimated for New Zealand relates to ESL (Section 5.3). 


\subsection{Quantifying Paleobathymetry}

Traditionally, paleobathymetry has been determined by an established relationship between lithofacies and water depth-sensitive extant molluscan and foraminiferal associations (e.g. Naish and Kamp, 1997b). This approach is well-suited to largeamplitude sea-level variability $(>50 \mathrm{~m})$ associated with significant changes in depositional environments but can be relatively insensitive to small-scale variations $(<50 \mathrm{~m})$ in sea level. More recently, observations of sediment distribution across a wave-graded shelf with increasing water depth for a range of modern wave climates have been used to understand sediment transport under low, moderate and high wave energy climates (Dunbar and Barrett, 2005). The approach is further developed below for variable wave climates in order to quantify water depth as a threshold response to sediment transport induced by (depth-dependent) wave action over glacial-interglacial cycles (Chapter 5.1.1).

A second independent approach to quantifying sea level, using a modern analogue technique based on extant benthic foraminifera abundance, presented in the manuscript that makes up Chapter 4, is compared to water depths derived from the grain size technique to develop a mid- to late Pliocene quantitative paleobathymetric record.

\subsubsection{Estimating paleowater depth from grain size}

Sediment distribution on the shelf is the result of complex interactions between sediment supply, and reworking and transport by local currents and waves (Figure 5.1). Wave-graded shelves are shallow-marine environments where sediment distribution is primarily determined by wave interaction with the seafloor, expressed by a seawardfining sediment profile, as a product of wave profile asymmetry and decreasing wave energy with water depth (Swift, 1970; Wright et al. 1999).

An investigation of wave formation and calculation of wave-induced near-bed velocity, was undertaken to determine at what depth the required velocity for sediment 
transport is exceeded. A series of simple equations following previous studies (e.g. Komar and Miller, 1975; Soulsby and Whitehouse, 1997; Dunbar and Barrett, 2005; Van Rijn, 2007) are used to derive profiles of near-bed velocity over a range of water depths for variable grain size under different wave climates.

The predicted sediment distribution from the model is compared to three modern shelf transects using the modern wave climate parameters to validate the application of the model to core stratigraphy.

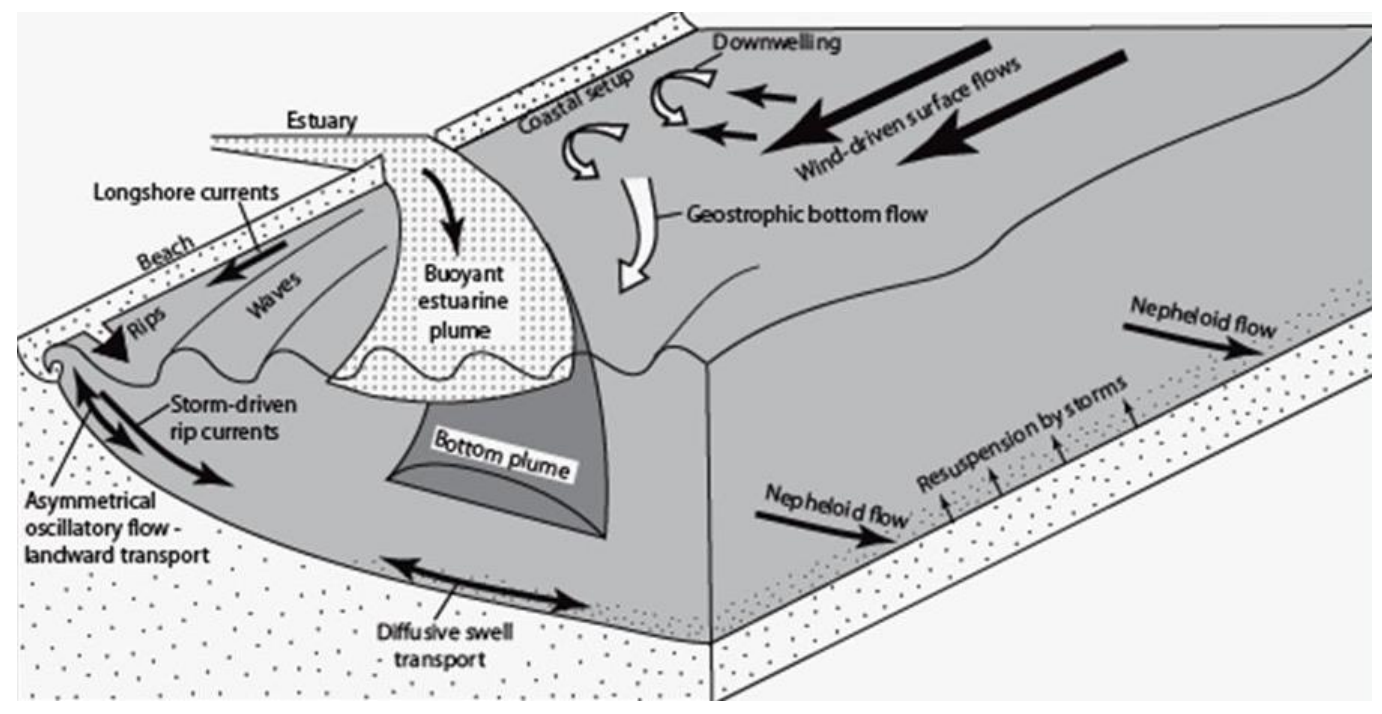

Figure 5.1 Sediment transport mechanisms from the coast to shelf by wave and currents on a shallow-marine margin (Boggs, 2011).

Wave theory

The term 'wave climate' refers to the height and wavelength of wind-generated waves experienced at the coast. These properties are determined by wind velocity and fetch (that is, the distance over which wind interacts with the ocean surface). Linear wave theory (or Airy wave theory) dictates that wind-induced waves will continue to increase in height and period under constant wind velocity, with unlimited fetch and no interaction of the waves with the sea floor (Airy, 1841). For many purposes, including sedimentology, waves are described by the significant wave height $(H s)$, that is the 
mean of the highest third of observed waves, the peak wave period (Tp; s), and wave length $(L ; m)$ in deep-water (depths over half the wavelength; Figure 5.2). These properties are used on the basis that the largest waves are the most important with respect to the erosion and deposition of sediment. Water depth becomes important during the propagation of waves into shallow water as the drag friction from the seafloor increases the wave height and reduces the wave length and speed.

Wave-graded shelves, as mentioned previously, display a seaward-fining profile, that reflect textural equilibrium with the hydraulic regime. This is not observable on short time-scales but is the result of net-transport on the order of a century or more (Moore and Curray, 1964), which includes the mixing of seafloor sediments by bioturbation. On some continental margins, increase of sediment supply to the shelf has the ability to overwhelm the hydraulic regime resulting in growth of shelf-margins (Carvajal et al., 2009). The Whanganui Basin, as a subsiding basin, provides adequate accommodation space, and sediment supply is such that the accumulation of sediment in the shelf shoreline environment occurs in textural equilibrium with contemporaneous hydraulic regime (Dunbar and Barrett, 2005).

The threshold for sediment movement under unidirectional current conditions (e.g. rivers), for which the velocity and the stresses on bed sediment can be relatively easily determined, has been under investigation since the early $20^{\text {th }}$ century (e.g. Sheilds, 1936). Empirical relationships between current velocity and grain diameter have been established for a range of conditions under which motion in suspension or bed-load can occur (Sunborg, 1956). Komar and Miller (1975) incorporate near-bed orbital diameter and orbital velocity to account for the different forces applied to grains under oscillatory water-waves which experience accelerating and decelerating flows rather than constant flow. Van Rijn (1993) developed the critical velocity for grain transport under waves based on a later equation by Komar and Miller, (1975) that includes the wave period related to the length of the near-bed orbital diameter.

To calculate the near-bed peak orbital velocity $\left(U w ; \mathrm{ms}^{-1}\right)$ induced by wave action the wave period is firstly used to determine wavelength, which is a function of water depth (Equation 5.1; Eckart, 1952). The wavelength, wave period and significant wave height (also measured in deep water), are then used to calculate the peak orbital velocity 
(Equation 5.2; Pickrill and Curie, 1983). The critical velocity $\left(U c r, w ; \mathrm{ms}^{-1}\right.$ ) required to initiate movement of a grain of diameter (Dmax; $m$ ) for a wave period $(T p ; s)$, includes the relative density difference between sediment and seawater ( $p s / p w$; nominally 2650/1025 kg.m ${ }^{-3}$ ), and the influence of gravity (g: $9.8 \mathrm{~m} \cdot \mathrm{s}^{-2}$ ) from Van Rijn (1993) after Komar and Miller (1975). For a predetermined wave climate (Hs and Tp) in shallow water, water depth (h) then determines the available velocity $(U w)$ and the grain diameter (Dmax; $m$ ) determines the critical required velocity (Ucr,w; Equation 5.3). Transport of a grain (Dmax) at a specific water depth occurs when the wave velocity exceeds the critical velocity $(U w>U c r, w)$, representing the maximum water depth that a given grain size can be transported, as that wave velocity increases at shallower depths.

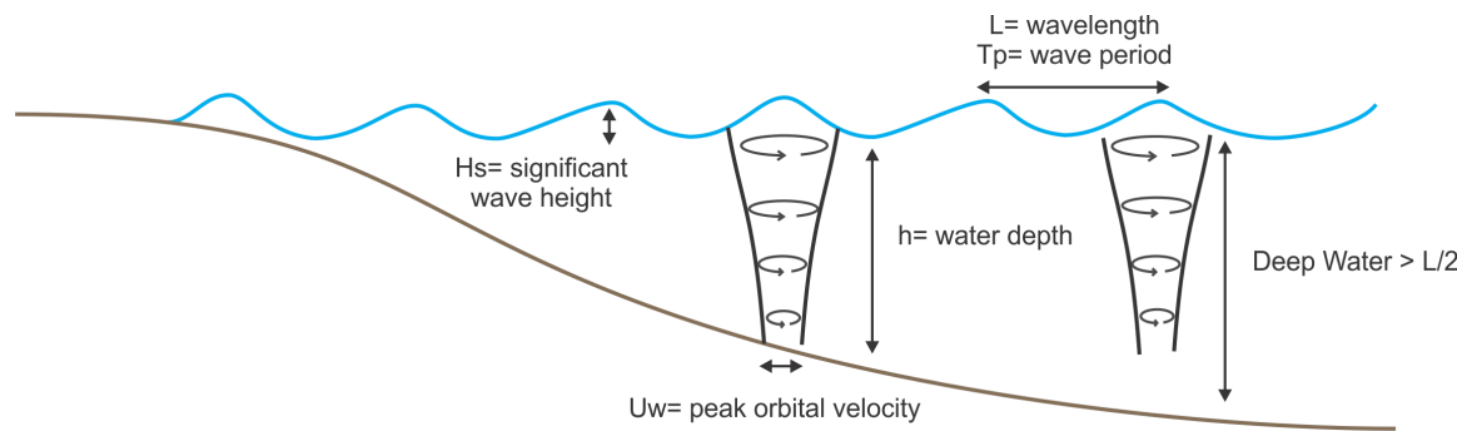

Figure 5.2 Schematic diagram describing wave parameters $H s, L, T p$, h and Uw, used in equations (5.1; 5.2; 5.3).

$$
\begin{aligned}
& L=\left(\frac{g T_{p}{ }^{2}}{2 \pi}\right) \sqrt{\left(\tanh \left(\frac{4 \pi^{2} h}{T_{p}^{2} g}\right)\right.} \\
& U_{w}=\frac{\pi H_{s}}{T_{p} \sinh \left(\frac{2 \pi h}{L}\right)} \\
& U_{c r, w}=0.24\left[\left(\frac{\rho_{s}}{\rho_{w}}-1\right) g\right]^{0.66} \operatorname{Dmax}^{0.43} T_{p}{ }^{0.33}
\end{aligned}
$$

Equation 5.1

Equation 5.2

Equation 5.3 
Orbital velocity and critical velocity were calculated for wave periods from $5 \mathrm{~s}$ to $22 \mathrm{~s}$ (at $1 \mathrm{~s}$ intervals), for all wave heights of $0.5 \mathrm{~m}$ to $4 \mathrm{~m}$ (at $0.1 \mathrm{~m}$ intervals), water depths up to $200 \mathrm{~m}$ (at $1 \mathrm{~m}$ intervals) and grain diameters from 63 to $2000 \mu \mathrm{m}$ in $1 \mu \mathrm{m}$ increment. These calculations yield a profile of decreasing maximum grain size able to be transported for increasing water depths under specified wave climates. This results in a very large dataset, for which the Matlab script is provided and a summary of the threshold water depths for selected wave heights ( 0.5 to $4 \mathrm{~m}$ every $0.2 \mathrm{~m}$ ) and wave periods ( 5 to $22 \mathrm{~s}$ at $0.5 \mathrm{~s}$ increments) for grain sizes of $64,146,234,320,408 \mu \mathrm{m}$ is supplied in Appendix K.

The calculations require a single grain size that represents the maximum grain size (Dmax; in Equation 5.3), as everything finer can also be transported under the same conditions. Mud $(<64 \mu \mathrm{m})$ is excluded from this assumption (and the calculations) as cohesion can increase required velocity for transport when the sample is mud dominated, and similarly requires less energy to settle rather than velocity to transport. This decreases the accuracy of this technique when samples have high mud content. As seafloor sediment is not comprised of a uniform size, but includes a range of sizes that reflect a spectrum of wave conditions from fair weather to storm weather on the shelf, a correlation between the maximum grain size and total sand percentage $\left(\Sigma \mathrm{V}_{>63}\right)$ of the sediment distribution was made (Figure 5.3$)$. This accounts for the natural variability of wave energy, and long-term mixing (bioturbation), to better describe the mean state of sediment distribution over long time periods (for which sediment transport is dominated by storm conditions). Sand percentage is readily measurable and reflects the relative abundance of material transported as bed load (as opposed to mud settling from suspension). The measurement of grain size by laser diffraction, as with traditional methods such as screening, generates data in predefined size-classes or 'bins' whose width increases log-normally with size. This limits the ability to precisely determine maximum grain size, which is shown by the correlation (Figure 5.3) made using the numerous grain size data measured in this study from the Siberia-1 and Tiriraukawa-1 cores, that were treated and measured in the same manner. A linear equation for the weighted mean of Dmax is given by Equation 
$5.4\left(R^{2}\right.$ value of 0.92$)$. Where the uncertainty is defined as the mean percentage of deviation $\left(\mu X_{D x}\right)$ from the weighted mean $\left(x_{i}\right)$ to the model $(m(x)$; Equation 5.5).

$\Sigma \mathrm{V}_{>63}=0.2872 . D \max -17$

Equation 5.4

$\mu X_{D x}=\left|x_{i}-m(x)\right|$

Equation 5.5

The spread of sand percentage for a maximum grain size demonstrates the need for this correlation, as the transport of coarser grains to very deep water is possible under rare storm waves but is not representative of the mean climate. This is more accurately conveyed by the total sand percentage in such samples, which must have experienced predominantly lower velocity conditions, allowing mud to settle and thus represents a lower overall wave climate than would be suggested by the maximum grain size.

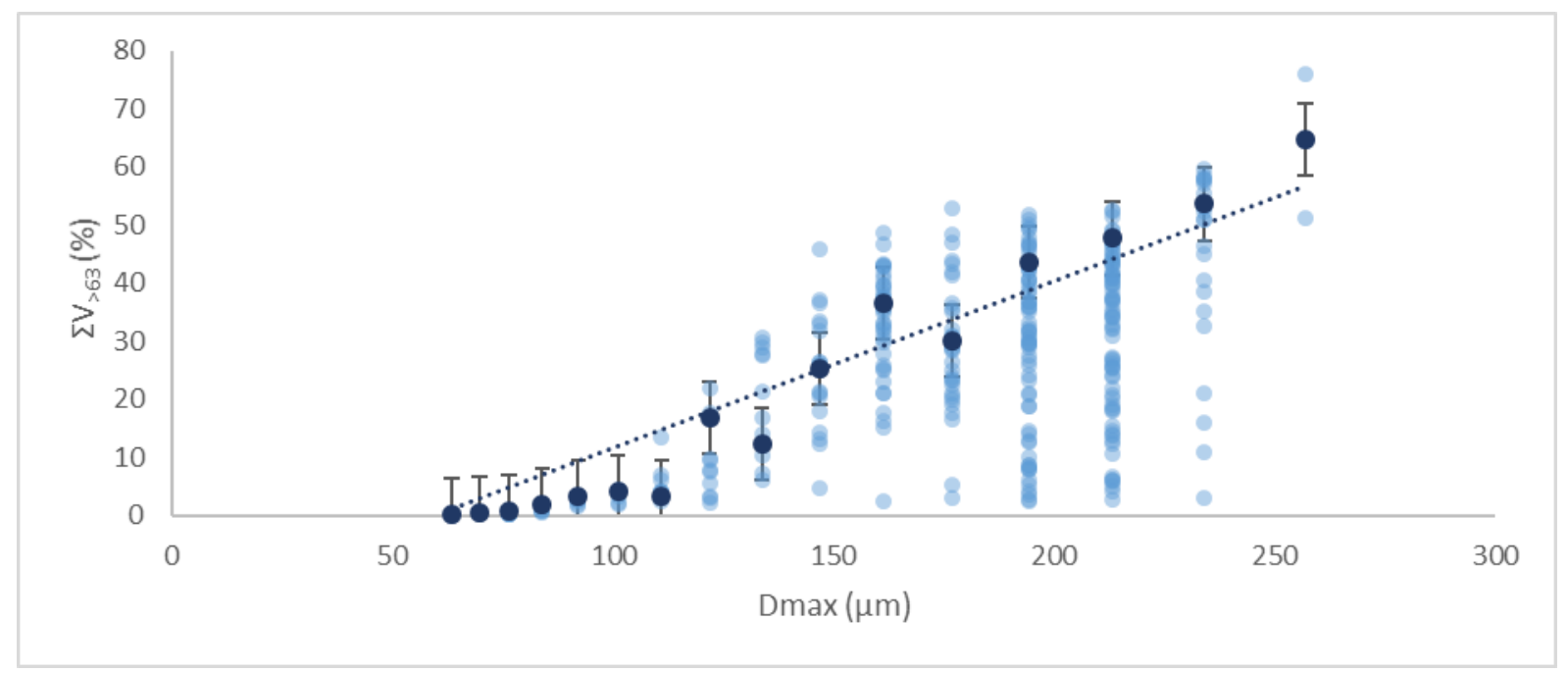

Figure 5.3 All maximum grain size (Dmax) and sand percentage $\left(\Sigma V_{>63}\right)$ for Siberia-1 and Tiriraukawa-1 samples (light blue) with weighted mean (dark blue) for which the linear relationship is defined (Equation 5.4).

Figure 5.4 shows for selected periods, the threshold $U w>U c r$ water depths at which no sand $(0 \%$ - coincident with mud fraction $<63 \mu \mathrm{m})$ and theoretically all sand $(100 \%)$ can be transported under all significant wave heights $(H s)$ for peak wave periods $(T p)$ of 5 , 10, 15 and 20s. Figure 5.5 shows the relative water depth difference between $0 \%$ and $100 \%$ sand for the same periods. The calculations show that the depth of threshold $U w>U c r$ is relatively insensitive to significant wave height for a given peak wave period (Figure 5.4). That is, increasing the peak wave period by $5 \mathrm{~s}$, the relative water depth of 
the threshold increases, approximately by a factor of 2 (Figure 5.5). For $5 \mathrm{~s}$ and $10 \mathrm{~s}$ wave periods, the change in significant wave height, doesn't make a significant difference to the relative water depth difference between $0 \%$ and $100 \%$ sand, while for the $15 \mathrm{~s}$ period wave, the relative difference increases up to a significant wave height of $1.6 \mathrm{~m}$ before stabilising, and the $20 \mathrm{~s}$ peak wave period increase up to a wave height of $2.2 \mathrm{~m}$.

This is important because in this study the relative water depth changes are being investigated but not absolute water depths. The peak wave period selected has a significant effect, but the wave heights for that chosen wave period are less significant. The wave period, which is driven primarily by fetch, is easier to predict with knowledge of the paleogeography.

Other studies (e.g. Li and Amos, 2001; Dunbar and Barrett, 2005) have utilised 'skin friction' shear stress as a determining factor for sediment transport. However, this includes a bed roughness factor which cannot accurately be determined in paleo instances. Indeed, Van Rijn (2007) does not include this parameter in their determination of bed-load transport, which provided the basis for this technique.

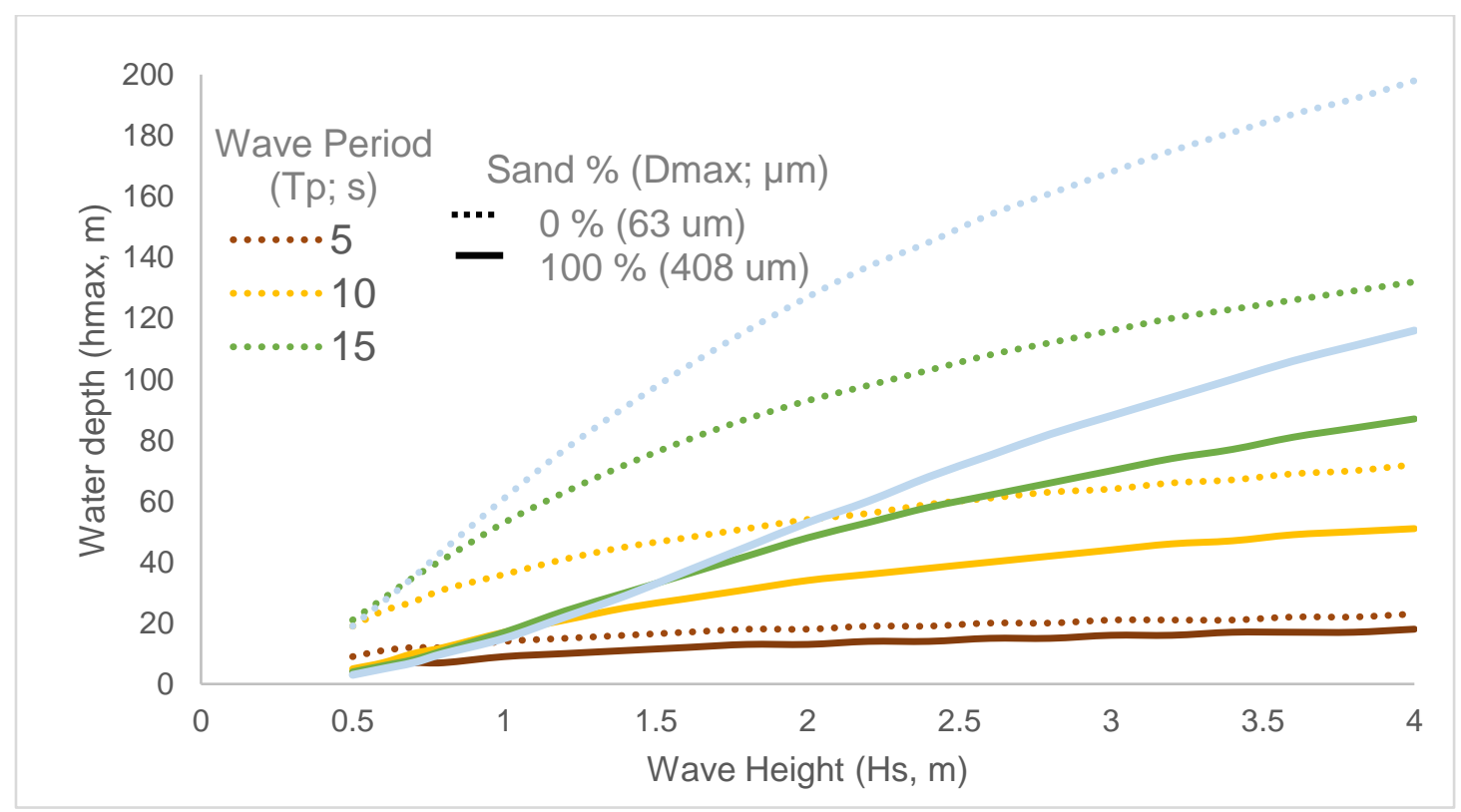

Figure 5.4 The water depth thresholds for deposition of sand (0\% and 100\%) as a function of selected wave periods (Tp: 5s, 10s, 15s and 20s) for varying wave heights (Hs). 


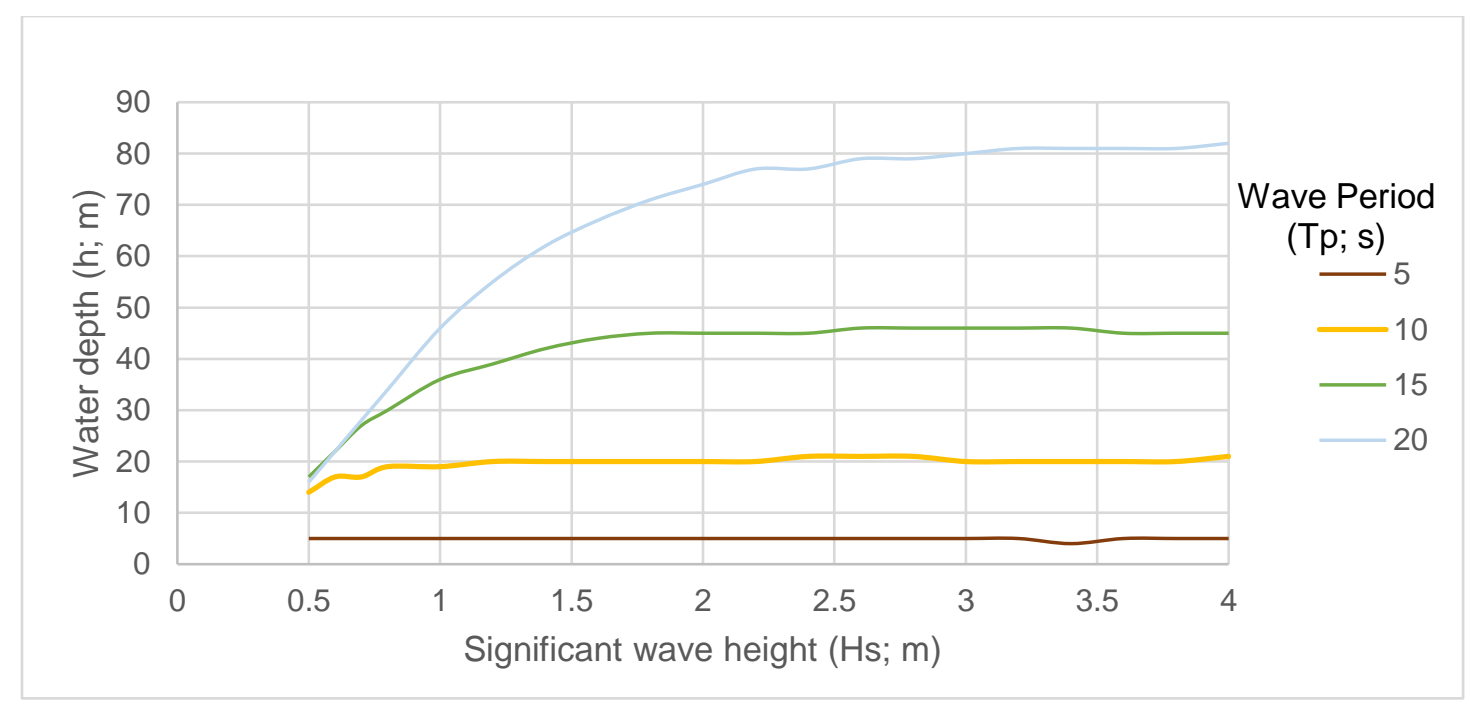

Figure 5.5 The relative water depth difference between the deposition of $0 \%$ and $100 \%$ for the wave periods (Tp) 5 $\mathrm{s}, 10 \mathrm{~s}, 15 \mathrm{~s}$ and $20 \mathrm{~s}$.

\section{Application to modern environments}

To validate the model, three modern across-shelf transects of seafloor sediment samples from locations with known wave climates are used to compare measured and predicted sand percentage for the wave climate (Tp and Hs) parameters. The modern transects (Appendix L) used, are located at Monterey Bay, California (Chin et al., 1984; Figure 5.6), Manawatu, New Zealand (Dunbar and Barrett, 2005; Perrett, 1990; Figure 5.7) and Whanganui Bight, New Zealand (Beaumont et al., 2013; Figure 5.7). The Whanganui Bight dataset was collected for a biological survey and thus doesn't extend over the full extent of the shelf. The gravel fraction was excluded in the sand percentage calculation as it has been identified previously as palimpsest or relict (Carter, 1980). However, the sand portion has been observed to turnover under modern storm conditions (Beaumont et al., 2013). 


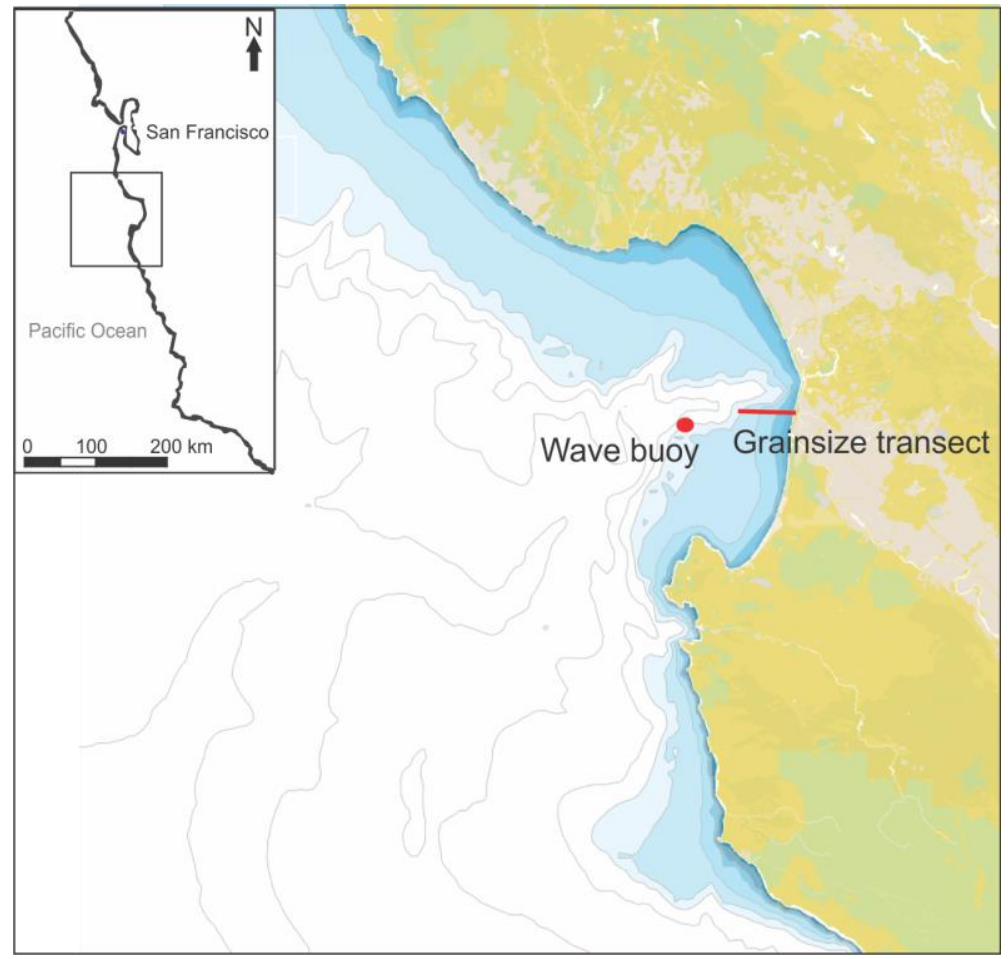

Figure 5.6 Location map of the wave buoy used to determine wave height (Hs) and peak wave period (Tp) for sea floor near-bed velocity calculations and modern grain size transect for the Monterey Bay dataset (Table 5.1; Figure 5.8).

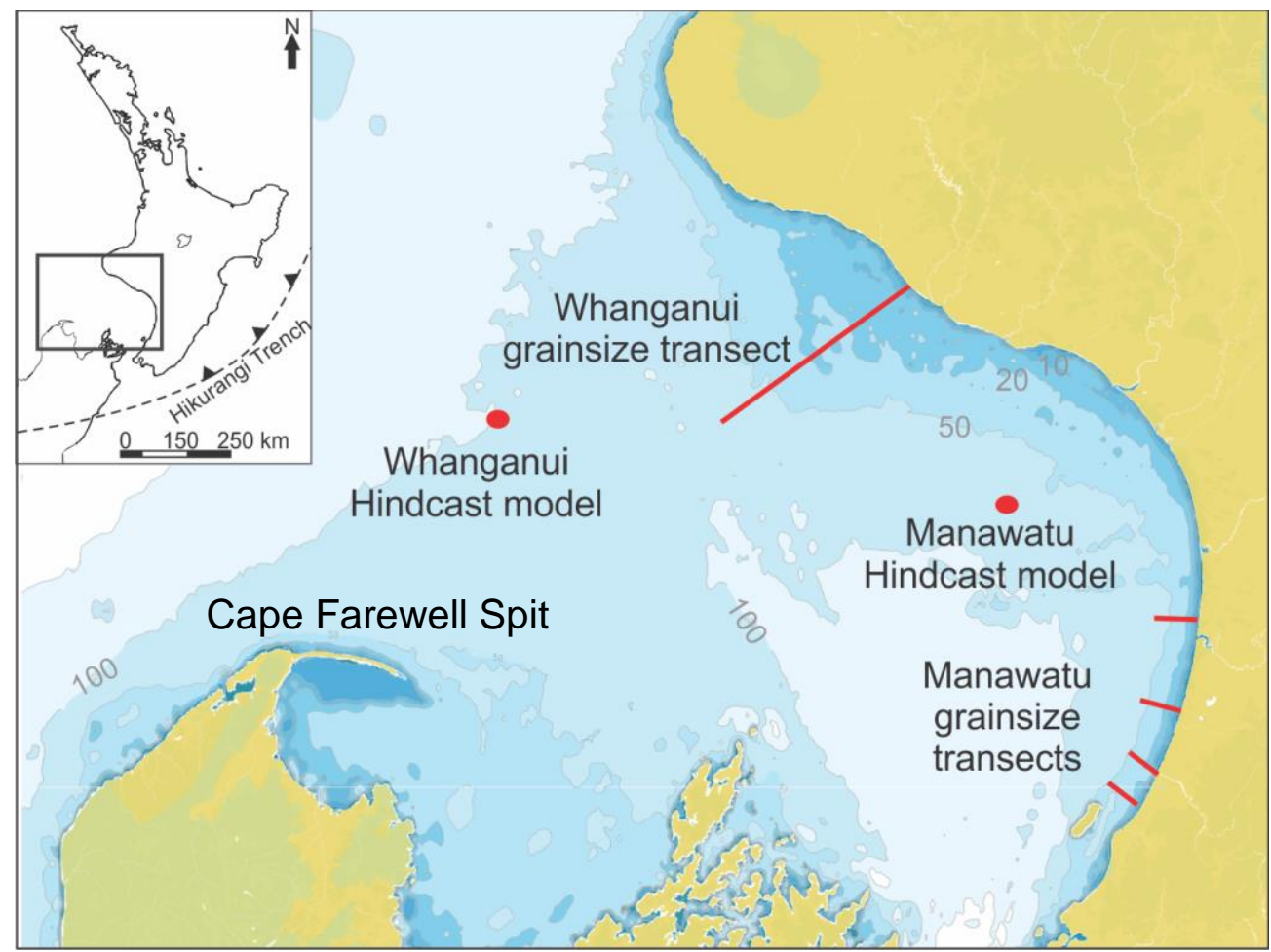

Figure 5.7 Location map of the hindcast wave models used to determine wave height and period for sea floor nearbed velocity calculations and grain size transects for the Whanganui and Manawatu coastlines (Table 5.1; Figure 5.8). 
The wave parameters (either measured or modelled) for Monterey, Manawatu and Whanganui are outlined in Table 5.1 (Figure 5.6 and Figure 5.7) and are used to inform on the wave climate parameters to select for the resulting sand versus water depth profile. The nearest available hindcast wave model for the Manawatu would suggest a significant wave height of $1.6 \mathrm{~m}$, however, it is apparent that this is much higher than the $1.2 \mathrm{~m}$ best fit in Figure 5.8. This is likely due to the location of the hindcast model being more exposed north of the Cape Farewell shadow and is therefore considered not suitable for predicting waves on the Manawatu coast. The significant wave height at $50 \mathrm{~m}$ depth (nearer the Manawatu transects) is predicted to be 1-1.4 m (Hume et al., 2013).

The resulting water depth (WD; Equation 5.6) under which the maximum grain size (Dmax) is transported, is then given by the water depth $(h)$ for the wave-induced nearbed velocity (Uw; Equation 5.2) when the near-bed velocity exceeds the critical velocity (Ucr,w; Equation 5.3) required to transport the maximum grain size (Dmax).

The three resulting profiles of water depth (WD) for $\Sigma V_{>63}$ are shown in Fig. 5.8, with the corresponding measured samples of the modern transects. The error of the model is calculated as the mean percentage of deviation $\left(\mu X_{D y}\right)$ of the observations $\left(y_{i}\right)$ for each transect to the respective model $(m(y)$; Equation 5.7). The sum error of the water depth predicted for Dmax for a given wave climate scenario is the standard deviation ( $\sigma_{n}$; Equation 5.8) of the range of errors provided by Equations $6 \& 7$ at any depth.

$W D(D \max )=h(U w)$ when $U w>U c r, w$

Equation 5.6

$\mu Y_{D y}=|y-m(y)|$

Equation 5.7

$\sigma_{n}$ where $n=\left[\begin{array}{c}\mu_{D x}^{\max } \\ \mu_{D x} \\ \mu_{D x}^{\min }\end{array}\right] \cdot\left[\begin{array}{lll}\mu_{D y}^{\max } & \mu_{D y} & \mu_{D y}^{\min }\end{array}\right]$

Equation 5.8

The model does not accurately resolve water depths for sediment containing $100 \%$ sand, as that covers a range of water depths, but it does provide the maximum depth for $100 \%$ sand. 
Table 5.1 Significant wave height (Hs) and peak wave period (Tp) for the three modern transects (Monterey: Scripps Institution of Oceanography, 2018; Whanganui Bight and Manawatu: Metocean View, 2018).

\begin{tabular}{llllll} 
& $\begin{array}{l}\text { Significant } \\
\text { wave height } \\
\text { (Hs; } \mathrm{m})\end{array}$ & $\begin{array}{l}\text { Peak wave } \\
\text { period } \\
\text { (Tp; } \mathrm{s})\end{array}$ & Coordinates & $\begin{array}{l}\text { Water } \\
\text { depth }(\mathrm{m})\end{array}$ & Source \\
\hline $\begin{array}{l}\text { Monterey } \\
\text { Bay }\end{array}$ & 1.8 & 20 & $\begin{array}{l}36.760^{\circ} \mathrm{N} \\
121.948^{\circ} \mathrm{W}\end{array}$ & 168 & Buoy data \\
\hline $\begin{array}{l}\text { Whanganui } \\
\text { Bight }\end{array}$ & 2.4 & 20 & $\begin{array}{l}40.028^{\circ} \mathrm{S} \\
173.273^{\circ} \mathrm{E}\end{array}$ & 100 & $\begin{array}{l}\text { Hindcast } \\
\text { model }\end{array}$ \\
\hline & & & $40.2^{\circ} \mathrm{S}$ & & Hindcast \\
model
\end{tabular}

A significant assumption in applying a wave-graded grain size-water depth relationship to estimate paleowater depths is that the paleoshelf experienced a similar wave climate as today. Formation of deep water waves is dictated by wind velocity and fetch (Coastal Engineering Research Centre, 1984). In the Whanganui Bight, winds alternate between south westerlies to westerlies, with a significant northerly component (Figure 5.9a) and the strongest wind speeds blow from the direction of longest fetch direction inducing the largest swells (Figure 5.9b). In the present Taranaki embayment, there is a wind wave shadow from Cape Farewell Spit, which severely reduces the wave height south of Patea and further down the Manawatu coast (Figure 5.7; Figure 5.9c), illustrating the importance of fetch. Paleogeographic reconstructions would suggest that the uninterrupted fetch to the west of Whanganui remained unobstructed in the Pliocene (Figure 5.10).

Paleo wind velocity is harder to ascertain. Studies suggest that glacial periods are defined by an intensification and equatorward shift of winds in response to an expanding Antarctic sea-ice field (Shulmeister et al., 2004). Indeed, a poleward migration of the westerly wind belt is observed in the current warming climate (Hill et al., 2008). Mid-Pliocene glacials are viewed as comparable to present conditions (Haywood et al., 2013), while the interglacials represent warmer-than-present climates (Naish and Zwartz, 2012). However, relating the position of the westerly wind belt to 
wind speeds is difficult to predict. As the glacial-interglacial cycles of the mid-Pliocene are of much lower amplitude than those of the Late Pleistocene (for which the westerly wind belt response is referred to above), a wind climate not too dissimilar to present is an assumption made in this study in the absence of any available wind-field modelling. There are significantly more sophisticated calculations available to determine volume of sediment transport under shallow marine conditions, especially three dimensional near shore wave models (e.g. SWAN; Booji et al., 1999), accounting for wave diffraction, variable wave heights and directions. However, given the sparse datasets available for regional paleobathymetry necessary for such models, the application is not justified. 


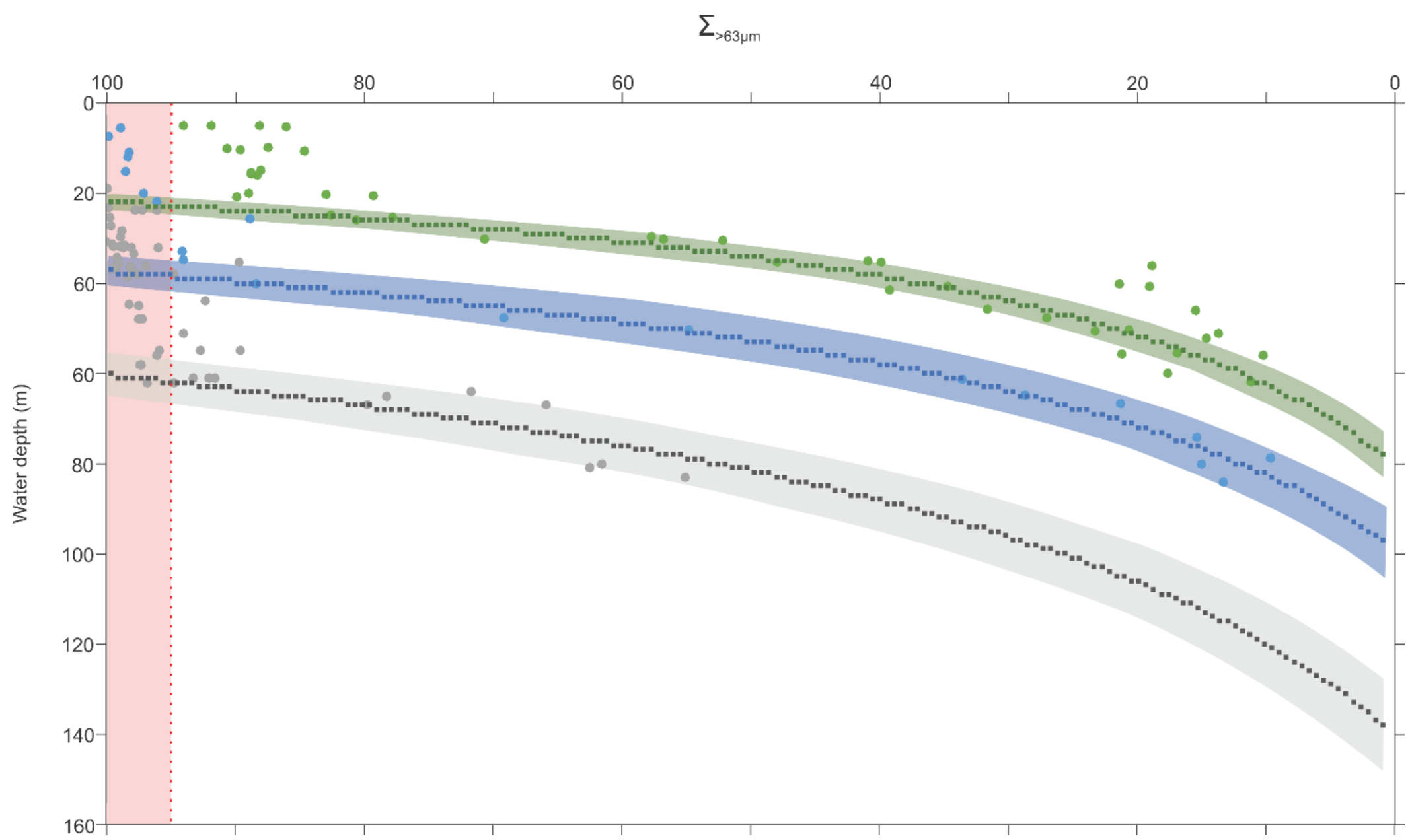

Figure 5.8 Observations of $\Sigma V_{>63}(\%)$ with water depth $(m)$ for three shelf transects (Manawatu: green, Dunbar and Barrett, 2005; Monterey Bay: blue, Chin et al., 1984 and Whanganui Bight: grey, Beaumont et al., 2013) in fill circles and respective model profiles (for wave parameters outlined in Table 5.1) in squares with the shaded bands representing the error described by Equation 5.8 (Appendix L). The red shaded band from $95-100 \% \Sigma V_{>63}$ represents a limit of the method where all water depths below the respective maximum contain $100 \% \Sigma V_{>63}$. 


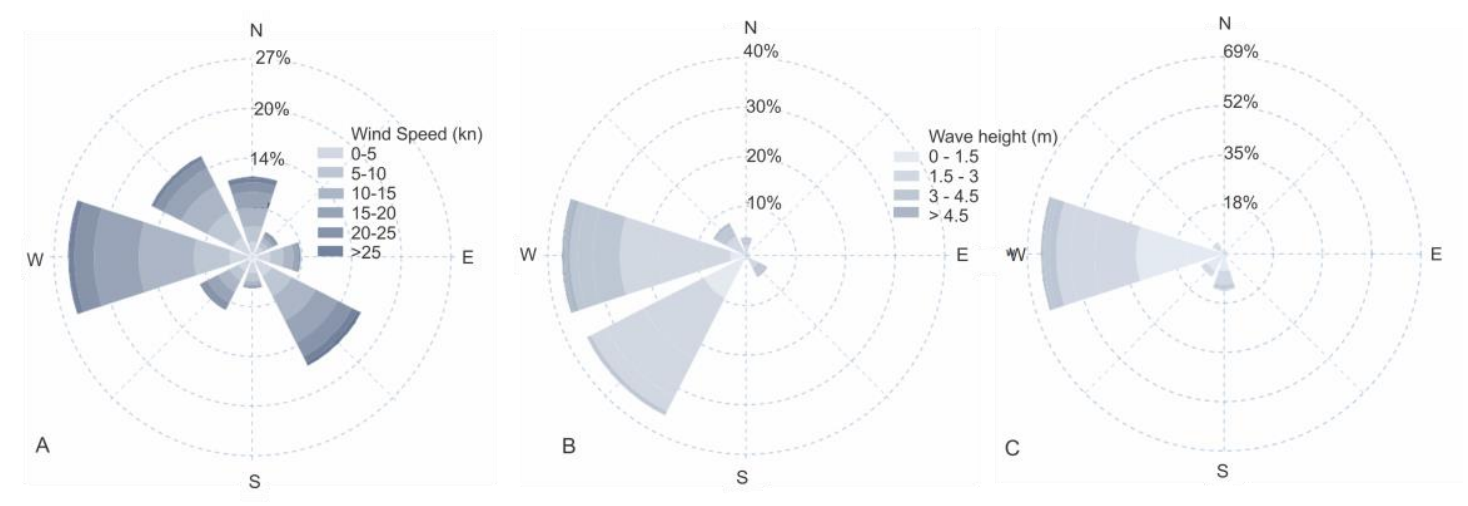

Figure 5.9 (a) Whanganui wind rose and (b) Wave height rose for the same location; (c) Manawatu wave height rose by percentage of occurrence (Metocean View, 2018).

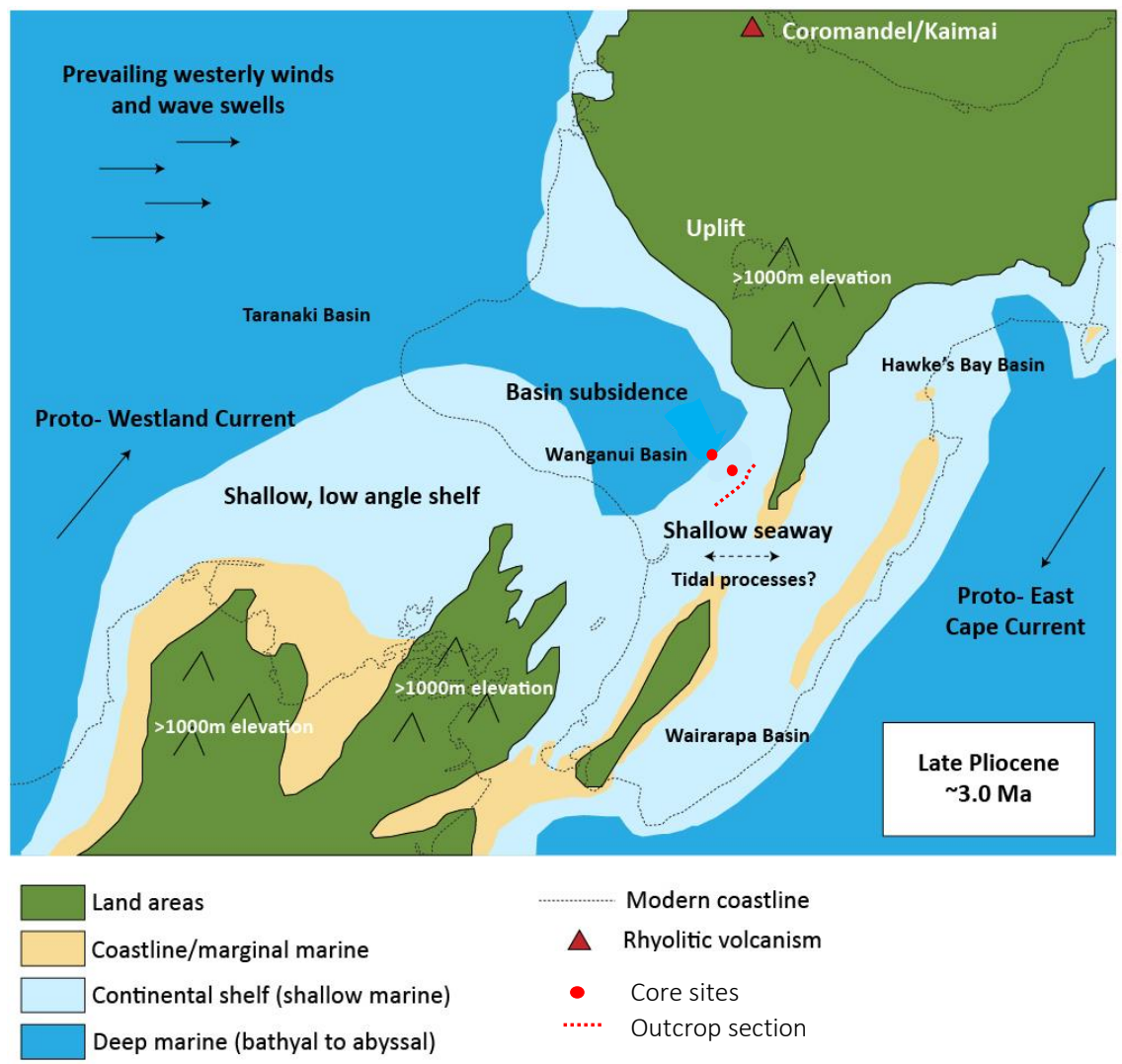

Figure 5.10 Paleogeographic reconstruction displaying open oceans to the west/south west, with the core and outcrop locations (Trewick and Bland, 2012).

In summary, a new development on established processes of sediment transport by waves, has provided a method of quantifying paleobathymetry, sensitive to small-scale sea-level variations. While a rather simple approach to quantifying the complex system of sediment 
transport and deposition on the shelf, this model has been able to predict the general response of sand percentage to changes in water depth in comparison to three modern transects (Figure 5.8). The use of sand percentage, rather than a more precise measurement of a single maximum grain size (a less sensitive measure of the sediment distribution on the seafloor), normalises the effect of the range of waves.

Application of this model to shallow-marine paleo-stratigraphy is made possible because of the limited data required to employ it, an understanding of the modern wave climate and paleogeography is also needed. While there remains uncertainty in the paleo wave climate assessment, the basin and orientation of the paleo shoreline with unimpeded fetch to the west, supports the interpretation of a similar wave climate to the modern (Figure 5.10).

\subsubsection{Mid- to late Pliocene paleobathymetry from the Whanganui Basin}

The grain size water depth model for the modern Whanganui transect was applied to the sand percentage for the Siberia-1 and Tiriraukawa-1 cores and outcrop of the Rangitikei River and Watershed Road Sections, and are displayed along with the Modern Analogue Technique paleowater depths from the foraminiferal census data (Figure 5.11; Appendix $\mathrm{H}$ and L). The Modern Analogue Technique results often over-estimate those depths calculated by the grain size method, but overall predict a similar range of depositional environments (inner, middle and outer shelf) that was previously estimated (see Chapter 4) supporting the suitability of the wave climate-grain size approach. The Modern Analogue Technique highlights the relative insensitivity of foraminiferal associations in contiguous shallow marine environments. This is in part due to using genera when particular species are more depth restricted, the presence of extinct genera in the paleo-assemblages, and other environmental variables that determine faunal abundance (Hayward et al., 2002).

The Utiku Sandstone recorded in the Rangitikei River Section is too shallow to record the full amplitude of the cycles. This is supported by the facies interpretation and sequence stratigraphy, whereby the lowstand and regressive systems tracts are not preserved due to lowstand subaerial exposure and erosion associated with each transgression, and the sand percentage is near $100 \%$ where the water depth-grain size model becomes insensitive. There 
is a localised deepening in the Utiku Sandstone shown at $500 \mathrm{~m}$ in the Rangitikei River Section and $\sim 150 \mathrm{~m}$ in the Tiriraukawa-1 core at $\sim 150 \mathrm{~m}$. This is possibly due to local faulting, which is not apparent in the Siberia-1 core. The Tiriraukawa-1 core is interpreted to represent deposition in the inner to upper middle shelf where the change in lithofacies is not as sensitive to changes in water depth. For these reasons, the Siberia-1 core, which shows regular glacialinterglacial cyclicity, is chosen to represent the most sensitive record for mid-Pliocene sea level.

The Mangaweka Mudstone, described in the Rangitikei and Watershed Road Sections, represents a significant deepening from the Utiku Group, and as such, the Rangitikei River Section records middle to outer shelf environments similar to the Siberia-1 core throughout the deposition of the Utiku Group. The Watershed Road Section, situated above the Tiriraukawa-1 core, is therefore deeper along the shelf transect, representing outer shelf environments where facies changes are less sensitive to changes in water depth. Due to this insensitivity and uncertainty of the stratigraphic thickness in the Watershed Road Section, the Rangitikei River Section is used to reconstruct paleobathymetry for late Pliocene sea level record. 


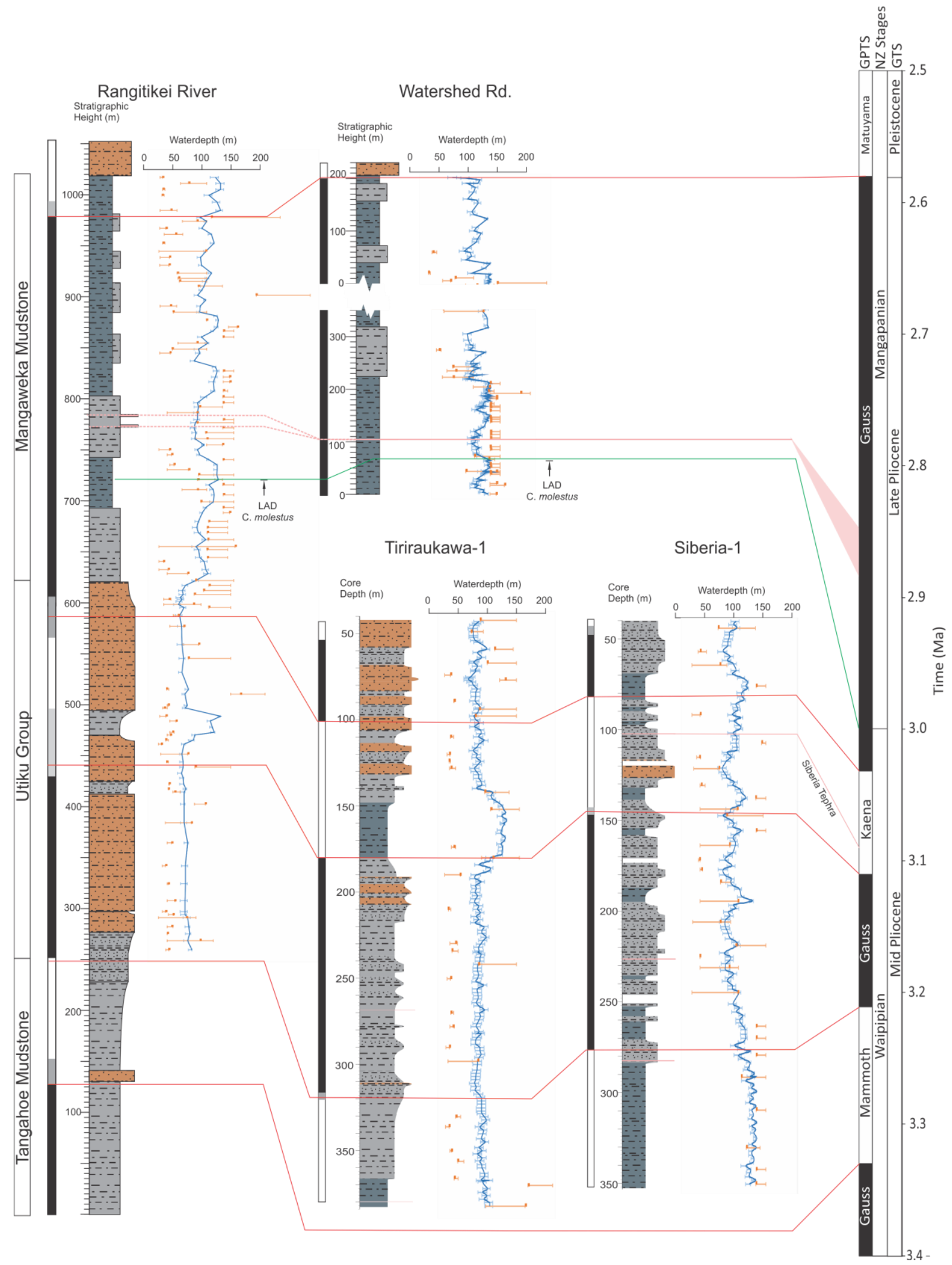

Figure 5.11 Paleobathymetric reconstruction for the Rangitikei River Section, Watershed Road Section and Tiriraukawa-1 and Siberia-1 cores. Depth estimates by Modern Analogue Technique (orange) where the error bars represent the minimum and maximum water depths of the analogues for each sample are shown. The grain size-water depth technique (blue) displays the error derived from the minimum and maximum water depth for a given sand \% (Appendix L). 


\subsection{Estimating relative sea-level (RSL)}

Local water depth changes recorded by any shallow-marine continental margin site, reflect a combination of relative sea-level (RSL) change, sediment accumulation and compaction, and basin subsidence (Figure 5.12). Backstripping is a well-established process of determining the influence of tectonic subsidence represented by the accommodation space, and the role of sediment and water loading, which allows the RSL (eustatic sea-level uncorrected for GlacioIsostatic Adjustment and thermal subsidence) to be isolated (e.g. Kominz and Pekar, 2001; Miller et al., 2012; Figure 5.12; Equation 5.4).

The composite stratigraphy from basement to cessation of sediment deposition is defined for the Siberia-1 core site and Rangitikei River Section to assess the effect of long-term tectonic subsidence on the paleobathymetric records developed in Section 5.1. Software provided by Prof. Michelle Kominz of Western Michigan University was used to calculate the sediment and water loading components for the long-term basin subsidence, prior to subtracting this from the high-resolution paleobathymetry to resolve a relative sea-level record (Kominz et al., 2008).

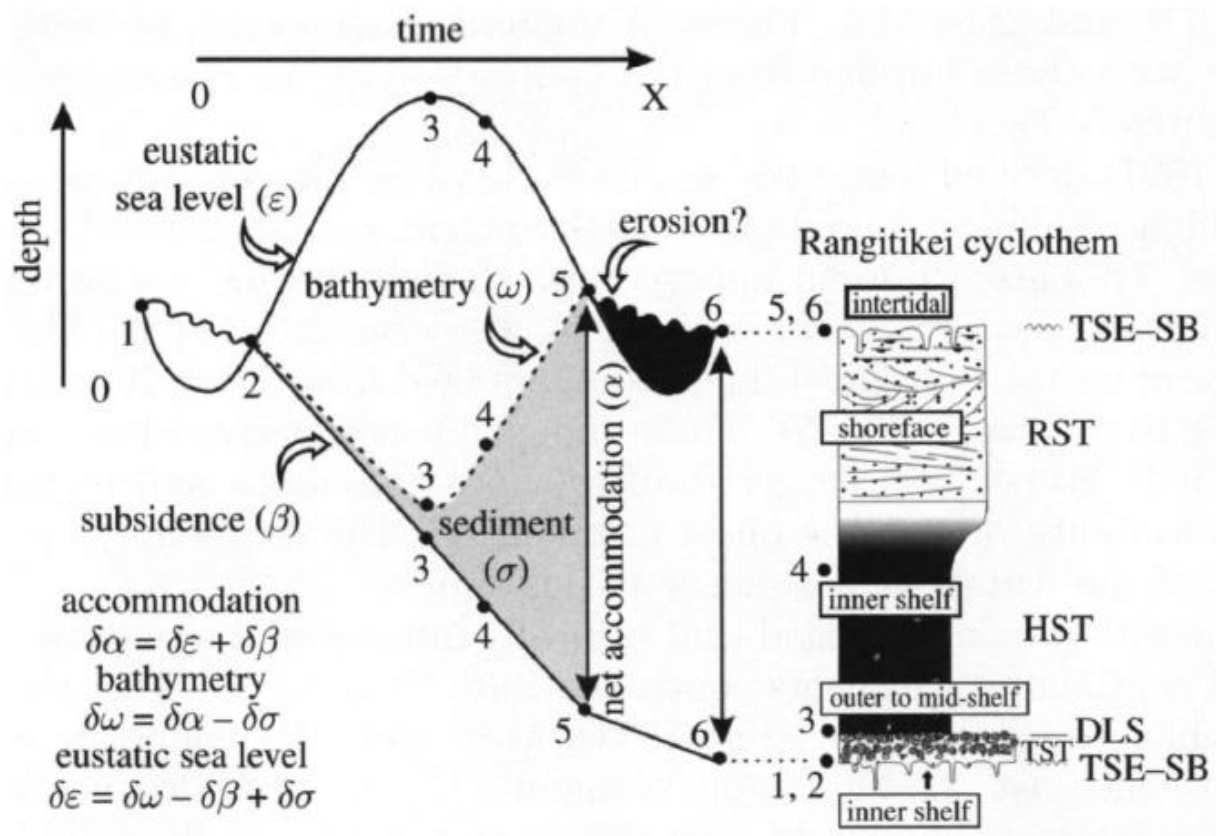

Figure 5.12 Schematic diagram displaying the relationship between accommodation space, sediment accumulation, bathymetry and eustatic sea-level for a Pleistocene Rangitikei cyclothem that experiences erosion during sea-level lowstand due to the amplitude of sea-level change and rate of basin subsidence (Naish and Wilson, 2009). 


\subsubsection{Backstripping method}

The one-dimensional backstripping method is expressed by Equation 5.9, where tectonic subsidence $(T s u b ; m)$ is quantified by the decompacted sediment thickness $\left(S^{*} ; \mathrm{m}\right)$ and subsequent loading (deformation) of the mantle $\left(\frac{p_{m-} p_{s}}{p_{m}-p_{w}}\right)$ as a function of the density of the mantle $\left(p_{m}\right)$, density of sediment $\left(p_{s}\right)$ and density of seawater $\left(p_{w}\right)$. From this, the change in RSL $(\triangle R S L ; m)$ corrected for water loading of the mantle $\left(\frac{p_{m}}{p_{m}-p_{w}}\right)$ is subtracted and the water depth $(W D ; m)$ which represents the depositional environment at the time of deposition of the unit is added (Equation 5.9). The tectonic subsidence (Equation 5.9a) is first calculated using the low-resolution dataset (Table 5.3) assuming no change in relative sea-level ( $\triangle R S L=0$ ). This result is used as the theoretical subsidence in Equation 5.9b in order to calculate the highresolution relative sea-level record, which is based on the high-resolution paleobathymetric records developed in the previous section to derive the RSL record.

$T s u b=S^{*} \cdot\left(\frac{p_{m-} p_{s}}{p_{m}-p_{w}}\right)+W D-\Delta R S L \cdot\left(\frac{p_{m}}{p_{m}-p_{w}}\right)$

Equation $5.9 a$

$\Delta R S L=\left[S^{*} \cdot\left(\frac{p_{m-} p_{s}}{p_{m}-p_{w}}\right)+W D-T s u b\right] /\left(\frac{p_{m}-p_{w}}{p_{m}}\right)$

Equation $5.9 b$

Tsub $=$ Tectonic subsidence $(\mathrm{m}) ; \mathrm{S}^{*}=$ Decompacted sediment thickness $(\mathrm{m}) ; \mathrm{pm}=$ mantle density $\left(3.18 \mathrm{~g} . \mathrm{cm}^{-3}\right)$; $\mathrm{ps}=$ density of sediment (lithology dependent; $\left.\mathrm{g} . \mathrm{cm}^{-3}\right) ; \mathrm{pw}=$ density of sea-water $\left(1.024 ; \mathrm{g} . \mathrm{cm}^{-3}\right) ; \triangle R S L=$ change in RSL (m); WD= water depth of depositional environment $(m)$.

This requires a basin deposition history, including the lithology, depositional environment, thickness and age of the stratigraphic units from the basement to the point of cessation of subsidence, including exhumed and eroded stratigraphy. Stratigraphic sections were defined for the Siberia-1 core site and a pseudo core site at the top of the Mangaweka Mudstone in the Rangitikei Valley. The pseudo core site was required because unit thicknesses are variable in the basin. The amount of exhumed and eroded material, which affects compaction of the previously underlying sediments, was determined by comparison of porosity (Equation 5.10) 
profiles from the Siberia-1 core and Rangitikei River Section outcrop to porosity-depth profiles compiled by Kominz et al., (2011; Equation 5.11 \& 5.12; e.g. Figure 5.13). This method estimated $975 \mathrm{~m}$ of subsequent erosion above the Utiku Group sandstone for the Siberia section (Figure 5.13) and $420 \mathrm{~m}$ above the Mangaweka Mudstone for the Rangitikei River Section.

$\left.\Phi=1-\left(\rho_{\mathrm{s}}-\rho_{\mathrm{w}}\right) /\left(\rho_{\text {quartz }}-\rho_{\mathrm{w}}\right)\right) * 100$

Equation 5.10

$\Phi_{\text {silt }}=75.5 e^{- \text {depth/1091 }}$

Equation 5.11

$\Phi_{\text {sand }}=54.5 e^{- \text {depth } / 1639}$

Equation 5.12

$\Phi=$ porosity $(\%) ; \rho_{\mathrm{s}}=$ observed sediment density; $\rho_{\mathrm{w}}=$ pore water $\left(1.024 \mathrm{~g} . \mathrm{cm}^{-3}\right) ; \rho_{\text {quartz }}=$ density of quartz $(2.65$ g. $\left.\mathrm{cm}^{-3}\right)$; depth $=$ depth buried to $(\mathrm{m})$.

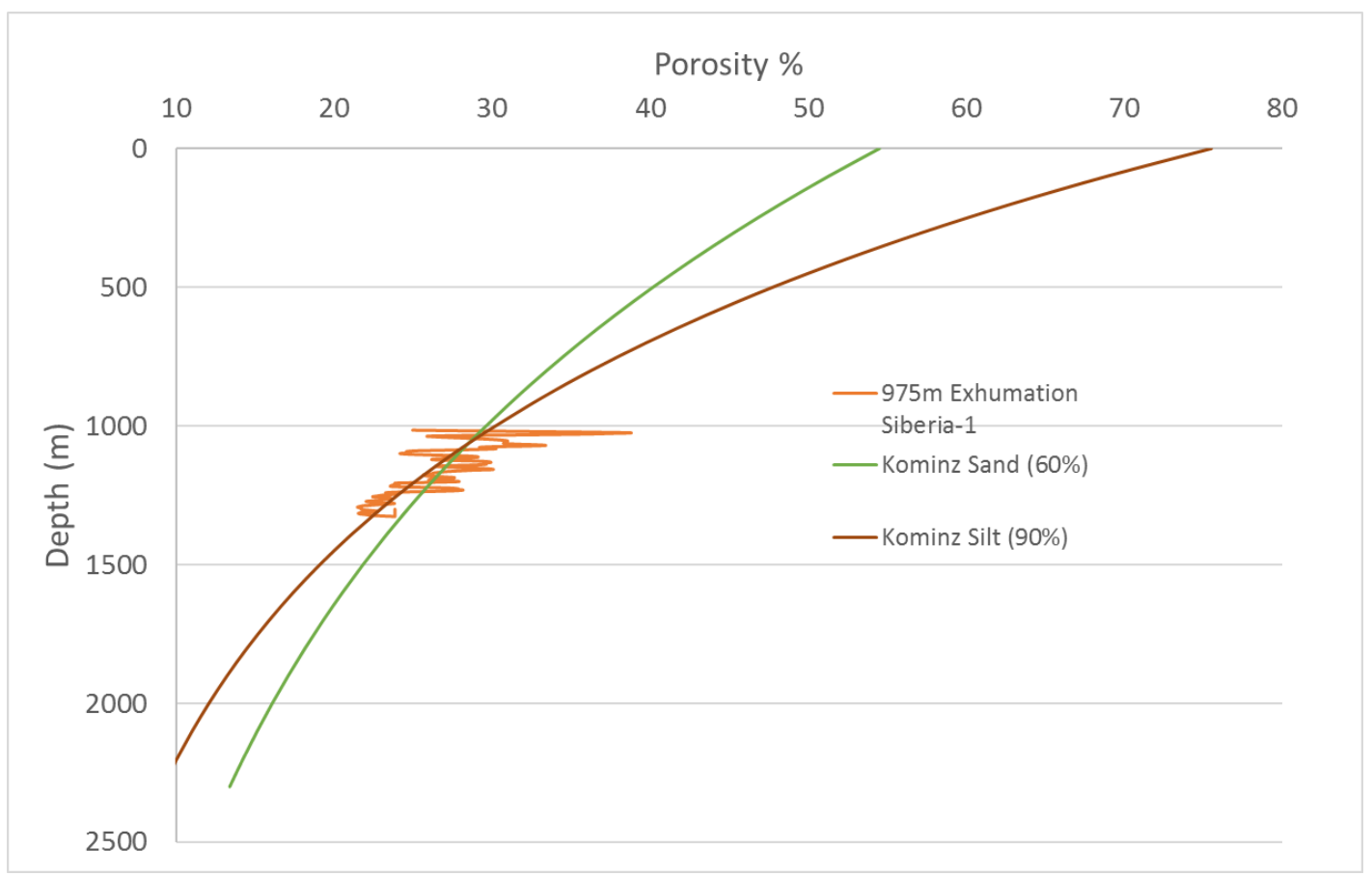

Figure 5.13 Depth of burial and thus amount of exhumation and erosion above the Siberia-1 core site, determined by the calculation of porosity (orange; Equation 5-5) from the density core log for Siberia-1 in comparison to porosity-depth curves previously determined for silt (brown; Equation 5-6) and sand (green; Equation 5-7) after Kominz et al. (2011). 
Cross sections were prepared by Prof. Peter Kamp of Waikato University, to provide the geological unit stratigraphy from basement, including the exhumed and eroded stratigraphy, by extrapolating thicknesses from the Stantiall-1 drill core (up dip $\sim 5^{\circ}$; Figure 5.14 ) for the Siberia-1 core and a Rangitikei pseudo-well. This was constrained by outcrop information (McGuire, 1989; Journeaux et al., 1996; Kamp et al., 1998) and regional geological mapping (Townsend et al., 2008), which also provided the lithology and depositional environments (Figure 5.14; Table 5.2). Ages of the units were obtained from the paleomagnetic study of Turner et al., (2005) and the age models outlined in Section 4.5. 


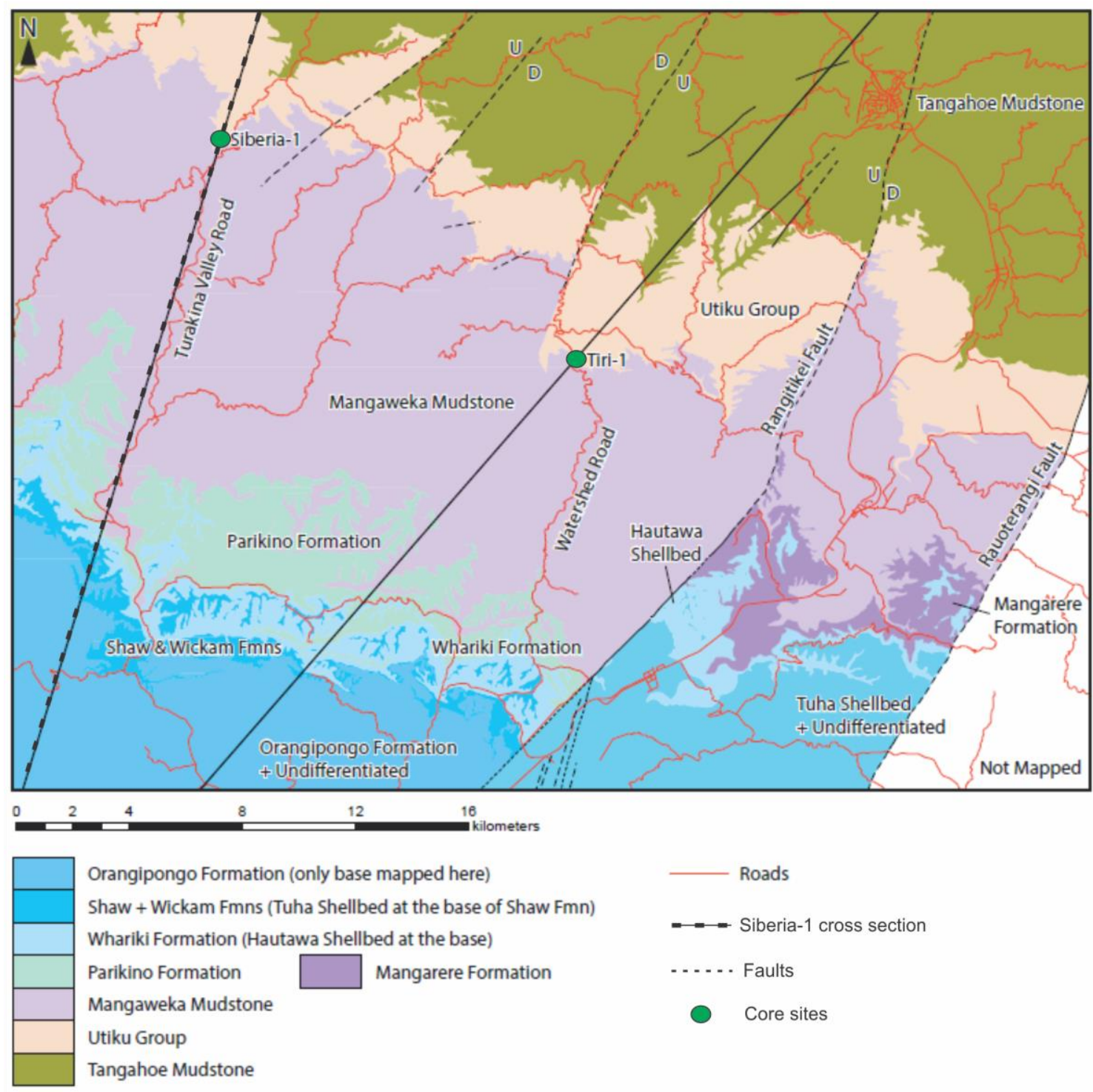

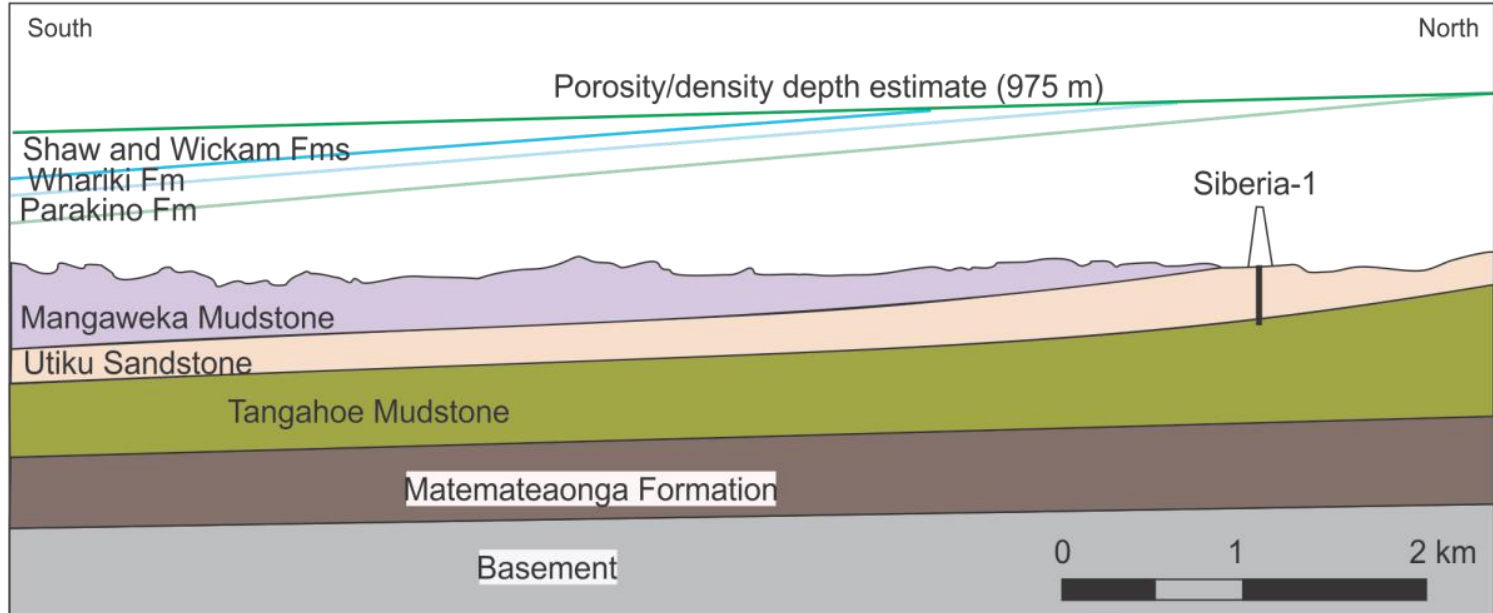

Figure 5.14 Geological map compiled by Prof. Peter Kamp with an example of the cross section from Siberia-1 drillcore to the coastal Stantiall1- exploration hole, focussing on the Siberia-1 site. This was used to determine unit thicknesses for the stratigraphic section, including exhumed material (projected formations). 
The stratigraphic information from which the input parameters are derived are outlined for each section in Table 5.2 (also used to bound the high-resolution datasets; Appendix M). The total Utiku Sandstone thickness determined by the cross-section, is more than was recovered in the core where the base of the Utiku Sandstone is marked by the top of the Mammoth paleomagnetic reversal. To reconcile these thickness differences, the additional thickness required is placed above the top of the core. The lower $\sim 70 \mathrm{~m}$ of the Siberia-1 core is assigned to the upper Tangahoe Mudstone Formation and represents a shallowing up sequence.

A linear sedimentation rate was applied from the top of the Kaena (3.032 Ma) in the Utiku Group to the Gauss/Matuyama boundary (2.581 Ma) to date the base of the Mangaweka Mudstone to $2.96 \mathrm{Ma}$. The age of the base of the Siberia-1 core, which includes sediments assigned to the Tangahoe Mudstone (>3.207 Ma), was also determined by linear sedimentation rates to the base of the Tangahoe Mudstone (4.19 Ma).

The paleowater depths assigned to the depositional environments are as follows: inner shelf (20-50 m), mid shelf (50-100 m), outer shelf (100-200 m) and the upper slope (200-400 m), unless otherwise indicated. The water depths and ages are assigned to the top of each unit, thus describing shallowing- or deepening-up over a unit from the top of the previous section (Table 5.2). More detailed paleobathymetry available for the Utiku Sandstone and Mangaweka Mudstone allow for more precise modelling.

The lithology and unit thickness, and therefore, depth in the section are used to calculate the original porosity (occupied by sea water) and to determine the decompacted thickness ( $S^{*}$; decompacted sediment thickness; Figure $5.15 \& 5.16)$ to provide the subsidence derived from sediment loading $S^{*} .\left(\frac{p_{m-} p_{s}}{p_{m}-p_{w}}\right)$ in Equation 5.4a (Tsubs sed in Figure 5.15 \& 5.16). The tectonic subsidence is first calculated with static sea-level $(\triangle R S L=0)$ to be the sum of the water depth (WD) and subsidence corrected for sediment loading (Equation 5.4a), using unit thicknesses and information from Table 5.2 (Figure $5.15 \& 5.16$ ). 
Table 5.2 Input parameters for the long-term backstripping for the two stratigraphic sections (Siberia-1 and Rangitikei pseudocore). The depositional environments (which dictate the water depth range), lithology (for porosity calculation), age of units (rate of subsidence) and stratigraphic thickness of each unit (to determine the decompacted sediment thickness) are required for the total stratigraphic section from the basement (including exhumed material).

\begin{tabular}{|c|c|c|c|c|c|c|c|}
\hline \multicolumn{6}{|c|}{ Siberia-1 } & & \\
\hline Formation Name & Depth $(\mathrm{m})$ & Thickness (m) & $\begin{array}{l}\text { Age of } \\
\text { top (Ma) }\end{array}$ & Lithology & $\begin{array}{l}\text { Depositional } \\
\text { Environment }\end{array}$ & \multicolumn{2}{|c|}{ Waterdepth range $(\mathrm{m})$} \\
\hline \multirow{2}{*}{ Whakaihuwaka } & 0 & 22 & 2.39 & Sandstone & Inner shelf & 20 & 50 \\
\hline & 22 & 32 & 2.41 & Mudstone & Mid shelf & 50 & 100 \\
\hline \multirow{2}{*}{ Whauteihi Fmn } & 54 & 14 & 2.43 & Sandstone & Inner shelf & 20 & 50 \\
\hline & 68 & 2 & 2.46 & Siltstone & Mid shelf & 50 & 100 \\
\hline U.Moukuku Fmn & 70 & 19 & 2.48 & Sandstone & Inner shelf & 20 & 50 \\
\hline Mangaweka & 89 & 20 & 2.58 & Mudstone & Outer shelf/upper & 100 & 200 \\
\hline Rest of Mangaweka & 109 & 877 & & Mudstone & Outer shelf/upper & 95 & 95 \\
\hline Utiku & 986 & 34.64 & 2.96 & Sandstone & Mid shelf & 100 & 100 \\
\hline Siberia -1 & 1020.64 & 239.36 & 2.981 & Sandstone & Mid shelf & 105 & 105 \\
\hline Tangahoe & 1260 & 655 & 3.207 & Siltstone & Mid to upper slope & 140 & 140 \\
\hline Paraconformity & 1915 & 1 & 4.19 & Siltstone & Mid slope (400 m) & 200 & 400 \\
\hline Matemateaonga & 1916 & 498 & 4.72 & Muddy Sandstone & Mid shelf & 20 & 100 \\
\hline Top of Basement & 2414 & & 5.66 & & & & \\
\hline & & & & & & & \\
\hline \multicolumn{8}{|c|}{ Rangitikei Pseudo Core } \\
\hline Formation Name & Depth $(\mathrm{m})$ & Thickness (m) & $\begin{array}{l}\text { Age of } \\
\text { top (Ma) }\end{array}$ & Lithology & $\begin{array}{l}\text { Depositional } \\
\text { Environment }\end{array}$ & \multicolumn{2}{|c|}{ Waterdepth range $(\mathrm{m})$} \\
\hline Makohine & 0 & 40.8 & 1.782 & Sandstone & Inner shelf & 5 & 50 \\
\hline Orangipongo & 40.8 & 110.1 & 1.99 & Sandy Mudstone & Inner to mid shelf & 20 & 70 \\
\hline Ohingahiti & 150.9 & 81.6 & 2.146 & Sandy Mudstone & Inner to mid shelf & 5 & 50 \\
\hline Whariki & 232.5 & 90.1 & 2.236 & Sandy Mudstone & Inner to mid shelf & 50 & 120 \\
\hline Magarere & 322.6 & 100.2 & 2.273 & Sandy Mudstone & Inner to mid shelf & 20 & 120 \\
\hline Mangaweka & 422.8 & 397 & 2.544 & Mudstone & Mid to outer shelf & 110 & 110 \\
\hline Utiku & 819.8 & 193.2 & 2.96 & Sandstone & Inner shelf & 80 & 80 \\
\hline Tangahoe & 1013 & 940 & 3.207 & Mudstone & Mid slope (400 m) & 100 & 200 \\
\hline Paraconformity & 1953 & 0.4 & 4.19 & Siltstone & & 200 & 400 \\
\hline Matemateaonga & 1953.4 & 400 & 4.72 & Muddy Sandstone & Inner to mid shelf & 20 & 100 \\
\hline Top of Basement & 2353.4 & & 5.131 & & & & \\
\hline
\end{tabular}




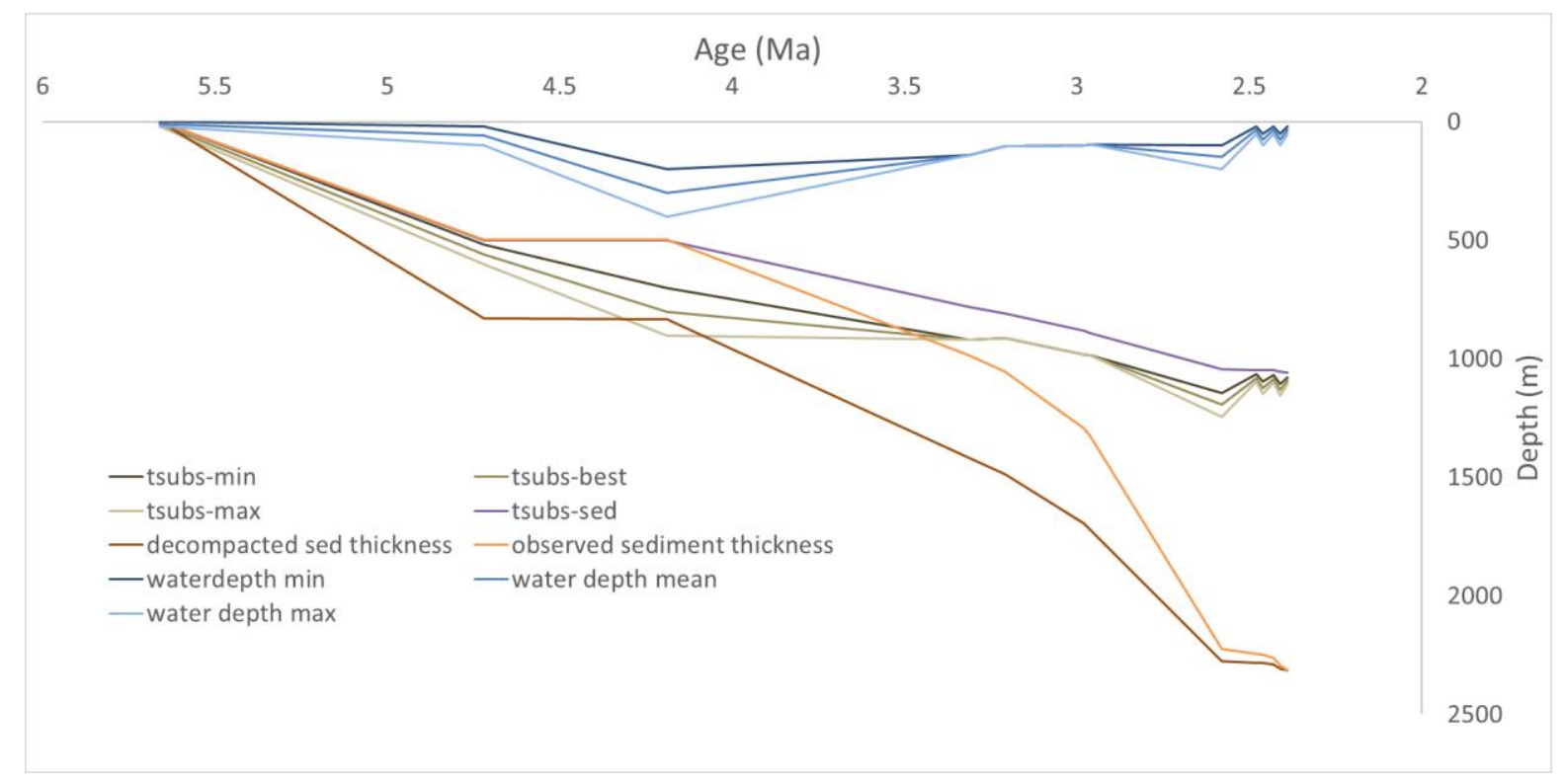

Figure 5.15 Backstripping results for the long-term dataset of the Siberia-1 section (Table 5.2). Where Tsubmin, max and best, represents the tectonic subsidence (Tsub) of equation 5.4, and the minimum and maximum are a result of the range of water depth min , max, mean. The stratigraphy of the core and Mangaweka Mudstone outcrop have a well constrained mean water depth of deposition and thus show no associated max or min for the Tsub. A comparison between the observed sediment thickness and decompacted thickness are displayed, along with the tectonic subsidence induced by sediment loading (tsubssed).

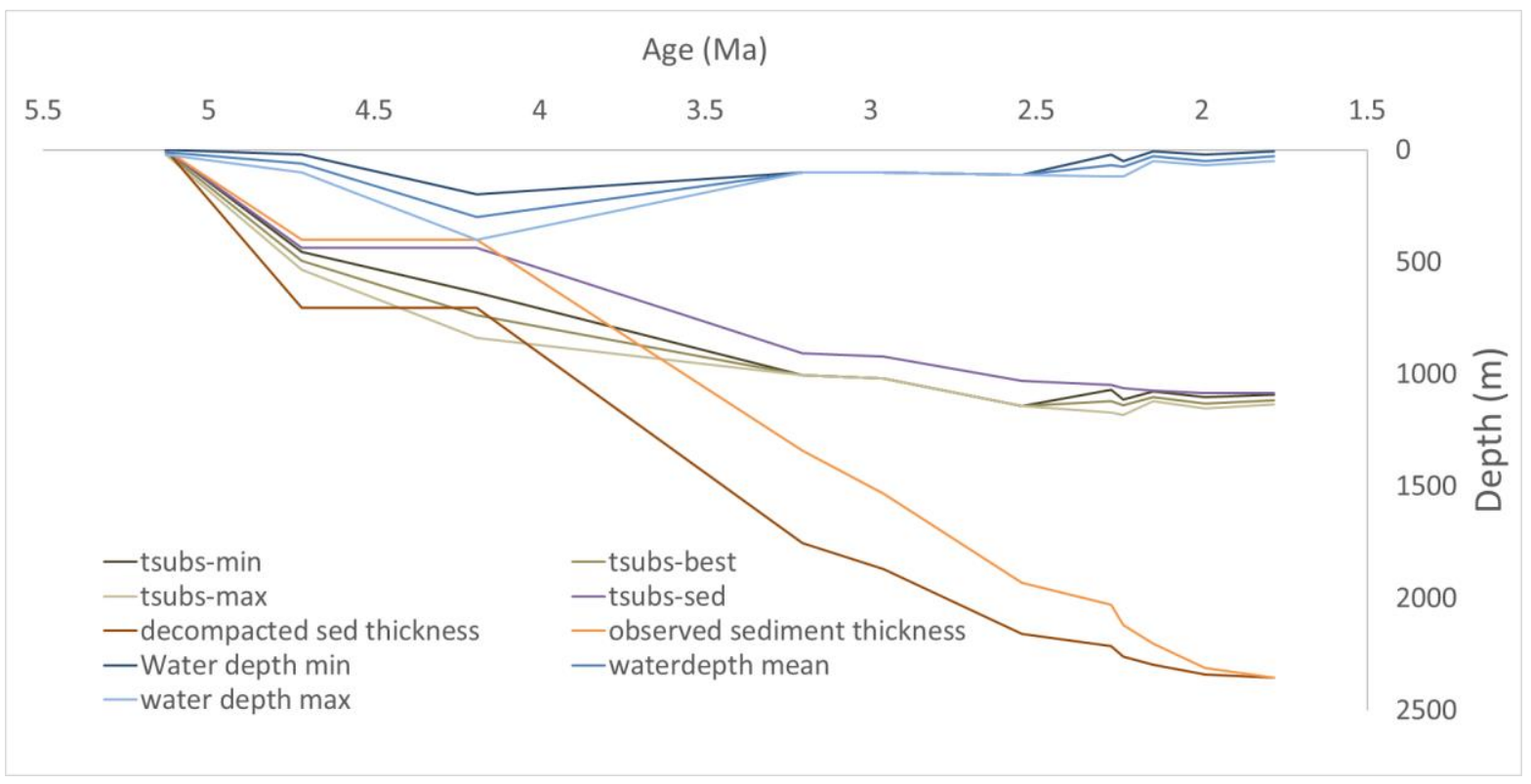

Figure 5.16 Backstripping results for the long-term dataset of the Rangitikei pseudo-well section (Table 5.3). Where Tsub min, max and best, represents the tectonic subsidence (Tsub) of equation 5.4, and the minimum and maximum are a result of the range of water depth min, max and mean. The stratigraphy of the core and Mangaweka Mudstone outcrop have a wellconstrained mean water depth of deposition and thus show no associated max or min for the Tsub. A comparison between the observed sediment thickness and decompacted thickness are displayed, along with the tectonic subsidence induced by sediment loading (tsubs-sed). 
RSL change for the Siberia-1 core and the Rangitikei pseudo-well were calculated by determining long term tectonic subsidence, from the broadly defined water depth constraints of the Utiku Sandstone and Mangaweka Mudstone (Equation 5.7a; where $\Delta \mathrm{SL}=0$; Figure 5.15 \& 5.16; Appendix M). The tectonic subsidence is then used in Equation 5.7b, along with the stratigraphy and paleowater depth properties of the high resolution datasets established in this study for the Utiku Sandstone and Mangaweka Mudstone, to resolve change in RSL ( $\triangle R S L$; Figure 5.17a \& b; Appendix M). These datasets include more detailed stratigraphy and accurate lithological information for calculating porosity. The water depths derived from the grain size technique with the error (explained in depth below), results in the mean, minimum and maximum RSL (Figure 5.17).

Relative sea-level calculated this way is not registered to a fixed datum (e.g. modern sea level) but does provide an estimate of the amplitude of sea-level cycles (Figure 5.17a \& b). The "HF sed" presented in Figure 5.17a \& b, represents the difference between the sediment loading of low-resolution and the high-resolution record. 

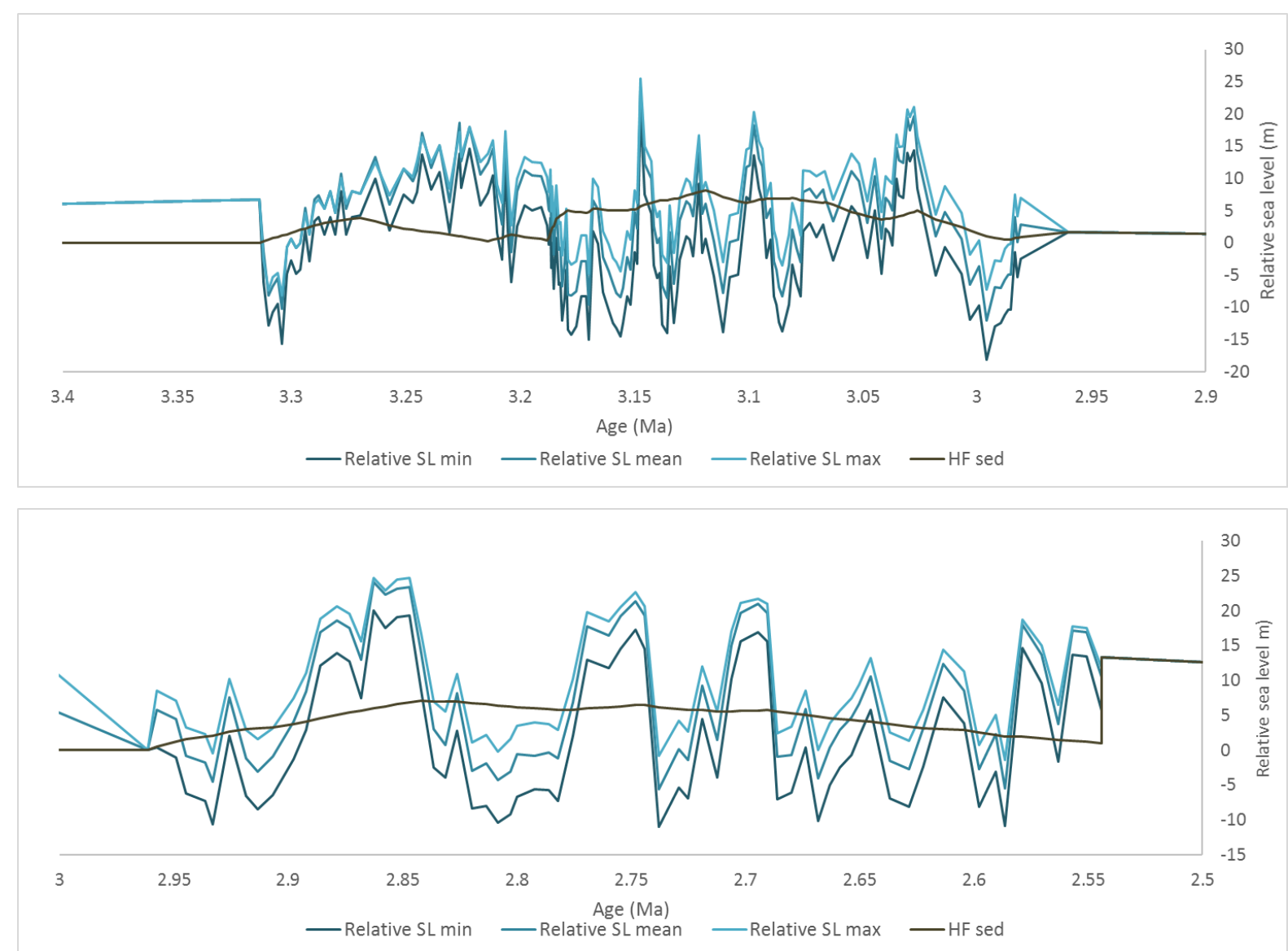

Figure 5.17 Relative sea-level (SSL; Equation 5.4b) for the high-resolution a) Siberia-1 (top figure) and b) Rangitikei pseudo-well (bottom figure). Where the RSL min, max and mean are now the product of the water depths derived from the grain size technique with the error determining the maximum and minimum water depths. The HFsed, represents the difference between the sediment loading of the long-term datasets (Table 5.3; Figures 5.15 \& 5.16) and the high-resolution datasets (Appendix M).

\section{Sources of Error}

\section{Paleobathymetry reconstruction}

A correlation between sand percentage and maximum grain size (Figure 5.3) was determined to address the relationship between the large range of grain sizes at a point on the seafloor and the single grain size used in Equation 5.3 that determines the critical velocity required for sediment transport. The maximum grain size is taken to represent the maximum velocity, which could also transport finer grain sizes. A linear relationship of the weighted mean for each maximum grain size and mean percentage error of deviation from the weighted mean to the linear relationship was used to describe the range of estimated sand percentage from the maximum grain size (Figure 5.3). The water depth threshold (for a specific wave climate) calculated for a maximum grain size, was then associated with a mean, minimum and 
maximum sand percentage. The sand percentage determined from grain size analysis of the core and outcrop sediments was taken as the mean and the associated error of sand percentage provided minimum and maximum water depths (Appendix L). As shown in Figure 5.3 , the error of calculating sand percentage nearing 0\% was smaller than that nearing $100 \%$ and as such the water depth error is larger at shallower depths (Figure 5.8).

Determining the correct wave climate for the paleo climate, has significant uncertainties with estimating the wind field strength and regional paleobathymetry. Figure 5.5 describes the water depth sensitivity of sediment transport for different wave periods and wave heights. This shows that wave period is of most significance, related to fetch, which paleogeographic reconstructions show is unimpeded from the predominant westerly direction during the Pliocene (Figure 5.10) and that the relative water depth difference becomes insensitive for wave heights larger than 2.2 $\mathrm{m}$ (Figure 5.5).

\section{Backstripping}

Higher rates of tectonic subsidence, exceeding the rate of sediment accumulation, results in an overall deepening of the depositional environment, while lower rates of subsidence result in a lower rate of deepening, or shallowing if less than sediment accumulation. Backstripping accounts for the influence of tectonic subsidence on the paleobathymetry curve in order to estimate RSL. If sediment supply keeps pace with subsidence, then any reconstructed water depth change will largely reflect RSL change. Thus, the rate of subsidence is therefore the product of decompacted sediment thickness, age and paleobathymetry. The age of the sediments is well-established in the Whanganui Basin, while estimating the thickness of the sediments including restoring eroded material is complicated, and constraining this uncertainty is unviable. However, sensitivity analyses have been undertaken. The Mangaweka Mudstone section displays the most relatively stable depositional environment, characterised by a massive mudstone lithology, following the initial deepening from the top of the Utiku Sandstone. Two deepening scenarios over the length of the Mangaweka Mudstone are undertaken to assess the range of uncertainty in the amplitude of reconstructed glacialinterglacial sea-level, introduced by possibly determining unit paleobathymetry incorrectly. The deepening from the top of Utiku Sandstone to the top of the Mangaweka Mudstone was 
changed in the long-term dataset for two scenarios: 1) Utiku $60 \mathrm{~m}$, Mangaweka $130 \mathrm{~m}$ and 2) Utiku $110 \mathrm{~m}$, Mangaweka $140 \mathrm{~m}$. All other parameters were kept the same. The initial paleobathymetry, based on the reconstructed high-resolution records, was $80 \mathrm{~m}$ for the top of the Utiku Sandstone and $110 \mathrm{~m}$ for the top of the Mangaweka Mudstone (ignoring the deepening that occurred immediately with the deposition of the Mangaweka Mudstone). The results are displayed in Figure 5.18 and show a consistent offset in RSL between the two scenarios but with no difference in the relative amplitudes.

The differences between the maximum and minimum water depth estimates are variable for all the scenarios based on the long-term subsidence, but the relative difference does not change.

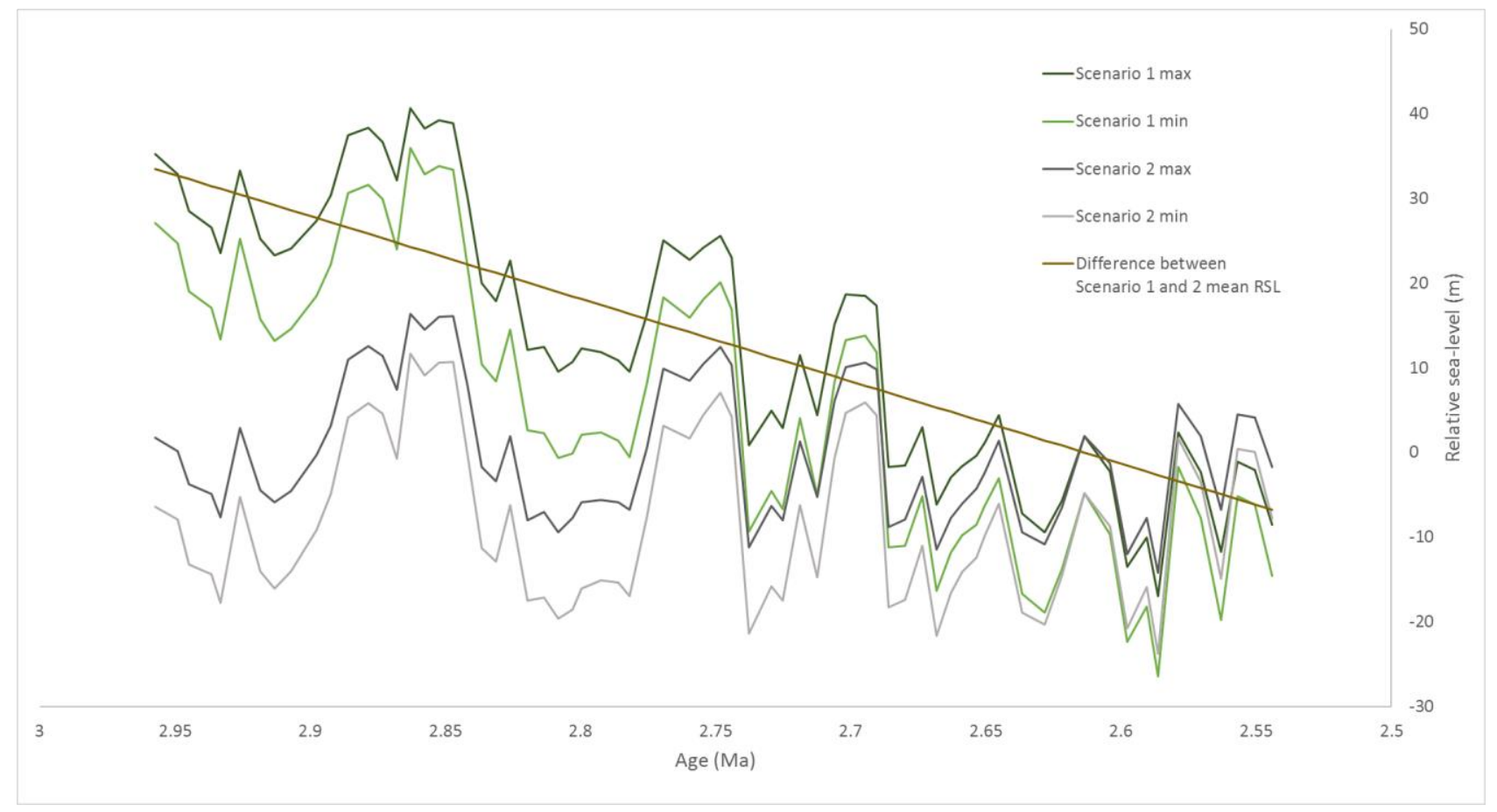

Figure 5.18 Relative sea-level maximum and minimum estimates for two scenarios (Scenario 1 deepening 60-130 m; Scenario 2 deepening from 110-140m) testing the effect of subsidence rates on relative sea-level amplitudes. 


\subsubsection{Relative sea-level record}

The depositional environments reconstructed for the Siberia-1 core and the Rangitikei River Section provide the most sensitive paleobathymetric records for the sediments of the Utiku Group and Mangaweka Mudstone, deposited on the middle to outer shelf (Chapter 4). The subsequent backstripping to account for tectonic subsidence, provides a near-continuous relative sea-level record from Whanganui Basin, New Zealand, unprecedented in temporal resolution (Figure $5.17 \mathrm{a} \& \mathrm{~b}$ ). The $\sim 20 \mathrm{kyr}$ break between the two records present at the top of the Siberia-1 core is coincident with the base of the Mangaweka Mudstone and corresponds to the well-documented non-eustatic deepening at this time (e.g. Kamp et al., 1998).

Figure 5.19 displays the combined RSL record for the Whanganui Basin. The amplitude of glacial-interglacial RSL is rescaled from previous figures, to better display the amplitude of consecutive cycles previously categorised by sequence stratigraphy in Chapter 4 (Figure 5.19). The $y$-axis is oriented so that lower sea level values are associated with shallowing sequences representing glacials. The amplitudes and associated error are presented in Table 5.3.

The reconstructed RSL record begins with a prominent glacial at $3.3 \mathrm{Ma}$, coincident with the M2 glaciation (Lisiecki and Raymo, 2005). There are 14 semi-symmetric cycles identified in the mid-Pliocene record, spanning 3.33-2.98 Ma (350 kyr) occurring at a frequency of 25 kyr, near the precession band (19-23 kyr). Three larger asymmetric cycles are also evident, of 100 kyr in length, indicating eccentricity modulation of precession-paced sea-level changes in the mid-Pliocene (Figure 5.19). The amplitudes primarily lie between $\sim 10-20 \mathrm{~m}$ with an average of $18 \mathrm{~m} \pm 6-8 \mathrm{~m}$. The shallowing from the Tangahoe Mudstone to Utiku Sandstone is detrended in the backstripping process to a variable trend from $3.3-3.2 \mathrm{Ma}$ not recorded in the paleobathymetry or grain size.

The late Pliocene record contains eleven significant sea level cycles in $450 \mathrm{kyr}(2.95-2.5 \mathrm{Ma})$, with an average frequency of $41 \mathrm{kyr}$, the orbital period of obliquity, and an average amplitude of $18 \pm 8 \mathrm{~m}$. There are higher frequency peaks of small amplitude $(<10 \mathrm{~m})$, superimposed on the larger 15-25 m amplitude, 41 kyr cycles (Figure 5.19). 


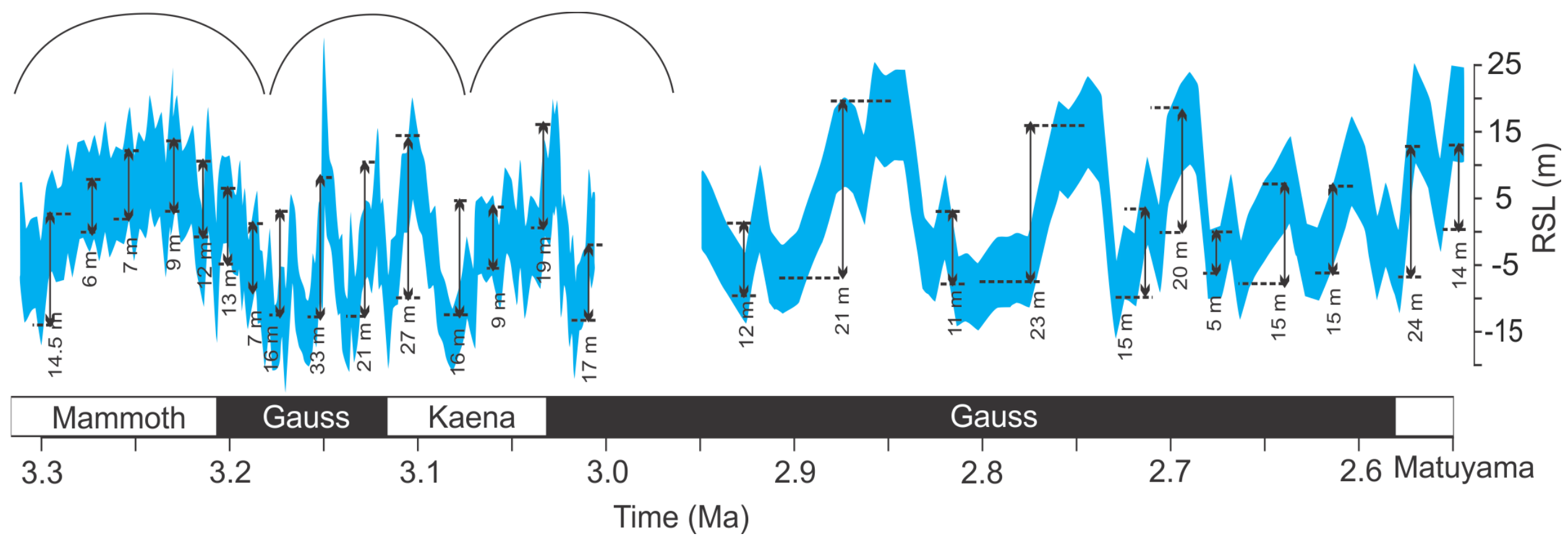

Figure 5.19 Relative sea-level record for the mid-to late Pliocene, with the thickness of the shaded band representing the maximum and minimum estimates. The noted amplitudes of the cycles are taken from the mean values of each peak and trough and the error is variable. While the Rangitikei and Siberia sections can be placed on the same scale, there is no relevance in the baseline shift between sections, which is a product of the backstripping. The semi-circles are highlighting the longer frequency 100 kyr cycles in the MPWP. 
Table 5.3 Mean amplitude of glacial-interglacial sea-level cycles with error defined by Equation 5.8.

\begin{tabular}{crr}
\multicolumn{1}{l}{$\begin{array}{l}\text { Age } \\
\text { (Ma) }\end{array}$} & \multicolumn{1}{l}{ RSL } & \\
\hline 2.55 & 14.14 & $\sigma(\mathrm{m})$ \\
\hline 2.57 & 24.27 & 6.92 \\
2.61 & 15.39 & 6.54 \\
2.65 & 15.09 & 6.34 \\
2.67 & 6.62 & 6.14 \\
2.70 & 19.64 & 6.79 \\
2.72 & 15.29 & 5.94 \\
2.76 & 22.50 & 6.62 \\
2.79 & 5.69 & 4.12 \\
2.82 & 7.31 & 5.97 \\
2.86 & 10.93 & 7.13 \\
2.89 & 20.86 & 6.37 \\
2.92 & 12.19 & 5.98 \\
3.01 & 17.01 & 5.63 \\
3.03 & 18.55 & 6.55 \\
3.05 & 8.77 & 6.20 \\
3.07 & 16.07 & 5.56 \\
3.11 & 26.79 & 6.16 \\
3.13 & 20.79 & 5.92 \\
3.15 & 32.68 & 6.51 \\
3.17 & 15.96 & 5.74 \\
3.19 & 7.34 & 6.14 \\
3.20 & 13.14 & 6.54 \\
3.23 & 11.97 & 7.57 \\
3.25 & 8.79 & 7.76 \\
3.26 & 7.20 & 7.90 \\
3.28 & 5.94 & 7.87 \\
3.29 & 14.55 & 7.60 \\
\hline & & \\
\hline
\end{tabular}




\subsection{Glacio-isostatic adjustment of eustatic sea level}

The term "eustasy" was used to describe global uniform sea-level changes as a result of ocean volume variation (Suess, 1906). This implies that the solid Earth is rigid and that gravity is neglected (Spada and Stocchi, 2007). This view stipulates that the oceans behave like a bathtub, in that eustatic sea level (ESL) change does not depend on the geographical location (Hay et al., 2014). RSL changes are governed by GIA, which incorporates the coupled effects of solid Earth deformations, gravitational perturbations and eustasy as well as Earth rotation and coastline migrations as a consequence of ice- and water-loading variations.

Far-field sites, such as Whanganui Basin, are less affected by GIA, on glacial-interglacial timescales compared to sites proximal to large ice sheets (Andrews, 1970). However, the instantaneous gravitational effect determines how GMSL is expressed regionally (Woodward, 1888). More specifically, during glaciation, sea-level is drawn upwards towards expanded ice sheets, while during deglaciation and the loss of gravitational attraction lowers sea-level in the near-field and increases it in the far field (e.g. Raymo et al., 2011; Rovere et al., 2016). By this process, in combination with subsidence around the glaciated margin during glaciation, a RSL rise may be observed at proximal sites and a RSL fall during deglaciation. Moreover, if mass loss is greater from one of the polar ice sheets than the other (e.g. the Antarctic) then RSL rise will be relatively more in the opposing hemisphere (e.g. Northern Hemisphere). This emphasises the difficulty in resolving GMSL or ESL from global RSL records. As such, the RSL record from Whanganui Basin may under or overestimate ESL depending on the meltwater source.

While the source of meltwater cannot be derived from the Whanganui Basin RSL curve, the amplitude of the RSL cycles throughout the MPWP cannot be accounted for from loss of the Greenland Ice Sheet (GIS) alone ( 7 m SLE; e.g. Hill et al., 2010). Significant continental Northern Hemisphere ice at this time is also precluded by climate and ice sheet models and geological data, which imply intensification of glaciation from about $\sim 2.7 \mathrm{Ma}$ (Jansen et al., 2000; Haug et al., 2005; Lunt et al., 2008; Brigham-Grette et al., 2013; Hill et al., 2010; Dolan et al., 2015). Thus, an Antarctic Ice Sheet (AIS) dominant source is tested for a range of ESL scenarios including an absent GIS, 5 m loss from GIS in phase, with loss from AIS and $5 \mathrm{~m}$ loss 
from GIS anti-phased with AIS melt (if precession-paced). The GIA modelling was undertaken by Dr. Paolo Stocchi of the Royal Netherlands Institute of Sea Research.

\subsubsection{GIA models}

The contribution of GIA to regional RSL changes can only be evaluated by means of forward process-based numerical modelling. The numerical models that account for all the relevant hydro- and glacio-isostatic feedbacks combine a pre-defined ice sheet geometry, and a solid Earth model that responds to the loading variations.

Farrell and Clark (1976) define the change of sea-level as a function of space and time $(S(\omega, t)$; Equation 5.8).

$S(\omega, t)=\frac{\phi}{\gamma}-U+c$ Equation 5.13

Where $\phi$ is incremental perturbation of the gravitational potential, $\gamma$ is the gravity acceleration at the Earth's surface, $U$ is the vertical displacement of the solid Earth's surface and $\mathrm{c}$ is a timedependent function. In Equation 5.13, $S$ is the sea-level change measured vertically, representing the RSL change.

The sea-level equation (Equation 5.13; Farrell and Clark, 1976) is solved using the SELEN Fortran 90 program (Mitrovica and Peltier, 1991; Spada and Stocchi, 2007). Ice sheet thickness variations are coupled to time-dependent, solid Earth responses, here, described by symmetric 20 kyr-paced glacial-interglacial cycles. The solid Earth is taken to be a radially-symmetric sphere, self-gravitating, rotating and deformable, but not compressible (Spada et al., 2004). The glacial state for the ice sheet models are defined as the extent at the Last Glacial Maximum (LGM), while the interglacial state is represented by present-day, with the simulation beginning at a configuration mid-way between these two conditions. Meltwater contributions are sourced by a linear scaling of ice-thickness continent wide. 
The sea-level equation was solved for three ESL values (15 m, $20 \mathrm{~m}$ and $25 \mathrm{~m}$ ) which describe a range of RSL amplitude recorded in Whanganui Basin. Scenario 1 specifies Antarctic contribution exclusively; Scenario 2 includes a $5 \mathrm{~m}$ contribution from the GIS in phase with AIS contributions; Scenario 3 increases the AIS contribution by $5 \mathrm{~m}$ to offset $5 \mathrm{~m}$ from the GIS antiphase (Table 5.4).

Table 5.4 Three scenarios of Antarctic Ice Sheet and Greenland Ice Sheet meltwater contribution to $15 \mathrm{~m}, 20 \mathrm{~m}$ and $25 \mathrm{~m}$ eustatic sea-level used in the glacio-isostatic models.

\section{Scenario 1 Scenario 2 Scenario 3}

$15 m E S L$

Greenland contribution $(\mathrm{m}) \quad$ -

$5-5$

$20 m$ ESL

$\begin{array}{llll}\text { Antarctic Contribution }(\mathrm{m}) & 20 & 15 & 25 \\ \text { Greenland contribution }(\mathrm{m}) & - & 5 & -5\end{array}$

$25 m$ ESL

Antarctic Contribution $(\mathrm{m}) \quad 25 \quad 20 \quad 30$

Greenland contribution $(\mathrm{m}) \quad-\quad 5 \quad-5$

\subsubsection{GIA results and estimates}

The resulting GIA models of global RSL change for a 20 kyr-paced symmetric glacial-interglacial cycle are displayed in Figure $5.19(\mathrm{a}-\mathrm{c})$ for the three meltwater source scenarios for three ESL amplitudes $(15,20$ and $25 \mathrm{~m})$. They show that ESL is approximated at the Whanganui Basin site, for all three amplitudes and each scenario within resolution of the model. That is, the ESL contribution is equal to the RSL amplitude recorded in Whanganui. This is due to the dominant melt-water contribution coming from Antarctica, where Whanganui sits at the node between near-field sea level fall and far-field rise. The small prescribed changes to the relative contributions from AIS and GIS do not appear to shift the location of the ESL contour away 
from Whanganui Basin. In other words, Whanganui Basin RSL approximated ESL and is not significantly influenced by GIA in these scenarios for the mid-Pliocene.

The colour scale in Figure 5.19 measures $2.5 \mathrm{~m}$ regional sea-level increments, which spans a broad area either side of the ESL contour. Thus, if the approximation of GMSL was slightly further south (or north), the RSL record at Whanganui Basin would increase or decrease by around $2.5 \mathrm{~m}$ based on the model resolution. As the model is a prediction of ESL implied by the RSL record that contains an error of up to $\pm 8 \mathrm{~m}$, we conclude that any error introduced by GIA is minimal and not additional.

While models were not run for a Northern Hemisphere dominated meltwater source, the LGM, provides a well-constrained example of the relative pattern of global sea level response. RSL in New Zealand during the Holocene highstand displays a 3-5 m overestimate of present day sea level (Clement et al., 2016). The meltwater contribution from the NHIS in the Holocene is an order of magnitude larger than that expected in the mid- to late Pliocene, but the cumulative response of NHIS overwhelming the AIS contribution would result in RSL at the Whanganui Basin overestimating ESL. This is suggested to be on the order of 2-3 $\mathrm{m}$ for the Pliocene (within the spatial resolution of the model; Dr. Paolo Stocchi, pers. comms.).

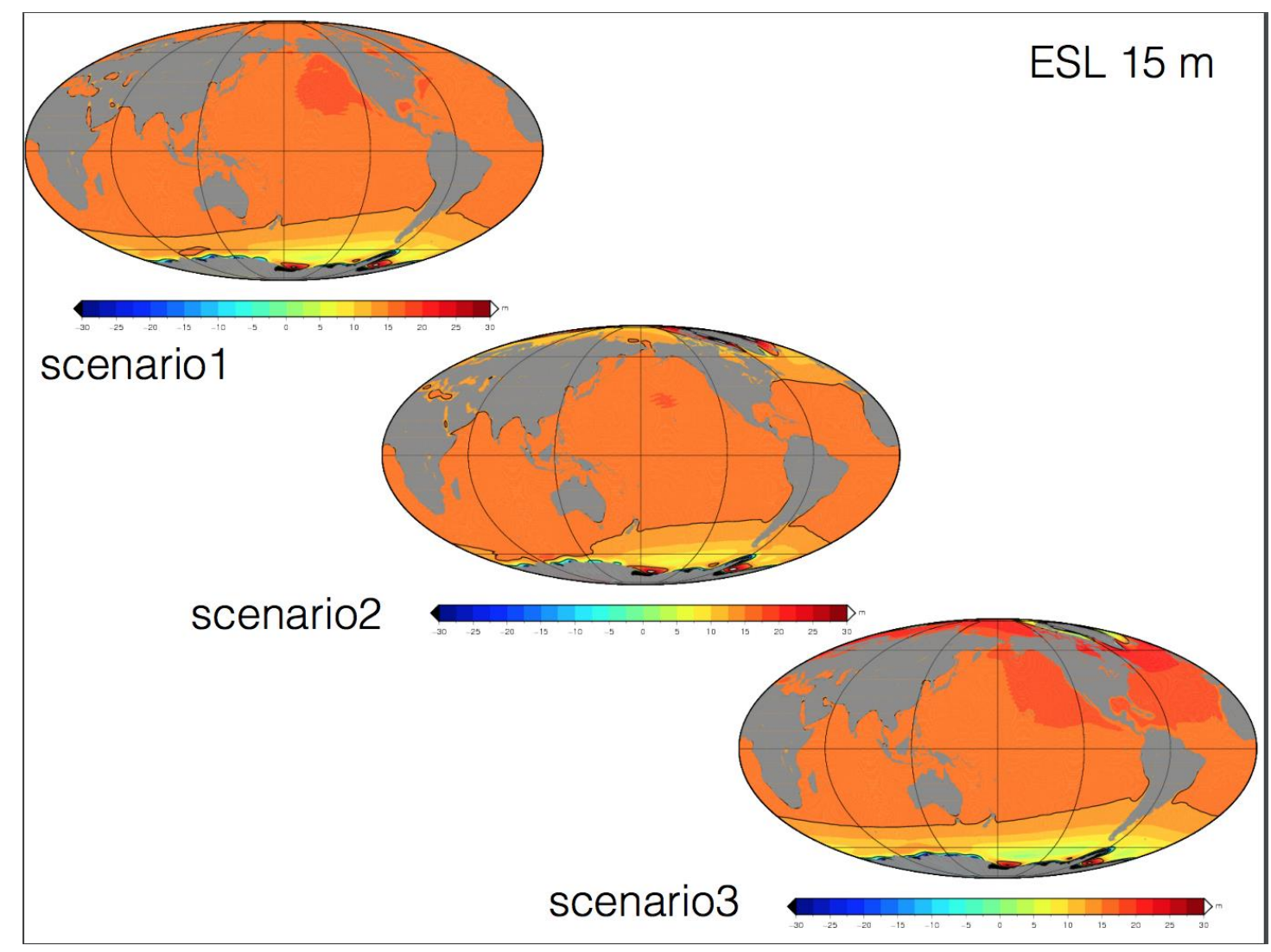



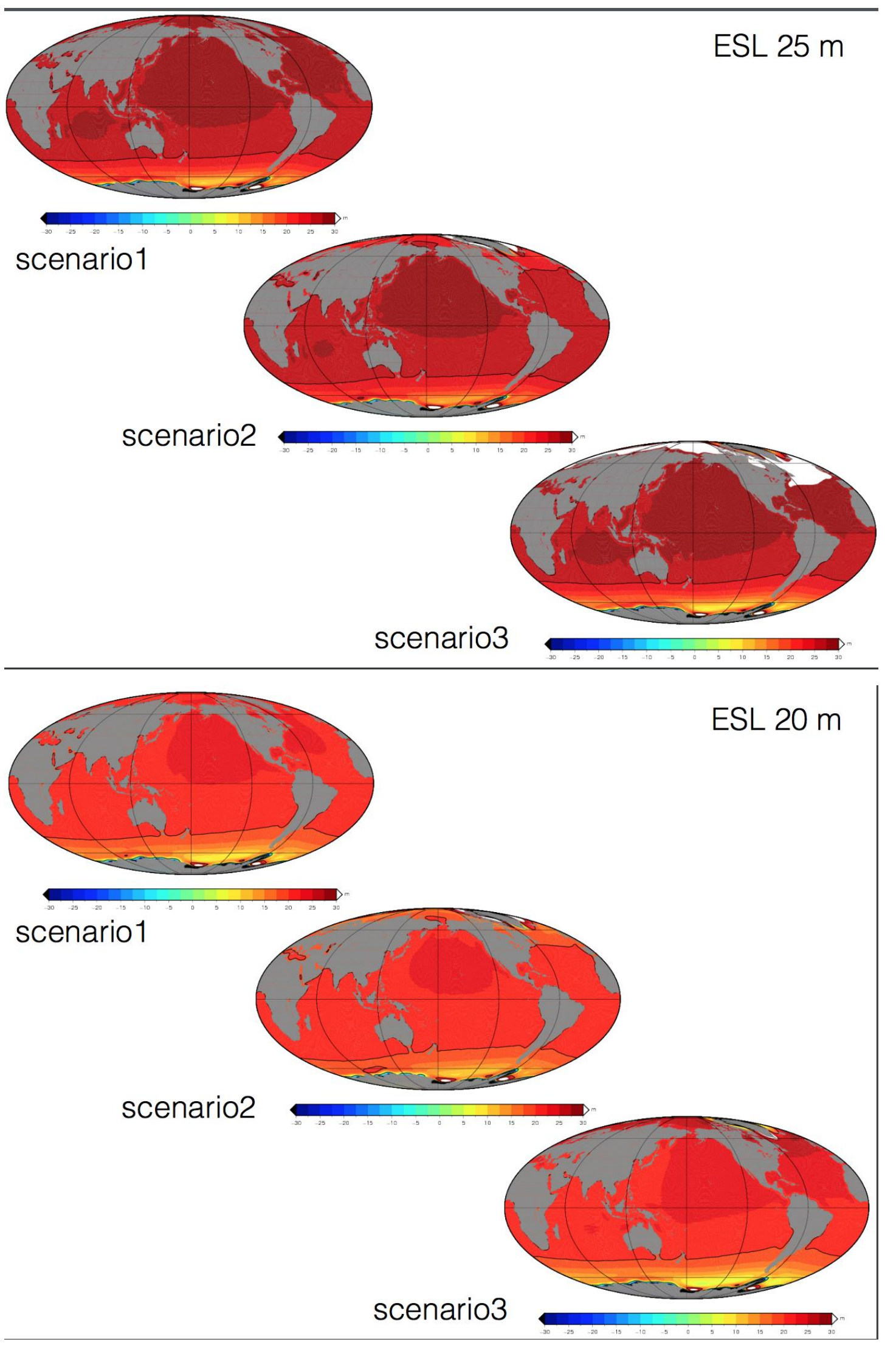

Figure 5.20 Regional sea-level maps for meltwater scenarios 1-3 (Table 5-3) showing relative sea-level change for ESL contributions of a) $15 \mathrm{~m}$, b) $20 \mathrm{~m}$, c) $25 \mathrm{~m}$; with the ESL contour indicated by the black contour. 


\subsection{Conclusions - A new glacial- interglacial relative sea level for the mid- to late}

Pliocene ( 3.3-2.5 Ma).

The continuity, resolution, chronology and environmental setting of the mid-late Pliocene shallow-marine sedimentary succession in Whanganui basin has afforded the opportunity to reconstruct the full amplitude of glacial-interglacial relative sea-level variability for the mid- to late Pliocene. While not registered to present-day sea-level, preliminary GIA modelling for a range of likely polar ice sheet configurations shows that the RSL record from the Whanganui Basin, approximates the relative amplitude of ESL variability, particularly for the mid-Pliocene. This record reconstructs glacial-interglacial "global" sea-level changes independently of the benthic oxygen isotope proxy record. The implications for how the polar ice sheets have responded to orbital-forcing and contributed to global sea-level change is explored further in Chapter 6.

In summary, the chronology implies precession-paced fluctuations with an average amplitude of $15 \pm 10 \mathrm{~m}$, and obliquity-paced fluctuations of $20 \pm 10 \mathrm{~m}$ for the mid-Pliocene (3.3-2.9 Ma) and late Pliocene (2.9-2.5 Ma), respectively. And that GIA on RSL at far-field sites are very limited and contribute no more than $\pm 2.5 \mathrm{~m}$ (the resolution of the model). 


\section{Discussion and Conclusions: Amplitude and frequency of the}

relative sea-level record for the mid- to late Pliocene: Implications for orbital forcing and meltwater source.

This study provides a record of the full-amplitude of relative sea-level (RSL) change for glacialinterglacial cycles during the mid- to late Pliocene (3.3-2.6 Ma). This chapter explores the relative influence of the polar ice sheets on global sea level prior to and during the development of the Northern Hemisphere Ice Sheets (NHIS), and the role of orbital forcing on each ice sheet.

An analysis of the orbital frequencies present in the RSL record, and the phase relationship of the RSL curve to local insolation, is undertaken to identify how the different orbital components are forcing polar ice sheet fluctuations during this time. A comparison is also made between the RSL record and the orbital pacing of an Antarctic-proximal ice volume proxy record (ice-berg rafted debris; IBRD; Patterson et al., 2014) and the benthic $\delta^{18} \mathrm{O}$ stack (Lisiecki \& Raymo, 2005) in an attempt to identify the relative importance of NHIS (including the Greenland Ice Sheet; GIS) and Antarctic Ice Sheets (AIS) in driving global sea-level fluctuations evident in the Whanganui RSL record (Section 6.1). The amplitude of the RSL record in the context of the orbital analysis together with GIA modelling of a number of meltwater scenarios, is used to further quantify the relative contributions of Antarctic and Greenland/Northern Hemisphere meltwater (Section 6.2). Finally, temperature and seawater composition (ice volume) components utilised in calibrations of the benthic $\delta^{18} \mathrm{O}$ stack, are evaluated using the RSL amplitudes from this study, to assess assumptions of polar ice sheet meltwater contribution to the benthic $\delta^{18} \mathrm{O}$ stack and the use of the benthic $\delta^{18} \mathrm{O}$ stack as a sea level proxy (Section 6.3). 


\subsection{Orbital pacing of relative sea level during the mid- to late Pliocene}

There is an unequivocal link between orbital cycles and Earth's climate (Masson-Delmotte et al., 2013). The benthic $\delta^{18} \mathrm{O}$ stack contains the most detailed record of orbitally-paced climate variability through the last $5 \mathrm{Ma}$ (Lisiecki and Raymo, 2005). However, as a globally integrated measure of ocean temperature and ice volume (which is further complicated by changing polar ice sheet composition), and therefore sea level, it does not provide a unique solution of either.

The Whanganui RSL record provides the first continuous, direct record of the mid-Pliocene warm period (MPWP) to late Pliocene global sea-level independent of the benthic $\delta^{18} \mathrm{O}$ stack. Frequency analysis of the RSL record is undertaken to firstly identify the relative influence of orbital components and their evolution through time, and then to assess the phasing of RSL curve with orbital solutions and local insolation time series.

A comparison of the orbital frequencies is then made with other proxy records of ice volume variability (benthic $\delta^{18} \mathrm{O}$ stack and Antarctic IBRD) within the context of a cooling background climate state represented by atmospheric $p \mathrm{CO}_{2}$ and global temperature reconstructions.

\subsubsection{Frequency analysis and phasing assessment}

Assessment of orbital frequencies is undertaken utilising the Astrochron package freely available in R (Meyers, 2014). The Mann and Lees (1996) Multi-taper Method (MTM) identifies frequencies that pass the robust red-noise confidence level (at least $90 \% \mathrm{CL}$ ) within \pm half the bandwidth (spectral frequency error) and also achieves the MTM harmonic F-test confidence level (Meyers, 2014). Evolutive Harmonic Analysis (EHA) uses the Thomson MTM (Thomson, 1982) to assess spectral frequency and power for a 'window' that is incrementally moved along the time-series ('step') resulting in a series of overlapped windows to display the evolution of spectral power through time. Spectral analysis requires 'even sampling' for which the mean sampling resolution of 3.5 kyr was resampled using linear interpolation in Astrochron (Meyers, 2014). The mean and linear trend are removed from the time-series prior to analysis and the resulting spectra are normalised (maximum power in each window normalised to unity) and 
are plotted on a logarithmic scale, where frequency represents 1 (cycle)/Period (kyr), that is $\mathrm{kyr}^{-1}$ (Meyers, 2014).

The RSL record developed in Chapter 5.2 is untuned with a mean sampling interval of 2 kyr for the mid-Pliocene and 6 kyr for the late Pliocene. The Nyquist frequency, which signifies the minimum frequency that can be assessed due to the sampling resolution is $0.14 \mathrm{kyr}^{-1}$ ( $7 \mathrm{kyr}$ period).

With sedimentation rates of $\sim 1 \mathrm{~m} / \mathrm{kyr}$ in the cores and sampling of $2 \mathrm{~m}$ (i.e. $2 \mathrm{kyr}$ ) for the midPliocene RSL record, the sampling resolution is higher than that of the MPWP part of the benthic $\delta^{18} \mathrm{O}$ stack (5 kyr sampling interval $>3.0 \mathrm{Ma}$; $2.5 \mathrm{kyr}$ sampling interval $<3.0 \mathrm{Ma}$ ) and is able to better resolve power at precession frequencies. The physical property logs, measured at $1 \mathrm{~cm}(0.1 \mathrm{kyr})$ show the same pattern of variability that the grain size and RSL record display, therefore a higher sampling resolution of $1 \mathrm{~m}$ (1 kyrs) is considered unnecessary.

The MTM spectra for the RSL record of the mid- to late Pliocene show significant orbital periods within the bandwidth error $\left(0.004 \mathrm{kyr}^{-1}\right)$ of eccentricity $\left(0.08-0.11 \mathrm{kyr}^{-1} ; 125-90 \mathrm{kyr}\right)$, obliquity (0.18-0.024 kyr $\mathrm{kg}^{-1} ; 54-41 \mathrm{kyr}$ ) and precession (0.043-0.053 kyr-1; 23 and $\left.19 \mathrm{kyr}\right)$, with significant peaks also recorded at 167 and $30-35 \mathrm{kyr}$ (Figure 6.1a). The MTM spectra is more precise as it assesses the length of the record but cannot assess the variance in predominant orbital frequencies. EHA of the RSL record, displays significant power in precession and eccentricity during the MPWP, with strengthening power in obliquity frequencies by $\sim 2.8 \mathrm{Ma}$ (Figure 6.1b). 

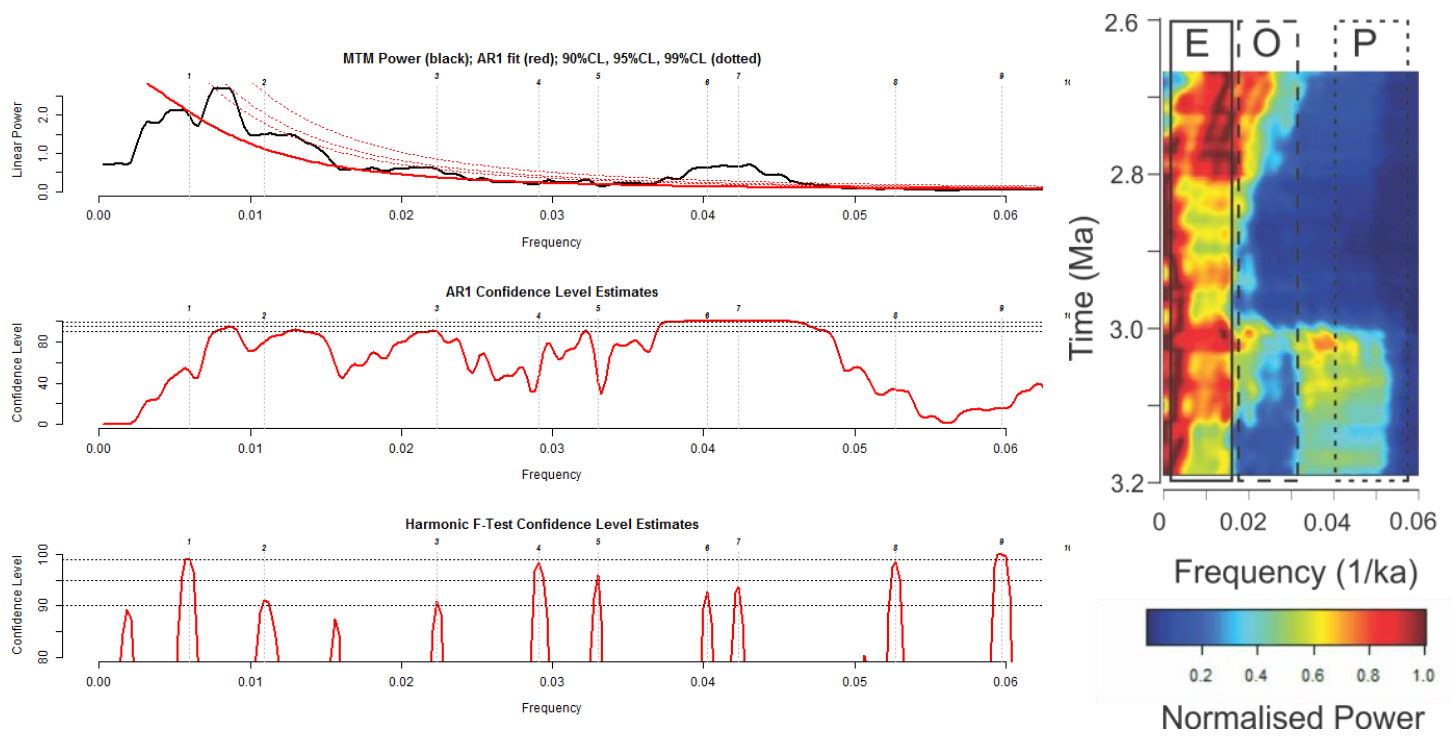

Figure 6.1 Spectral analysis using the a) Multi-taper Method with the Mann and Lees (1996) red noise test (function mtmML96 in Astrochron; Meyers, 2014) of the Whanganui RSL record for the mid-to Late Pliocene, displaying significant harmonic peaks at the $90 \%$ Confidence Level in kyr: 1) 167.4; 2) 91.7; 3) 44.8; 4) 34.4; 5) 30.3; 6) 24.8; 7) 23.6; 8) 19; 9) 16.7. And b) EHA spectra of the RSL record using a $200 \mathrm{kyr}$ window, $3.5 \mathrm{kyr}$ step and power is normalised to unity, eccentricity (E: 0.08-0.11 kyr-1), obliquity (0: 0.18-0.024 kyr-1) and precession ( $P$ : 0.043-0.053 kyr-1) frequency bands are identified.

The MPWP contains two reversed paleomagnetic intervals, providing three age tie points that constrain correlation of RSL cyclicity to orbital solutions (as the base of the Mammoth subchron is not recovered). As the RSL is dominantly precession-paced during this period, a comparison to Northern and Southern Hemisphere high latitude daily insolation $\left(65^{\circ} \mathrm{N} \mathrm{Jul} 1^{\text {st }}\right.$ and $65^{\circ} \mathrm{S} \mathrm{Jan}$ 1st; Laskar et al., 2004), which are anti-phased, is displayed in Figure 6.2. An assessment of the timing between the RSL and insolation solutions at the three paleomagnetic transitions, displays a coherent relationship between the $65^{\circ} \mathrm{S}$ insolation and RSL for all three transitions, suggesting Southern Hemisphere (AIS) ice volume fluctuations drove eustatic sea-level in the MPWP (Figure 6.2). The exact lead or lag in phasing between insolation and RSL cannot be accurately assessed due to the timing of paleomagnetic transitions and error (while limited $\pm 1 \mathrm{kyr}$ ) of the RSL age model. The late Pliocene RSL record, which is dominated by obliquity, represents most of the first Gauss normal chron, but only contains the upper paleomagnetic transition and thus does not contain enough age constraints to accurately assess the phasing with respect to orbital forcing for this part of the record. 

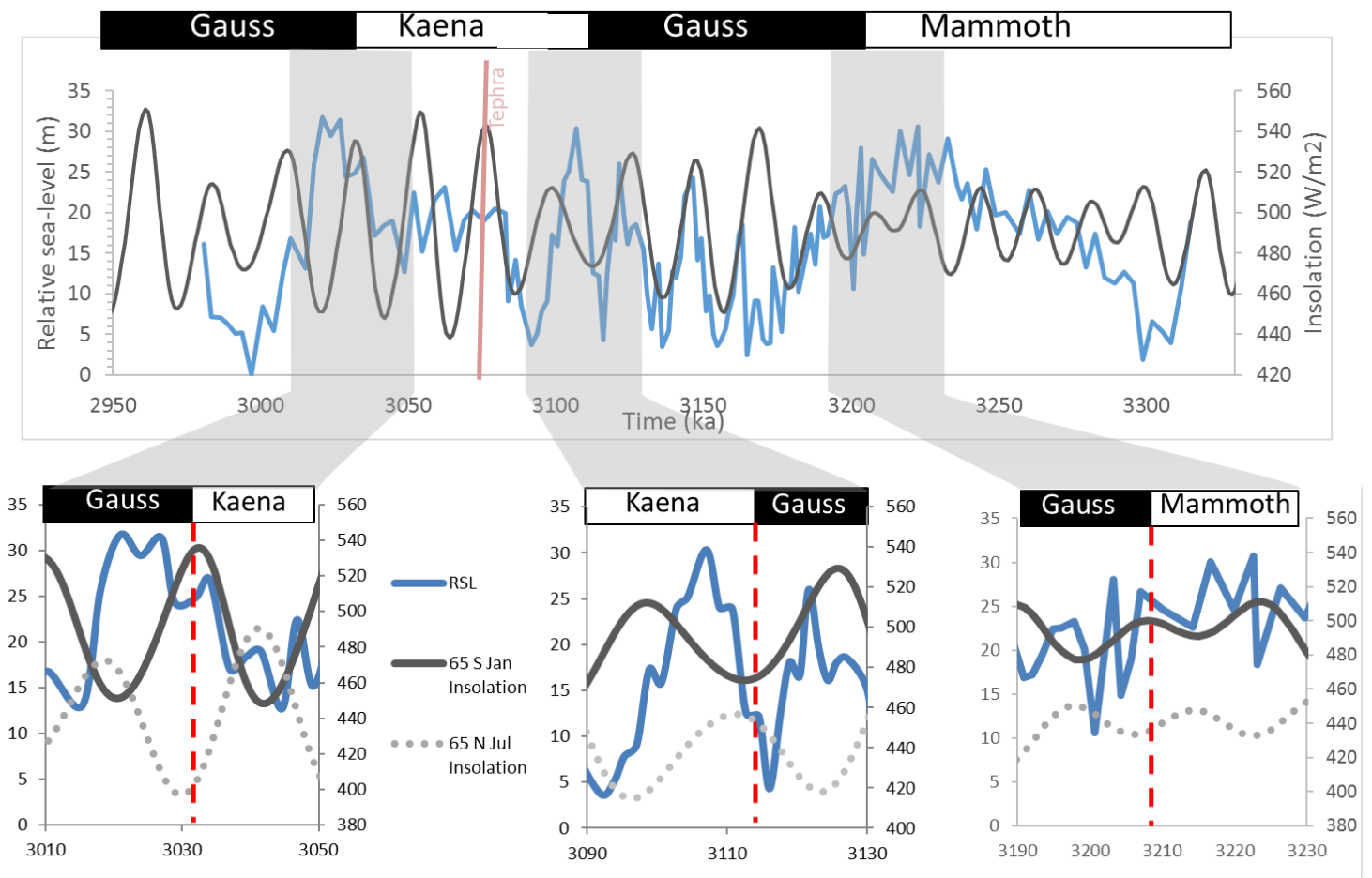

Figure 6.2 Phase comparison between the Whanganui RSL curve and peak summer insolation at $65^{\circ} \mathrm{N}$ (dotted) and $65^{\circ} \mathrm{S}$ (solid) highlighted for the three paleomagnetic transitions (red dashed lines) of the MPWP. Peak summer insolation for $65^{\circ} \mathrm{S}$ is shown with the whole RSL record untuned.

6.1.2 Using frequency to constrain ice sheet contributions to relative sea level for the midto late Pliocene

Traditional Milankovitch theory invokes summer insolation, paced by precession and periods of cooler summers leading to the glaciation of the Northern Hemisphere. However, the dominance of obliquity and general lack of precession in spectral assessment of the benthic $\delta^{18} \mathrm{O}$ stack contradicts this. Consequently two prevailing hypothesis have been proposed: i) an out-of-phase precession signal masked by out-of-phase ice volume and the $\delta^{18} \mathrm{O}$ composition of the meltwater (Raymo et al., 2006), and ii) integrated summer insolation paced by obliquity for a NHIS melt threshold (i.e. an insolation value above which melting occurs) of $275 \mathrm{w} / \mathrm{m}^{2}$ or less, causing polar ice sheet melt (Huybers, 2006). These views both require insolation driven top-down melt of ice sheets to be the predominant mode by which they grow and decay. A third model of how orbital forcing could introduce a strong obliquity signal in ice volume 
fluctuations and therefore the benthic $\delta^{18} \mathrm{O}$ stack, involves the influence of Earth's tilt on the latitudinal temperature gradient (e.g. Young and Bradley, 1984). The magnitude of this gradient drives the position and intensity of the Southern Hemisphere westerly wind belt over the Antarctic Circumpolar Current. Positioning of the westerly wind belt over the ACC has been inferred to increase overturning and upwelling of relatively warmer Circumpolar Deep Water (CDW) onto the Antarctic continental shelf (Naish et al., 2009; Levy et al., 2016; in review). This process requires a warmer ocean climate precluding significant summer sea-ice but allowing marine-based ice to persist. The ocean heat causes marine grounding lines to retreat, subsequent ice shelf collapse and ice sheet thinning, removes significant parts of the marine based sectors of the AIS. While fully coupled ocean-ice sheet models are yet to simulate this process, it is supported by modern observations and ocean models (Toggweiler and Russell, 2009; Spence et al., 2014; Stewart \& Thompson, 2015), and implied by ice sheet models that require ocean warming to destabilise the Antarctic marine-based margins (DeConto and Pollard, 2016; Golledge et al., 2017).

The Raymo et al. (2006) anti-phase precession hypothesis requires the presence of significant dynamic ice volume at both poles. However, there is no substantive evidence for extensive NHIS until 2.7 Ma (e.g. Maslin et al., 1998) and the presence of obliquity in other climate proxies (e.g. sea-level reconstruction for the Pleistocene by Naish et al., 1998, polar IBRD records [Maslin et al., 1998; Patterson et al., 2014] and tropical sea surface temperatures [Herbert et al., 2010]) which cannot be a product of anti-phase polar ice volume diminished the Raymo et al., 2006 argument. An ice sheet model (Huybers and Tzipermann, 2008) was able to produce obliquity variability of NHIS volume if the ablation zone is north of $60^{\circ} \mathrm{N}$ latitude and the melt threshold is exceeded for a significant portion of summer. However, the melt threshold for the modern Arctic is $275 \mathrm{~W} / \mathrm{m}^{2}$, while the modern Antarctic melt threshold does not meet the same criteria of the Huybers (2006) approach, as Antarctica's geographic situation, surrounded by ocean and marine-based ice, is very different.

The recent well-dated record of IBRD from the continental rise offshore of the Wilkes subglacial basin, East Antarctica (U1361 IBRD), displayed obliquity pacing from 4.3-3.5 Ma, and precession pacing from 3.5-2.2 Ma (Figure 6.3; Patterson et al., 2014). These authors invoked a combination of integrated summer insolation and ocean dynamics to explain the periodicity evident in the record (explained above). For the former, they proposed a varying threshold 
melt response to background climate; whereby a lower melt threshold $\left(200 \mathrm{~W} / \mathrm{m}^{2}\right)$ in the Early Pliocene produced long summer melt period paced by the role of obliquity on mean annual insolation. While a higher melt threshold $\left(400 \mathrm{~W} / \mathrm{m}^{2}\right)$ following the late Pliocene cooling of Antarctica marked by the M2 glaciation (Mckay et al., 2012), results in a reduced summer melt period responding only to precession-paced peak summer insolation. For the Early Pliocene they also proposed ocean circulation changes driven by the influence of obliquity on the meridional temperature gradient introduced heat via warm CDW incursions into the cavities of ice shelves and marine grounding lines (Patterson et al., 2014). However, around 3.5-3.3 Ma the growth of perennial sea-ice produced a barrier to CDW and associated cooling meant melt only occurred during peak summer insolation controlled by precession.

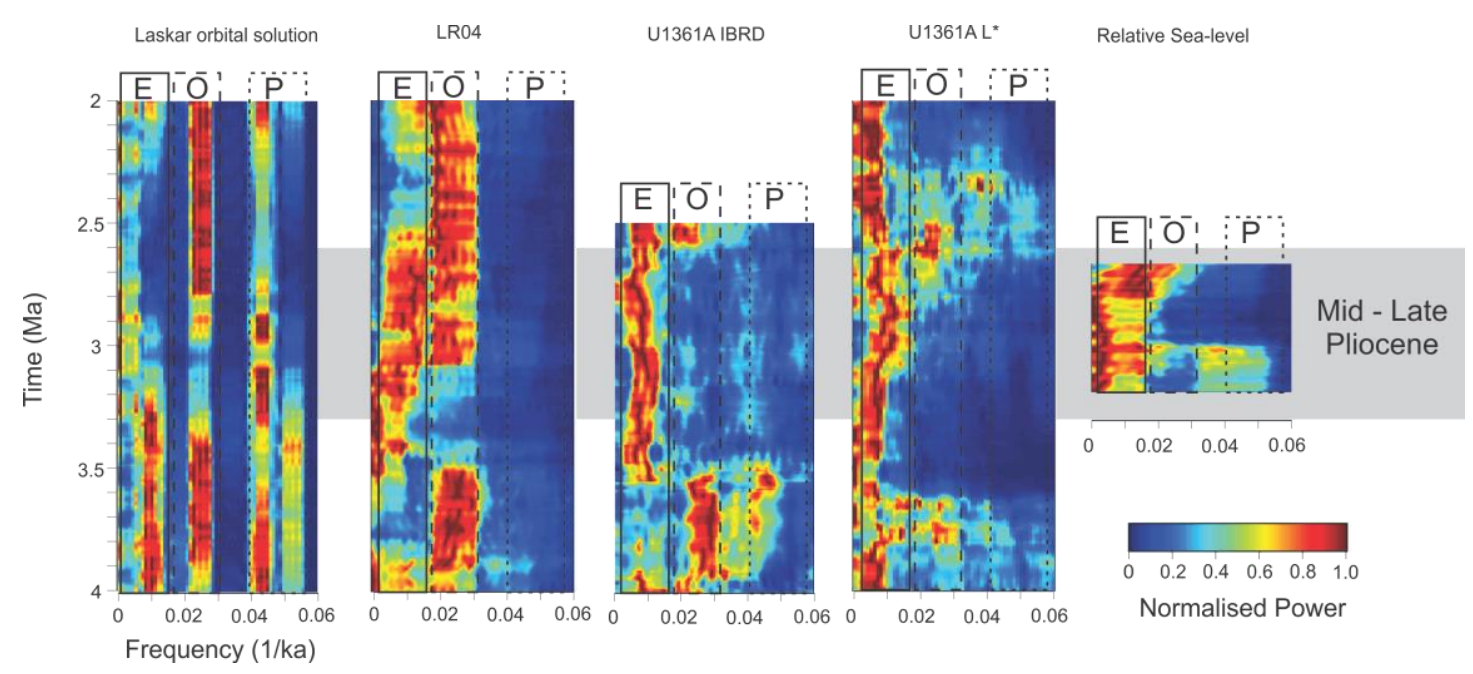

Figure 6.3 Evolutionary harmonic analysis of (left to right): the eccentricity, tilt, precession orbital solution (Laskar et al., 2004), global benthic $\delta 180$ stack (Lisiecki and Raymo, 2005), East Antarctic U1361A IBRD record (Patterson et al., 2014), East Antarctic U1361A L* colour reflectance (Facies proxy; Grant, 2012), Whanganui RSL (this study). All evolutionary spectra display the general absence of obliquity in the climate records through the MPWP during a 1.2 Myr node in obliquity, with the obliquity returning strongly in the LRO4 stack, but not in the U1361A Antarctic ice volume proxy time series or the Antarctic-driven Whanganui basin RSL record until $2.8 \mathrm{Ma}$. Evolutionary spectra were obtained using the EHA function in Astrochron (Meyers, 2014) using a window of $200 \mathrm{kyr}$ for the RSL record and $400 \mathrm{kyr}$ for the others, with a step of the sampling interval and the power is normalised (maximum in each window in normalised to unity). Eccentricity (E: 0.08-0.11 kyr-1), obliquity (0: 0.180.024 kyr-1) and precession (P: 0.043-0.053 kyr-1) frequency bands are identified. 
Table $6.1 \mathrm{pCO}_{2}$ (compiled by Foster, 2015) and global mean temperature (Dowsett et al., 2012; Haywood et al 2013; MassonDelmotte et al., 2013; Golledge et al., 2017) for the early Pliocene, MPWP and late Pliocene, with dominant orbital frequencies indicated by various proxy records for the Antarctic Ice sheet (AIS) and Greenland / Northern Hemisphere Ice sheets (GIS/NHIS), the benthic $\delta 180$ stack (Lisiecki and Raymo, 2005) and relative sea-level of Whanganui Basin.

\begin{tabular}{|c|c|c|c|c|c|c|}
\hline $\begin{array}{l}\text { Time } \\
\text { (Ma) }\end{array}$ & $\begin{array}{l}\mathrm{pCO}_{2} \\
\text { (Foster, } \\
2015 \text { ) }\end{array}$ & $\begin{array}{l}T \\
\text { anomaly }\end{array}$ & $\begin{array}{l}\text { AIS } \\
\text { variability }\end{array}$ & $\begin{array}{l}\text { NHIS/GIS } \\
\text { Variability }\end{array}$ & $\begin{array}{l}\delta^{18} \mathrm{O} \\
\text { (Lisiecki and } \\
\text { Raymo, } \\
\text { 2005) }\end{array}$ & $\begin{array}{l}\text { RSL - } \\
\text { Whanganui }\end{array}$ \\
\hline $5-3.3$ & $350-450$ & $3-4^{\circ} \mathrm{C}$ & $\begin{array}{l}\text { Obliquity } \\
\text { (Naish et al., } \\
\text { 2009; } \\
\text { Patterson et } \\
\text { al., } 2014\end{array}$ & $\begin{array}{l}\text { Precession? } \\
(G / S)\end{array}$ & Obliquity & $\begin{array}{l}\text { Not } \\
\text { recovered }\end{array}$ \\
\hline $\begin{array}{l}3.3- \\
2.9\end{array}$ & $350-450$ & $2-3^{\circ} \mathrm{C}$ & $\begin{array}{l}\text { Precession } \\
\text { (Patterson et } \\
\text { al., 2014) }\end{array}$ & $\begin{array}{l}\text { GIS } \\
\text { Precession } \\
\text { Maslin et } \\
\text { al., 1998; } \\
\text { Wennrich et } \\
\text { al., 2014) }\end{array}$ & $\begin{array}{l}\text { Eccentricity- } \\
\text { (clipped } \\
\text { precession) }\end{array}$ & Precession \\
\hline $\begin{array}{l}2.9- \\
2.6\end{array}$ & $300-400$ & $0-2^{\circ} \mathrm{C}$ & $\begin{array}{l}\text { Precession } \\
\text { (Patterson et } \\
\text { al., 2014; } \\
\text { Grant, 2012) }\end{array}$ & $\begin{array}{l}\text { Obliquity } \\
\text { (NHIS) } \\
\text { Jansen et } \\
\text { al., } 2000\end{array}$ & Obliquity & Obliquity \\
\hline
\end{tabular}

\section{Early Pliocene (5-3.3 Ma)}

The Early Pliocene is characterised by $\mathrm{pCO}_{2}$ of $350-450 \mathrm{ppm}$ and corresponding global temperatures of $3-4^{\circ} \mathrm{C}$ warmer than present (Haywood et al., 2013; Golledge et al., 2017). Under these conditions NHIS were restricted to a much smaller than present Greenland Ice Sheet (Maslin et al., 1998; Brigham-Grette et al., 2013) that paleoclimate data (Wennrich et al., 2014; from 3-3.4 Ma) might suggest responded to the precession-paced peak summer insolation. Regular advances of grounded ice at the AND-1B site (Naish et al., 2009) and fluctuations in IBRD to the Wilkes Land margin (Patterson et al., 2014) demonstrate obliquitypacing of the AIS (Table 6.1). AIS variability may respond to obliquity forcing of latitudinal temperature gradient and oceanic influences on heat transport to grounding lines (e.g. Levy et al., in review) and/or a low melt threshold for the relatively warm climate of the Early Pliocene favouring obliquity forcing (Huybers, 2006; Patterson et al., 2014). The benthic $\delta^{18} \mathrm{O}$ stack is 
paced by obliquity, recording ice volume variability predominantly from the AIS in the absence of significant NHIS.

\section{Mid-Pliocene Warm Period (3.3-3 Ma)}

While global temperature and $\mathrm{pCO}_{2}$ levels remained similar to those of the early Pliocene, the beginning of the MPWP is marked by a significant cooling in Antarctica, the M2 glaciation, associated with a $\sim 1$ per mil enrichment in the benthic $\delta^{18} \mathrm{O}$ stack and associated with widespread expansion of the AIS and increased duration of summer sea-ice in the Ross Sea (McKay et al., 2012). Climate reconstructions suggest a limited GIS was present at this time (Hill et al., 2012; Brigham-Grette et al., 2013), favouring AIS forcing of the $M 2 \delta^{18} \mathrm{O}$ excursion. The MPWP is coincident with a node in obliquity and a maximum in 400 kyr eccentricity (Figure $6.3 \& 6.4)$, resulting in an extended period of cold summers and low seasonality thought to drive the cooling of Antarctica and expansion of sea-ice.

The expanded sea-ice field and regional cooling following the $\mathrm{M} 2$ glaciation may have acted to isolate the AIS from ocean-induced melt (through internal feedbacks from the sea-ice), therefore responding predominantly to precession-driven peak summer insolation (Patterson et al., 2014; Figure 6.4). The significant cooling coincident with the M2 glaciation (McKay et al., 2012) may also have acted to increase the surface melt threshold of the AIS favouring precession-paced peak summer insolation melting (Huybers, 2006; Patterson et al., 2014). An IBRD record from the North Pacific displays moderate eccentricity and an absence of obliquity frequencies (Maslin et al., 1998), while climate-driven grain-size variability recorded in Lake

El'gygytgyn similarly displays a lack of obliquity and predominance eccentricity-pacing (Wennrich et al., 2014). This is interpreted to support the argument of precession-paced modest GIS variability in the warm Early to mid-Pliocene, which is generally lacking highresolution climate and ice volume proxy records. While I acknowledge that the extent and frequency of NHIS is contentious, the dominance of precession in the RSL record and EAIS IBRD record is interpreted as a period of anti-phase climate.

In this thesis, it is argued that the noise-to-signal ratio is much higher in the benthic $\delta^{18} \mathrm{O}$ stack prior to $3 \mathrm{Ma}$ due to the low temporal resolution of some of the contributing records. The 
benthic $\delta^{18} \mathrm{O}$ stack therefore, does not resolve the precession-paced cyclicity that a single highresolution deep-sea $\delta^{18} \mathrm{O}$ record exhibits (e.g. ODP 846). However, a noticeable lack of obliquity and significant power in the eccentricity band, attributed to modulation of precession, is consistent with the precession-paced AIS and GIS (Figure 6.3; Table 6.1). That is, power in the eccentricity modulator is transferred from precession, termed clipping of precession (e.g. Patterson et al., 2014). The Whanganui RSL record developed in this study also displays precession-paced global sea-level cycles, in phase with $65^{\circ} \mathrm{S}$ insolation intensity, suggesting an AIS meltwater source (Figure 6.2). This is supported by the precession-paced U1361 IBRD record (Patterson et al., 2014), for which Cook et al. (2013) determined an East Antarctic Wilkes subglacial basin source of U1361 sediments, implying significant AIS fluctuations. Thus, while an anti-phase bi-polar ice sheet melt is interpreted from climate records for the MPWP, the Whanganui RSL record implies the predominant influence on global sea-level was the AIS in phase with $65^{\circ} \mathrm{S}$ insolation.

\section{Late Pliocene (3-2.6 Ma)}

The late Pliocene is characterised by the intensification of significant NHIS, indicated by the increasing enrichment of the benthic $\delta^{18} \mathrm{O}$ stack and the presence of IBRD in the North Pacific Ocean (Maslin et al., 1998). The expansive, largely continental, NHIS is inferred to have been dominated by obliquity forcing based on the dominance of obliquity in ice volume (Lisiecki and Raymo, 2005), paleoclimate (Brigham-Grette et al., 2013; Wennrich et al., 2014), and tropical ocean sea surface temperature records (Herbert et al., 2010). One possible origin of the $40 \mathrm{kyr}$ dominance as discussed, is that the melt threshold was exceeded for most of the summer and ablating margins were north of $60^{\circ} \mathrm{N}$ latitude (Huybers, 2006; Huybers and Tzipermann, 2008). However, AIS continue to be paced by precession (Patterson et al., 2014), as outlined above. The shift to dominant obliquity pacing of the RSL record during the late Pliocene (more apparent in one-to-one correlation; Figure 6.4) is consistent with the benthic $\delta^{18} \mathrm{O}$ stack (Lisiecki and Raymo, 2005; Figure 6.3). This is interpreted as a reduced AIS contribution to global mean sea-level and a dominant NHIS influence on sea-level cyclicity as recorded by the obliquity dominance in the RSL record and benthic $\delta^{18} \mathrm{O}$ stack (Figure 6.4). 
Global ice-volume and sea-level

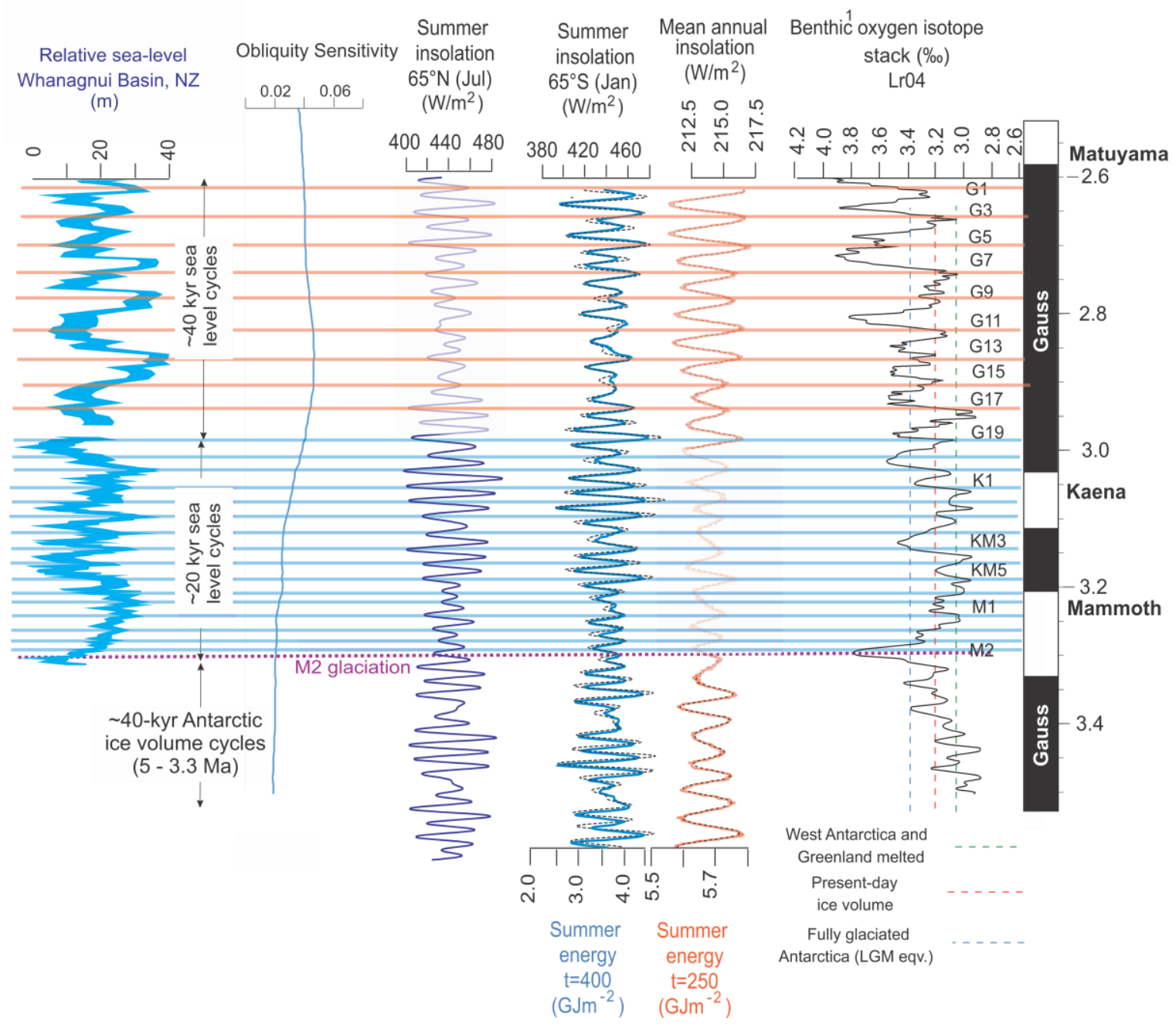

Figure 6.4. The Whanganui RSL record (untuned age model as per Chapter 5) correlated (from left to right) with summer insolation for $65^{\circ} \mathrm{N}$ (Laskar et al., 2004), summer insolation for $65 \mathrm{~S}$ (Laskar et al., 2004), summer energy for a melt threshold of $400 \mathrm{GJ} / \mathrm{m} 2$ (calculated after Huybers and Tziperman, 2008), mean annual insolation (Laskar, 2004), summer energy for a melt threshold of $250 \mathrm{GJ} / \mathrm{m} 2$ (calculated after Huybers and Tziperman, 2008) and the benthic $\delta 180$ stack (Lisiecki and Raymo, 2005).

The MPWP is thought to provide a time period to observe the response of ice sheets to the relative influence of precession-paced insolation with the generally low influence of obliquity, and therefore, test the Raymo et al., (2006) precession-paced model. We show that dominantly precession-paced AIS variability is represented in the Whanganui RSL record (Figure 6.4). While precession frequencies occur in the RSL throughout the MPWP, and it is assumed an anti-phased, precession-paced contribution form GIS might be hidden in the RSL, the lack of apparent $20 \mathrm{kyr}$ cycles in the benthic $\delta^{18} \mathrm{O}$ stack is considered to be more a product 
of smoothing and stacking of low resolution individual members, with overall low amplitude throughout this period. This is also supported by lack of evidence for the large-volume GIS/NHIS changes necessary to offset the Antarctic signature (Haywood et al., 2012; BrighamGrette et al., 2013; Dolan et al., 2015).

The obliquity-paced integrated summer energy concept proposed by Huybers et al. (2006), was developed for the continental based NHIS, which have a lower melt threshold, especially prior to the Mid-Pleistocene Transition (1.2-0.8 Ma) and progression to 100,000 duration glacial cycles during the last 1 Myr. Some studies (as discussed above e.g. Patterson et al., 2014) have proposed this direct insolation-driven melt process could also influence the AIS under a warmer climate state in the Early Pliocene prior to the M2 glaciation. However, the shift from obliquity to precession dominant frequencies in the U1361 IBRD record following the M2 glaciation and expansion of sea-ice (McKay et al., 2012) and prior to a return to obliquity-pacing in the early Pleistocene (Grant, 2012; Figure 6.3) highlights the important role of the ocean in the response of AIS. The modelling of internal feedbacks such as sea-ice expansion (e.g. following the M2 glaciation), meltwater stratification amplifying cooling through ice-albedo (e.g. Kohler et al., 2010), the formation of bottom-waters sequestering $\mathrm{CO}_{2}$ (e.g. Paillard and Parrenin, 2004), or NHIS driven sea level, triggering AIS response (e.g. Mackintosh et al., 2014) and marine ice-shelf instability (Golledge et al., 2017) suggest that ocean-ice dynamics for marine-based margins are likely to be more important than top-down melting.

\subsection{Using the amplitude to constrain polar ice sheet contributions to relative sea} level for the mid- to late Pliocene

The RSL curve developed in this thesis, provides the highest-resolution continuous record of full amplitude direct sea-level during the mid- to late Pliocene. Previous far-field, sea level records from shallow-marine margins have been discontinuous (Naish et al., 1998; Kamp et al., 1998) and have utilised extant foraminiferal water depth indicators (Naish et al., 1997a) that have been shown in this study as relatively insensitive to low amplitude paleobathymetry 
variability. Far-field sea level records attempting to estimate the absolute magnitude of peak interglacial conditions during the MPWP have large age uncertainties and have been subsequently affected by dynamic topography to the extent that sea-level registered to present is currently considered unknowable (Rovere et al., 2014 and references therein). Sites proximal to polar ice sheets also experience significant cumulative glacio-isostatic adjustment (GIA) in response to immediate and subsequent glaciations (Raymo et al., 2011).

Dutton et al. (2015) proposed peak sea level for the MPWP may have been between 6-40 m above present. This estimate is a reassessment of the datasets compiled by Miller et al., (2012) and Masson-Delmotte et al. (2013), in response to uncertainties outlined above. However, this thesis has focussed on the significance of reconstructing the full amplitude of glacialinterglacial sea-level variability, which takes into account interglacial highstands and glacial sea-level lowstands, and thus, is indicative of total ice volume change and therefore ice sheet sensitivity to climate forcing.

While it isn't registered to present day sea level, the Whanganui RSL record developed in this thesis provides the opportunity to assess the amplitude of orbitally-paced glacial-interglacial change in global sea-level and compare with amplitudes implied by calibrations of the benthic $\delta^{18} \mathrm{O}$ stack, ice sheet models and previous sea-level records (Figure 6.5).

\section{Mid-Pliocene Warm Period (3.3-3 Ma)}

During the MPWP, precession pacing of the RSL curve and the inferred precession pacing of AIS and GIS variability (discussed above) implies bi-polar, anti-phase glaciation. Ice sheet models suggest the GIS, during peak interglacial conditions of the MPWP, was reduced to 2.14.4 m sea level equivalent (SLE; Dolan et al., 2015) while Northern Hemisphere continentalscale glaciation conditions are not reached until to 2.6 Ma (Jansen et al., 2000; BrighamGrette et al., 2013). The limited contribution available from the GIS during the MPWP and the synchronicity of the RSL record with $65^{\circ} \mathrm{S}$ insolation (Figure 6.2) implies a larger contribution from the AIS dominating the RSL record, and masking anti-phased precession-paced variability in the GIS. 
The average amplitude of the RSL record through the MPWP is $\sim 15 \pm 10 \mathrm{~m}$ (Figure 6.5). GIA modelling of anti-phase deglaciation for an estimated -5 $\mathrm{m}$ from the GIS (present day to minimum interglacial; Lhomme et al., 2005; Dolan et al., 2015), offset by growth of $+20 \mathrm{~m}$ from AIS, manifests as $+15 \mathrm{~m}$ RSL amplitude recorded at Whanganui Basin, which appears to approximate ESL for a range of mid-Pliocene ice volume scenarios (Chapter 5.3 Figures 6.6 \& 6.7). Ice sheet models (Pollard et al., 2015; DeConto and Pollard, 2016; Golledge et al., 2017) and oxygen-isotope capable ice sheet models (e.g. Gasson et al., 2016) propose marine-based AIS are capable of contributing 13-17 m above-present day sea-level (ASL) from a modern configuration during the Pliocene. While this is within the error of the RSL record and may also be 'solved for' by invoking lower anti-phased contributions from the GIS, we suggest that the AIS may have been larger-than-present during some glacials of the MPWP to provide up to 20 m SLE (Fretwell et al., 2013), which would imply a higher level of sensitivity than previously thought. The amplitudes of the RSL record are on average, half of that suggested by $\mathrm{Mg} / \mathrm{Ca}$ calibrated benthic $\delta^{18} \mathrm{O}$ stack (Miller et al., 2012; Figure 6.5).

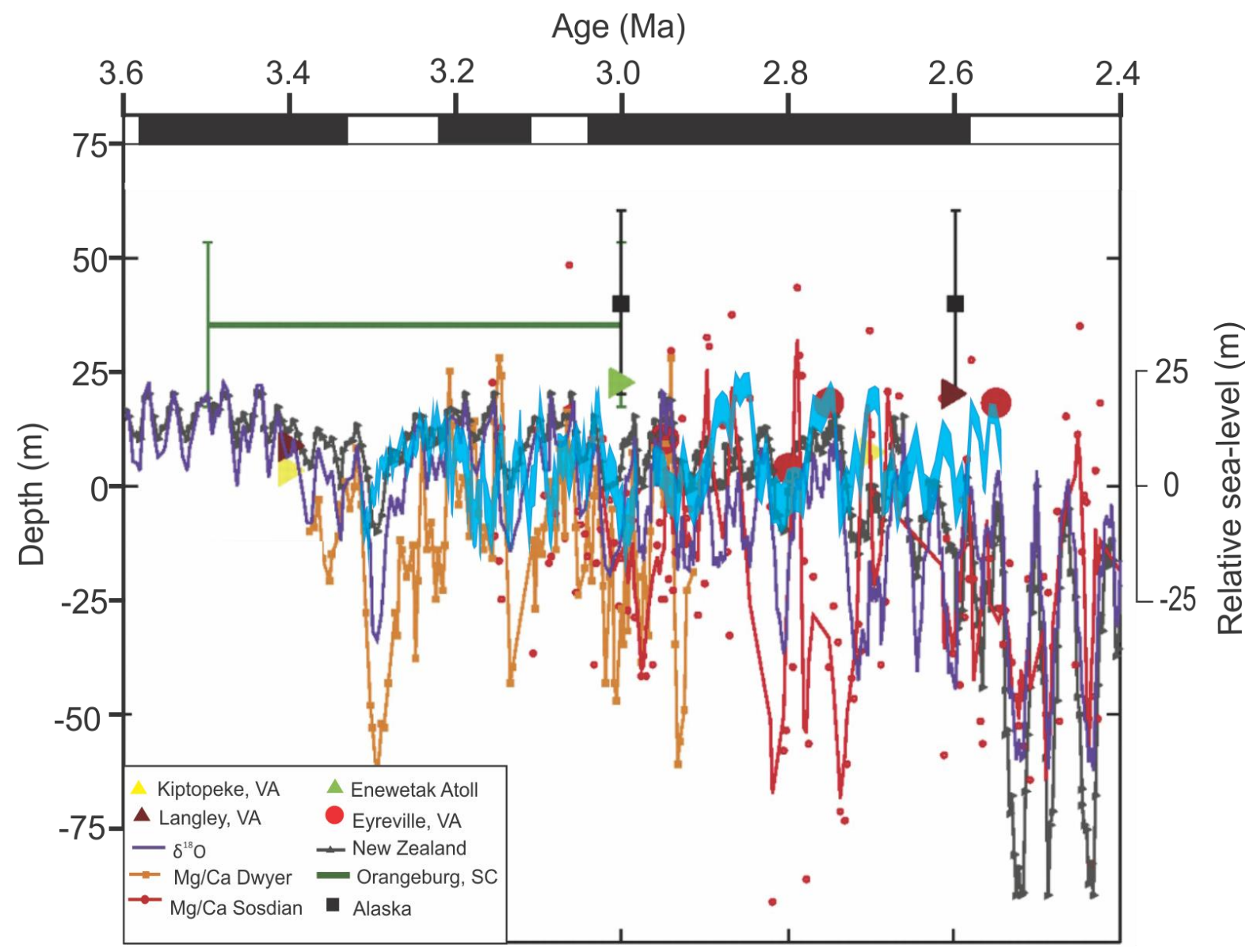

Figure 6.5 Comparison of Whanganui Basin RSL amplitudes to the sea-level estimates of Miller et al., (2012) that include those discussed in text, two different calibrated $\delta^{18} \mathrm{O}$ records ( $\delta 180$ - Miller et al., 2012; New Zealand - Naish and Wilson, 2009), 
Mg/Ca estimates (Dwyer and Chandler, 2009; Sosdian and Rosenthal, 2009) and geological deposits (Miller et al., 2012 and references therein). The RSL record is scaled to the Miller et al. (2012) compilation, however the absolute magnitudes are not registered to present day and has been overlain for an observational best fit, but could move vertically. Note the RSL record is not tuned and therefore displays some offset of cycles between the benthic $\delta 180$ stack calibrated records.

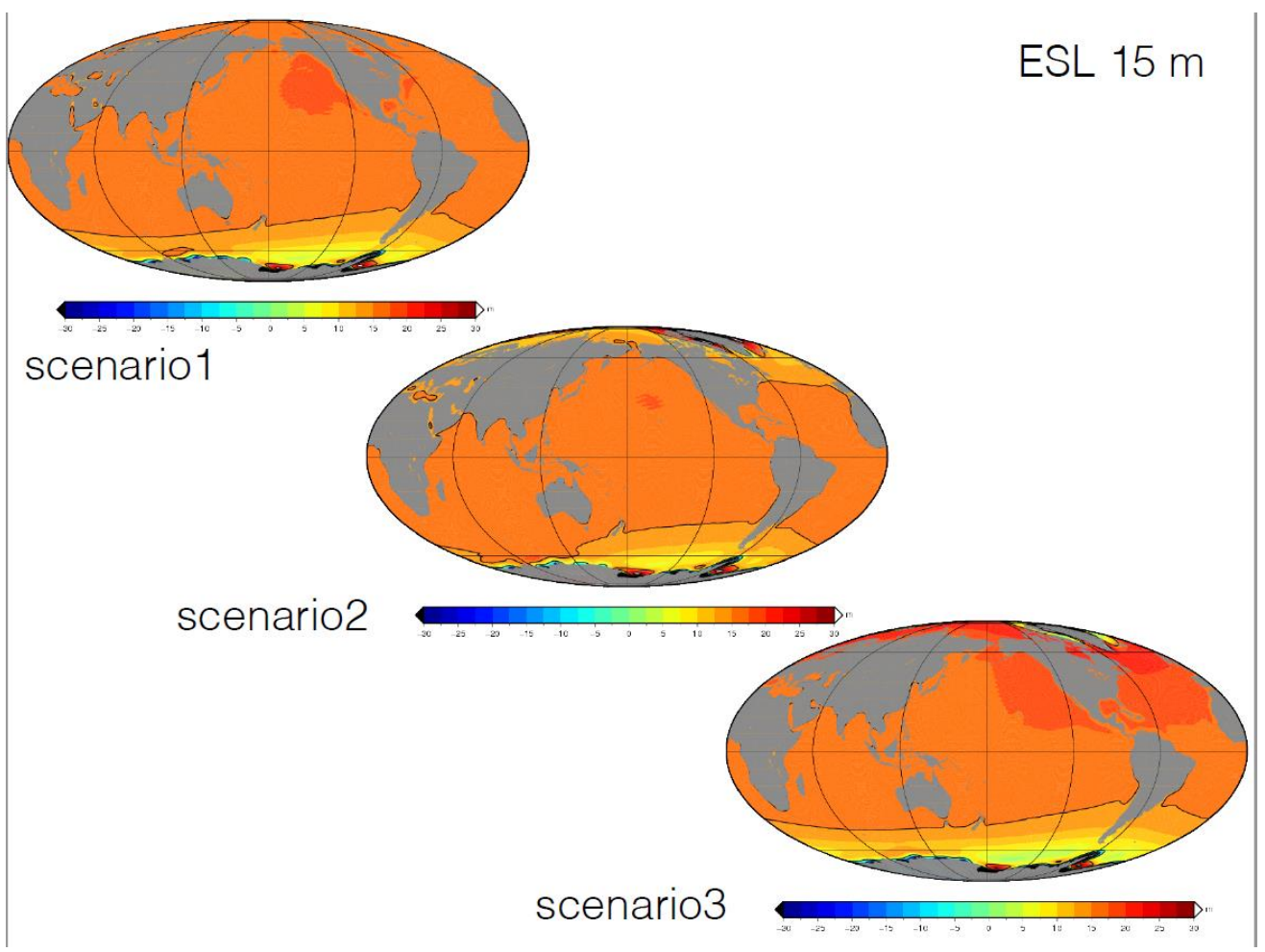

Figure 6.6 GIA model for 15m ESL; Scenario 1) $20 \mathrm{~m}$ from AIS; 2) $15 \mathrm{~m}$ from AIS and $5 \mathrm{~m}$ from GIS; 3) $25 \mathrm{~m}$ from AIS offset by 5 $m$ from GIA. The models display the amplitude of sea-level change from a glacial to interglacial period, where the black bold line demonstrates the location of ESL. 


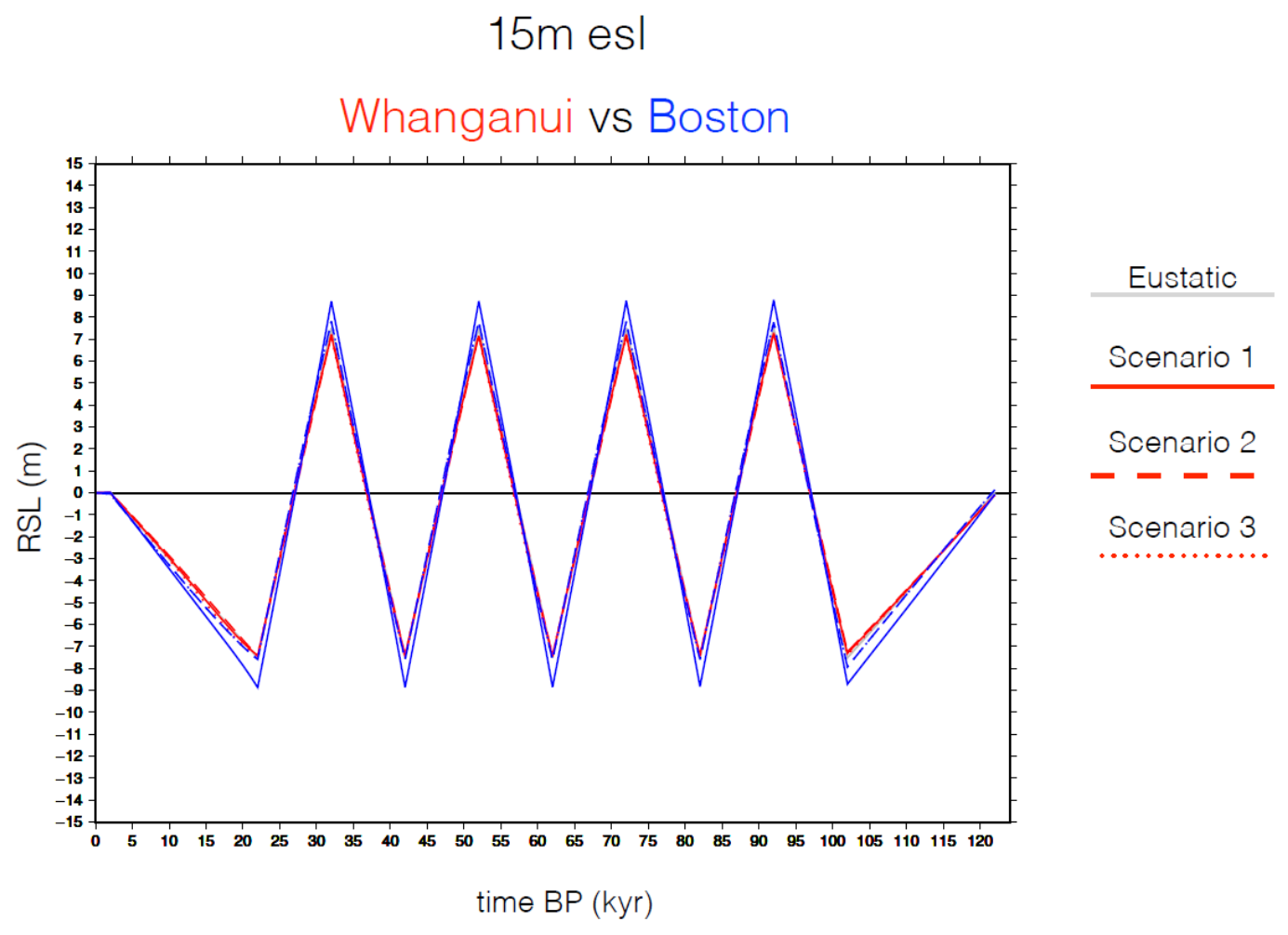

Figure 6.7 The RSL amplitude for Whanganui Basin (which approximates ESL) and Boston for Scenarios 1-3 (undifferentiated) with respect to the initial condition (halfway between interglacial and glacial).

Late Pliocene (3.0-2.6 Ma)

The intensification of NHIS's at $\sim 2.7 \mathrm{Ma}$ is widely recognised from climate records (BrighamGrette et al., 2013), glacial deposits in the Alaskan Brooks Range (Hamilton et al., 1986) and the presence of IBRD in the North Atlantic (Jansen et al., 2000) and North Pacific (Maslin et al., 1998; Haug et al., 2005). GIA modelling of global sea level for dominant NHIS contribution, is best observed from the well-constrained datasets of the LGM to present, where RSL in New Zealand, is shown to overestimate ESL (Clement et al., 2016). While GIA models specific to the late Pliocene scenarios, are not available at the time of writing this thesis, I propose that the level of overestimation of the Whanganui RSL record is of a similar magnitude to that of RSL at Boston, USA, overestimating ESL for AIS dominant scenarios of the MPWP (Figure 6.7; Dr. Paolo Stocchi, pers. comms.). That is, on the order of 2-3 $\mathrm{m}$ for the full glacial-interglacial amplitude (Figure 6.7).

Sea-level calibrations of the seawater component of the benthic $\delta^{18} \mathrm{O}$ stack using $\mathrm{Mg} / \mathrm{Ca}$ derived (Sosdian and Rosenthal, 2009) or constant inferred temperature contributions of 33\% (Miller et al., 2012) suggest increasing amplitudes of glacial-interglacial global sea-level cyclicity 
from 2.8 Ma, that are not displayed by the Whanganui RSL record (Figure 6.5). However, the New Zealand calibration using 20\% regular temperature contribution shows comparable amplitudes (Figure 6.5).

In summary, the MPWP displays RSL amplitudes on average of $15 \pm 8 \mathrm{~m}$, with individual cycles up to $25 \pm 8 \mathrm{~m}$. These are considered to be driven AIS fluctuations (up to $\sim 20 \mathrm{~m}$ contribution of marine based ice; Fretwell et al., 2013; Pollard et al., 2015) offset by limited influence from the GIS ( $\sim 5$ m contribution; Brigham-Grette et al., 2013; Dolan et al., 2015) under warmerthan-present climate conditions. The larger amplitude cycles are coincident with eccentricity modulated precession, favouring lower seasonality and colder extended summers, and following the expansion of sea-ice and cooling associated with the M2 glaciation (McKay et al., 2012). I speculate, that RSL amplitudes over $15 \mathrm{~m}$ (requiring $>20 \mathrm{~m}$ from AIS to offset $5 \mathrm{~m}$ from GIS) are associated with larger-than-present AIS during glacials, rather than interglacial melt above that available from present marine-based ice ( 19 m SLE; Pollard et al., 2015).

In the late Pliocene, the AIS continue to be paced by precession (Patterson et al., 2014), while NHIS and the benthic $\delta^{18} \mathrm{O}$ stack is dominated by obliquity (Lisiecki and Raymo, 2005; Jansen et al., 2000). The obliquity-paced RSL record then suggests that a NHIS meltwater source dominates sea-level and exceeds that of the AIS. The intensification of NHIS glaciation is dated to 2.7 Ma (Jansen et al., 2000; Haug et al., 2005), with a drop in pCO2 occurring earlier, at 2.8 Ma (Seki et al., 2010) coincident with a significant increase in amplitude of benthic $\delta^{18} \mathrm{O}$ from 2.8 Ma (Lisiecki and Raymo, 2005). The relative contributions of NHIS and AIS to RSL are more difficult to determine for this time period with the variable orbital-pacing and thus phasing, incurring positive or negative amplification of meltwater signatures at different times. The Whanganui RSL curve provides an upper limit on maximum Pliocene interglacial sea-level with respect to present day. If all the marine based ice from Antarctic ( $20 \mathrm{~m} \mathrm{SLE}$, Fretwell et al., 2013; Pollard et al., 2015) and up to 7m SLE was lost from Greenland, and the maximum glacial interglacial amplitude allowed by the RSL curve is $30 \mathrm{~m}$, then Pliocene sea-level could be no higher than $30 \mathrm{~m}$ above present day, compared with the $40 \mathrm{~m}$ implied by Dutton et al. (2015). 


\subsection{Sea level calibration of the benthic $\delta^{18} \mathrm{O}$ stack for the mid- to late Pliocene}

While the benthic $\delta^{18} \mathrm{O}$ stack remains the most detailed record of climate variability for the Neogene, a unique solution for the ice volume/sea-level component continues to be unrealised. In part this is hampered by an inability to constrain the temperature effect $\left(\delta^{18} \mathrm{O}_{\text {temperature}}\right)$ in the benthic $\delta^{18} \mathrm{O}$ stack (and other deep-sea $\delta^{18} \mathrm{O}$ records), but the contribution of polar ice sheet $\left(\delta^{18} \mathrm{O}_{\text {ice }}\right)$ to $\delta^{18} \mathrm{O}_{\text {seawater }}$ is similarly unconstrained. Nonetheless, the benthic $\delta^{18} \mathrm{O}$ stack does provide an important upper-limit on possible meltwater

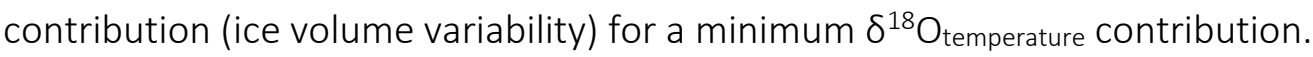

The Late Pleistocene provides a period for which there are numerous geological sea-level records combined with direct evidence of polar ice sheet extent, for comparison with ice-core and deep-sea $\delta^{18} \mathrm{O}$ to derive a calibration of $0.011 \% \mathrm{~m}$ SLE for the benthic $\delta^{18} \mathrm{O}$ records (Pillans et al., 1998). However, this Pleistocene calibration represents a combined polar ice

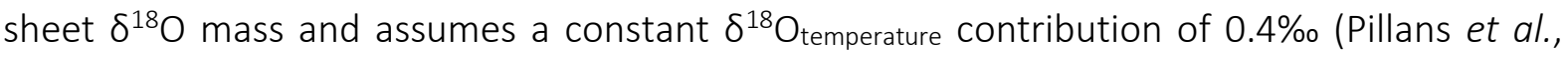
1998). It remains unclear if the Late Pleistocene calibration is valid for the Pliocene, especially under a warmer mean climate state.

$\mathrm{Mg} / \mathrm{Ca}$ paleothermometry was used to determine the relative $\delta^{18} \mathrm{O}_{\text {temperature component and }}$ calibrate the remaining $\delta^{18} \mathrm{O}_{\text {seawater }}$ (Dwyer and Chandler, 2009; Sosdian and Rosenthal, 2009). Whereby, the resulting $\delta^{18} \mathrm{O}_{\text {seawater }}$ is driven by variations in continental ice volume and by applying a calibration of $0.01 \% / \mathrm{m}$ (Shackleton and Opdyke, 1973), global mean sea-level is derived. Naish and Wilson (2009) determined SLE ice volume fluctuations from the benthic $\delta^{18} \mathrm{O}$ stack (Lisiecki and Raymo, 2005) by assuming a $\delta^{18} \mathrm{O}_{\text {temperature: }} \delta^{18} \mathrm{O}_{\text {seawater }}$ ratio of 20:80 and calibrating the remaining $\delta^{18} \mathrm{O}_{\text {seawater }}$ utilising the Late Pleistocene relationship of 0.011\%/m (Pillans et al., 1998).

Winnick and Caves (2015) identified the need to include variable $\delta^{18} \mathrm{O}_{\text {ice }}$ compositions of the polar ice sheets when calibrating the $\delta^{18} \mathrm{O}_{\text {seawater }}$ component of deep-sea $\delta^{18} \mathrm{O}$ records. Gasson et al. (2016) improved on this to account for an evolving Antarctic $\delta^{18} \mathrm{O}_{\text {ice }}$ composition where marginal and marine-based ice are not as depleted compared to the interior (Figure 6.8). Both of these studies assumed a $\delta^{18} \mathrm{O}_{\text {temperature: }} \delta^{18} \mathrm{O}_{\text {seawater }}$ ratio of 33:67 following the scaled calibration of Miller et al. (2012). 
Here, I correlate the Whanganui RSL record one-to-one with the benthic $\delta^{18} \mathrm{O}$ stack and compare the $\Delta \delta^{18} \mathrm{O}_{\text {benthic }}$ for glacial-interglacial Marine Isotope Stages (MIS) $101-\mathrm{M} 2$ with the associated RSL amplitudes for these cycles. On visual observation (Figure 6.9), the amplitudes of RSL during the MPWP correlate to relatively smaller changes in the benthic $\delta^{18} \mathrm{O}$ stack, while during an intermediate period between 3.0 and $2.8 \mathrm{Ma}$, some of the largest variations in the benthic $\delta^{18} \mathrm{O}$ stack are compared to small amplitudes in the Whanganui RSL curve. From 2.8 $\mathrm{Ma}$, the amplitudes of the benthic $\delta^{18} \mathrm{O}$ stack increase while the Whanganui RSL decreases. This is interpreted as a smaller calibration (less depleted $\delta^{18} \mathrm{O}_{\text {ice }}$ ) of $\delta^{18} \mathrm{O}_{\text {benthic }}$ to SLE for the MPWP, that is a lighter ice sheet contributing to SLE, more similar to that of the marine-based margins of Antarctica (Figure 6.8) or modern GIS. While the late Pliocene, in view of the previous statements made, would suggest a higher calibration (more depleted $\delta^{18} \mathrm{O}_{\text {ice}}$ ) for NHIS then currently assumed. Here, we investigate calibrations of $\delta^{18} \mathrm{O}_{\text {seawater }}$ using the RSL

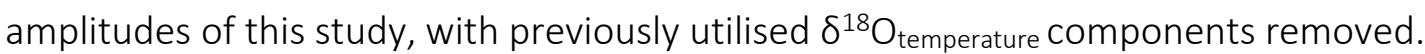



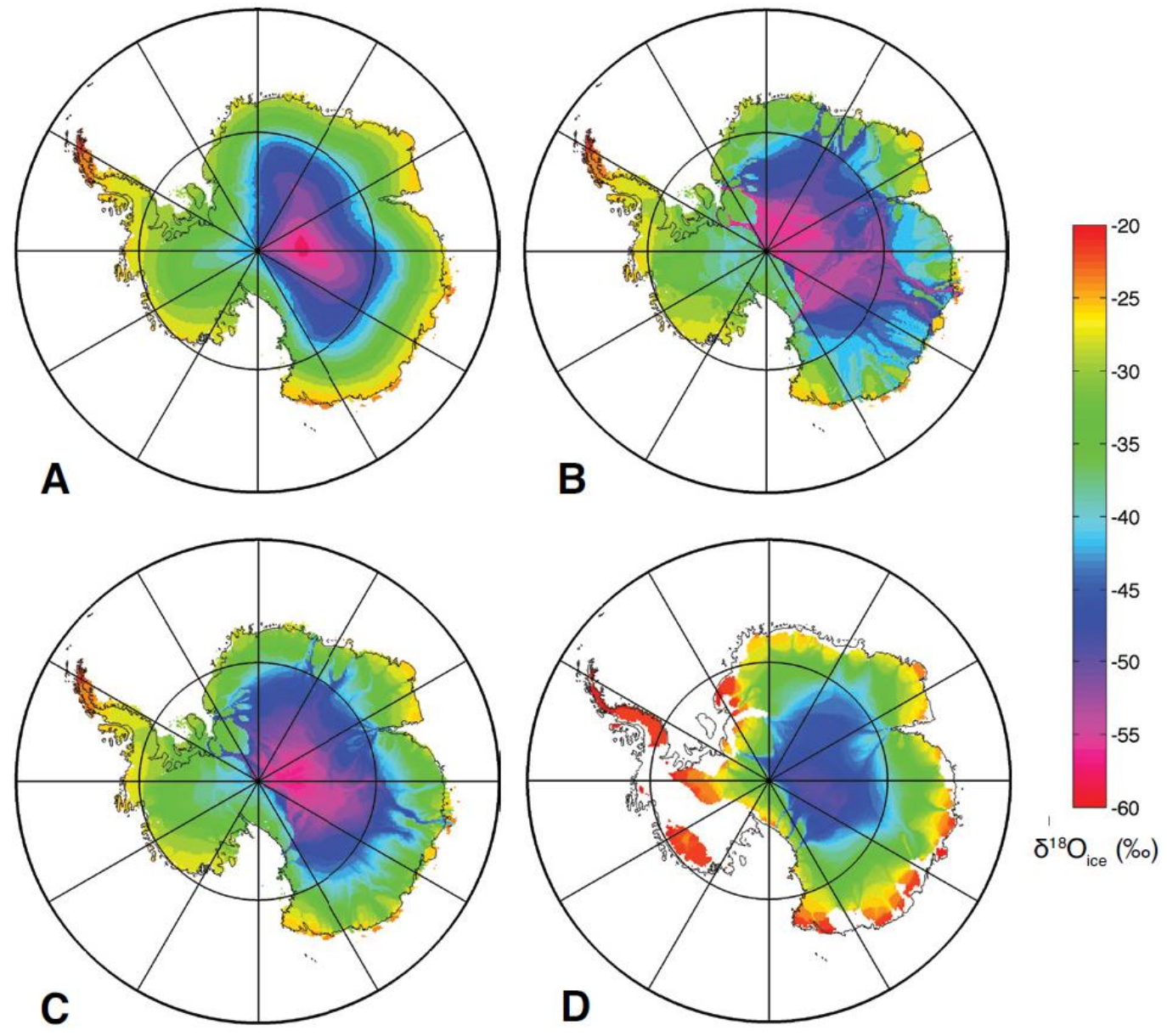

Figure 6.8 Modelled Antarctic ice sheet $\delta^{18} O$ composition (DeConto and Pollard, 2016) for A) modern ice surface. B) modern ice basal layer, C) modern depth-averaged D) Pliocene depth-averaged. 


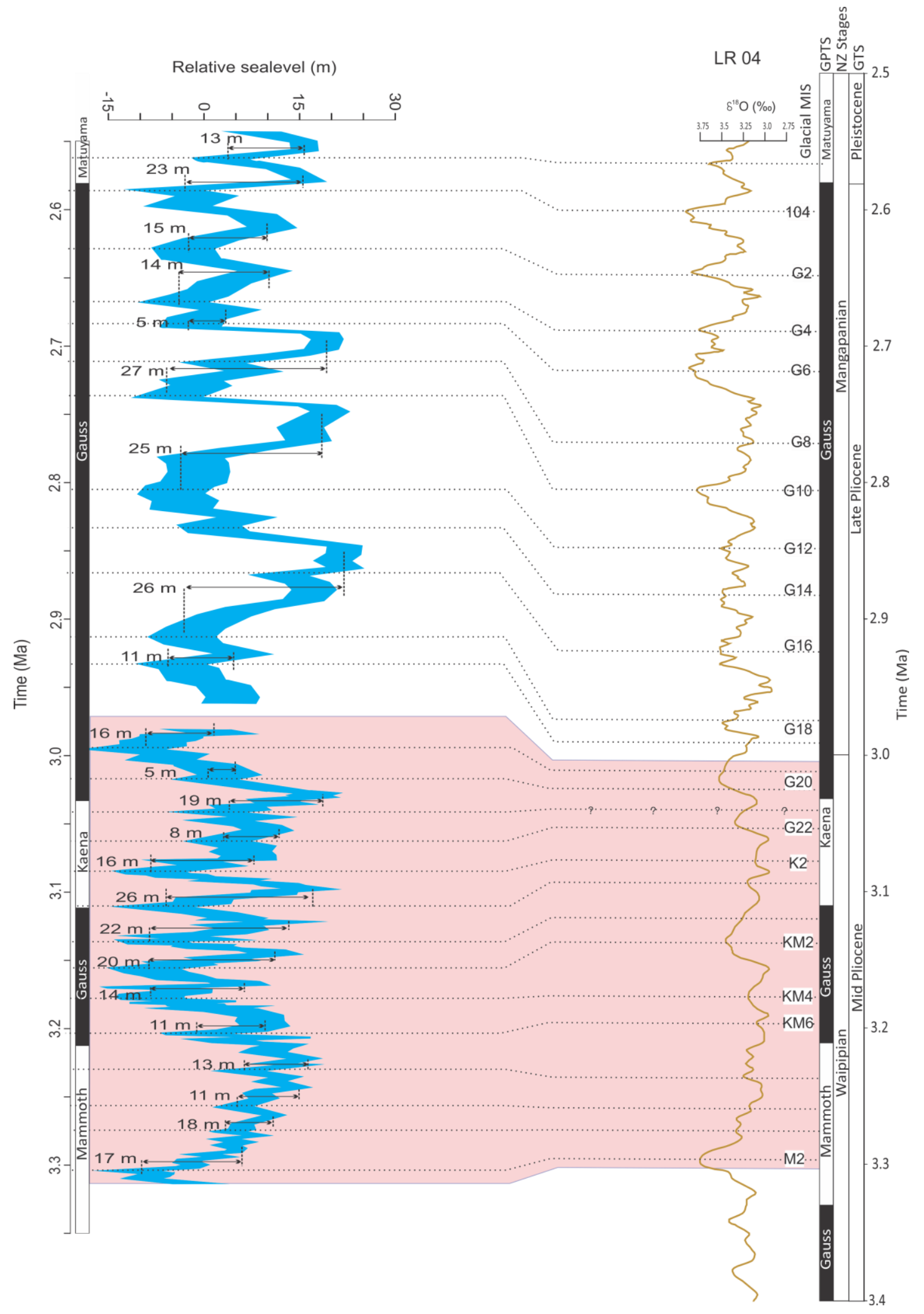

Figure 6.9 One-to-one correlation of sea-level fluctuations in the Whanganui RSL record with sea-level cycles implied from the benthic $\delta^{18} \mathrm{O}$ stack (Lisiecki and Raymo, 2005). Note that only identified marine isotope stages are used for $\triangle \delta 180$ seawater calibration purposes. It is also noted that during the MPWP the LRO4 stack is of lower resolution than the Whanganui RSL. The pink shaded area defines the MPWP. The RSL record is untuned accounting for the offset of the one-to-one correlations to the benthic $\delta^{18} \mathrm{O}$ stack. 


\section{Temperature-derived calibrations}

To determine sea-level calibrations of $\Delta \delta^{18} \mathrm{O}_{\text {benthic }}$ for glacial-interglacial MIS 101-M2, constant temperature contributions $\left(\Delta \delta^{18} \mathrm{O}_{\text {temperature}}\right.$ ) of $20 \%, 33 \%$ and $50 \%$ are removed to find the remaining $\Delta \delta^{18} \mathrm{O}_{\text {seawater }}$ (Equation 6.1), prior to dividing by the equivalent amplitude from the Whanganui RSL record (termed Calibration A; Equation 6.2; Table 6.2). These are compared to modern sea-level calibrations of marine-based and non-marine portions of the AIS and GIS (Table 6.3). Where WAIS marine contributes to the $\delta^{18} \mathrm{O}_{\text {seawater }}$ depletion but not to sea level in a linear manner.

$\Delta \delta^{18} \mathrm{O}_{\text {benthic }}-\Delta \delta^{18} \mathrm{O}_{\text {temperature }}=\delta^{18} \mathrm{O}_{\text {seawater }}$

Calibration $_{\mathrm{A}}(\% \mathrm{\%} / \mathrm{m})=\delta^{18} \mathrm{O}_{\text {seawater }} / \mathrm{RSL}$

Calibration $(\% \circ / m)=\left(\delta^{18} O_{\text {seawater }}\right.$ - WAIS marine $) /$ RSL
Equation 6.1

Equation 6.2

Equation 6.2

The $\delta^{18} \mathrm{O}_{\text {temperature }}$ contribution of $33 \%$ (Table 6.2) show an average of $0.009 \% / \mathrm{m}$ most similar to that of the modern GIS calibration (Table 6.3) compared to those of the modern variable AIS (Table 6.3). However, there is a significant difference between those of the MPWP (average $0.005 \% / \mathrm{m})$ and the late Pliocene $(0.011 \% / \mathrm{m}$; Table 6.2).

We then test the hypothesis that the marine-based portion of the West Antarctic Ice Sheet (WAIS marine) must retreat prior to further melt from AIS or in response to significant melt from the NHIS. Calibration B (Equation 6.3) reflects that, by excluding the WAIS marine $\delta^{18} \mathrm{O}_{\text {seawater }}$

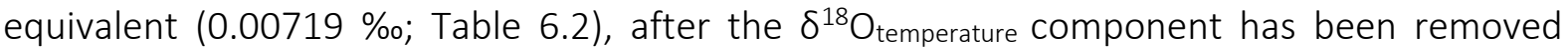
(Equation 6.3). The resulting calibrations for the mid- to late Pliocene decrease (for a 33\% temperature component) but remain very high in the late Pliocene ( $0.02 \% \circ / \mathrm{m})$, suggesting a more depleted ice sheet (similar to that of modern AIS; $-55 \% \delta^{18} \mathrm{O}_{\text {ice }} ; 0.14 \% / \mathrm{m}$ ) than the less depleted GIS (-35 \%o $\delta^{18} \mathrm{O}_{\text {ice}} ; 0.009 \% / \mathrm{m}$; Table 6.3$)$, which is assumed to predominantly contribute to meltwater for this time period. 
While a stepped cooling from the M2 glaciation to NHIS glaciation is persistent in some records (McKay et al., 2012, Brigham-Grette et al., 2013), a warming is observed in North Pacific bottom water temperatures (Woodard et al., 2014). As the benthic $\delta^{18} \mathrm{O}$ stack is dominated by

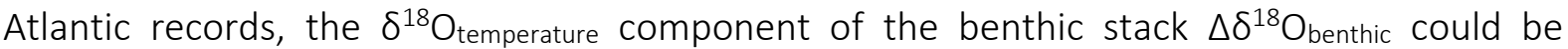

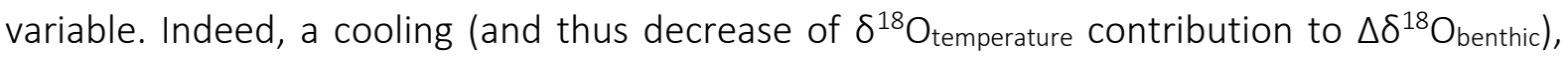
further increases the calibrations (accounts for higher $\delta^{18} \mathrm{O} \%$ o per $\mathrm{m}$ SLE) for the late Pliocene

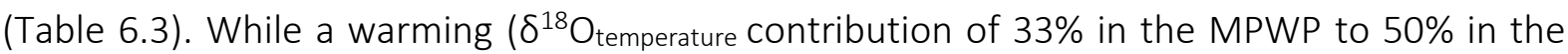
late Pliocene) reduces the calibrations to values nearing modern GIS (0.0092\%o/m; Table 6.2 Calibration B variable temperature). Calibration values nearing modern AIS (0.014\%o/m; Table 6.2) during the MPWP only occur when using a $\delta^{18} O_{\text {temperature: }} \delta^{18} \mathrm{O}_{\text {seawater }}$ ratio of 20:80 and without removing WAIS marine.

We suggest that, as shown by Gasson et al. (2016; Figure 6.8), East Antarctic Ice Sheet (EAIS) contributions are likely to be less depleted than the interior, and therefore, a lower calibration could be more suitable. However, Woodward et al., (2014) also show a decoupling of deep sea temperature and $\delta^{18} \mathrm{O}_{\text {benthic }}$ during the MPWP, suggesting that a calibration of the benthic $\delta^{18} \mathrm{O}$ stack is inappropriate for this time period, due to differing deep-sea signatures. Indeed, the complication of marine-based ice volume contribution to $\delta^{18} \mathrm{O}_{\text {seawater }}$ but limited sea level contribution also suggests a calibration may be unsuitable at this time.

Calibrations during the late Pliocene, driven by NHIS meltwater, could be explained by a more depleted $\delta^{18} \mathrm{O}_{\text {ice }}$ compared to the modern GIS, occurring as the NHIS developed, to provide a higher calibration. Alternatively, and in light of the calibrations suggested with the variable temperature components, the Whanganui RSL amplitudes in the Mangaweka Mudstone may underestimate the full amplitude. This could be a result of the lower sensitivity of the grain size method when nearing $100 \%$ mud providing a minimum of maximum water depth, which is observed in interglacial periods present in the Mangaweka Mudstone.

While it is acknowledged that this is a simplistic approach to a complex issue of marrying $\delta^{18} \mathrm{O}_{\text {benthic, }} \delta^{18} \mathrm{O}_{\text {temperature, }} \delta^{18} \mathrm{O}_{\text {seawater }} \delta^{18} \mathrm{O}_{\text {ice }}$ and $\mathrm{GMSL}$, and that a more comprehensive study utilising an oxygen-isotope capable ice sheet model, with additional GIA models of the RSL record would better address the sources of error. This provides an initial assessment of the assumptions often applied to calibrations of the benthic $\delta^{18} \mathrm{O}$ stack. 
Table 6.2 Calibration of resulting $\Delta \delta 180$ seawater for variable $\Delta \delta 180$ temperature contributions with RSL amplitudes for glacial-interglacial amplitudes of MIS 101-M2. Note the exclusion of WAISmarine $\Delta \delta 180$ seawater equivalent (Winnick and Caves, 2015) for the last two calibrations and the variable temperature component consists of 50\% for the late Pliocene and $33 \%$ for the MPWP.

\begin{tabular}{|c|c|c|c|c|c|c|c|c|}
\hline \multirow[b]{2}{*}{ MIS } & \multirow[b]{2}{*}{ Age (ka) } & \multirow[b]{2}{*}{ RSL mean (m) } & \multirow[b]{2}{*}{$\begin{array}{l}\Delta \mathrm{d} 180 \text { benthic } \\
\text { (LR04) }\end{array}$} & \multicolumn{3}{|c|}{ CalibrationA } & \multicolumn{2}{|c|}{ CalibrationB } \\
\hline & & & & $\begin{array}{l}\text { Calibration } \\
\text { (\%o/m) for } \\
\Delta \delta 180 \text { te mp } \\
20 \%\end{array}$ & $\begin{array}{l}\text { Calibration } \\
\text { (\%o/m) } \\
\Delta \delta 18 \text { Otemp } \\
33 \%\end{array}$ & $\begin{array}{l}\text { Calibration } \\
\text { (\%o/m) } \\
\Delta \delta 180 \text { te mp } \\
50 \%\end{array}$ & $\begin{array}{l}\text { Calibration }(\% / \mathrm{m}) \\
\Delta \delta 18 \text { Otemp } 33 \% \\
\text { exc. WAISmarine }\end{array}$ & $\begin{array}{l}\text { Calibration }(\% / \mathrm{m}) \\
\text { variable } \\
\Delta \delta 18 \text { Otemp } \\
\text { exc. WAISma rine }\end{array}$ \\
\hline $102-101$ & 2556 & 13.1 & 0.42 & 0.026 & 0.021 & 0.016 & 0.016 & 0.011 \\
\hline $104-103$ & 2585 & 23.4 & 0.74 & 0.025 & 0.021 & 0.016 & 0.018 & 0.013 \\
\hline G2- G1 & 2630 & 15.1 & 0.61 & 0.032 & 0.027 & 0.020 & 0.022 & 0.015 \\
\hline $\mathrm{G} 4-\mathrm{G} 3$ & 2657 & 14.5 & 0.7 & 0.039 & 0.032 & 0.024 & 0.027 & 0.019 \\
\hline G6 - G5 & 2697 & 6.7 & 0.39 & 0.047 & 0.039 & 0.029 & 0.028 & 0.018 \\
\hline G8 - G7 & 2747 & 19.5 & 0.27 & 0.011 & 0.009 & 0.007 & 0.006 & 0.006 \\
\hline G10 - G9 & 2787 & 14.7 & 0.62 & 0.034 & 0.028 & 0.021 & 0.023 & 0.023 \\
\hline G12- G11 & 2830 & 25 & 0.39 & 0.012 & 0.010 & 0.008 & 0.008 & 0.008 \\
\hline G14 - G13 & 2862 & 7.4 & 0.31 & 0.034 & 0.028 & 0.021 & 0.018 & 0.018 \\
\hline G16 - G15 & 2900 & 11.1 & 0.36 & 0.026 & 0.022 & 0.016 & 0.015 & 0.015 \\
\hline G18 - G17 & 2945 & 21.6 & 0.56 & 0.021 & 0.017 & 0.013 & 0.014 & 0.014 \\
\hline G20 - G19 & 2990 & 16 & 0.45 & 0.023 & 0.019 & 0.014 & 0.014 & 0.014 \\
\hline G22- G21 & 3035 & 19 & 0.24 & 0.010 & 0.008 & 0.006 & 0.006 & 0.005 \\
\hline $\mathrm{K} 2-\mathrm{K} 1$ & 3060 & 16 & 0.14 & 0.007 & 0.006 & 0.004 & 0.003 & 0.001 \\
\hline KM2- KM1 & 3105 & 22 & 0.39 & 0.014 & 0.012 & 0.009 & 0.011 & 0.009 \\
\hline KM4-KM3 & 3155 & 14 & 0.24 & 0.014 & 0.011 & 0.009 & 0.009 & 0.006 \\
\hline KM6-KM5 & 3190 & 11 & 0.14 & 0.010 & 0.009 & 0.006 & 0.004 & 0.002 \\
\hline M2 & 3280 & 17 & 0.48 & 0.023 & 0.019 & 0.014 & 0.018 & 0.015 \\
\hline
\end{tabular}

Table 6.3 Modern $\delta^{18}$ Oice values (Lhomme et al., 2005) and sea-level equivalent (Fretwell et al., 2013) for calibrations after Winnick and Caves (2015). The WAISmarine total $\delta^{18}$ Oseawater equivalent is the value used in Table 6-1 and 6-3.

\begin{tabular}{lllll}
\hline & $\begin{array}{l}\delta^{18} \text { Oice } \\
(\%)\end{array}$ & SLE $(\mathrm{m})$ & $\begin{array}{l}\text { Calibration } \\
\left(\% \circ \mathrm{m}^{-1}\right)\end{array}$ & $\begin{array}{l}\text { Total } \\
\text { equivalent } \\
\Delta \delta^{18} \mathrm{O}_{\text {seawater }} \\
(\% \circ)\end{array}$ \\
\hline EAIS & -54.7 & 53.3 & -0.014 & -0.8533 \\
GIS & -35 & 7.3 & -0.0092 & -0.0672 \\
$\begin{array}{l}\text { WAIS (non- } \\
\text { marine) }\end{array}$ & -41 & 0.9 & -0.0106 & -0.0095 \\
$\begin{array}{l}\text { WAlS } \\
\text { (marine) }\end{array}$ & -41 & 3.4 & & -0.0719 \\
\hline
\end{tabular}




\subsection{Summary}

In summary, the MPWP and late Pliocene represent two significantly different periods in the Whanganui RSL record. The MPWP is characterised by $15 \pm 8 \mathrm{~m}$ sea-level amplitudes paced by 20 kyr precession, in-phase with Southern Hemisphere high-latitude summer insolation, indicating a dominant Antarctic source. A limited anti-phase GIS contribution is favoured by climate models and is taken to be no more than $\pm 5 \mathrm{~m}$, while the AIS is considered to contain 20 m SLE of dynamic marine-based ice, from present-day configuration. Figure 6.10 illustrates that for the MPWP, $20 \mathrm{~m}$ contributed from AIS offset by $5 \mathrm{~m}$ from GIS produces 15 m of RSL. GIA modelling of said meltwater contributions shows that RSL at Whanganui approximates ESL. Larger amplitudes would then require smaller GIS contribution or largerthan-present AIS (i.e. LGM) to contribute more to ESL (Figure 6.10). The cyclicity of the Whanganui RSL record for the MPWP does not correlate well to cyclicity recorded in the benthic $\delta^{18} \mathrm{O}$ stack, suggesting that a sea-level calibration of deep-sea $\delta^{18} \mathrm{O}$ may be unsuitable at this time due to low temporal and spatial resolution of the individual records, decoupling of deep-sea temperature and $\delta^{18} \mathrm{O}_{\text {seawater, }}$ and the non-linear relationship between marinebased ice and sea level.

The late Pliocene is characterised by obliquity in both the Whanganui RSL record and benthic $\delta^{18} \mathrm{O}$ stack. This is interpreted as increasing influence of NHIS, as AIS fluctuations are shown to continue at precession frequencies. The average amplitude of $20 \pm 8 \mathrm{~m}$ is interpreted as larger contributions from NHIS and more limited AIS contributions (Figure 6.10). 


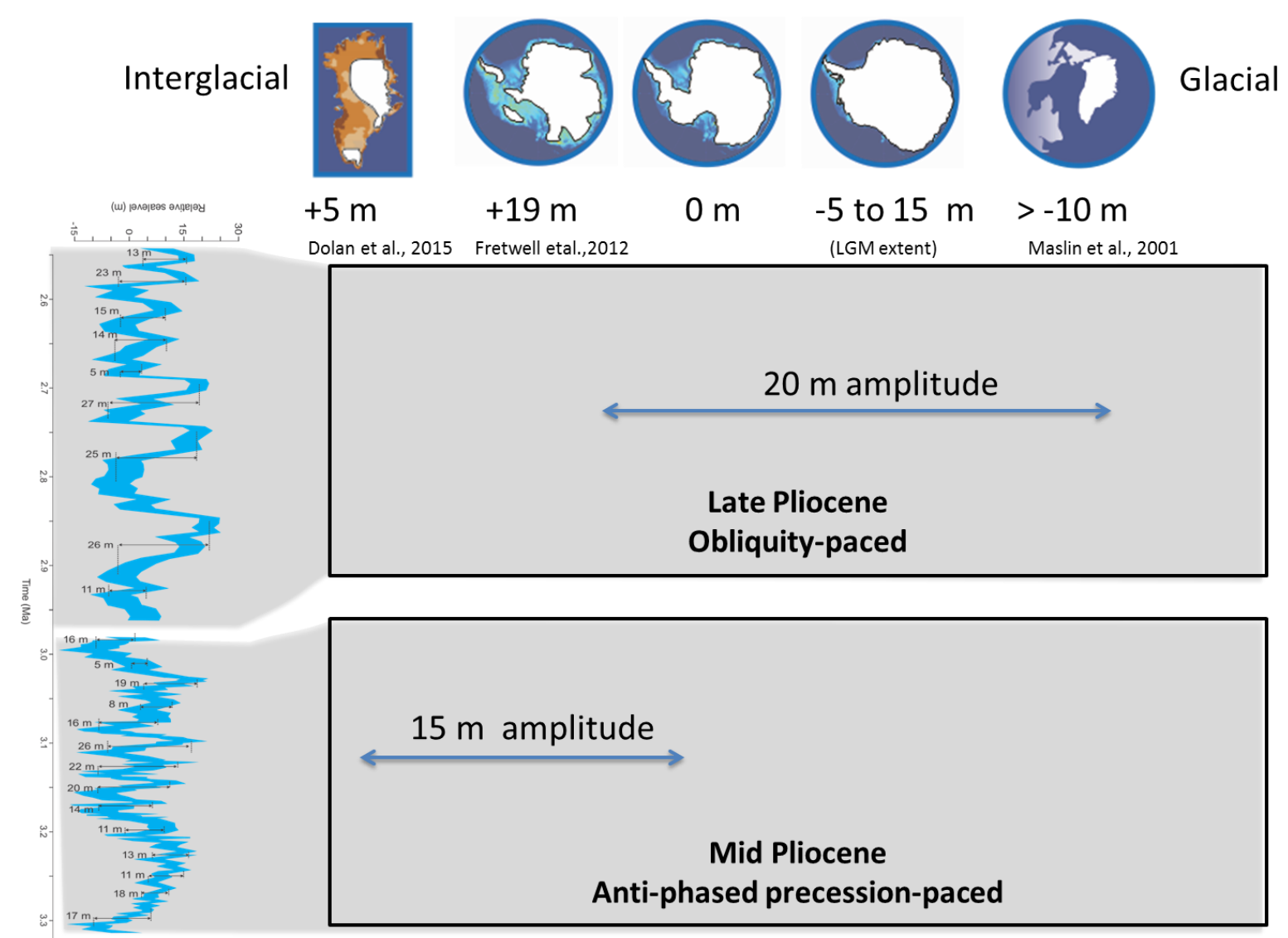

Figure 6.10 The Whanganui RSL record on the left with the precession-paced MPWP and obliquity-paced late Pliocene sections highlighted with different GIS, AIS and NHIS configurations and SLE illustrated for interglacial and glacial extreme conditions relative to present-day Antarctica ( $0 \mathrm{~m}$; central figure). The anti-phased $15 \mathrm{~m}$ amplitudes of the MPWP are interpreted as $5 \mathrm{~m}$ from GIS offset by $\sim 20 \mathrm{~m}$ from AIS present day to peak interglacial. Higher amplitudes would then include larger-than-present AIS (nearing LGM; Clarke and Tarasov, 2014). While the late Pliocene amplitudes include increasing NHIS contributions and smaller interglacial configurations.

\subsubsection{Future work}

This thesis has provided a novel significant contribution in developing a technique to quantify paleobathymetry from shallow-marine sequences. It is intended that this technique will be applied to global sequences that fit the criteria (i.e. are shown to be wave-graded) for comparison with this RSL record following backstripping, and to extend the direct RSL record for the past. This would also require further GIA modelling.

The RSL record derived in this thesis has provided insights into the orbital pacing of global sea level, contributing to the understanding of polar ice sheet response and sensitivity in varying climates. This requires further exploration utilising ice sheet climate models to assess ice sheet response, driven by the RSL record presented here. 
The orbital frequencies recorded in the RSL record in comparison to the benthic $\delta^{18} \mathrm{O}$ stack has significant implications for the interpretation of deep-sea $\delta^{18} \mathrm{O}$ records. The de-coupling of RSL and benthic $\delta^{18} \mathrm{O}$ stack during the MPWP is a likely result of multiple factors including deep-sea ocean temperature, stacking of low temporal resolution records and the non-linear relationship of marine-based ice sheet contributions to $\delta^{18}$ Oseawater and sealevel. It is intended that with oxygen-isotope mass-balance equations and oxygen-isotope capable models this can be further explored. 


\section{References}

Abbott, S.T. and Carter, R.M., 1994. The sequence architecture of mid-Pleistocene (c. 1.1-0.4 Ma) cyclothems from New Zealand: facies development during a period of orbital control on sea-level cyclicity. Orbital forcing and cyclic sequences, pp.367-394.

Abe-Ouchi, A., Saito, F., Kawamura, K., Raymo, M.E., Okuno, J.I., Takahashi, K. and Blatter, H., 2013. Insolation-driven 100,000-year glacial cycles and hysteresis of ice sheet volume. Nature, 500(7461), p.190.

Alloway, B.V., Pillans, B.J., Naish, T.R., and Westgate, J.A. (2004). Age and correlation of Ototoka tephra. Appendix in "Molluscan biostratigraphy of oxygen isotope stages of the last 2 million years in New Zealand". Part 1. Revised generic positions and recognition of warm- and cool-water migrants. Beu, A.G. Journal of the Royal Society of New Zealand 34, pp.261-265.

Alloway, B.V., Pillans, B.J., Carter, L., Naish, T.R. and Westgate, J.A., 2005. Onshore-offshore correlation of Pleistocene rhyolitic eruptions from New Zealand: implications for TVZ eruptive history and paleoenvironmental construction. Quaternary Science Reviews, 24(14), pp.1601-1622.

Anderson, J.B., Shipp, S.S., Lowe, A.L., Wellner, J.S. and Mosola, A.B., 2002. The Antarctic Ice Sheet during the Last Glacial Maximum and its subsequent retreat history: a review. Quaternary Science Reviews, 21(1-3), pp.49-70.

Andersen, K.K., Azuma, N., Barnola, J.M., Bigler, M., Biscaye, P., Caillon, N., Chappellaz, J., Clausen, H.B., Dahl-Jensen, D., Fischer, H. and Flückiger, J., 2004. High-resolution record of Northern Hemisphere climate extending into the last interglacial period. Nature, 431(7005), p.147.

Anderton, P.W., 1981. Structure and evolution of the south Wanganui Basin, New Zealand. New Zealand journal of geology and geophysics, 24(1), pp.39-63.

Andrews, J.T., 1970. A Geomorphological Study of Postglacial Uplift With Particular Reference to Arctic Canada. Oxford Univ. Press, New York.

Austermann, J., Pollard, D., Mitrovica, J.X., Moucha, R., Forte, A.M., DeConto, R.M., Rowley, D.B. and Raymo, M.E., 2015. The impact of dynamic topography change on Antarctic ice sheet stability during the mid-Pliocene warm period. Geology, 43(10), pp.927-930.

Bartoli, G., Hönisch, B. and Zeebe, R.E., 2011. Atmospheric CO2 decline during the Pliocene intensification of Northern Hemisphere glaciations. Paleoceanography, 26(4).

Berger, A. and Loutre, M.F, 1991. Insolation values for the climate of the last 10 million years. Quaternary Science Reviews, 10(4), pp.297-317.

Beu, A.G. and Edwards, A.R. 1984. New Zealand Pleistocene and late Pliocene glacio-eustatic cycles. Palaeogeography, palaeoclimatology, palaeoecology, 46(1-3), pp.119-142.

Beu, A. G., and Maxwell, P. A. 1990. Cenozoic Mollusca of New Zealand. New Zealand Geological Survey Paleontological Bulletin 58, 518 pp.

Beaumont, J., Anderson, T. J., and MacDiarmid, A.B. 2013. Benthic flora and fauna of the Patea Shoals region, South Taranaki Bight. NIWA client report WLG2012-55. 183 pg. 
Böning, C.W., Dispert, A., Visbeck, M., Rintoul, S.R. and Schwarzkopf, F.U., 2008. The response of the Antarctic Circumpolar Current to recent climate change. Nature Geoscience, 1(12), p.864.

Booij, N.R.R.C., Ris, R.C. and Holthuijsen, L.H., 1999. A third-generation wave model for coastal regions: 1. Model description and validation. Journal of geophysical research: Oceans, 104(C4), pp.7649-7666.

Braun, J., 2010. The many surface expressions of mantle dynamics. Nature Geoscience, 3(12), p.825.

Brigham-Grette, J., Melles, M., Minyuk, P., Andreev, A., Tarasov, P., DeConto, R., Koenig, S., Nowaczyk, N., Wennrich, V., Rosén, P. and Haltia, E., 2013. Pliocene warmth, polar amplification, and stepped Pleistocene cooling recorded in NE Arctic Russia. Science, p.1233137.

Browning, J.V., Miller, K.G., McLaughlin, P.P., Jr., Edwards, L.E., Kulpecz, A.A., Powars, D.S., Wade, B.S., Feigenson, M.D., and Wright, J.D., 2009, Integrated sequence stratigraphy of the post-impact sediments from the Eyreville core holes, Chesapeake Bay impact structure inner basin, in Gohn, G.S., et al., eds., The ICDP-USGS deep drilling project in the Chesapeake Bay impact structure: Results from the Eyreville core holes: Geological Society of America Special Paper 458, p. 775-810.

Bunce, M., Worthy, T.H., Phillips, M.J., Holdaway, R.N., Willerslev, E., Haile, J., Shapiro, B., Schofiled, R.P., Drummond, A., Kamp, P.J.J. and Cooper, A. 2009: The evolutionary history of the extinct ratite moa and New Zealand Neogene paleogeography. Proceedings National Academy of Sciences www.pnas.org/cgi/doi/10.10.1073/pnas.0906660106

Carter, L., 1980. Ironsand in continental shelf sediments off western New Zealand-a synopsis. New Zealand journal of geology and geophysics, 23(4), pp.455-468.

Carter, L., Shane, P., Alloway, B., Hall, I. R., Harris, S., Westgate, J. A. 2003. Demise of one volcanic zone and birth of another - A 12 m.y. marine record of major rhyolitic eruptions from New Zealand. Geology, 31(6), 493-496.

Carter, L., Carter, R.M. and McCave, I.N., 2004. Evolution of the sedimentary system beneath the deep Pacific inflow off eastern New Zealand. Marine Geology, 205(1), pp.9-27.

Carvajal, C., Steel, R. and Petter, A., 2009. Sediment supply: the main driver of shelf-margin growth. Earth-Science Reviews, 96(4), pp.221-248.

Chappell, J. and Shackleton, N., 1986. Oxygen isotopes and sea level. Nature, 324(6093), p.137.

Chin, J.L., 1984. Late Quaternary coastal sedimentation and depositional history, south-central Monterey Bay, California(Doctoral dissertation, San Jose State University).

Clark, P.U. and Tarasov, L., 2014. Closing the sea level budget at the Last Glacial Maximum. Proceedings of the National Academy of Sciences, 111(45), pp.15861-15862.

Clement, A.J., Whitehouse, P.L. and Sloss, C.R., 2016. An examination of spatial variability in the timing and magnitude of Holocene relative sea-level changes in the New Zealand archipelago. Quaternary Science Reviews, 131, pp.73-101.

Coastal Engineering Research Center. 1984. Shore Protection Manual, Vol I and II, U.S. Army Corps of Engineers, Vicksbourg, Mississippi. 
Cook, C.P., Van De Flierdt, T., Williams, T., Hemming, S.R., Iwai, M., Kobayashi, M., Jimenez-Espejo, F.J., Escutia, C., González, J.J., Khim, B.K. and McKay, R.M., 2013. Dynamic behaviour of the East Antarctic ice sheet during Pliocene warmth. Nature Geoscience, 6(9), p.765.

Cooper, R. A., Agterberg, F.P., Alloway, B. V., Beu, A. G., Campbell, H. J., Cooper, R. A., Crampton, J. S., Crouch, E. M., Crundwell, M. P., Graham, I. J., Hollis, C. J., Jones, C. M., Kamp, P. J. J., Mildenhall, D. C., Morgans, H. E. G., Naish, T. R., Raine, J. I., Roncaglia, L., Sadler, P. M., Schioler, P., Scott, G. H., Strong, C. P. Wilson, G. J., \& Wilson, G. S. 2004. The New Zealand Geological Timescale. Intitue of Geological and Nuclear Sciences Monograph 22, 284 pp.

Crowley, T.J. and Hyde, W.T., 2008. Transient nature of late Pleistocene climate variability. Nature, 456(7219), p.226.

De Boer, B., Haywood, A. M., Dolan, A. M., Hunter, S. J., Prescott, C. L., 2017. The transient response of ice volume to orbital forcing during the warm Late Pliocene. Geophysical Research Letters, $44(20) p$ 10486-10494.

DeConto, R.M., Pollard, D., Wilson, P.A., Pälike, H., Lear, C.H. and Pagani, M., 2008. Thresholds for Cenozoic bipolar glaciation. Nature, 455(7213), p.652.

DeConto, R.M. and Pollard, D., 2016. Contribution of Antarctica to past and future sea-level rise. Nature, 531(7596), p.591.

Denton, G.H. and Hughes, T.J., 2002. Reconstructing the Antarctic ice sheet at the Last Glacial Maximum. Quaternary Science Reviews, 21(1-3), pp.193-202.

Ding, Z.L., Derbyshire, E., Yang, S.L., Yu, Z.W., Xiong, S.F. and Liu, T.S., 2002. Stacked 2.6-Ma grain size record from the Chinese loess based on five sections and correlation with the deep-sea $\delta 180$ record. Paleoceanography and Paleoclimatology, 17(3).

Dolan, A.M., Hunter, S.J., Hill, D.J., Haywood, A.M., Koenig, S.J., Otto-Bliesner, B.L., Abe-Ouchi, A., Bragg, F., Chan, W.L., Chandler, M.A. and Contoux, C., 2015. Using results from the PlioMIP ensemble to investigate the Greenland Ice Sheet during the mid-Pliocene Warm Period. Climate of the Past, 11(3), pp.403-424.

Dowsett, H.J. and Cronin, T.M., 1990. High eustatic sea level during the middle Pliocene: Evidence from the southeastern US Atlantic Coastal Plain. Geology, 18(5), pp.435-438.

Dowsett, H.J., Robinson, M.M., Haywood, A.M., Hill, D.J., Dolan, A.M., Stoll, D.K., Chan, W.L., AbeOuchi, A., Chandler, M.A., Rosenbloom, N.A. and Otto-Bliesner, B.L., 2012. Assessing confidence in Pliocene sea surface temperatures to evaluate predictive models. Nature Climate Change, 2(5), p.365.

Droser, M., \& Bottjet, D. 1986. A semiquantitative classification of ichnofabric. Research Methods Papers, 558-559.

Dunbar, G.B. and Barrett, P.J., 2005. Estimating palaeobathymetry of wave-graded continental shelves from sediment texture. Sedimentology, 52(2), pp.253-269.

Dutton, A., Carlson, A.E., Long, A.J., Milne, G.A., Clark, P.U., DeConto, R., Horton, B.P., Rahmstorf, S. and Raymo, M.E., 2015. Sea-level rise due to polar ice sheet mass loss during past warm periods. science, 349(6244). 
Dwyer, G.S. and Chandler, M.A., 2009. Mid-Pliocene sea level and continental ice volume based on coupled benthic Mg/Ca palaeotemperatures and oxygen isotopes. Philosophical Transactions of the Royal Society of London A: Mathematical, Physical and Engineering Sciences, 367(1886), pp.157-168.

Eckart, C., 1952, November. The propagation of gravity waves from deep to shallow water. In Gravity waves (p. 165).

Elderfield, H., Greaves, M., Barker, S., Hall, I.R., Tripati, A., Ferretti, P., Crowhurst, S., Booth, L. and Daunt, C., 2010. A record of bottom water temperature and seawater $\delta 18 \mathrm{O}$ for the Southern Ocean over the past 440kyr based on $\mathrm{Mg} / \mathrm{Ca}$ of benthic foraminiferal Uvigerina spp. Quaternary Science Reviews, 29(1), pp.160-169.

Embry, A.F., 1993. Transgressive-regressive sequence stratigraphic analysis of the Jurassic succession of the Sverdrup Basin, Canadian Arctic Achipelago. Canadian Journal of Earth Sciences, 30, pp.301320.

Emiliani, C., 1966. Paleotemperature analysis of Carribean cores P6304-8 and P6304-9 and a generalized temperature curve for the past 425,000 years. Journal of Geology 74 (2), pp. 102-126.

EPICA Community Members. 2004. Eight glacial cycles from an Antarctic core. Nature, 429, pp. 623628.

Fairbanks, R.G. and Matthews, R.K., 1978. The Marine Oxygen Isotope Record in Pleistocene Coral, Barbados, West Indies 1. Quaternary Research, 10(2), pp.181-196.

Farrell, W.E., and Clark, J.A., 1976. On postglacial sea-level. Geophysical Journal of Royal Astronomical Society, 46:647-667.

Fedorov, A.V., Brierley, C.M., Lawrence, K.T., Liu, Z., Dekens, P.S. and Ravelo, A.C., 2013. Patterns and mechanisms of early Pliocene warmth. Nature, 496(7443), p.43.

Fleming, C. A. 1953. The geology of Wanganui Subdivision. New Zealand Geological Survey bulletin, 52.

Fretwell, P., Pritchard, H.D., Vaughan, D.G., Bamber, J.L., Barrand, N.E., Bell, R., Bianchi, C., Bingham, R.G., Blankenship, D.D., Casassa, G. and Catania, G., 2013. Bedmap2: improved ice bed, surface and thickness datasets for Antarctica.

Friedman, I., O'neil, J., \& Cebula, G. 1982. Two new carbonate stable isotope standards, Geostandards Newsletter $6111-12$.

Ganopolski, A., Calov, R. and Claussen, M., 2010. Simulation of the last glacial cycle with a coupled climate ice sheet model of intermediate complexity. Climate of the Past, 6(2), pp.229-244.

Gasson, E., DeConto, R.M., Pollard, D. and Levy, R.H., 2016. Dynamic Antarctic ice sheet during the early to mid-Miocene. Proceedings of the National Academy of Sciences, 113(13), pp.3459-3464.

Gille, S.T., 2008. Decadal-scale temperature trends in the Southern Hemisphere ocean. Journal of Climate, 21(18), pp.4749-4765. 
Golledge, N.R., Menviel, L., Carter, L., Fogwill, C.J., England, M.H., Cortese, G. and Levy, R.H., 2014. Antarctic contribution to meltwater pulse $1 \mathrm{~A}$ from reduced Southern Ocean overturning. Nature communications, 5, p.5107.

Golledge, N.R., Levy, R.H., McKay, R.M. and Naish, T.R., 2017. East Antarctic ice sheet most vulnerable to Weddell Sea warming. Geophysical Research Letters, 44(5), pp.2343-2351.

Grant, G. R., 2012. Pliocene-Pleistocene orbital cyclostratigraphy and glacial evolution of the East Antarctic Ice Sheet from continental rise IODP core site U1361, Wilkes Land margin, East Antarctica. Unpublished MSc thesis, Victoria University of Wellington.

Hambrey, M.J. and McKelvey, B., 2000. Major Neogene fluctuations of the East Antarctic ice sheet: Stratigraphic evidence from the Lambert Glacier region. Geology, 28(10), pp.887-890.

Hamilton, T. D., Reed, K., Thorson, R., 1986. Glaciation in Alaska: the Geologic Record. Alaska Geology Society, Anchorage, AK.

Hammer, $\varnothing$., Harper, D.A.T. and Ryan, P.D., 2009. Paleontological statistics. ver, 1, p.92.

Hammer, $\varnothing$., Harper, D.A.T. and Ryan, P.D., 2001. PAST-Palaeontological statistics. www. uv. es/ pardomv/pe/2001_1/past/pastprog/past. pdf, acessado em, 25(07), p.2009.

Haug, G.H. and Tiedemann, R., 1998. Effect of the formation of the Isthmus of Panama on Atlantic Ocean thermohaline circulation. Nature, 393(6686), p.673.

Haug, G.H., Ganopolski, A., Sigman, D.M., Rosell-Mele, A., Swann, G.E., Tiedemann, R., Jaccard, S.L., Bollmann, J., Maslin, M.A., Leng, M.J. and Eglinton, G., 2005. North Pacific seasonality and the glaciation of North America 2.7 million years ago. Nature, 433(7028), p.821.

Hay, C, Mitrovica JX, Gomez N, Creveling JR, Austermann J, Kopp RR, 2014. The sea-level fingerprints of ice sheet collapse during interglacial periods. Quaternary Science Review. 2014;87:60.

Hayden, T., Kominz, M., Powars, D.S., Edwards, L.E., Miller, K.G., Browning, J.V. and Kulpecz, A.A., 2008. Impact effects and regional tectonic insights: Backstripping the Chesapeake Bay impact structure. Geology, 36(4), pp.327-330.

Hays, J.D., Imbrie, J. and Shackleton, N.J., 1976, December. Variations in the Earth's orbit: pacemaker of the ice ages. Washington, DC: American Association for the Advancement of Science.

Hayton, S. H. 1998. Sequence stratigraphic, paleoenvironmental, and chronological analysis of the late Neogene Wanganui River section, Wanganui Basin. Unpublished PhD thesis, University of Waikato.

Hayward, B. W. 1986. A guide to paleoenvironmental assessment using New Zealand Cenozoic foraminiferal faunas. New Zealand Geological Survey Report Paleontology, 109, 73 p.

Hayward, B.W., Grenfell, H.R., Reid, C. M., and Hayward, K.A., 1999. Recent shallow-water benthic foraminifera: taxonomy, ecologic distribution, biogeography and use in paleoenvironmental assessment. New Zealand Geological Survey Paleontological Bulletin, 75. 
Hayward, B.W., Neil, H., Carter, R., Grenfell, H.R. and Hayward, J.J., 2002. Factors influencing the distribution patterns of Recent deep-sea benthic foraminifera, east of New Zealand, Southwest Pacific Ocean. Marine Micropaleontology, 46(1), pp.139-176.

Hayward, B.W. and Triggs, C.M., 2016. Using multi-foraminiferal-proxies to resolve the paleogeographic history of a lower Miocene, subduction-related, sedimentary basin (Waitemata Basin, New Zealand). The Journal of Foraminiferal Research, 46(3), pp.285-313.

Haywood, A.M., Hill, D.J., Dolan, A.M., Otto-Bliesner, B.L., Bragg, F., Chan, W.L., Chandler, M.A., Contoux, C., Dowsett, H.J., Jost, A. and Kamae, Y., 2013. Large-scale features of Pliocene climate: results from the Pliocene Model Intercomparison Project. Climate of the Past, 9(1), p.191.

Herbert, T.D., Peterson, L.C., Lawrence, K.T. and Liu, Z., 2010. Tropical ocean temperatures over the past 3.5 million years. Science, 328(5985), pp.1530-1534.

Hill, K.L., Rintoul, S.R., Coleman, R. and Ridgway, K.R., 2008. Wind forced low frequency variability of the East Australia Current. Geophysical Research Letters, 35(8).

Hill, D.J., Dolan, A.M., Haywood, A.M., Hunter, S.J. and Stoll, D.K., 2010. Sensitivity of the Greenland Ice Sheet to Pliocene sea surface temperatures. Stratigraphy, 7(2-3), pp.111-121.

Hönisch, B., Hemming, N.G., Archer, D., Siddall, M. and McManus, J.F., 2009. Atmospheric carbon dioxide concentration across the mid-Pleistocene transition. Science, 324(5934), pp.1551-1554.

Hume, T., Gorman, R., Green, Malcolm., MacDonald, lain., 2013. Coastal stability in the South Taranaki Bight - Phase 2: Potential effects of offshore sand extraction on physical drivers and coastal stability. NIWA Client Report HAM2013-082. 132 pgs.

Huybers, P., 2006. Early Pleistocene glacial cycles and the integrated summer insolation forcing. science, 313(5786), pp.508-511.

Huybers, P. and Tziperman, E., 2008. Integrated summer insolation forcing and 40,000-year glacial cycles: The perspective from an ice-sheet/energy-balance model. Paleoceanography, 23(1).

Huybers, P., 2009. Pleistocene glacial variability as a chaotic response to obliquity forcing. Climate of the Past, 5(3), pp.481-488.

Imbrie, J., Boyle, E.A., Clemens, S.C., Duffy, A., Howard, W.R., Kukla, G., Kutzbach, J., Martinson, 7., Mclntyre, A., Mix, A.C. and Molfino, B., 1992. On the structure and origin of major glaciation cycles 1. Linear responses to Milankovitch forcing. Paleoceanography, 7(6), pp.701-738.

Jaccard, S.L., Galbraith, E.D., Sigman, D.M. and Haug, G.H., 2010. A pervasive link between Antarctic ice core and subarctic Pacific sediment records over the past 800 kyrs. Quaternary Science Reviews, 29(1-2), pp.206-212.

Jaccard, S.L., Hayes, C.T., Martínez-García, A., Hodell, D.A., Anderson, R.F., Sigman, D.M. and Haug, G.H., 2013. Two modes of change in Southern Ocean productivity over the past million years. Science, 339(6126), pp.1419-1423. 
James, N.P., Bone, Y., Carter, R.M., \& Murray-Wallace, C. V. 2006. Origin of the Late Neogene Roe Plains and their calcarenite veneer: implications for sedimentology and tectonics in the Great Australian Bight. Australian Journal of Earth Science, 53, pp. 407-419.

Jansen, E., Fronval, T., Rack, F. and Channell, J.E., 2000. Pliocene-Pleistocene ice rafting history and cyclicity in the Nordic Seas during the last 3.5 Myr. Paleoceanography, 15(6), pp.709-721.

Jones, R.S., Mackintosh, A.N., Norton, K.P., Golledge, N.R., Fogwill, C.J., Kubík, P.W., Christl, M. and Greenwood, S.L., 2015. Rapid Holocene thinning of an East Antarctic outlet glacier driven by marine ice sheet instability. Nature communications, 6, p.8910.

Journeaux, T.D. 1995. Lithostratigraphy, foraminiferal paleoecology and sequence stratigraphy of Middle Pliocene marine strata, Wanganui Basin, New Zealand. Unpublished M.Sc. thesis, University of Waikato.

Journeaux, T.D., Kamp, P.J. and Naish, T., 1996. Middle Pliocene cyclothems, Mangaweka region, Wanganui Basin, New Zealand: a lithostratigraphic framework. New Zealand Journal of Geology and Geophysics, 39(1), pp.135-149.

Kamp, P.J. and Turner, G.M., 1990. Pleistocene unconformity-bounded shelf sequences (Wanganui Basin, New Zealand) correlated with global isotope record. Sedimentary geology, 68(1-2), pp.155-161.

Kamp, P.J., Journeaux, T.D. and Morgans, H.E., 1998. Cyclostratigraphy of middle Pliocene mid shelf to upper slope strata, eastern Wanganui Basin (New Zealand): correlations to the deep sea isotope record. Sedimentary Geology, 117(3-4), pp.165-192.

Kamp, P.J., Vonk, A.J., Bland, K.J., Griffin, A., Hayton, S., Hendy, A.J., Mclntyre, A.P., Nelson, C.S. and Naish, T.R., 2002. Megasequence architecture of Taranaki, Wanganui, and King Country basins and Neogene progradation of two continental margin wedges across western New Zealand.

Kamp, P.J., Vonk, A.J., Bland, K.J., Hansen, R.J., Hendy, A.J., Mclntyre, A.P., Ngatai, M., Cartwright, S.J., Hayton, S. and Nelson, C.S., 2004. Neogene stratigraphic architecture and tectonic evolution of Wanganui, King Country, and eastern Taranaki Basins, New Zealand. New Zealand Journal of Geology and Geophysics, 47(4), pp.625-644.

Köhler, P., Bintanja, R., Fischer, H., Joos, F., Knutti, R., Lohmann, G. and Masson-Delmotte, V., 2010. What caused Earth's temperature variations during the last 800,000 years? Data-based evidence on radiative forcing and constraints on climate sensitivity. Quaternary Science Reviews, 29(1-2), pp.129145.

Komar, P.D. and Miller, M.C., 1975. On the comparison between the threshold of sediment motion under waves and unidirectional currents with a discussion of the practical evaluation of the threshold: Reply. Journal of Sedimentary Research, 45(1).

Kominz, M.A., and Pekar, S., 2001: Oligocene eustasy from two-dimensional sequence stratigraphic back-stripping. Bulletin of the Geological Society of America. 113, 291-304.

Kominz, M.A., Browning, J.V., Miller, K.G., Sugarman, P.J., Mizintseva, S. and Scotese, C.R., 2008. Late Cretaceous to Miocene sea-level estimates from the New Jersey and Delaware coastal plain coreholes: An error analysis. Basin Research, 20(2), pp.211-226. 
Kominz, M.A., Patterson, K. and Odette, D., 2011. Lithology dependence of porosity in slope and deep marine sediments. Journal of Sedimentary Research, 81(10), pp.730-742.

Kulpecz, A.A., Miller, K.G., Browning, J.V., Edwards, L.E., Powars, D.S., McLaughlin Jr, P.P., Harris, A.D. and Feigenson, M.D., 2009. Post-impact deposition in the Chesapeake Bay impact structure: Variations in eustasy, compaction, sediment supply, and passive-aggressive tectonism. The ICDP-USGS deep drilling project in the Chesapeake Bay impact structure: Results from the Eyreville core holes: Geological Society of America Special Paper, 458, pp.811-837.

Kukla, G.J., 1977. Pleistocene land-sea correlations I. Europe. Earth-Science Reviews, 13(4), pp.307374.

Lambeck, K., 2008: Glacial Isostasy. In Encyclopedia of Paleoclimatology and Ancient Environments, (Vivien Gornitz, Ed), Springer, The Netherlands, 374-380.

Lambeck, K., 2011. Glacio-hydro-isostasy. In Encyclopedia of Modern Coral Reefs. (D. Hopley, ed.), Springer, Dordrecht, pp 491-497.

Lambert, F., Delmonte, B., Petit, J.R., Bigler, M., Kaufmann, P.R., Hutterli, M.A., Stocker, T.F., Ruth, U., Steffensen, J.P. and Maggi, V., 2008. Dust-climate couplings over the past 800,000 years from the EPICA Dome C ice core. Nature, 452(7187), p.616.

Lang, N. and Wolff, E.W., 2011. Interglacial and glacial variability from the last $800 \mathrm{ka}$ in marine, ice and terrestrial archives. Climate of the Past, 7(2), p.361.

Laskar, J., Robutel, P., Joutel, F., Gastineau, M., Correia, A. C. M. and Levrard, B. 2004. A long-term numerical solution for the insolation quantities of the Earth. Astronomy \& Astrophysics, 428, 261-285.

Lear, C.H., Elderfield, H. and Wilson, P.A., 2000. Cenozoic deep-sea temperatures and global ice volumes from Mg/Ca in benthic foraminiferal calcite. Science, 287(5451), pp.269-272.

Lhomme, N., Clarke, G.K. and Ritz, C., 2005. Global budget of water isotopes inferred from polar ice sheets. Geophysical Research Letters, 32(20).

Li, M.Z. and Amos, C.L., 2001. SEDTRANS96: the upgraded and better calibrated sediment-transport model for continental shelves. Computers \& Geosciences, 27(6), pp.619-645.

Lisiecki, L.E. and Raymo, M.E., 2005. A Pliocene-Pleistocene stack of 57 globally distributed benthic $\delta 180$ records. Paleoceanography, 20(1).

Lisiecki, L.E., Raymo, M.E. and Curry, W.B., 2008. Atlantic overturning responses to Late Pleistocene climate forcings. Nature, 456(7218), p.85.

Lea, D. W. 2010. Elemental and Isotopic Proxies of Past Ocean Temperatures. In Holland, H. D., \& Turekian, K. K. (eds.) Treatise on Geochemistry, Second Edition, 8, pp. 373-397.

Le Maitre, R.W., 1984. A proposal by the IUGS Subcommission on the Systematics of Igneous Rocks for a chemical classification of volcanic rocks based on the total alkali silica (TAS) diagram: (on behalf of the IUGS Subcommission on the Systematics of Igneous Rocks). Australian Journal of Earth Sciences, 31(2), pp.243-255. 
Levy, R., Harwood, D., Florindo, F., Sangiorgi, F., Tripati, R., von Eynatten, H., Gasson, E., Kuhn, G., Tripati, A., DeConto, R. and Fielding, C., 2016. Antarctic ice sheet sensitivity to atmospheric CO2 variations in the early to mid-Miocene. Proceedings of the National Academy of Sciences, 113(13), pp.3453-3458.

Levy, R. H., Meyers, S. R., Naish, T. R., McKay, R. M., Golledge, N. R., Crampton, J. S., DeConto, R. M., De Santis, L., Florindo, F., Gasson, E. G. W., Harwood, D. M., Luyendyk, B. P., Powell, R. D., Clowes, C., and Kulhanek, D. 2018. Antarctic ice sheet-ocean connections enhance Earth system sensitivity to obliquity forcing. In review for Nature Geosciences. 23 pp.

Lunt, D.J., Foster, G.L., Haywood, A.M. and Stone, E.J., 2008. Late Pliocene Greenland glaciation controlled by a decline in atmospheric CO 2 levels. Nature, 454(7208), p.1102.

Lunt, D.J., Haywood, A.M., Schmidt, G.A., Salzmann, U., Valdes, P.J. and Dowsett, H.J., 2010. Earth system sensitivity inferred from Pliocene modelling and data. Nature Geoscience, 3(1), p.60.

Lunt, D.J., Haywood, A.M., Schmidt, G.A., Salzmann, U., Valdes, P.J., Dowsett, H.J. and Loptson, C.A., 2012. On the causes of mid-Pliocene warmth and polar amplification. Earth and Planetary Science Letters, 321, pp.128-138.

Lüthi, D., Le Floch, M., Bereiter, B., Blunier, T., Barnola, J.M., Siegenthaler, U., Raynaud, D., Jouzel, J., Fischer, H., Kawamura, K. and Stocker, T.F., 2008. High-resolution carbon dioxide concentration record 650,000-800,000 years before present. Nature, 453(7193), p.379.

Mackintosh, A.N., Verleyen, E., O'Brien, P.E., White, D.A., Jones, R.S., McKay, R., Dunbar, R., Gore, D.B., Fink, D., Post, A.L. and Miura, H., 2014. Retreat history of the East Antarctic Ice Sheet since the last glacial maximum. Quaternary Science Reviews, 100, pp.10-30.

Malan, J. A. 1991. Lithostratigraphy of the De Hoopvlei Formation (Bredasdorp Group). Dept. of Mineral and Energy Affairs, Geological Survey, Pretoria.

Mann, M.E., and Lees, J.M., 1996, Robust estimation of background noise and signal detection in climatic time series, Clim. Change, 33, 409-445.

Marchitto, T. M., Curry, W. B., Lynch-Stieglitz, J., Bryan, S. P., Cobb, K. M., \& Lund, D. C. 2014. Improved oxygen isotope temperature calibrations for cosmopolitan benthic foraminifera. Geochemica et Cosmochimica Acta, 130, 1-11.

Martínez-Botí, M.A., Foster, G.L., Chalk, T.B., Rohling, E.J., Sexton, P.F., Lunt, D.J., Pancost, R.D., Badger, M.P.S. and Schmidt, D.N., 2015. Plio-Pleistocene climate sensitivity evaluated using highresolution CO 2 records. Nature, 518(7537), p.49.

Martínez-Garcia, A., Rosell-Melé, A., Jaccard, S.L., Geibert, W., Sigman, D.M. and Haug, G.H., 2011. Southern Ocean dust-climate coupling over the past four million years. Nature, 476(7360), p.312.

Maslin, M.A., Li, X.S., Loutre, M.F. and Berger, A., 1998. The contribution of orbital forcing to the progressive intensification of Northern Hemisphere glaciation. Quaternary Science Reviews, 17(4-5), pp.411-426. 
Masson-Delmotte, V., Schulz, M., Abe-Ouchi, A., Beer, J., Ganopolski, A., González Rouco, J.F., Jansen, E., Lambeck, K., Luterbacher, J., Naish, T. and Osborn, T., 2013. Information from paleoclimate archives. Climate change, 383464, p.2013.

Mazzulllo, J., \& Graham, A. G. 1988. Handbook for shipboard sedimentologists. Ocean Drilling Program, Texas A\&M University, Technical Notre no. 8, 67pp.

McGuire, D. M. 1989. Paleomagnetic stratigraphy and magnetic properties of Pliocene strata, Turakina River, North Island, New Zealand. Unpublished PhD thesis, Victoria University of Wellington.

McIntyre, A. P. 2002. Geology of Mangapanian (late Pliocene) strata, Wanganui Basin: lithostratigraphy, palaeontology and sequence stratigraphy. Unpublished PhD thesis, University of Waikato.

McKay, R., Naish, T., Carter, L., Riesselman, C., Dunbar, R., Sjunneskog, C., Winter, D., Sangiorgi, F., Warren, C., Pagani, M. and Schouten, S., 2012. Antarctic and Southern Ocean influences on Late Pliocene global cooling. Proceedings of the National Academy of Sciences, 109(17), pp.6423-6428.

Melles, M., Brigham-Grette, J., Minyuk, P.S., Nowaczyk, N.R., Wennrich, V., DeConto, R.M., Anderson, P.M., Andreev, A.A., Coletti, A., Cook, T.L. and Haltia-Hovi, E., 2012. 2.8 million years of Arctic climate change from Lake El'gygytgyn, NE Russia. science, p.1222135.

MetOcean View. 2018. MetOcean View Hindcast. Retrieved $7^{\text {th }}$ May 2017, from Metocean https://hindcast.metoceanview.com/

Meyers, S.R. and Hinnov, L.A., 2010. Northern Hemisphere glaciation and the evolution of PlioPleistocene climate noise. Paleoceanography, 25(3).

Meyers, S. R., 2014. Astrochron: An R Package for Astrochronology. https://cran.rproject.org/package=astrochron

Milankovitch, M.M. 1941. Kanon der Erdbestrahlung und seine Anwendung auf das Eiszeitenproblem. Royal Serbian Sciences, Special Publications 132, Section of Mathematical and Natural Sciences, Belgrade, (Canon of Insolation and the Ice Age Problem, English translation by Israel Program for Scientific Translation, published for the US Department of Commerce and the National Science Foundation, Washington DC, 1969).

Mercer, J.H., 1978. West Antarctic ice sheet and CO2 greenhouse effect: a threat of disaster. Nature, 271(5643), p.321.

Mikutta, R., Kleber, M., Kaiser, K., \& Jahn, R. 2005. Review: Organic matter removal from soils using hydrogen peroxide, sodium hypochlorite and disodium peroxodisulfate. Soil Science Society of America Journal, 69, 1, 120-135.

Mildenhall, D.C., 2003. Deep-sea record of Pliocene and Pleistocene terrestrial palynomorphs from offshore eastern New Zealand (ODP Site 1123, Leg 181). New Zealand Journal of Geology and Geophysics, 46(3), pp.343-361.

Mildenhall, D.C., Hollis, C.J. and Naish, T.R., 2004. Orbitally-influenced vegetation record of the midPleistocene climate transition, offshore eastern New Zealand (ODP Leg 181, Site 1123). Marine Geology, 205(1-4), pp.87-111. 
Miller, K.G., Kominz, M.A., Browning, J.V., Wright, J.D., Mountain, G.S., Katz, M.E., Sugarman, P.J., Cramer, B.S., Christie-Blick, N. and Pekar, S.F., 2005. The Phanerozoic record of global sea-level change. science, 310(5752), pp.1293-1298.

Miller, K.G., Wright, J.D., Browning, J.V., Kulpecz, A., Kominz, M., Naish, T.R., Cramer, B.S., Rosenthal, Y., Peltier, W.R. and Sosdian, S., 2012. High tide of the warm Pliocene: Implications of global sea level for Antarctic deglaciation. Geology, 40(5), pp.407-410.

Mitrovica, J.X. and Peltier, W.R., 1991. On postglacial geoid subsidence over the equatorial oceans. Journal of Geophysical Research: Solid Earth, 96(B12), pp.20053-20071.

Moore, D.G. and Curray, J.R., 1964. Wave-base, marine profile of equilibrium, and wave-built terraces: discussion. Geological Society of America Bulletin, 75(12), pp.1267-1273.

Moucha, R., Forte, A.M., Mitrovica, J.X., Rowley, D.B., Quéré, S., Simmons, N.A. and Grand, S.P., 2008. Dynamic topography and long-term sea-level variations: There is no such thing as a stable continental platform. Earth and Planetary Science Letters, 271(1-4), pp.101-108.

Müller, R.D., Sdrolias, M., Gaina, C., Steinberger, B. and Heine, C., 2008. Long-term sea-level fluctuations driven by ocean basin dynamics. science, 319(5868), pp.1357-1362.

Naish, T. and Kamp, P.J., 1995. Pliocene-Pleistocene marine cyclothems, Wanganui Basin, New Zealand: A lithostratigraphic framework. New Zealand journal of geology and geophysics, 38(2), pp.223-243.

Naish, T., Kamp, P.J., Alloway, B.V., Pillans, B., Wilson, G.S. and Westgate, J.A., 1996. Integrated tephrochronology and magnetostratigraphy for cyclothemic marine strata, Wanganui Basin: implications for the Pliocene-Pleistocene boundary in New Zealand. Quaternary International, 34, pp.29-48.

Naish, T., 1997. Constraints on the amplitude of late Pliocene eustatic sea-level fluctuations: new evidence from the New Zealand shallow-marine sediment record. Geology, 25(12), pp.1139-1142.

Naish, T. and Kamp, P.J., 1997a. Sequence stratigraphy of sixth-order (41 ky) Pliocene-Pleistocene cyclothems, Wanganui basin, New Zealand: a case for the regressive systems tract. Geological Society of America Bulletin, 109(8), pp.978-999.

Naish, T. and Kamp, P.J., 1997b. Foraminiferal depth palaeoecology of Late Pliocene shelf sequences and systems tracts, Wanganui Basin, New Zealand. Sedimentary Geology, 110(3-4), pp.237-255.

Naish, T.R., Abbott, S.T., Alloway, V., Beu, A.G., Carter, R.M., Edwards, A.R., Journeaux, T.D., Kamp, P.J., Pillans, B.J., Saul, G. and Woolfe, K.J., 1998. Astronomical calibration of a southern hemisphere Plio-Pleistocene reference section, Wanganui Basin, New Zealand. Quaternary Science Reviews, 17(8), pp.695-710.

Naish, T.R., Field, B.D., Zhu, H., Melhuish, A., Carter, R.M., Abbott, S.T., Edwards, S., Alloway, B.V., Wilson, G.S., Niessen, F. and Barker, A., 2005. Integrated outcrop, drill core, borehole and seismic stratigraphic architecture of a cyclothemic, shallow-marine depositional system, Wanganui Basin, New Zealand. Journal of the Royal Society of New Zealand, 35(1-2), pp.91-122. 
Naish, T., Powell, R., Levy, R., Wilson, G., Scherer, R., Talarico, F., Krissek, L., Niessen, F., Pompilio, M., Wilson, T. and Carter, L., 2009. Obliquity-paced Pliocene West Antarctic ice sheet oscillations. Nature, 458(7236), p.322.

Naish, T.R. and Wilson, G.S., 2009. Constraints on the amplitude of Mid-Pliocene (3.6-2.4 Ma) eustatic sea-level fluctuations from the New Zealand shallow-marine sediment record. Philosophical Transactions of the Royal Society of London A: Mathematical, Physical and Engineering Sciences, 367(1886), pp.169-187.

Naish, T. and Zwartz, D., 2012. Palaeoclimate: looking back to the future. Nature Climate Change, 2(5), p.317.

Ogg, J.G., 2012. Geomagnetic polarity time scale. In Gradstein, F.M., Ogg, J.G., Schmitz, M. and Ogg, G. (Eds.), The geologic time scale 2012, (pp. 85-113), Elsevier.

Pahnke, K., Zahn, R., Elderfield, H. and Schulz, M., 2003. 340,000-year centennial-scale marine record of Southern Hemisphere climatic oscillation. Science, 301(5635), pp.948-952.

Paillard, D. and Parrenin, F., 2004. The Antarctic ice sheet and the triggering of deglaciations. Earth and Planetary Science Letters, 227(3-4), pp.263-271.

Paolo, F.S., Fricker, H.A. and Padman, L., 2015. Volume loss from Antarctic ice shelves is accelerating. Science, 348(6232), pp.327-331.

Parrenin, F., Masson-Delmotte, V., Köhler, P., Raynaud, D., Paillard, D., Schwander, J., Barbante, C., Landais, A., Wegner, A. and Jouzel, J., 2013. Synchronous change of atmospheric CO2 and Antarctic temperature during the last deglacial warming. Science, 339(6123), pp.1060-1063.

Passchier, S., 2011. Linkages between East Antarctic Ice Sheet extent and Southern Ocean temperatures based on a Pliocene high-resolution record of ice-rafted debris off Prydz Bay, East Antarctica. Paleoceanography, 26(4).

Patterson, M. O. 2014. The response of Antarctic ice volume, global sea-level and southwest Pacific Ocean circulation to orbital variations during the Pliocene to Early Pleistocene. Unpublished PhD thesis, Victoria University of Wellington.

Patterson, M.O., McKay, R., Naish, T., Escutia, C., Jimenez-Espejo, F.J., Raymo, M.E., Meyers, S.R., Tauxe, L., Brinkhuis, H., Expedition, I.O.D.P. and Klaus, A., 2014. Orbital forcing of the East Antarctic ice sheet during the Pliocene and Early Pleistocene. Nature Geoscience, 7(11), p.841.

Pekar, S.F., Christie-Blick, N., Kominz, M.A. and Miller, K.G., 2002. Calibration between eustatic estimates from backstripping and oxygen isotopic records for the Oligocene. Geology, 30(10), pp.903906.

Perrett, T.L., 1990. Variations in sediment texture and biota off a wave-dominated coast, Peka Peka, New Zealand. Unpublished MSc thesis, Victoria University of Wellington. 
Petit, J.R., Jouzel, J., Raynaud, D., Barkov, N.I., Barnola, J.M., Basile, I., Bender, M., Chappellaz, J., Davis, M., Delaygue, G. and Delmotte, M., 1999. Climate and atmospheric history of the past 420,000 years from the Vostok ice core, Antarctica. Nature, 399(6735), p.429.

Pillans, B., Chappell, J. and Naish, T.R., 1998. A review of the Milankovitch climatic beat: template for Plio-Pleistocene sea-level changes and sequence stratigraphy. Sedimentary Geology, 122(1-4), pp.521.

Pithan, F. and Mauritsen, T., 2013. Comments on "Current GCMs' Unrealistic Negative Feedback in the Arctic". Journal of Climate, 26(19), pp.7783-7788.

Pollard, D. and DeConto, R.M., 2009. Modelling West Antarctic ice sheet growth and collapse through the past five million years. Nature, 458(7236), p.329.

Pollard, D., DeConto, R.M. and Alley, R.B., 2015. Potential Antarctic Ice Sheet retreat driven by hydrofracturing and ice cliff failure. Earth and Planetary Science Letters, 412, pp.112-121.

Proust, J.N., Lamarche, G., Nodder, S. and Kamp, P.J., 2005. Sedimentary architecture of a PlioPleistocene proto-back-arc basin: Wanganui Basin, New Zealand. Sedimentary Geology, 181(3-4), pp.107-145.

Pulford, A. K. 2002. Crustal structure and lithospheric doming: aspects of deformation along an obliquely convergent plate margin, New Zealand. Unpublished PhD thesis, Victoria University of Wellington.

Pulford, A. and Stern, T., 2004. Pliocene exhumation and landscape evolution of central North Island, New Zealand: the role of the upper mantle. Journal of Geophysical Research: Earth Surface, 109(F1).

Pritchard, H., Ligtenberg, S.R.M., Fricker, H.A., Vaughan, D.G., Van den Broeke, M.R. and Padman, L., 2012. Antarctic ice sheet loss driven by basal melting of ice shelves. Nature, 484(7395), p.502.

Prokopenko, A.A., Hinnov, L.A., Williams, D.F. and Kuzmin, M.I., 2006. Orbital forcing of continental climate during the Pleistocene: a complete astronomically tuned climatic record from Lake Baikal, SE Siberia. Quaternary Science Reviews, 25(23-24), pp.3431-3457.

Raine, J.I., Beu, A.G., Boyes, A.F., Campbell, H., Cooper, R.A., Crampton, J.S., Crundwell, M.P., Hollis, C.J. and Morgans, H.E.G., 2015. Revised calibration of the New Zealand Geological Timescale: NTGT2015/1. Lower Hutt: GNS Science.

Raymo, M.E., 1994. The initiation of Northern Hemisphere glaciation. Annual Review of Earth and Planetary Sciences, 22(1), pp.353-383.

Raymo, M.E. and Nisancioglu, K.H., 2003. The 41 kyr world: Milankovitch's other unsolved mystery. Paleoceanography, 18(1).

Raymo, M.E., Lisiecki, L.E. and Nisancioglu, K.H., 2006. Plio-Pleistocene ice volume, Antarctic climate, and the global 8180 record. Science, 313(5786), pp.492-495. 
Raymo, M.E. and Huybers, P., 2008. Unlocking the mysteries of the ice ages. Nature, 451(7176), p.284.

Raymo, M. E., J. X. Mitrovica, M. J. O'Leary, R. M. DeConto, and P. J. Hearty, 2011: Departures from eustasy in Pliocene sea level records. Nature Geoscience, 4, 328-332.

Rignot, E., Bamber, J.L., Van Den Broeke, M.R., Davis, C., Li, Y., Van De Berg, W.J. and Van Meijgaard, E., 2008. Recent Antarctic ice mass loss from radar interferometry and regional climate modelling. Nature geoscience, 1(2), p.106.

Rignot, E., Mouginot, J., Morlighem, M., Seroussi, H. and Scheuchl, B., 2014. Widespread, rapid grounding line retreat of Pine Island, Thwaites, Smith, and Kohler glaciers, West Antarctica, from 1992 to 2011. Geophysical Research Letters, 41(10), pp.3502-3509.

Rintoul, S.R., Silvano, A., Pena-Molino, B., van Wijk, E., Rosenberg, M., Greenbaum, J.S. and Blankenship, D.D., 2016. Ocean heat drives rapid basal melt of the Totten Ice Shelf. Science advances, 2(12).

Rohling, E.J., Grant, K., Bolshaw, M., Roberts, A.P., Siddall, M., Hemleben, C. and Kucera, M., 2009. Antarctic temperature and global sea level closely coupled over the past five glacial cycles. Nature Geoscience, 2(7), p.500.

Rohling, E.J., Foster, G.L., Grant, K.M., Marino, G., Roberts, A.P., Tamisiea, M.E. and Williams, F., 2014. Sea-level and deep-sea-temperature variability over the past 5.3 million years. Nature, 508(7497), p.477.

Rovere, A., Raymo, M.E., Mitrovica, J.X., Hearty, P.J., O'Leary, M.J. and Inglis, J.D., 2014. The MidPliocene sea-level conundrum: Glacial isostasy, eustasy and dynamic topography. Earth and Planetary Science Letters, 387, pp.27-33.

Rovere, A., Stocchi, P. and Vacchi, M., 2016. Eustatic and relative sea level changes. Current Climate Change Reports, 2(4), pp.221-231.

Rowley, DB, Forte, A.M., Mouch, R., Mitrovica, J. X., Simmons, N.A., Grand, GP., 2013. Dynamic topography change of the eastern United Sates since 3 million years ago, Science (Express), 16th May, 2013.

Sagar, M.W. and Palin, J.M., 2011. Emplacement, metamorphism, deformation and affiliation of midCretaceous orthogneiss from the Paparoa Metamorphic Core Complex lower-plate, Charleston, New Zealand. New Zealand Journal of Geology and Geophysics, 54(3), pp.273-289.

Salzmann, U., Haywood, A.M. and Lunt, D.J., 2009. The past is a guide to the future? Comparing Middle Pliocene vegetation with predicted biome distributions for the twenty-first century. Philosophical Transactions of the Royal Society of London A: Mathematical, Physical and Engineering Sciences, 367(1886), pp.189-204.

Saul, G., Naish, T.R., Abbott, S.T. and Carter, R.M., 1999. Sedimentary cyclicity in the marine PliocenePleistocene of the Wanganui basin (New Zealand): Sequence stratigraphic motifs characteristic of the past 2.5 my. Geological Society of America Bulletin, 111(4), pp.524-537. 
Schoof, C., 2007. Ice sheet grounding line dynamics: Steady states, stability, and hysteresis. Journal of Geophysical Research: Earth Surface, 112(F3).

Scripps Institution of Oceanography. 2018. Coastal Data Information Program, retrieved on $7^{\text {th }}$ May 2017 from

http://cdip.ucsd.edu/themes/cdip?d2=p70\&u3=dt:201101:p id:p70:ibf:1:mode:all:s:156:st:1:t:data

Sefton, J. P. 2015. An assessment of the influence of orbital forcing on Late Pliocene global sea-level using a shallow-marine sedimentary record from the Wanganui Basin, New Zealand. Unpublished MSC thesis, Victoria University of Wellington.

Seki, O., Foster, G.L., Schmidt, D.N., Mackensen, A., Kawamura, K. and Pancost, R.D., 2010. Alkenone and boron-based Pliocene pCO 2 records. Earth and Planetary Science Letters, 292(1), pp.201-211.

Seki, O., Schmidt, D.N., Schouten, S., Hopmans, E.C., Sinninghe Damsté, J.S. and Pancost, R.D., 2012. Paleoceanographic changes in the Eastern Equatorial Pacific over the last 10 Myr. Paleoceanography, 27(3).

Shackleton, N.J. and Opdyke, N.D., 1973. Oxygen isotope and palaeomagnetic stratigraphy of equatorial Pacific core V28-238: Oxygen isotope temperatures and ice volumes on a 105 year and 10 6 year scale. Quaternary research, 3(1), pp.39-55.

Shackleton, N.J., Backman, J., Zimmerman, H.T., Kent, D.V., Hall, M.A., Roberts, D.G., Schnitker, D., Baldauf, J.G., Desprairies, A., Homrighausen, R. and Huddlestun, P., 1984. Oxygen isotope calibration of the onset of ice-rafting and history of glaciation in the North Atlantic region. Nature, 307(5952), p.620.

Shackleton, N.J., Hall, M.A. and Pate, D., 1995. 15. Pliocene stable isotope stratigraphy of Site 846. In Proc. Ocean Drill. Program Sci. Results (Vol. 138, pp. 337-355).

Shakun, J.D., Clark, P.U., He, F., Marcott, S.A., Mix, A.C., Liu, Z., Otto-Bliesner, B., Schmittner, A. and Bard, E., 2012. Global warming preceded by increasing carbon dioxide concentrations during the last deglaciation. Nature, 484(7392), p.49.

Shepherd, A., Ivins, E., Rignot, E., Smith, B., van den Broeke, M., Velicogna, I., Whitehouse, P., Briggs, K., Joughin, I., Krinner, G. and Nowicki, S., 2018. Mass balance of the Antarctic Ice Sheet from 1992 to 2017. Nature, 556, pp. 219-222.

Shields, A., 1936. Application of similarity principles and turbulence research to bed-load movement. Mitteilungen der Preussischen Versuchsanstalt fur Wasser und Schiffbau, Berlin. In Ott, W. P \& van Uchelen, J. C. (translators), California Inst. Tech., W. M. Keck Lab. Of Haydraulics and Water Resources, Rept. No. 167.

Shulmeister, J., Goodwin, I., Renwick, J., Harle, K., Armand, L., McGlone, M.S., Cook, E., Dodson, J., Hesse, P.P., Mayewski, P. and Curran, M., 2004. The Southern Hemisphere westerlies in the Australasian sector over the last glacial cycle: a synthesis. Quaternary International, 118, pp.23-53. 
Sigman, D.M., Hain, M.P. and Haug, G.H., 2010. The polar ocean and glacial cycles in atmospheric CO 2 concentration. Nature, 466(7302), p.47.

Siegenthaler, U., Stocker, T.F., Monnin, E., Lüthi, D., Schwander, J., Stauffer, B., Raynaud, D., Barnola, J.M., Fischer, H., I, V. and Jouzel, J., 2005. Stable carbon cycle-climate relationship during the late Pleistocene. Science, 310(5752), pp.1313-1317.

Smith Jr, W.O., Sedwick, P.N., Arrigo, K.R., Ainley, D.G. and Orsi, A.H., 2012. The Ross Sea in a sea of change. Oceanography, 25(3), pp.90-103.

Sokolov, S. and Rintoul, S.R., 2009. Circumpolar structure and distribution of the Antarctic Circumpolar Current fronts: 1. Mean circumpolar paths. Journal of Geophysical Research: Oceans, 114(C11).

Sosdian, S. and Rosenthal, Y., 2009. Deep-sea temperature and ice volume changes across the Pliocene-Pleistocene climate transitions. Science, 325(5938), pp.306-310.

Soulsby, R.L. and Whitehouse, R.J.S., 1997. Threshold of sediment motion in coastal environments. In Pacific Coasts and Ports' 97: Proceedings of the 13th Australasian Coastal and Ocean Engineering Conference and the 6th Australasian Port and Harbour Conference; Volume 1 (p. 145). Centre for Advanced Engineering, University of Canterbury.

Spada, G., Antonioli, A., Boschi, L., Boschi, L., Brandi, V., Cianetti, S., Galvani, G., Giunchi, C., Perniola, B., Agostinetti, N.P. and Piersanti, A., 2004. Modeling Earth's post-glacial rebound. Eos, Transactions American Geophysical Union, 85(6), pp.62-64.

Spada, G. and Stocchi, P., 2007. SELEN: A Fortran 90 program for solving the "sea-level equation". Computers \& Geosciences, 33(4), pp.538-562.

Spence, P., Griffies, S.M., England, M.H., Hogg, A.M., Saenko, O.A. and Jourdain, N.C., 2014. Rapid subsurface warming and circulation changes of Antarctic coastal waters by poleward shifting winds. Geophysical Research Letters, 41(13), pp.4601-4610.

Stanton, T.P., Shaw, W.J., Truffer, M., Corr, H.F.J., Peters, L.E., Riverman, K.L., Bindschadler, R., Holland, D. and Anandakrishnan, S., 2013. Channelized ice melting in the ocean boundary layer beneath Pine Island Glacier, Antarctica. Science, 341(6151), pp.1236-1239.

Stap, L.B., Van de Wal, R.S.W., De Boer, B., Bintanja, R. and Lourens, L.J., 2014. Interaction of ice sheets and climate during the past 800000 years. Climate of the Past, 10(6), p.2135.

Stern, T.A. and Davey, F.J., 1989. Crustal structure and origin of basins formed behind the Hikurangi subduction zone, New Zealand. Origin and evolution of sedimentary basins and their energy and mineral resources, pp.73-85.

Stern, T.A., Quinlan, G.M. and Holt, W.E., 1992. Basin formation behind an active subduction zone: three-dimensional flexural modelling of Wanganui Basin, New Zealand. Basin research, 4(3-4), pp.197214. 
Stern, T., Houseman, G., Salmon, M. and Evans, L., 2013. Instability of a lithospheric step beneath western North Island, New Zealand. Geology, 41(4), pp.423-426.

Stevens, M. T., 2010. Miocene and Pliocene silicic Coromandel Volcanic Zone etphras from ODP Site 1124-C: Petrogenetic applications and temporal evolution. Unpublished MSc thesis, Victoria University of Wellington.

Stewart, A.L. and Thompson, A.F., 2015. Eddy-mediated transport of warm Circumpolar Deep Water across the Antarctic Shelf Break. Geophysical Research Letters, 42(2), pp.432-440.

Suess, E., 1906. The face of the earth. Oxford: Clarendon Press.

Sundborg, A., 1956. The river Klarälven a study of fluvial processes. Geografiska Annaler, 38(2-3), pp.125-316.

Swift, D.J., 1970. Quaternary shelves and the return to grade. Marine Geology, 8(1), pp.5-30.

Tapia, C.A., Grant, G.R., Turner, G.M., Ohneiser, C., Naish, T.R., Dunbar, G.B. (Submitted). Highresolution magnetostratigraphy of mid-Pliocene warm period ( $\sim 3.3-3 \mathrm{Ma}$ ) shallow-marine sediments, Whanganui Basin, New Zealand. Geophysical Journal International.

Thomas, R.H. and Bentley, C.R., 1978. A model for Holocene retreat of the West Antarctic ice sheet. Quaternary Research, 10(2), pp.150-170.

Thomson, D. J., 1982, Spectrum estimation and harmonic analysis, Proc. IEEE, 70, 1055-1096, doi:10.1109/PROC.1982.12433.

Timmermann, A., Timm, O., Stott, L. and Menviel, L., 2009. The roles of CO2 and orbital forcing in driving southern hemispheric temperature variations during the last $21000 \mathrm{yr}$. Journal of Climate, 22(7), pp.1626-1640.

Toggweiler, J.R. and Russell, J., 2008. Ocean circulation in a warming climate. Nature, 451(7176), p.286.

Townsend D , Vonk A. , Kamp PJJ (compilers) 2008 . Geology of the Taranaki area: scale 1:250,000. Lower Hutt: GNS Science . Institute of Geological \& Nuclear Sciences 1:250,000 geological map 7. 77 p.

Trewick, S.A. and Bland, K.J., 2012. Fire and slice: palaeogeography for biogeography at New Zealand's North Island/South Island juncture. Journal of the Royal Society of New Zealand, 42(3), pp.153-183.

Turner, G.M., 2001. Toward an understanding of the multicomponent magnetization of uplifted Neogene marine sediments in New Zealand. Journal of Geophysical Research: Solid Earth, 106(B4), pp.6385-6397.

Turner, G.M., Kamp, P.J., McIntyre, A.P., Hayton, S., McGuire, D.M. and Wilson, G.S., 2005. A coherent middle Pliocene magnetostratigraphy, Wanganui Basin, New Zealand. Journal of the Royal Society of New Zealand, 35(1-2), pp.197-227. 
Urey, H.C., 1947. The thermodynamic properties of isotopic substances. Journal of the Chemical Society (Resumed), pp.562-581.

Vail, P.R., 1987. Seismic stratigraphy interpretation using sequence stratigraphy: Part 1: Seismic stratigraphy interpretation procedure.

Van Hinsbergen, D.J.J., Kouwenhoven, T.J. and Van der Zwaan, G.J., 2005. Paleobathymetry in the backstripping procedure: Correction for oxygenation effects on depth estimates. Palaeogeography, Palaeoclimatology, Palaeoecology, 221(3-4), pp.245-265.

Van Rijn, L.C., 1993. Principles of sediment transport in rivers, estuaries and coastal seas (Vol. 1006). Amsterdam: Aqua publications.

Van Rijn, L.C., 2007. Unified view of sediment transport by currents and waves. I: Initiation of motion, bed roughness, and bed-load transport. Journal of hydraulic engineering, 133(6), pp.649-667.

Van Wagoner, J.C., Posamentier, H.W., Mitchum, R.M.J., Vail, P.R., Sarg, J.F., Loutit, T.S. and Hardenbol, J., 1988. An overview of the fundamentals of sequence stratigraphy and key definitions. SEPM Special Publication 42.

Van Wagoner, J.C., 1995. Sequence stratigraphy and marine to nonmarine facies architecture of foreland basin strata, Book Cliffs, Utah, USA.

Waelbroeck, C., Labeyrie, L., Michel, E., Duplessy, J.C., McManus, J.F., Lambeck, K., Balbon, E. and Labracherie, M., 2002. Sea-level and deep water temperature changes derived from benthic foraminifera isotopic records. Quaternary Science Reviews, 21(1-3), pp.295-305.

Wardlaw, B.R. and Quinn, T.M., 1991. The record of Pliocene sea-level change at Enewetak Atoll. Quaternary Science Reviews, 10(2-3), pp.247-258.

Weertman, J., 1974. Stability of the junction of an ice sheet and an ice shelf. Journal of Glaciology, 13(67), pp.3-11.

Wennrich, V., Minyuk, P.S., Borkhodoev, V., Francke, A., Ritter, B., Nowaczyk, N.R., Sauerbrey, M.A., Brigham-Grette, J. and Melles, M., 2014. Pliocene to Pleistocene climate and environmental history of Lake El'gygytgyn, Far East Russian Arctic, based on high-resolution inorganic geochemistry data.

Whitehead, J.M., Wotherspoon, S. and Bohaty, S.M., 2005. Minimal Antarctic sea ice during the Pliocene. Geology, 33(2), pp.137-140.

Winnick, M.J. and Caves, J.K., 2015. Oxygen isotope mass-balance constraints on Pliocene sea level and East Antarctic Ice Sheet stability. Geology, 43(10), pp.879-882.

Woodard, S.C., Rosenthal, Y., Miller, K.G., Wright, J.D., Chiu, B.K. and Lawrence, K.T., 2014. Antarctic role in Northern Hemisphere glaciation. Science, 346(6211), pp.847-851.

Woodward, R.S., 1888. On the form and position of mean sea level. United States Geological Survey Bulletin 48, 87-170. 
Wright, J., Colling, A. and Park, D. eds., 1999. Waves, tides, and shallow-water processes (Vol. 4). Gulf Professional Publishing.

Young, M. A., \& R. S. Bradley, 1984: Insolation gradients and the paleoclimatic record. In Milankovitch and Climate, Part 2, A. Berger et al., (Eds.), 707-713.

Zachos, J., Pagani, M., Sloan, L., Thomas, E. and Billups, K., 2001. Trends, rhythms, and aberrations in global climate $65 \mathrm{Ma}$ to present. Science, 292(5517), pp.686-693. 